\title{
REDEFINING THE BOUNDARIES OF HIDDEN HOMELESSNESS: AN EXAMINATION OF THE EXPERIENCES OF WOMEN IN TORONTO AND BARRIE
}

\author{
by \\ Rosemary Muzorewa \\ MSW, Laurentian University, 2014 \\ BSW, Laurentian University, 2012
}

A dissertation presented to

Ryerson University

in partial fulfillment of the requirements for the degree of

Doctor of Philosophy

in the program of

Policy Studies (Social Policy)

Toronto, Ontario, 2019

@ Rosemary Muzorewa, 2019 


\title{
Redefining the Boundaries of Hidden Homelessness: An Examination of the Experiences of Women in Toronto and Barrie \\ Doctor of Philosophy in the program of Policy Studies (Social Policy) \\ Ryerson University, 2019
}

\section{Rosemary Muzorewa}

\begin{abstract}
Following the devolution of affordable housing to lower levels of government, municipalities have been partnering with private developers to address the growing problem of hidden homelessness, through the inclusionary housing (IH) policy. Very little has been written about this policy in Ontario, hence the purpose of this qualitative case study was (i) to uncover how women experience hidden homelessness in Toronto and Barrie, (ii) to analyze, understand, and evaluate the implementation of IH policy in Ontario, and (iii) to examine the effect of IH policy as it relates to women experiencing hidden homelessness in Toronto and Barrie. In-depth interviews were conducted with eleven women who were currently experiencing hidden homelessness or had a history of hidden homelessness, five policy experts, two private developers, and five frontline workers from community organizations working to end homelessness in Toronto and Barrie. An intersectional gender-based analysis was used to uncover the prevalence of hidden homelessness among women, and the effect of the $\mathrm{IH}$ policy in addressing this problem. Data analysis was done using thematic analysis and particular attention was given to women's experiences with hidden homelessness and the perspectives of policy-makers and stakeholders. The findings suggests that, women experiencing hidden homelessness were situated within a hostile housing market where some were compelled to live in unsafe, substandard, overcrowded conditions, and were exposed to violence, while others lived in houses they could not afford, often working two jobs to cover rent. Although the introduction of Bill 7of the Affordable Housing Act, 2016, gave municipalities authority to implement IH strategies to boost affordable housing stock, yet slow implementation processes, challenges in negotiating a happy medium, red tape and the high cost of land, minimizes the effect of the IH strategy in Ontario. As such, the IH policy has not yielded any significant effect in Toronto or Barrie, and is only targeted at middle to upper middle income earners, at the exclusion of low-income women experiencing hidden homelessness. In addition, poor conceptualization of gendered homelessness, coupled with the absence of gendered statistics, and gender neutrality in the formulation and implementation of the IH policy, exacerbates women's experiences with hidden homelessness. Moreover, a lack of political will to end homelessness further dampens the effects of IH strategies. Participants suggested a more integrative, multidimensional approach to ending homelessness.
\end{abstract}




\section{Acknowledgments}

First and foremost I would like to thank the Most High God, for giving me the strength and a strong will to persevere through this project. To my husband, Wilson, and my beautiful daughters

Shamiso, Tinashe, and Rufaro, I thank you for cheering me up and for believing in me. A special thanks goes to my supervisor Dr. Melanie Knight, for your unwavering support. You stood by me in this long, complicated and at times trying journey. You provided guidance, encouragement and pushed me to be the best that I can. Your wisdom and guidance helped me produce what I believe is an outstanding research study. For that I am forever grateful. I would not have reached this milestone without the sound recommendations and invaluable insights from my committee members, Dr. John Shields and Dr. Dawn Onishenko. I really appreciate the time you spent reading through this project and providing constructive feedback. In addition I am thankful for the exceptional recommendations from my external committee member Dr. Tim Aubry. Last but not least, this study was made possible because of the women, policy experts, community stakeholders and private developers, who were brave enough to add a voice to the problem of hidden homelessness among women and the policy responses thereof. 


\section{Table of Contents}

Abstract.....

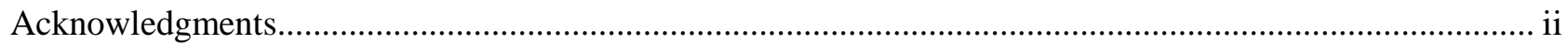

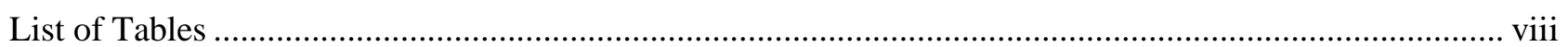

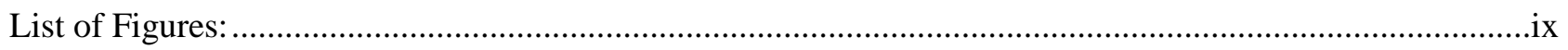

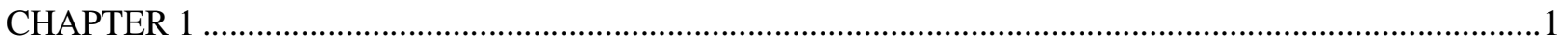

1 Hidden Homelessness in Canada: Where are women? .................................................................

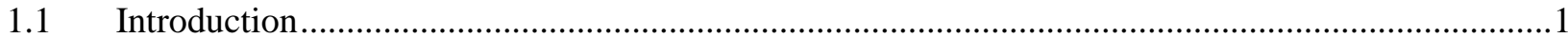

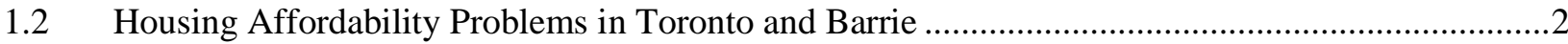

1.3 Contemporary Housing Trends (1985 - present): The Privatization and Marketization of Housing 5

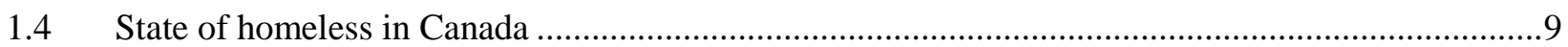

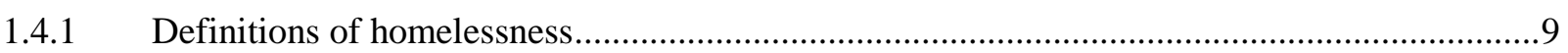

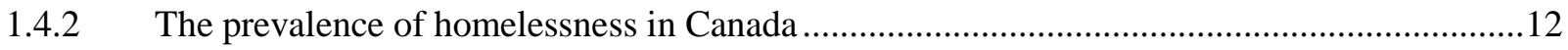

1.5 The Limitations in the Workings of Definitions on Hidden Homelessness....................................14

1.6 A case for the Redefining of Hidden Homelessness ................................................................17

1.7 Purpose of the Study and Contributions to the Field of Knowledge .............................................23

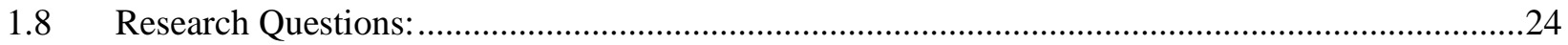

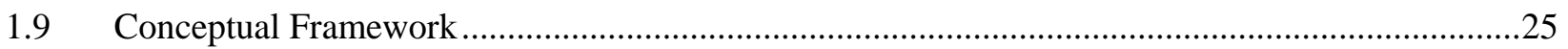

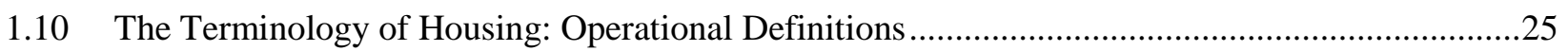

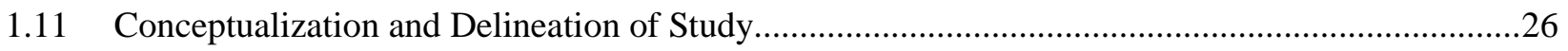

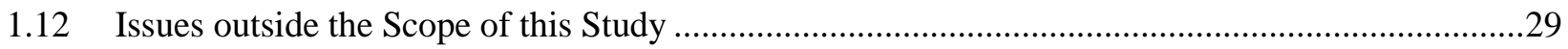

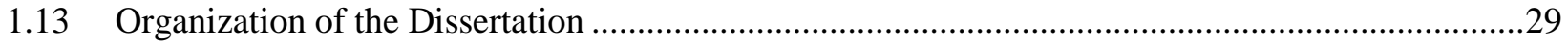

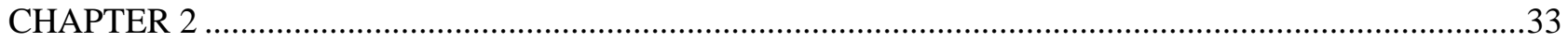

2 The De-gendering of Hidden Homelessness - Where are Women?......................................................33

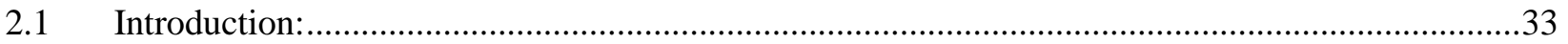

2.2 Where are Women: Contentions in the Conceptualization of Homelessness ..................................34

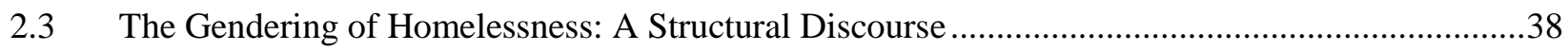

$2.4 \quad$ An Intersectional Discourse: Structural and Individual Risks ......................................................41

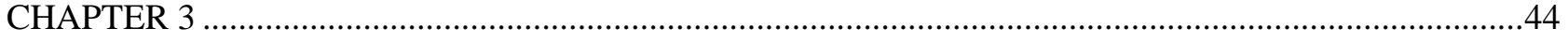

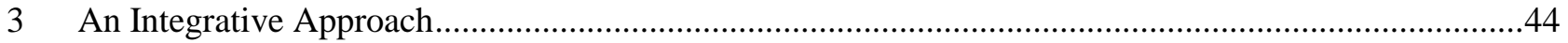

3.1 Introduction: Feminist Critical Policy Analysis....................................................................... 
3.2 The Challenges of Feminist-Based Policy Analysis

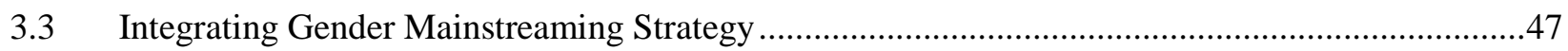

3.4 Instrumentation and Best Practices of Gender Mainstreaming ...................................................50

3.5 Assessing Measurability of Gender Mainstreaming ….............................................................52

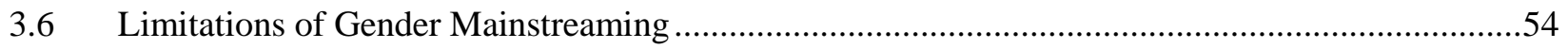

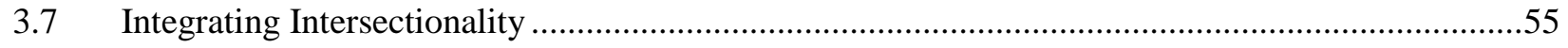

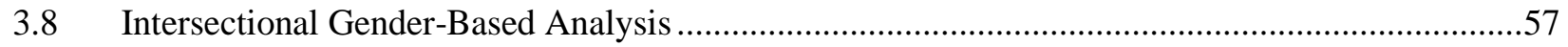

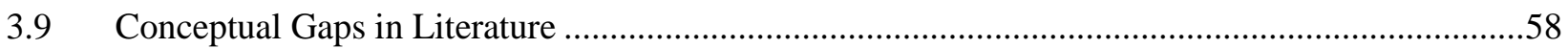

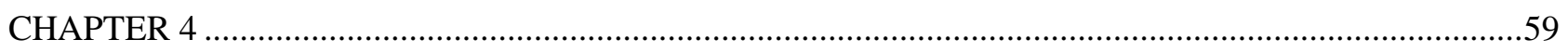

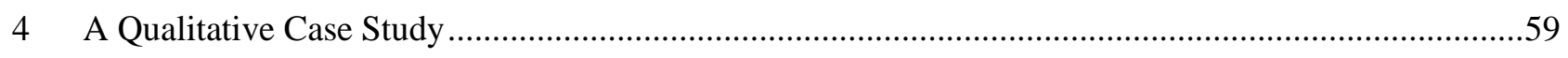

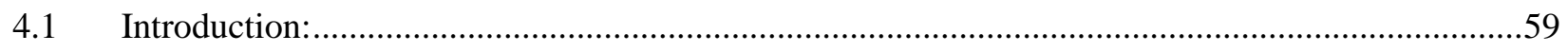

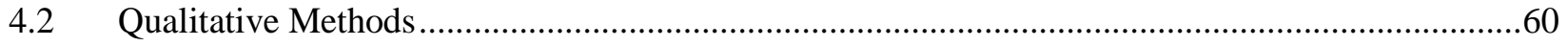

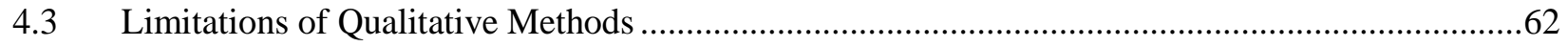

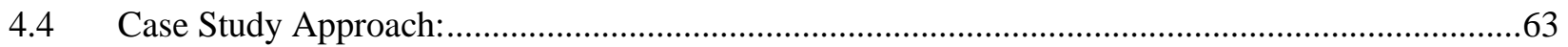

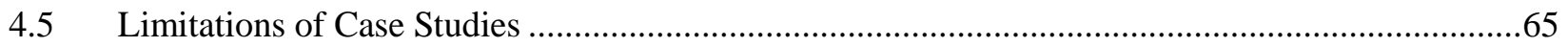

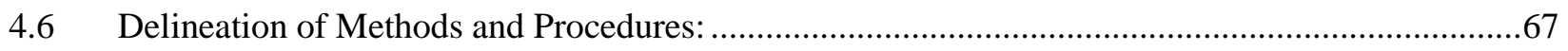

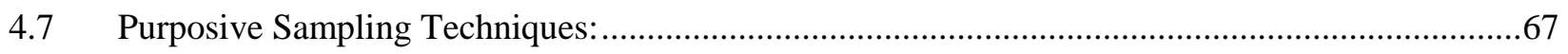

4.8 Limitations of Purposive Sampling Techniques ...................................................................68

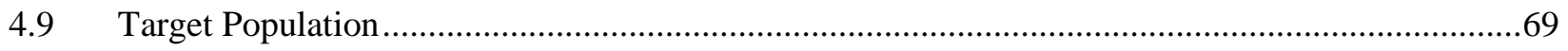

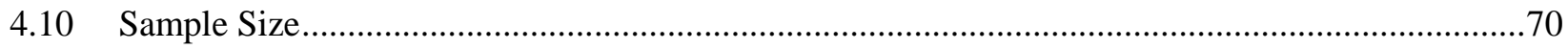

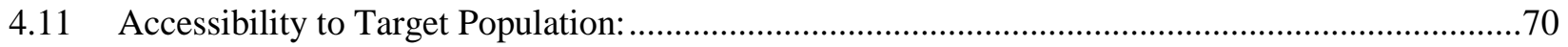

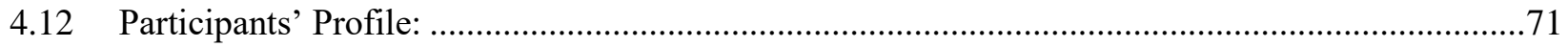

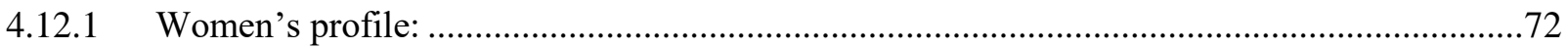

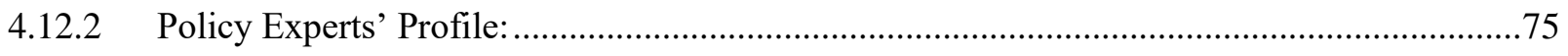

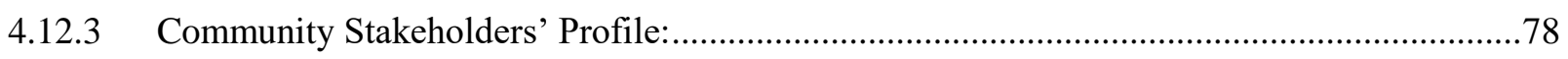

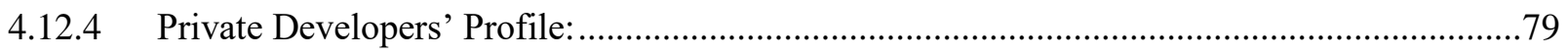

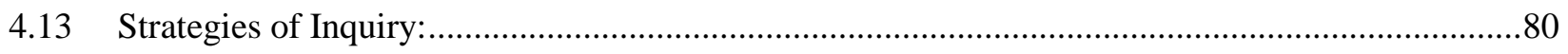

Data collection: In-depth interviewing techniques: ........................................................................ 80

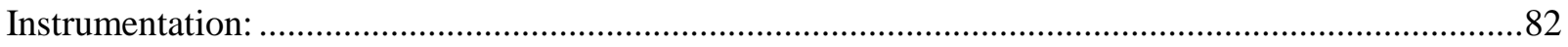

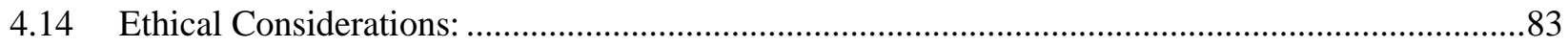

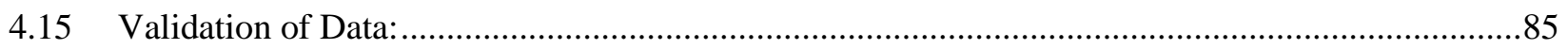

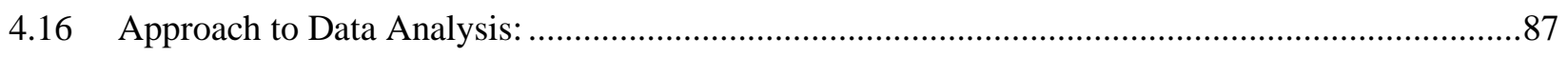

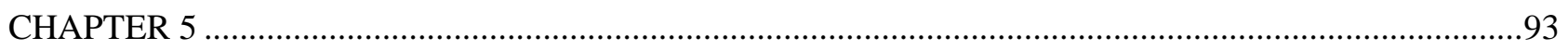


5 Hidden Homelessness, Daily Survival and Vigilance

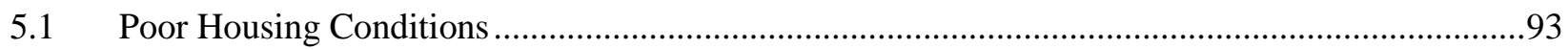

5.2 Power and Greed: The Struggle with Slumlords.....................................................................

5.3 The Racialization of Hidden Homelessness and Heteronormative Biases ....................................103

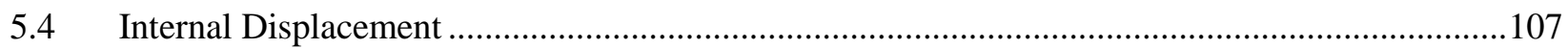

5.5 The Paradoxes of Hidden Homelessness: Making Tough Decisions to Survive ..........................109

5.6 Impact of Hidden Homelessness: Women are "Emotionally Tossed!" ........................................112

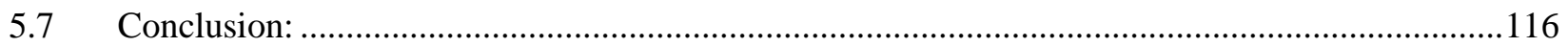

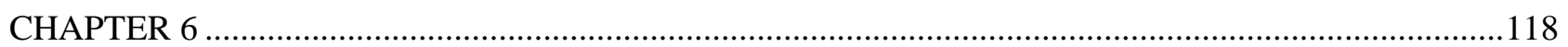

6 Factors Influencing Women's Experience with Hidden Homelessness.............................................. 118

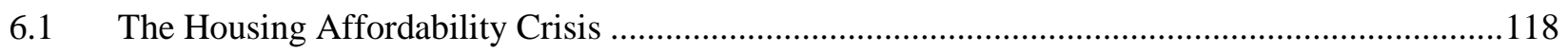

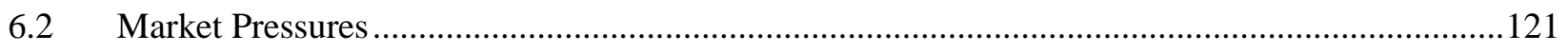

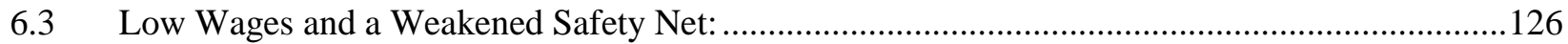

6.3.1 Strict Eligibility Criterion: Deserving and Undeserving ...................................................127

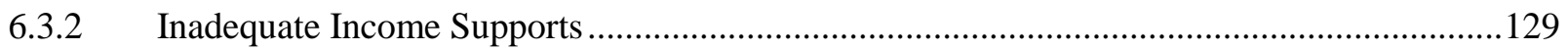

6.3.3 Shortage of Shelter Space and Permanent Affordable Housing ..........................................130

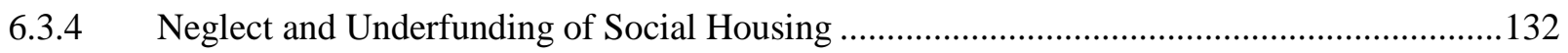

6.4 Negative Perception of Community Services ….................................................................... 135

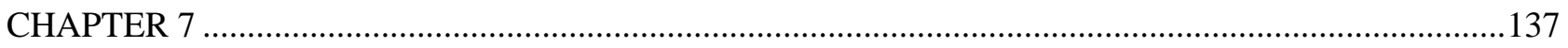

7 The Concealed Tentacles of Hidden Homelessness: Perceptions from City Policy Experts and Private

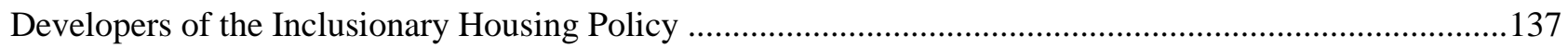

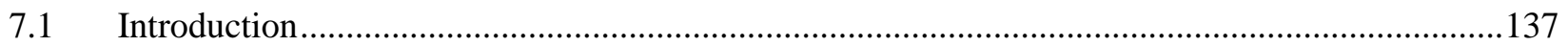

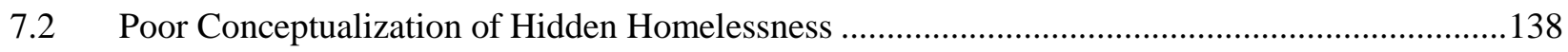

7.3 Political Correctness and the De-gendering of Hidden Homelessness ...................................... 140

7.4 Lack of Political Will to End Homelessness:............................................................................143

7.5 Institutional Inertia and the Complexities of Policy-Making .....................................................148

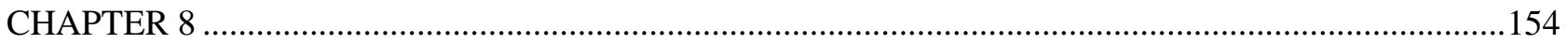

8 The Inclusionary Housing Policy \& the Marketization of Housing .................................................... 154

$8.1 \quad$ Introduction:

8.2 New Public Management: Ontario’s Big Society: ................................................................. 154

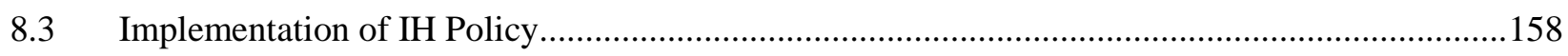

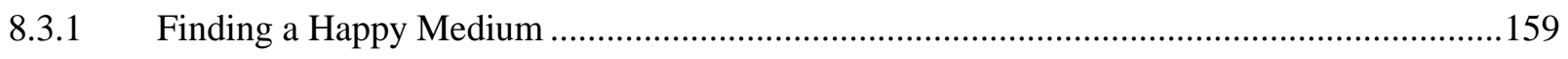

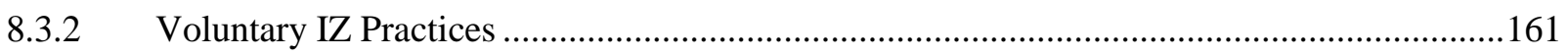

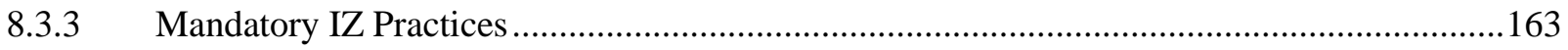




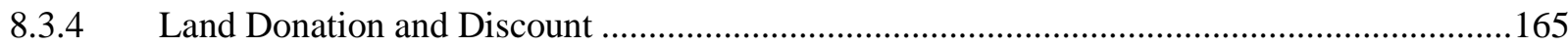

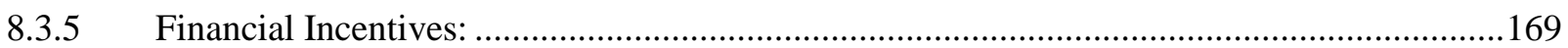

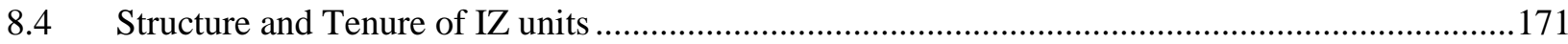

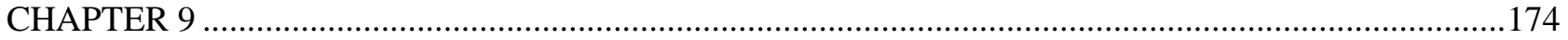

9 Perceived Outcomes of the Implementation of Inclusionary Housing Policies in Toronto and Barrie.174

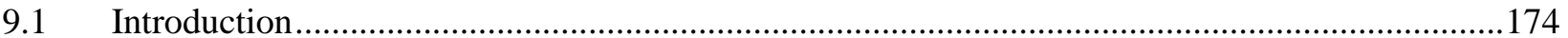

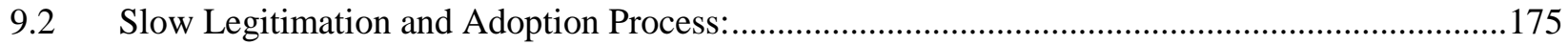

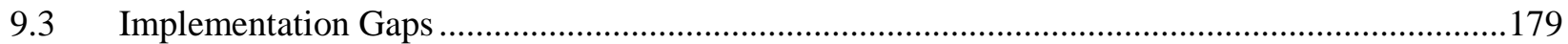

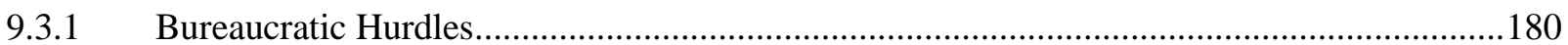

9.3.2 Contentions over Cost-sharing: Finding a Happy Medium ................................................. 182

9.4 Perceived Outcomes of IZ strategies on Canadian Housing Landscape ......................................184

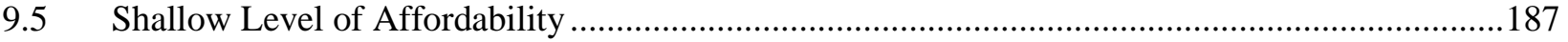

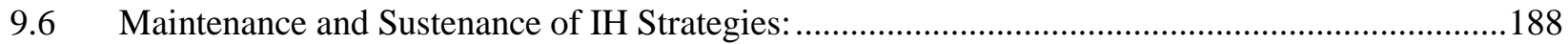

9.7 Recommendations in Light of Women's Experiences:..............................................................190

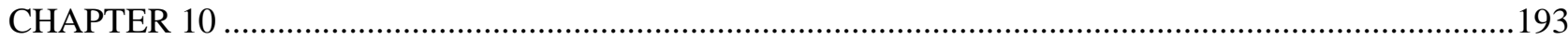

10 Way Forward to Ending Hidden Homelessness among Women: An Integrative Approach .............193

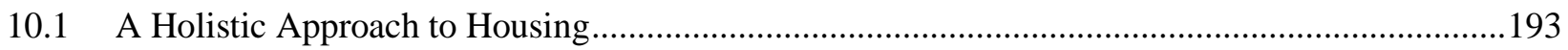

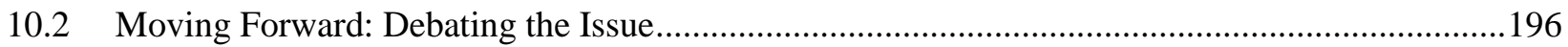

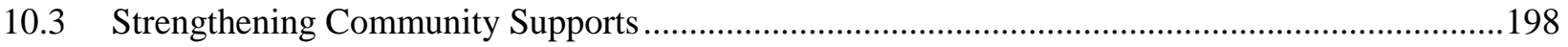

10.4 Broadening Affordable Housing Options: .................................................................................. 199

10.5 The Question of Political Will to End Homelessness ...............................................................201

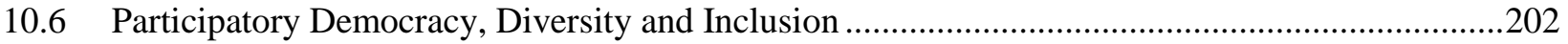

10.7 The Re-gendering of Homelessness: Gender-based National Housing Strategy .........................206

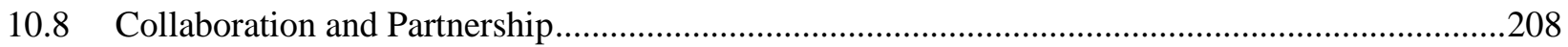

10.9 The Critical Feminist Policy Analysis and Participatory Democracy.........................................210

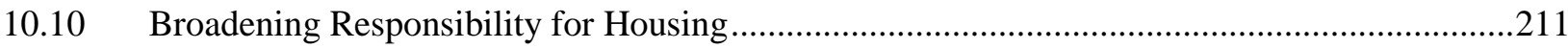

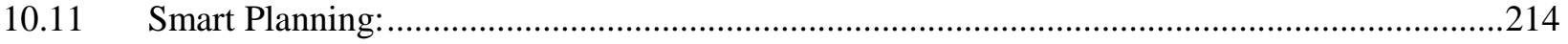

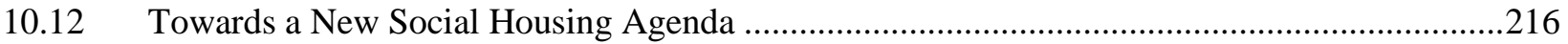

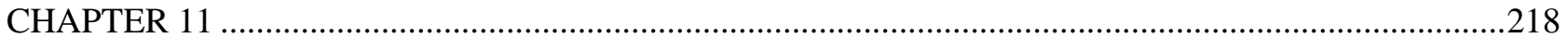

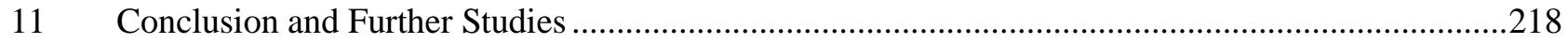

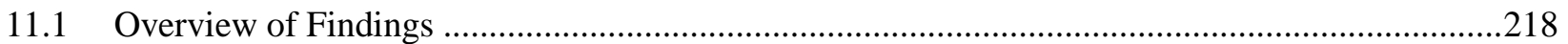

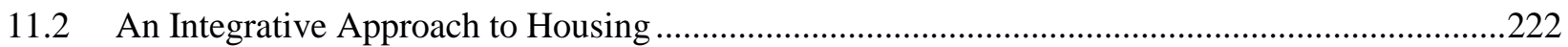

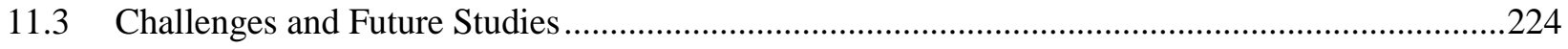


11.4 Limitations and Delimitations

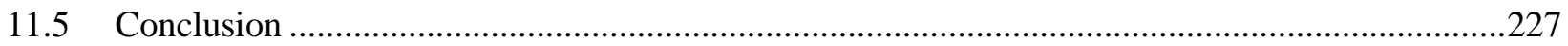

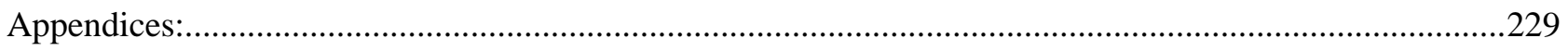

Appendix A: Recruitment Poster for Women participants ...................................................................229

Appendix B: Recruitment Letter to Experts in the Field …................................................................230

Appendix C: Informed Consent: Housing Expert/Stakeholder.............................................................232

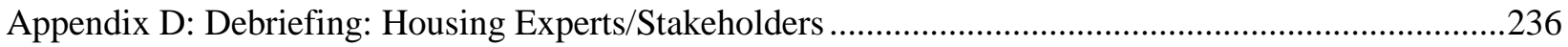

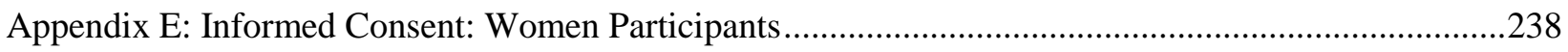

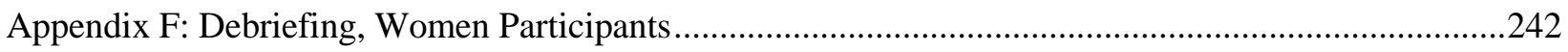

Appendix G: Community Resources: Barrie …..............................................................................243

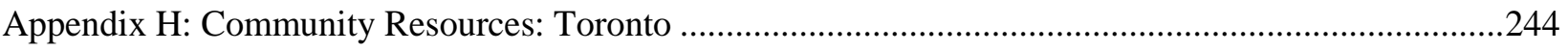

Appendix I: Interview Protocol: Experts/Stakeholders......................................................................246

Appendix J: Interview Protocol: Women Participants .........................................................................247

Appendix K: Factors influencing women's experiences with hidden homelessness ...............................248

Appendix L: Inclusionary Housing Projects in Toronto and Barrie: ........................................................249

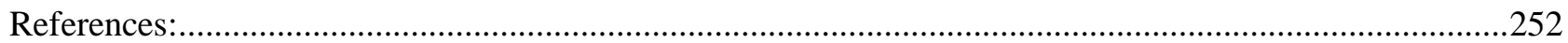




\section{List of Tables}

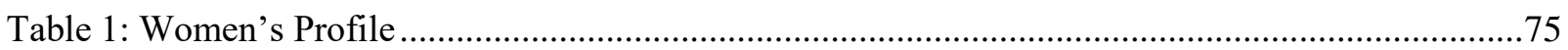

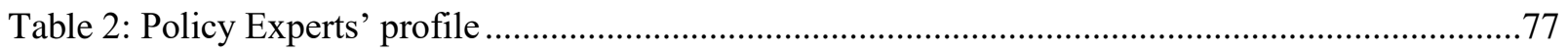

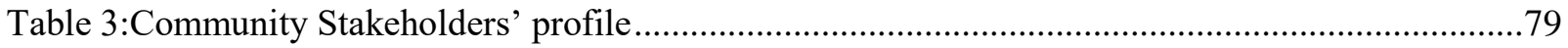

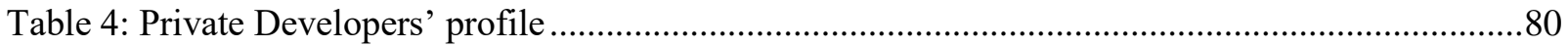

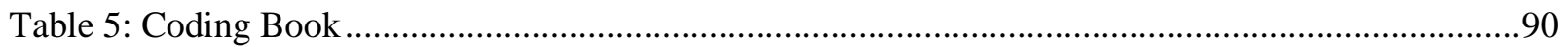

Table 6: Time Frame - Implementation of IH Policy in Ontario ...........................................................177

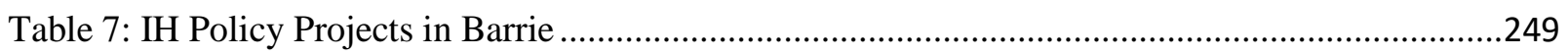

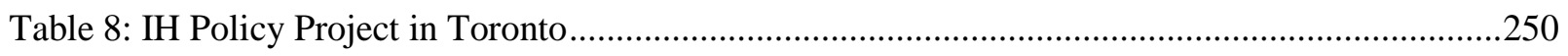




\section{List of Figures:}

Figure 1: Factors influencing women's experiences with hidden homelessness ...................................248 


\section{CHAPTER 1}

\section{Hidden Homelessness in Canada: Where are women?}

There is no doubt that homelessness is a complex individual and societal problem, and this complicates efforts to define it. It is not simply an easily bounded and measurable 'category' of persons, as the boundary between the experience of homelessness and not being homelessness is in many ways quite fluid. Many people experience the individual and structural problems that can lead to homelessness, but relatively few actually reach this state. It is this uncertain outcome that makes defining homelessness, especially in the preventive sense, a daunting task.

(Canadian Observatory on Homelessness, 2010, p. 1)

\subsection{Introduction}

Canada once enjoyed 50 years of a successful housing strategy characterized by active federal government involvement in the funding and administration of affordable housing. This period came to an end in the mid 1980's, when the federal government stepped back and delegated the provision of affordable housing to provinces, which further offloaded it to municipalities. The impact of the devolution of housing to provinces and municipalities is well recorded by various scholars (Brushett, 2007; Carroll, 1989; Colderley 1999; Hulchanski 2007; Purdy, 2003; Roberto \& Carroll 2010; Wolfe 1998). What is most evident in these studies is how the reshaping of the Canadian welfare regime is closely associated to the residual nature of social programs. In particular, these studies argue that the underfunding of affordable housing and the subsequent termination of the National Housing Strategy (NHS) in 1985 is directly linked to the introduction of new right wing ideals. In fact Donnan (2014), put forward that "the neoliberal philosophy not only informed the decision to eliminate Canada's federal Affordable Housing Policy, it has allowed the continuing neglect of public housing support despite the tragic consequences, and it has motivated decades of other social welfare cuts, as well as destruction of the welfare state" (p. 585). 
The irony of the Canadian housing landscape is that although the demand for affordable housing is growing, funding for affordable housing is decreasing. In the past three decades, the Canadian population grew by $30 \%$, yet capital investment in affordable housing fell by over $46 \%$ (Gaetz et al., 2014; Ministry of Municipal Affairs, 2014). Given the ongoing underfunding of affordable house, Ontario has limited affordable housing options for its growing population (Klassen, 2016; AMO, 2016; Shapcott, 2007). Over the years, public housing in Ontario has become synonymous with segregated, dilapidated and overcrowded ghettos. The majority of social housing built in the 1970s is in dire need of repairs and the City of Toronto alone requires $\$ 860 \mathrm{M}$ to renovate social housing units (Toronto Foundation, 2015).

At a global level, Canada and the United States of America, have the lowest percentages of social housing stock, compared to their counterparts in the developed world. For example, whereas only $4.1 \%$ of all Canadian housing is social housing, in the Netherlands, $34.1 \%$ of all housing is social housing; $22.2 \%$ in Denmark, $18.7 \%$ in France; $17.6 \%$ in United Kingdom; $12.8 \%$ in Finland; and $8.7 \%$ in Ireland is social housing (OECD, 2016). With limited public housing stock, lowincome households look to the private market for their housing needs. However, the Canadian housing market is increasingly out of reach for low-income to middle- income households and emerging data points to a worsening housing situation in big cities like Toronto (TD Bank, 2017) and smaller cities like Barrie (CBC News, 2018; CTV Barrie, 2017).

\subsection{Housing Affordability Problems in Toronto and Barrie}

In most recent years, various policy entrepreneurs in Ontario have raised issues over housing affordability in Toronto (Association of Municipalities of Ontario AMO 2015; Canadian Centre for Policy Alternatives CCPA 2015; Ontario Coalition Against Poverty 2007; Ontario Co-operative Housing Federation of Canada OCHFC 2015; Ontario Non-Profit Housing Association ONPHA 2016; 2015; Toronto Foundation 2016; 2015; Wellesley Institute, 2010; 2012) and Barrie (Simcoe 
Muskoka Vital Signs, 2016; Zolo Realty, 2017). These reports reveal a record low social housing stock, long wait times of up to 15 years for social housing, and a huge increase in the number of families in core housing need in Ontario, and particularly in Toronto and Barrie.

As much as accessing social housing is increasingly becoming difficult for low-income households in Ontario, accessing affordable housing within the private market is not an option either. In fact, Toronto has been rated the second most expensive city to buy a house in Canada and the second most expensive real estate market in the world (Toronto Foundation, 2016). Despite being a smaller city, in most recent years, Barrie has been rated one of the "tightest and most expensive rental markets in Ontario," (Canadian Mortgage and Housing Corporation CMHC, 2016 p. 2) and the third most expensive city to rent a one bed-roomed apartment, in Canada (CBC News, 2018; CTV Barrie, 2017). The housing market in Toronto and Barrie has not shown any signs of cooling off. Indicators reveal that the average cost of owning a house in Toronto increased by $32 \%$ to $\$ 920,791$ between 2016 and 2017 (Toronto Real Estate Board, 2017) and the average cost of owning a home in Barrie increased by $37.3 \%$ to $\$ 520,624$, during the same period (Canadian Real Estate Association, 2017; Zolo Realty, 2017). Subsequently, families and individuals in Toronto and Barrie are feeling shut-out of the homeownership market. Whereas the door to homeownership appears completely closed, the rental market in Toronto and Barrie is no longer a viable option either for those who cannot afford to own a home. Low-income renters are gradually feeling squeezed out of the private rental market due to record low vacancy rates ${ }^{1}$ and the high rental prices in Toronto and Barrie. For example, a real estate report by Padmapper, listed Barrie as the third most expensive city to rent a one bed-roomed apartment, in Canada (CBC News, 2018; CTV Barrie, 2017).

\footnotetext{
${ }^{1}$ Whereas a $5.5 \%$ is considered a healthy vacancy rate, Toronto's vacancy rate is $1.3 \%$ and Barrie's is $2.2 \%$. (CMHC, 2016).
} 
As a result of a lack of housing affordability, a growing number of individuals are facing increasing precarity with regards to housing. Various indicators point to a growing number of individuals and families in core housing need (Canadian Centre for Policy Alternatives CCPA 2015; CMHC-Stats Canada, 2016; Cooper \& Skelton, 2015; Gaetz, 2010; Gaetz et al, 2014; Ontario Co-operative Housing Federation of Canada OCHFC, 2016; 2015; Ontario Non-Profit Housing Association ONPHA 2016, 2015; Waterston, Grueger \& Samson, 2015). According to CMHC, families and individuals in core housing need are inadequately housed in overcrowded conditions, dwellings that need repairs, and/or houses they cannot afford and are spending over $30 \%$ of their income before tax on rent (CMHC-Stats Canada, 2016). In Ontario alone, 273,000 households are in core housing need (OCHFC, 2016) and 171,360 households are on the waiting list for affordable housing (ONPHA 2016). At issue is not simply a question of overcrowding and repair, but of economics. Those in core housing need face greater likelihood of homelessness that may result from loss of income due to unexpected life events such as job loss, divorce and separation, or being diagnosed with a chronic disease.

Despite efforts to document and address homelessness or the inadequately housed in Canada, a hidden element has become more pronounced. I will delve into greater details of the hidden component later in this chapter but the hidden aspects stem from individuals who lack stable and safe housing and are not on the streets or in shelters/transitional housing, and who do not access housing supports and who are not openly homeless (Crawley et al, 2013; Gaetz et al, 2014; Keung, 2012; Watson, Crawley \& Kane, 2016). Let me briefly situate the issue of inadequate housing and housing affordability within housing trends since the mid-1980s. 


\subsection{Contemporary Housing Trends (1985 - present): The Privatization and Marketization of Housing}

Perhaps, one of the greatest institutional changes witnessed in the 1980's to 1990's in Western countries was the move towards new forms of governance, which began with the diffusion of power to lower levels of government and the creation of a big society. In a big society, the welfare of citizens is no longer the primary responsibility of the government but of families, local communities, non-governmental organizations, charitable organizations, individual philanthropists and private businesses (Alcock, 2014). It has been argued that the establishment of the big society is closely tied to welfare retrenchments and the commodification of social services (Dean, 2012; Jones, 2012; Joy \& Sheilds, 2013; Prince 2014). In particular, Joy and Shields (2013) explored the characteristics of the welfare state in a big society and make a case that the main focus of the government in a big society is devolution, outsourcing of services to the private sector, tax-breaks to charities to encourage philanthropic activities, and reduction in government spending on social services. It should however be noted that the key elements of public management in a big society, is the privatization of state assets and marketization of public services.

The two major arguments behind the privatization and marketization of public services centre on ethical and economic considerations. The ethical consideration arguments put forward the notion that, forcing citizens to receive public services through the government violates their right of choice and results in mandatory heavy taxation that citizens have not agreed upon. Moreover, from an economic perspective, it is believed that citizens, with the inherent right of choice, will tend to gravitate towards organizations that offer the most efficient and cost effective services, thereby inducing competition and enhancing productivity on the market.

Since the 1990's, local governments in Western countries have used various models of market type mechanisms (MTMs) in their public service delivery. A review of seven papers by 
Hansen and Lindholst (2016) analysing the current state of marketization and MTMs at local governments, in six countries, namely, Italy, Australia, England, Denmark, Norway, and Sweden, and in three policy areas, discovered four ideal-types of marketization models that underpin public service delivery. These are the; (i) quasi-market model in which the government encourages provider competition and free choice for users; (ii) classical contracting out, where the government contracts some of its services to private enterprises, (iii) use of benchmarking and yardstick competition to enhance performance and efficiency; and (iv) public-private collaboration, to incentivise and promote partnerships and corporation between government departments, private organization and/or the third sector. Of particular interest is that, this review identifies a key trend towards public-private collaboration and cross-sectorial and inter-organizational institutional arrangements (Hansen \& Lindholst, 2016). This trend has been most visible in the provision of affordable housing in Canada, following the devolution of housing to lower levels of government. This will be explored further in the next few sections of this chapter.

The weaknesses, dilemmas, pitfalls, paradoxes, and trade-offs of new forms of public management have been explored extensively by various scholars, in different sectors, and in various countries (Bardouille, 2000; Evans, Mitchell \& Shields, 2010; Evans, Richmond \& Shields, 2005; Hansen, \& Lindholst, 2016; Joy \& Shields, 2013; Dearnaley, 2013; Kantola \& Squires, 2012; Le Grand et al., 2007; Maguire, 2012;). Whereas proponents of new public management put forward that competition, incentivisation, disaggregation and reliance on the third sector, fosters efficiency, transparency, productivity, better services and ultimately lower prices (Bach, 2012; Kantola \& Squires, 2012), critics of the privatization and marketization of public services, argue that the expansion of ideals of economic liberalism, market individualism and neo-conservatism, (a) increases economic vulnerability of citizens, by placing societal burdens on individuals (Joy \& Shields, 2013; Evans, Mitchell \& Shields, 2010; Evans, Richmond \& Shields, 2005; Burke \& 
Shields, 2000), and (b) erodes our collective efforts to narrow the growing inequality gap through the provision of universal entitlements (Alcock, 2014; Dearnaley, 2013; Donnan 2014; Hansen, 2011; Joy \& Shields, 2013; Le Grand et al., 2007; Prince 2014).

Nonetheless, with limited resource in the aftermath of the devolution, and with the federal funding agreements ending by $2033^{2}$ (CHRA, 2014; Cooper, 2015), local governments, in Canada, are increasingly looking to the private market for housing solutions. Of particular interest in the past few decades has been the emphasis on home ownership (Hulchanski, 2007) and the move towards partnering with homeowners and private developers in the provision of affordable housing through the inclusionary housing policy (Balfour, 2010; Mah \& Hackworth 2011; Mah, 2009; Ontario Ministry of Housing, 2016; Shapcott, 2007; Toronto Metro News, 2017). Subsequently, over the past decade, the inclusionary housing policy has gained traction and is now being viewed as the most viable housing policy option in an environment of fiscal restraint. It bridges the old and new ways of providing affordable housing within the private sector (Buitelaar, Needham \& Kam 2014; Calavita \& Mallach 2010; Crook \& Monk 2011; Kam 2014; Mah, \& Hackworth, 2011; Morrison \& Burgess 2014; Wellesley, 2010).

The inclusionary housing policy focuses on "ways in which a country, through its public policy, can stimulate the provision of social or affordable housing" (Buitelaar, Needham \& Kam 2014, p. 389). There are two distinct types of Inclusionary Housing (IH) strategies: (a) mandatory and (b) voluntary/incentive-based IH policies. Some studies have shown that mandatory IH policy approaches tend to yield better outcomes than incentive-based approaches (Armstrong et al, 2007; Been, Meltzer \& Schuetz, 2007; Lerman, 2006; Karki, 2015; Schueltz et al, 2009;). The mandatory

\footnotetext{
${ }^{2}$ Fig.4 attached, reveals the dwindling federal funding for investment in affordable housing in Ontario. In the next 10 years, federal spending for social housing in Ontario will be $\$ 267$ million less and by 2033 , it will have ceased.
} 
IH policy gives local authorities power to influence the production of affordable housing in new developments. As such, over the past two decades, local planning authorities across the United Kingdom and Australian have used their legal powers to negotiate S106 planning agreements with developers as a sustainable way of providing affordable housing (Morrison \& Burgess, 2014). Others suggest that the overall success of the IH policy hinges on extensive negotiations, manipulations and trade-offs between local authorities and private developers, noting that, more often than not, local authorities have agreed to higher densities on a project site to offset the cost of IH requirement (Balfour, 2010; Morrison 2014; Williams, 2015).

However, although the IH policy is well developed in USA and Europe, Australia and New Zealand (Armstrong et al, 2007; Buitelaar, Needham \& De Kam. 2014; Mah 2009), it is still under developed in Canada. Whereas some local governments in Ontario, notably Toronto and Barrie, have attempted to use IH strategies to boost affordable housing units in their jurisdiction, what has been lacking for years are specific policies to back up this strategy. Only most recently, did the Ontario government pass Bill 7 of the Affordable Housing Act, to allow for Inclusionary Zoning (IZ) by municipalities (Ministry of Housing Ontario, 2016). As a result, very little is known about the effect of this policy on affordable housing stock in Ontario.

In addition, although much has been written about $\mathrm{IH}$ policies in England, Italy, Netherlands, France, Turkey, USA, Australia and New Zealand (Buitelaar, Calavita \& Mallach 2010; Needham \& Kam 2014; Kam 2014; Karki, 2014; Pogliani, 2014; William 2015; Morrison \& Burgess 2014;), only limited scholarly articles have focused on the IH policy in Canada (Balfour, 2010; Mah, 2009; Mah \& Hackworth 2011; Wellesley, 2010). Furthermore, despite an increased interest in the IH policy by Canadian municipalities, only Mah (2009) and Balfour (2010) have attempt to understand the potential effect of the IH policy on the Canadian housing landscape. However, in the absence of specific laws and statistics related to this policy, findings from these 
studies were inconclusive. In addition, despite the heightened vulnerability of women due to the prevailing housing affordability crisis in Canadian cities, none of the studies on the IH policy, in Canada and elsewhere, incorporates a gendered lens in the evaluation of the IH policy.

\subsection{State of homeless in Canada}

\subsubsection{Definitions of homelessness}

Prior to 2012, Canada and other Western countries did not have a clear, precise or consistent definition of homelessness. Generally, according to Watson and Austenberry (1986), being homeless depended on who was doing the defining. Up until the 1980s, in Canada, Europe, Australia and USA, homelessness focused on absolute homelessness and involved a small number of largely single men in urban areas experiencing chronic homelessness and sleeping on the streets or accessing shelters (Frankish et al, 2005; Gaetz, Ritcher \& Redman, 2016). However, the inclusion of only those who slept rough or who accessed emergency shelters in the definitions of homelessness was narrow in focus. It failed to capture the extent of homelessness because other forms and locations of homelessness, outside the urban population, were unaccounted for (Cloke et al, 2002; Collins, 2010).

Given that how we define a problem determines the direction of policy responses, there was an urgent need to broaden definitions of homelessness, from the narrow focus on the 'chronicity' of homelessness, to a more encompassing ‘typology’ of homelessness based on individual or family housing situation (Canadian Observatory on Homelessness, 2010). In Australia, the move towards redefining homelessness can be seen in the early works of Chamberlain and Mackenzie (1992). They suggested we understand homelessness as a continuum from primary (people without shelter), secondary (those couch-surfing with friends or relatives and those in emergency or short term 
shelter), to tertiary (people living in single rooms in private boarding houses without their own bathroom or kitchen, or security of tenure). However, others argue that "the overall definition of homelessness based on the binary distinctions between 'primary homelessness' and 'secondary homelessness' is too broad and is not detailed or sophisticated enough to offer much applicability to the Canadian context" (Canadian Observatory on Homelessness, 2010 p. 2).

Taking into account the Canadian context, the Canadian Observatory on Homelessness $(\mathrm{COH})^{3}$ released a new definition of homelessness in 2012. The COH Researchers described homelessness in Canada as, "the situation of an individual or family without stable, permanent, appropriate housing, or the immediate prospect, means and ability of acquiring it" (Gaetz, et al, 2012 p. 1. The $\mathrm{COH}$ further categorized homelessness based on a range of physical living situations and degrees of homelessness, organized here in a typology that includes:

"1) Unsheltered, or absolutely homeless and living on the streets or in places not intended for human habitation;

2) Emergency Sheltered, including those staying in overnight shelters for people who are homeless, as well as shelters for those impacted by family violence;

3) Provisionally Accommodated, referring to those whose accommodation is temporary or lacks security of tenure, and finally,

4) At Risk of Homelessness, referring to people who are not homeless, but whose current economic and/or housing situation is precarious or does not meet public health and safety standards." (p.2)

\footnotetext{
3 "The Canadian Observatory on Homelessness (formerly the Canadian Homelessness Research Network) established a working group in 2012 comprising of experts in the area of housing and homelessness, policy and practice, to develop, refine and test a new definition of homelessness. This working group included - Dr. Stephen Gaetz, Director, Canadian Observatory on Homelessness, York University; Carolann Barr, Executive Director, Raising the Roof; Anita Friesen, Senior Policy Advisor, Program Policy and Planning, Family Violence Prevention and Homeless Supports, Alberta Human Services; Bradley Harris, Social Services Consultant, The Salvation Army; Charlie Hill, Executive Director, National Aboriginal Housing Association; Dr. Kathy Kovacs-Burns, Associate Director, Health Sciences Council, University of Alberta; Dr. Bernie Pauly, Associate Professor, School of Nursing, University of Victoria; Bruce Pearce, President, Canadian Housing Renewal Association; Alina Turner, VP Strategy, Calgary Homeless Foundation; Allyson Marsolais, Project Manager, Canadian Observatory on Homelessness. Based on national consultation, the definition was revised in 2017. The various definitions presented here are excepts from the final work of this team: https://www.homelesshub.ca/sites/default/files/COHhomelessdefinition.pdf
} 
Whereas hidden homelessness is captured under the category of "provisionally housed," I will delve into that later in this chapter. At this point, let me provide a bit more expansion to COH's category of "At Risk of Homelessness."

According to the Ontario Non-Profit Housing Association (ONPHA), individuals and families at-risk-of-homelessness are often precariously housed and face challenges that may, or may not leave them homeless in the immediate or near future (in the absence of an intervention) (ONPHA, n.d). These individuals and families live in substandard housing that is improperly constructed with poor building materials and whose structure is considered inadequate (Homelessness Hub, n.d). Although precariously housed individuals and families may want to change their situation, they lack the means to do so and hence they remain precariously housed, often struggling to keep up with heating their homes, providing proper child care and, meeting nutritional needs and other expenses that contribute to good health and well-being (Homelessness Hub, n.d). As well, precariously housed families and individuals lack access to necessary supports and opportunities, including employment, health care services, clean water and sanitation, schools, child care centres and other social supports and facilities (Gaetz, et al., 2012).

Those who manage to retain their housing in such precarious circumstances are said to be in core housing need and often do so at the expense of not meeting other basic necessities (ONPHA, 2018). According to CMHC's website,

"a household is said to be in core housing need if its housing falls below at least one of the adequacy, affordability or suitability, standards, and it would have to spend $30 \%$ or more of its total before-tax income to pay the median rent of alternative local housing that is acceptable (meets all three housing standards)." 4

\footnotetext{
${ }^{4}$ CMHC definition of core housing need https://www.cmhc-schl.gc.ca/en/housing-observer-online/2018-housingobserver/13-point-6-percent-urban-households-were-core-housing-need-2016
} 
CMHC (2018) further describes the housing standards used to determine aspects of adequacy, affordability and suitability of housing in Canada. A dwelling is considered adequate, suitable and affordable if it is reported by their residents as not requiring major repairs and has enough bedrooms for the size and makeup of resident households according to National Occupancy Standard (NOS) requirements, and if housing costs are less than $30 \%$ of the total before-tax household incomes. When in core housing need the risk of homelessness is therefore much greater.

\subsubsection{The prevalence of homelessness in Canada}

The enumeration of homelessness in Canada has been a major source of contention among scholars. Some have tried to capture the prevalence of homelessness in Canadian cities through the point-in-time (PiT) count and the national shelter survey (Gaetz et al, 2014; Gaetz, Ritcher \& Redman, 2016). Using these methods, it is estimated that 235,000 Canadians experience homelessness every year (Gaetz, Ritcher \& Redman, 2016). If we factor in those in core housing need and those that are precariously housed in unaffordable, substandard or over-crowded conditions, the numbers would increase considerably. According to data from the Canadian Income Survey, 2016, 1.6 million urban households in Canada (13.6\% of all Canadian households living in urban areas), were in core housing need (Statistics Canada, 2019). Compared to other provinces, Ontario had the largest number of households in core housing need, noting that about 769,000 of the 1.6 million urban households in core housing need in Canada were from Ontario (CMHC, 2018). Nonetheless, despite efforts to enumerate the homeless community, these numbers would not be complete without taking into account the hidden population. It is estimated that that " $80 \%$ of all people experiencing homelessness are hidden," and temporarily housed with friends, relatives, (Crawley, 2013, p.674). In accounting for the hidden population, it is estimated that a total number of 2.3 million Canadians, aged 15 and over, reported having temporarily lived with family, friends, 
in their car, or anywhere else in 2014, because they had nowhere else to live (Advocacy Centre for Tenants Ontario, n.d; Rodgrigue, 2016).

Some have argued that although the demographics of homelessness in Canada have shifted over the years, from a small group of single white males, to a larger, more diverse group consisting of women, youth, seniors and the Indigenous population, adult males are still more likely to present as homeless than women (Gaetz et al, 2014; Gaetz, Ritcher \& Redman, 2016). For example, The State of Homelessness in Canada 2016, estimated that of the 235,000 Canadians who experience homelessness every year, $27 \%$ were women, $34 \%$ were Indigenous people, youth were at $19 \%$ and seniors were $24 \%$ of the homeless population (Gaetz, Ritcher \& Redman, 2016). However, although the reports on The State of Homelessness in Canada, $(2014,2016)$, present a positive step towards understanding homelessness in Canada, Gaetz and his colleagues $(2014 ; 2016)$ caution that these reports do not capture the full magnitude and extent of homelessness in Canada. First, data used to determine the state of homelessness in Canada is largely dependent on the existence of emergency shelters ( $\mathrm{COH}$ typology 1 and 2) and does not give a full picture of homelessness in communities with fewer or no shelters (Gaetz, Ritcher \& Redman, 2016). Second, data from Violence Against Women shelters, transitional housing and people who are homeless but are not accessing emergency shelters (the unsheltered), is not included in these studies (Gaetz, et al 2014; Gaetz, Ritcher \& Redman, 2016). Third, given that most shelters operate at over $90 \%$ capacity, individuals and families who came to shelters but were turned away because of lack of shelter space, are also excluded from the enumeration of homelessness in these studies (Gaetz, Ritcher \& Redman, 2016).

Lastly, assessing homelessness for women through the lens of shelters or PiT street surveys is inadequate because women experiencing homelessness often shy away from accessing shelters because they feel infantilized and unsafe, and they avoid being on the streets for safety reasons and 
to protect their children from apprehension by authorities (Donley \& Wright, 2012; Drabble, 2017;

Duchesne, 2015; Klodawsky, 2006; Laird, 2007; Muzorewa, 2014; Walsh, et. al, 2016; 2015;

Watson, 2011; Whitzman, 2006). Moreover, homelessness among women in Canada is not yet well understood, and the exact number of women experiencing homelessness is unknown because incidences of homelessness among women are difficult to measure (Collins, 2010; Gaetz et al, 2014; Klawdosky, 2009).

Failure to capture the full spectrum of women experiencing homelessness may result in homeless women falling through the cracks. It has been suggested that resources are not allocated to provide adequate support for individuals experiencing hidden homelessness, because they remain hidden (Crawley, 2013). As such, the following section, of this chapter will focus on exploring the discourse on hidden homelessness as it relates to women's experiences.

\subsection{The Limitations in the Workings of Definitions on Hidden Homelessness}

According to the Canadian definition of homelessness, hidden homelessness falls under the category of "provisionally accommodated" and is defined as;

People who live temporarily with others but without guarantee of continued residency or immediate prospects for accessing permanent housing. Often known as "couch surfing," this describes people who are staying with relatives, friends, neighbours or strangers because they have no other option. They generally are not paying rent and it is not a sustainable long-term living arrangement but they do not have the ability to secure their own permanent housing immediately or in the near future. This population is considered to be "hidden" because they usually do not access homeless supports and services even though they are improperly or inadequately housed (Homeless Hub website, n.d $)^{5}$.

\footnotetext{
${ }^{5}$ Except from the Homeless Hub Website https://www.homelesshub.ca/about-homelessness/populationspecific/hidden-homelessness
} 
The Canadian definition of hidden homelessness is problematic. Whereas it touches on aspects of instability, non-permanency and non-monetary accommodations, it fails to address gender-specific aspects of hidden homelessness. Specifically, it does not capture women's experiences with violence, intimidation and trauma, at the hands of family and intimate partners they depend on to remain housed due to poverty and the lack of affordable housing (Drabble, 2017). It ignores issues of safety, affordability, and human dignity. It relies heavily on tenure and monetary measures in defining hidden homelessness. For example, according to this definition, to be considered as someone experiencing hidden homelessness in Canada, one must be temporarily housed for a short period, without paying rent and with no immediate prospect of finding permanent housing (Homeless Hub, 2019). Let us briefly assess this definition in relation to women.

Although women who are housed may appear not to be in a unstable position and, may appear permanently settled with no desire or intent to change their predicament of housing insecurity, yet this is a false assumption. One must acknowledge the systemic barriers that may prohibit women from changing such situations. These broader systemic issues that shape women's housing insecurity include the feminization and racialization of poverty, lack of affordable housing, limited shelter space for women fleeing abuse, lack of affordable childcare, inadequate income supports and job precarity (Drabble, 2017; Walsh et al, 2016). Research shows that in many instances, women stay in seemingly 'permanent', 'stable' situations that are often within violent relationships, rough neighbourhoods, in rundown dwellings, or in unaffordable housing, for the sake of the resemblance of stability. As such they fall outside of the hidden homelessness definition. 
In addition to the narrow definition of hidden homelessness, very little effort has been put toward locating women experiencing hidden homelessness. A few scholars who sought to uncover who and where the hidden homeless community are located discovered that, ironically the strategy of women to seek invisibility to avoid unwanted attention has resulted in homelessness being seen as a problem faced overwhelmingly by men in Western Countries (Drabble, 2017; Klowdasky, 2006; Piercy, 1994). Again, data on homelessness in Canada estimates that women constitute $27 \%$ to $30 \%$ of the homeless population (Gaetz, 2016; Klowdasky, 2006; Piercy, 1994). Furthermore, in a recent StatsCan study, also based on the current hidden homelessness definition, $8 \%$ of Canadian males reported having experienced hidden homelessness at some point in their lives, compared to only $7 \%$ of Canadian females (Rodgrigue, 2016).

However some have cautioned that statistics on homelessness are more likely to be higher than normally reported when considering aspects of hidden homelessness, as the hidden population often do not access services (Homeless Hub, n.d). Others have argued that when it comes to homelessness among women, the point-in-time count and the national shelter survey, fail to capture the exact number of women experiencing homelessness because women are less likely than men to access emergency shelters and, their experiences with homelessness is often not captured in the data collected from shelters (Drabble, 2017; Klodawsky, 2009, Gaetz et al, 2014).

In acknowledging these limitation, Gaetz and his colleagues (2014) pointed out that although data from emergency shelter survey indicate that there were more men than women experiencing homelessness, on any given night in Canada, there were slightly more females (7\%) than males (6.3\%) who reported an episode of homelessness (Gaetz et al, 2014). Moreover, there was a substantial difference between age groups, noting that younger individuals between the ages of 18 to $24(15.7 \%)$ were almost twice as likely to report being homeless at some point in time, compared 
to older individuals between the ages of 25 to $65(7 \%)$ and seniors over the age of $65(0.9 \%)$. According to Gaetz et al (2014), these figures show that "both women and youth are much more likely to experience 'hidden homelessness' and not necessarily engage our emergency support systems" (Gaetz et al, 2014 p.42).

In addition to the above suggestions, that women are more likely to experience episodic homelessness and hidden forms of homelessness (Gaetz et al (2014), it has been recorded that 44\% of single parents in core housing need are female and only 37 percent are male (CMHC, 2016). Yet failure to locate this hard-to-reach population have led to half-baked policies and it has been argued that "the specific needs of sub-populations, such as youth and women fleeing violence, have not been addressed" (Gaetz et al, 2014 p.15). Regrettably, women's plight with homelessness will remain invisible if we simply assess hidden homelessness based on the tenure and housing precarity, because women's seemingly stable fee-paying housing situation, does not necessarily constitute security and affordability issues.

Although housing precarity captures the physical condition of housing, it does not capture the intersectionality of housing affordability with precarious employment, unemployment, discontinued supports, eviction, gender-based division of labour, violence and inadequate institutional care that place barriers to proper housing for women.

\subsection{A case for the Redefining of Hidden Homelessness}

Early feminist contributions to the redefining of homelessness among women are found in the works of Watson and Austenberry (1986) and Watson (1988). They put forward the idea that women's homelessness should be understood as a continuum of more and more fragile housing arrangements which are closely tied to the sexual division of labour and women's social 
vulnerabilities as wives, mothers, and daughters. In more recent years, feminist scholars have discovered that the feminization and racialization of poverty, is directly linked to the overrepresentation of women, recent immigrants and visible minorities within the homeless community (Drabble, 2017; Klodawsky, et al, 2015; Muzorewa, 2014; Walsh, et. al, 2016; 2015; Watson, 2011). These studies reveal that women experiencing homelessness are often hidden and inadequately housed in unsafe, substandard, unaffordable and unsuitable housing. Although they would want to change their living conditions, they do not have the means or capacity to do so due to the lack of affordable housing, limited social housing stock, inadequate income supports, lack of affordable childcare, the persistence of gender-income gap and the new social risks associated with job precarity.

Despite women's vulnerabilities in meeting housing costs, a clear definition of housing affordability is lacking in the Canadian definition of hidden homelessness. $\mathrm{COH}$ (2012) put forward the importance of context in the definition of housing affordability and argue, "there cannot be a universal definition of a minimum standard of community housing, nor of affordable housing" (p. 2). Hence, there are few statistical measures used in Canadian provinces and cities that can help to clear the confusion around definitions of housing affordability standards, based on local needs. For example, housing affordability can be measured as a percentage of the Average Market Rents (AMR) in a city. This is normally at $80 \%$ or less. It can also be measured as a percentage of household income, that is; housing costs should not exceed $30 \%$ of total-before-tax household income (CMHC, 2018, Government of Ontario, 2018). However, the use of $30 \%$ of household income as a measure of housing affordability may be viewed as a possible 'catch all'. For example, someone could be earning $\$ 60,000$ yearly but spending $50 \%$ of their income on housing. Taking into account context, that level of income in high market rentals such as Toronto and in Barrie make such an individual precariously housed. As such it is not about the choices that are being 
made by this individual, but rather, it is about the condition of the housing market and, this is systemic.

As indicated in the previous section of this chapter, CMHC's definition of people in core housing captures affordability, adequacy and suitability issues. It also focuses on the fact that individuals and families in core housing either spend over $30 \%$ of their total household income before-tax on rent, live in dwellings that need major repairs or live in over-crowded conditions that lack enough bedrooms for the size of a household (CMHC, 2018). Whereas CMHCs definition of core housing need, best captures low-income women's experiences on the housing market, this definition does not acknowledge systemic barriers to one's current housing situation. That is, CMHC's definition of housing precarity is gender neutral and ignores issues of safety hence it fails to capture women in abusive relationships because they lack the means or capacity to overcome housing precarity. Again COH's definition of hidden homelessness does not account for safety/violence that precariously housed women face at the hands of male partners they depend on for housing.

In this regard, hidden homelessness has not been captured well by $\mathrm{COH}$ or $\mathrm{CMHC}$ in their definitions of housing precarity and/or housing affordability. These narrow definitions, may give a façade that precariously housed individuals are in fact permanently housed, regardless of how insecure they feel, in terms of safety and affordability. As such they are not a priority in agenda setting. Subsequently, policy makers in liberal welfare states like Canada, fail to make inroads in addressing the housing needs of low-income women because often narrow definitions of hidden homelessness are used in an environment of fiscal restraint to conceal the extent and gravity of homelessness in Canada.

Although some women experiencing hidden forms of homelessness may qualify in the category of 'at-risk-of-homelessness' as some are faced with eviction notices and others are a pay- 
cheque away from being homeless (Drabble, 2017), yet the majority of precariously housed women have the appearance of housing security. They may not even be deemed at risk. Women may be in precarious employment but may live with abusive partners that provide relative financial security. Hence, despite the fact that the violence may place them at risk of homelessness, the relative economic security somewhat conceals the risk. With their income/employment alone, they face various systemic barriers that hinder them from acquiring safe and adequate housing.

Although gender economic inequality has been acknowledged by many, lack of mobility, job precarity and limited affordable housing options are a part of women's experiences with hidden homelessness that is rarely talked about. Yet these systemic barriers fuel continued housing instability in the lives of women and are extremely stressful and put women in survival mode. They will work two jobs to cover rent or engage in survival sex where they will stay with their abusers to avoid absolute homelessness and to protect their children from being taken away by child protection (Drabble, 2017; Watson, 2011). In light of the limitations laid here, there is an urgent need to re-define hidden homelessness to incorporate women's diverse experiences. Also, to begin a conversation to determine whether using terminologies such as 'housing precarity' or 'corehousing-need,' in fact masks women's experiences with hidden homelessness and delays the urgency that vulnerable women may be facing. Without a doubt use of flowery language such as this, has often been used to propagate neoliberal agenda related to individualism and drawbacks on social spending.

It is not surprising that some researchers and policy entrepreneurs have sought for the redefining of hidden homelessness among women, in ways that incorporate women's experiences and give a voice to women's rights to adequate shelter and human dignity (Drabble, 2017; Spring \& Klassen, 2015). These studies argue that the definition of adequate housing should include issues of safety, affordability, quality and suitability standards. For example, in his report on women's 
homelessness, titled Finding Her Home: A Gender-Based Analysis of the Homelessness Crisis in

Winnipeg, Drabble, 2017 identifies hidden homelessness among women as follows:

Women experiencing homelessness are more likely to be hidden via overcrowded stays with acquaintances, friends or family. Women are less likely to search out the existing shelter system due to safety fears. Women's role as caregiver and mother, intersecting with race and poverty leads many women to avoid help due to risk of child apprehension from CFS. Women with addictions struggle to get help and fear their children being removed. The entire experience of homelessness is extremely stressful and places women in survival mode, exasperating mental health and physical health. (p. 8).

Spring and Klassen (2015) further explain, that women's hidden homelessness

might include "overcrowding, staying in violent relationships to maintain housing, living in unsuitable or violent situations to maintain custody of one's children and paying high rents that make other necessities like food, unaffordable" (p.1).

Whereas Drabble (2017) and Spring and Klassen (2015)'s definitions describe women's experiences with hidden homelessness, the Homelessness Hub, went even further to incorporate a critical perspective in defining the nature of hidden homelessness among single women:

Women's homelessness is often hidden. A woman may be temporarily staying with friends or family or living in a household where she is subject to family violence. Women at risk of eviction or living in illegal, overcrowded or unsafe buildings are also part of the hidden homelessness problem. Often a woman has very few choices when looking to access safe, appropriate and affordable housing. Various economic, political and social issues further hamper a single woman's hope of finding housing. There is a need for research that takes into account the gender-specific experiences of trauma faced by women, such as family violence, separation and divorce... and poverty which disproportionately affect women and exist as root causes of homelessness. ...In addition to women's experiences of intimate partner and family violence, immigration issues, lack of social supports and other barriers to stability, also play a role in the pathways to homelessness for women. (Homelessness Hub, n.d) ${ }^{6}$.

${ }^{6}$ Except from Homelessness Hub Website https://www.homelesshub.ca/about-homelessness/population-specific/singlewomen 
Despite these definitions or acknowledgment of women's experiences in the definitions of hidden homelessness, more needs to be done at policy level, to direct housing strategies in ways that honour women's diverse experiences. With the recent introduction of a gender-based National Housing Strategy (NHS) 2017, Canada is beginning to recognize, acknowledge and accept the knowledge gaps that exist in defining homelessness among women. Through the NHS, Canada conceded for the first time, that a knowledge gap exists at the policy level, specifically in attempting to understand the discrimination and housing insecurity faced by women. These women are single, racialized, seniors, refugees, members of the LGBTQ2, LGBTQ2 youth and Indigenous youth (Government of Canada, 2018). The NHS policy document further details that the current gaps in knowledge extends to a lack of data on women who are homeless, noting that women fleeing family violence and those experiencing hidden homelessness, are not captured in Canadian homelessness statistics. According to the NHS, women are over-represented in low-income earners by $70 \%$ and constitute $65 \%$ of social housing renters, which leads to a lack of understanding on how the poor conditions of social housing affects women.

Inadequate enumeration of homelessness among women, limited research on hidden homelessness and limitations in the established definition of what constitutes hidden homelessness in Canada, can result in the issue of gendered homelessness, being put on the back burner at policy planning tables. As such, we should not rejoice in seeing equal numbers for men and women experiencing hidden homelessness. Rather, we should challenge the narrow definitions that lead to the silencing of women's experiences in the enumeration of homelessness. Therefore, in light of the above, calling the condition that women find themselves in, 'housing precarity,' 'at risk or homelessness' or anything less than hidden homelessness, undermines their right to adequate shelter and dignity as human beings. The discourse on homelessness and responses to the housing crisis ought to be inclusive of women's experiences with hidden forms of homelessness. Although 
the IH policy is considered the most viable response in an environment of fiscal restraint (Buitelaar, Needham \& Kam, 2014; Calavita \& Mallach, 2010; Crook \& Monk, 2011; Kam, 2014; Mah \& Hackworth, 2011; Morrison \& Burgess, 2014; Wellesley, 2010), what remains to be discovered is how this policy is being implemented and sustained in Ontario, and how effective it is in increasing affordable housing stock particularly for women experiencing hidden homelessness in Toronto and Barrie.

\subsection{Purpose of the Study and Contributions to the Field of Knowledge}

For the first time, the Canadian government, through the NHS, conceded that the current knowledge gaps in Canada's understanding of gender-based homelessness, and a lack of gendersegregated statistics on homelessness, is problematic as it "makes it difficult to assess the impact housing programs and initiatives may have on certain groups" (Government of Canada, 2018 p.27). Given the current housing problems throughout Canada, and the multitude of alternative policy solutions vying for the attention of policy-makers, what is left to be discovered is how women experience hidden forms of homelessness and how service managers are using inclusionary housing policies to respond to this problem.

Whereas women's experiences with hidden homelessness are not being measured in definitions of hidden homelessness or evaluations of inclusive housing policies, this study argues that one cannot separate issues of homelessness from violence against women, lack of affordable housing (particularly lack of social housing), poor housing conditions, job precarity, mobility issues and the feminization and racialization of poverty. In taking these various issues and concerns into account, to say that women are precariously housed is an understatement. Some low-income women may be working two jobs to remain housed and others may be living in abusive relationships to avoid absolute homelessness, all these acts of survival mask housing insecurity and 
give an illusion of stability. To call these experiences anything outside of hidden homelessness, minimizes the seriousness and often tragic consequences women find themselves in attempting to remain housed.

As such, the purpose of this study was three folded. First, this study sought to uncover how women experience hidden homelessness in Toronto and Barrie, and called for the re-defining of hidden homeless to capture women's experiences. Second, the study endeavoured to analyze, understand, and, evaluate the implementation of various Inclusionary Housing programs and strategies in Toronto and Barrie. Third, the study examined the effect of IH policy on the Ontario housing landscape as it relates to the needs of diverse groups of women experiencing hidden homelessness. This study brings a gendered lens to the IH policy and highlights its strengths and weaknesses in meeting the needs of diverse groups of low-income women experiencing hidden homelessness. This study also brings a feminist intersectional lens into the definition of hidden homelessness, which may be useful in guiding policy responses to hidden homelessness. To achieve this, I sought to answer a very specific core question:

\subsection{Research Questions:}

\section{Core Questions:}

How do low-income women in Toronto and Barrie experience hidden homelessness? How do their experiences expand or challenge the established definition of hidden homelessness?

\section{Sub-questions:}

1. How have service managers in Toronto and Barrie used the Inclusionary Housing policy to address housing affordability issues in their jurisdiction?

2. How do inclusive housing policies relate to the experiences of low-income women in Ontario?

3. What data needs to be collected or incorporated to inform levels of success of inclusionary housing policies in general, and specifically to include women's experience? 


\subsection{Conceptual Framework}

To better understand the phenomenon of hidden homelessness and expose policy gaps, power dynamics and structures of domination that influences this phenomenon, I integrated a Feminist Critical Policy Analysis (FCPA), with the concept of gender mainstreaming and intersectionality, throughout this study. A feminist gender-based analysis is a more coherent theory that enabled me to analyze the IH policy from participant's standpoint, to determine the extent to which it is able to meet the diverse needs of women experiencing hidden homelessness. This approach also enabled me to unpack the underlying nuances at play in policy processes that influences women's experiences with hidden homelessness. In addition, given that not all women experience homelessness the same, I incorporated the intersectionality framework to examine how interlocking systems of power disproportionately impact racialized women, immigrant women and women from the LGBT community.

\subsection{The Terminology of Housing: Operational Definitions}

It is essential to provide the array of definitions being used in debates on housing and homelessness in Canada. These concepts are sometimes used interchangeably by some creating some confusion. To clarify any confusion that may arise in this study, I present the following glossary of terms:

Affordable housing refers to any type of housing or build-form that is demeaned affordable, according to well defined measures by the local government, provincial government or CMHC. In Ontario, affordable housing is measured as $30 \%$ of the total gross household income or a percentage of the Average Market Rent, which is determined by the local government (CMHC, 2018; ONPHA, n.d) 
Public housing: Refers to predominantly large housing projects and high-rise buildings built in large urban centres in the 1960s, through CMHC, for low-income families. Ownership was downloaded from the Province to the 47 municipal service managers in 2001. These housing complexes are therefore owned and managed by local housing authorities with local boards. They are 100 per cent rent-geared-to-income (ONPHA, n.d).

Social housing refers to either non-profit rentals or co-operative housing funded by a legally-prescribed government program (although some social housing providers are now building housing with no government funding). In Ontario, the majority of social housing is owned and operated by the members of the Ontario Non-Profit Housing Association or Ontario Co-operative Housing Federation (ONPHA, n.d).

Rent-geared-to-income (RGI) or rent subsidy: Is the subsidy paid to a housing provider to allow a certain number of units to be rented to low-income tenants at an affordable rate. The RGI or rent subsidy covers the difference between the government approved average market rent (AMR) and the actual rent paid by the qualifying tenant, which is $30 \%$ of their total household income before tax (ONPHA, n.d).

Rent supplements: Is the amount paid to a landlord to bridge the gap between a tenant's rentgeared-to-income and the market rent ceiling set by the municipality, for units rented to applicants from the social housing waiting list. Historically, private landlords have been interested in signing rent supplement agreements when vacancy rates are high; otherwise they have not been quite so interested (ONPHA, n.d).

\subsection{Conceptualization and Delineation of Study}

Hidden homelessness: Given the various limitations in the definition of hidden homelessness, mentioned in this chapter, there appears to be an urgent need to re-define the 
boundaries of hidden homelessness with a gendered lens. The definition of hidden homelessness in this study is all encompassing and takes into account women's experiences with hidden homelessness. It will capture aspects of adequacy, suitability and affordability, as laid out by CMHC's definition of core housing need. However, in integrating the feminist-intersectional perspectives, the current definition of hidden homelessness sought to encapsulate specific experiences of the violence that women face at the hands of partners they depend on for housing, the discrimination immigrants and visible minorities face in trying to secure or remain housed, and the instability and stressors associated with being precariously housed. This new definition of hidden homelessness views adequate housing as a human right, and anything less as a gross violation of individual rights as a citizen.

Hidden homelessness in this study is informed by an intersectional gendered lens and focuses on systemic barriers that may hinder women from accessing safe, adequate, suitable and affordable housing, and may contribute to violence and the removal of human dignity in the lives of women. As such hidden homelessness in this study is defined as having one or more of the following housing typology:

- Safety/dignity - Being forced to live in cheap but substandard dwellings that need major repairs and often exposed to health hazards such as mould, insect infestation and outside elements.

- Safety/Dignity - Being forced to live in cheap but overcrowded and often unsanitary conditions that lack enough bathrooms, kitchens and bedrooms to accommodate household size as laid down by the National Occupancy Standard (NOS) requirements.

- Safety/Dignity - Having no choice but to double up with friends and relatives to avoid absolute homelessness and living in cheap hostels, motels, rooming houses or other dwellings to avoid absolute homelessness, whether short term or long term.

- Safety/Dignity - Being forced to live with an abusive partner, abusive friend, abusive relatives or an abusive stranger to remain housed or being forced to return to an abusive relationship to avoid absolute homelessness 
- $\quad$ Systemic - Being forced to live in cheap but rough neighbourhoods, where one does not feel safe due to lack of affordable housing.

- Systemic - Having a household income of $\$ 60,000$ or less and spending more than $30 \%$ of total household income before-tax on housing costs, resulting in food insecurity.

- Systemic - Being institutionalized in hospitals, prison, rehab centres, transitional housing, with no permanent housing or immediate prospect of finding one, after leaving the institution.

- Systemic - Being denied residency in some buildings and having difficulties obtaining adequate, safe and affordable housing due to discriminatory tendencies by landlords or housing support workers, based on gender, race, ethnicity, sexual orientation, age and ableism.

This gender-based intersectional definition of hidden homelessness moves away from exclusionary practices, and offers a framework that is all encompassing and that can influence housing policies in a positive way. It broadens future discourse on hidden homelessness to bring about a renewed focus to the untold stories of various vulnerable groups in their quest to find adequate housing or remain housed.

As well, this study focuses on the implementation of inclusionary housing policies in Toronto and Barrie only. The Inclusionary Housing policy, (also known as Inclusionary Zoning in Canada), refers to policies and programs aimed at increasing affordable housing stock in preexisting and new developments, through the use of zoning and re-zoning practices, concessions and trade-offs between local governments, private developers, not-for-profit agencies and private homeowners (Mah, 2011).

Literature review in this study is limited to the past 15 years and only focuses on literature on (a) housing and homelessness among women in Toronto, Barrie, Ontario and elsewhere, and (b) the discourse of the Inclusionary Housing policy in Canada and other developed countries. The sample for this study was drawn from a population of women experiencing hidden homelessness, policy makers, private developers and housing stakeholders in Toronto and Barrie, only. 


\subsection{Issues outside the Scope of this Study}

Although this study focuses on contemporary housing trends and the problem of hidden homelessness among women in Toronto and Barrie, I did not conduct a content analysis of the history of the housing policy in these two cities. Whereas various housing initiatives that have taken place in Toronto and Barrie were mentioned, detailed specifics of these initiatives were beyond the scope of this study. In addition, although this study sought to evaluate the inclusionary housing policy as it relates to low-income women, it does not address the historical context the inclusionary housing policy.

\subsection{Organization of the Dissertation}

This study seeks to explore the problem of hidden homelessness as it relates to low-income women in Toronto and Barrie. I was interested in understanding why, and how, women experience hidden homelessness, and how policy-makers are responding to this problem. I am arguing that although there are no statistics on hidden homelessness among women, in Toronto and in Barrie, this problem is more prevalent and widespread than normally reported. I am also arguing that despite the move towards the marketization and corporatization of affordable housing through IH policies, very little is known about the effectiveness of this program, particularly as it relates to women in core housing need. As such I am evaluating perceptions of the IH policies on the Canadian housing landscape, in general, and specifically on women experiencing hidden homelessness. In this regard, the next few chapters will be laid out as follows:

Chapter 2 begins literature review and focuses on exploring the discourse of homelessness from the individual, structural, and integrative approaches. Effective responses to homelessness among women, is grossly tied to proper conceptualization of this problem. As such, specific attention is given to structural explanations in the gendering of hidden homelessness. 
Chapter 3 theoretically grounds the study within an integrative model which encompasses the feminist critical policy analysis, gender mainstreaming and intersectionality. I considered the importance of feminist knowledge in informing policy and argued for gender mainstreaming of woman friendly policies as the basis of this evaluative research. I also considered the diversity of women experiencing hidden homelessness and acknowledged the differences in their lived experiences. As such, I incorporated an intersectionality approach, which makes room for the multiple forms of oppression, in shaping the lives of racialized women, immigrant women, and women from the LGBTQ communities.

Chapter 4 focuses on research methodology. I chose qualitative research methods in order to allow me to produce data grounded in the participants' standpoint, to better understand the problem of gendered hidden homelessness among women and policy responses thereof. The sample was drawn from diverse women experiencing hidden homelessness in Toronto and Barrie and policy makers, private developers, and community stakeholders working to end homelessness in these two cities.

Chapter 5 begins the data analysis. Data in this chapter confirms the worsening housing situation in the cities of Toronto and Barrie. This chapter unpacks women's struggles with hidden homelessness within a hot and hostile private market, and identifies how they are rendered powerless, compelled to live in poor, substandard conditions, and taken advantage of by slumlords.

In Chapter 6 I sought to understand factors influencing hidden homelessness among women. I focused on analyzing the perception of policy-makers, stakeholders, women and private developers, as it relates to gendered homelessness. In applying gender mainstreaming to data analysis, I was particularly attentive to the language used by policy makers and stakeholders in describing hidden forms of homelessness among women, and in the conceptualization of housing affordability. In addition, employing an intersectional approach, I examined the politics of 
differences in women's experiences of hidden homelessness and addressed systemic layers of oppression that go beyond gender.

Chapter 7 Is an extension of issues raised in Chapter 6, but it explores the concealed tentacles of hidden homelessness and brings to open underlying factors that contribute to the persistence and maintenance of hidden homelessness among women. Evidence points to a lack of understanding by some policy-makers and stakeholders, as to what constitutes hidden homelessness among women, and how to end it.

Chapter 8 examines how the IH policy is being implemented and sustained in Toronto and Barrie. Focus was given to the challenges raised by policy makers, private developers and stakeholders, in the implementation of various types of IZ strategies in Toronto and Barrie.

Chapter 9 deals with the perceived outcomes of the IH policy as it relates to diverse groups of women experiencing hidden homelessness. It should be noted here, that the impact assessment of the IH policy is situated within the Feminist Critical Policy Analysis framework.

Chapter 10 presents a discussion of findings from this study and the way forward. Data from in-depth interviews with Policy-makers and frontline workers suggests that, when it comes to hidden homelessness among women, what was lacking was an integrative holistic approach that caters for the diverse needs of women experiencing hidden homelessness.

Chapter 11 provides a summary and overview of key findings and speaks to the contribution this study makes to the literature. This study reveals that, women situated within the current hostile housing market were systemically disempowered, felt unheard and either lived in unaffordable, unsafe, substandard housing or shared spaces that negatively impacted their health and wellbeing. Most evident was the violence experienced by women as a result of their living conditions, and the underfunding of women's causes. Frontline workers and community stakeholders revealed that lack 
of funding limit their ability to effectively deal with the problem of hidden homelessness and proposed a more integrative approach to ending homelessness.

In addition, this study shows that despite increased interest and the move towards $\mathrm{IH}$ strategies, policy-makers believed the IH policy has not yielded any significant effect on the housing landscape. Whereas the recent introduction of Bill 7of the Affordable Housing Act (2016), that gives municipalities authority to implement IH strategies, is a welcome move, the slow implementation process, challenges in negotiating with developers, the high cost of land, and lack of political will to end the problem of hidden homelessness, particularly from higher levels of government, further dampens the effects of $\mathrm{IH}$ strategies and exacerbates the problem of hidden homelessness among women. Policy-makers were however hopeful that the recent re-introduction of the National Housing Strategy2017 with a gendered lens will go a long way in addressing the problem of gendered hidden homelessness among women. However, implementation of the NHS is slow and its impact is yet to be discovered. 


\section{CHAPTER 2}

\section{The De-gendering of Hidden Homelessness - Where are Women?}

A woman-friendly state would enable women to have a natural relationship to their children, their work and public life ... A womanfriendly state would not force harder choices on women than on men, or permit unjust treatment on the basis of sex. In a woman-friendly state women will continue to have children, yet there will also be other roads to self-realization open to them. In such a state women will not have to choose futures that demand greater sacrifices from them than are expected of men.

(Hernes, 1987, p.15)

\subsection{Introduction:}

Homelessness is an ongoing problem world-wide, despite numerous policies aimed at addressing this issue. Poor conceptualization of the problem of homelessness can result in unintended consequences, or ineffective housing policies. In attempting to understand homelessness, some researchers have used metaphors to describe various facets of homelessness, notably "sliding" into homelessness, "pathways", "revolving doors", "exit points" and homeless "careers" (Fopp, 2009, p. 272). Others have explored the importance of theory in the conceptualization of homelessness among various groups of people, and have argued that our understanding of social problems shape the way we respond to those problems, and the policy solutions thereof (Horsell 2006; Kuskoff, 2018; Watson \& Cuervo 2017). Using theories of homelessness can help us to better understand how complex societal issues affect the lives of women experiencing homelessness. Moreover, theories of homelessness can also help us to think critically about issues, that we often take for granted, to uncover why and how people experience homelessness, and why programs intended to end homelessness have not achieved what they were 
set out to do. As such, I begin this chapter by exploring theories of homelessness to enable me to situate women within the context of their lived experiences.

\subsection{Where are Women: Contentions in the Conceptualization of Homelessness}

Historically, there are two schools of thought that seek to explain the issue of housing and homelessness, namely, the risk discourse and the structural discourse. Whereas the risk discourse focuses on individual actions in the creation and maintenance of homelessness, the structural discourse focuses on how broader structures of dominance influence incidences of homelessness among various groups of people (Gerrard 2015; Kuskoff, 2018; Kelly, 2001; Mullaly, 2007; Watson and Cuervo 2017). Over the years, different approaches to ending homelessness have been suggested in various disciplines of public policy, sociology, social work, medicine, women's studies and urban planning. Most notably is the neoliberal govermentality approach (Kelly 2001) and the critical discourse analysis ${ }^{7}$ approach (Fairclough,Mulderrig \& Wodak, 2011), which encompasses the structural approach (Mullay, 2007) and the social justice approach (Watson \& Cuervo 2017).

My choice of structural approach in the conceptualization of hidden homelessness among women comes from the urgent need to move away from the risk discourse and its pre-occupation with individualism and responsibilisation of citizenry (Kelly, 2001), to a more encompassing approach that takes into consideration the new social risks ${ }^{8}$ and the risks associated with the new

\footnotetext{
${ }^{7}$ see see Foucault $(2007 ; 2008)$

${ }^{8} \mathrm{New}$ social risks associated with changing demographics includes the influx of immigrants into Western countries, the increasing role of women in paid work, the erosion of the nucleus family and the prevalence of lone mothers in need of government assistance. see Pateman, Schierup \& Castles (2014). The welfare state reader in Eds. Pearson, Castles \& Naumans. Cambridge: Polity Press.
} 
the Liberal Welfare State ${ }^{9}$ (Esping-Andersen, 2014). Moreover, research underpinning the risk discourse of homelessness is heavily imbedded in the neoliberal governmentality approach which "attempts to reconfigure the practices of government by conceiving the subject as rational, autonomous, choice making and responsible" (Kelly 2001, p.29). Unlike the risk discourse, research underpinning the structural approach argue that poor responses to homelessness is directly linked to the hegemonic masculinity practices that prime policy processes, and the paradigm shift, from Keynesian policies to neoliberal policies, since the mid 1980's (Brushett, 2007; Donnan, 2014; Colderley, 1999; Hulchanski; 2007; 2004; Roberto \& Carroll, 2010). Moreover, the visibly apparent trend related to the feminization of poverty and the subsequent gendering of hidden homelessness, has also been linked to neo-liberal ideals (Drabble, 2017, Little, 2015; Muzorewa, 2014; Oliver, 2013; Price 2012; Watson, 2011).

The contentions in the conceptualization of homelessness have polarized social scientists and politicians since the shift towards neoliberal forms of governance. In recent years, several studies have connected the issue of hidden homelessness among low-income households to structural issues related to the weakening safety net, including inadequate housing policies, claw backs in the area of affordable housing, spiralling housing costs and unregulated rental markets (Toronto Foundation 2016; 2015; UN, 2016; 2009; OCHFC, 2016; 2015; ONPHA 2016, 2015; Cooper \& Skelton, 2015; CCPA 2015; Gaetz at al 2016; 2014; Gaetz, 2010; Waterston, Grueger \& Samson, 2015;). Various feminist scholars have sought to understand why homelessness among women remain unnoticed at policy level (Donley \& Wright, 2012; Drabble 2017; Klowdawsky, 2015; 2006; Mayo, 2011; Murray, 2011; Rahder, 2006; Watson, 2011; Whitzman, 2006;). These feminist studies discovered that homelessness among women is complex and often manifest as

\footnotetext{
${ }^{9}$ In his ground breaking seminal, The Three Worlds of Welfare Capitalism, Esping-Andersen, Gøsta (2014). He situates Canada and the United States of America within the Liberal Welfare Regime that provide localized residual policies that are means-tested and targeted at the least poor within the society.
} 
hidden homelessness. These studies reveal that women are more likely to survive through various means, to avoid absolute homelessness, including; staying away from homeless shelter, living with abusive partners, exchanging sex for accommodation, surf couching with family and friends, living in houses they cannot afford or dwellings that need major repair, using educational residences, sharing a room or an apartment, living in hotels, single rented rooms, or transitional housing, due to affordability problems and for safety reasons.

However, although overwhelming evidence points to structural explanations of hidden homelessness among women, the choices made by the agency in trying to survive experiences of homelessness brings into question structural definitions of homelessness. The contentions around the risk discourse of homelessness is that, individual choices made by women in the course of life may in fact trigger experiences with hidden homelessness. Moreover the decisions they make in the process of surviving hidden homelessness may further exacerbate worsen their condition. As such it has been argued, particularly within debates on neoliberalism in government, that removing agency limit policy responses to homelessness and may result in insufficient housing policies.

However, some have raised issue with the underlying neoliberal expectation in Western governments which requires individuals to "demonstrate greater self-reliance, responsibility and a commitment to self-improvement, and so become empowered to operate independently and successfully within a competitive market-driven economy" (Stonehouse, Threlkeld, \& Farmer, p. 394). They put forward that the move towards the individualization and responsibilization of homelessness in liberal welfare states as driven by anxieties around 'welfare dependency' and 'fiscal responsibility' (Stonehouse, Threlkeld, \& Farmer, 2015). Others have critiqued policies and programs that stem from the risk discourse, and put forward that by situating the problem of homelessness within individual defects, the government abandons its mandate as the protector of basic human rights and dignity and encourages family and/or community responsibility (Kelly, 
2001). In this it offers the least possible supports to the most visibly vulnerable women with addictions and mental health problems (Kirst et al, 2014; O'Campo et al, 2016); victims of domestic violence (Fotheringham, Walsh \& Burrowes, 2014; Dewey, Hankel, \& Brown, 2017), displaced women (Montgomery et al, 2017; Rimawi, Mardama \& John, 2014) and non-institutionalized women (Washington et al, 2010). The risk discourse focuses on exclusionary policies and programs whose main aim is to mitigate risk-factors by increasing funding for women's shelters, temporary transition housing, and training and skills development for back to work programs, and offer limited subsidy within the market at the exclusion of the safety, suitability, and quality of such permanent housing.

Despite continued failed efforts to ending homelessness among women, Canada, like many liberal residual welfare states, continues to use the risk-based discourse, as evidenced by meanstested social assistance and workfare policies adopted in the 1990s (Esping-Andersen, 2014; Pulkingham, 2010). It has been argued that Ontario's workfare policies are the most advanced compared to UK and the rest of Canada, and they push lone mothers into work regardless of how precarious the work is (Caragata, 2010; Evans, 2007; Pulkingham, 2010). The assumptions underpinning workfare policies are that if only able-bodied individuals, who have moral virtues and are devoid of laziness, can advance their education and skills, and work hard enough within the labour market, they should be able to afford housing of their choice. Nonetheless, with the emerging new social risks associated with neoliberalism and the shrinking welfare state, social scientists are gradually moving away from risk based narratives of housing and homelessness to structural narratives, particularly in the feminization of poverty and the gendering of homelessness. 


\subsection{The Gendering of Homelessness: A Structural Discourse}

The gendering of hidden homelessness can be viewed as formal or informal, written or unwritten, stated or unstated statutes, policies, strategies and/or procedures that render women powerless and economically vulnerable to experiences of hidden homelessness. In this regard, the discourse on gender-based homelessness should begin with studies that document the shrinking welfare state and the downloading of family responsibilities on women, and extends to studies that examine the gender income gap, to job precarity, to lack of family support. An extensive body of research reveal that the shrinking welfare state in Canada and other English speaking countries, disproportionately affect women and influences high incidences of poverty and hidden homelessness among women (Baker, et al, 2010; Donley \& Wright, 2012; Drabble, 2017; Duchesne, 2015; Gaetz, Gulliver \& Richter, 2014; Huey \& Berndt, 2008; Klowdawsky, 2015; 2006; Laird, 2007; Walsh, 2016; 2015; Whitzman, 2006). These studies reveal the positionality of women in today's liberal welfare state and contend that with the shrinking welfare state, women are increasingly expected to look to the labour market for income security that allows them to pay rent and put food on the table.

Nonetheless, the emerging phenomenon of gendered homelessness has been connected to demographic shifts related to increases in single motherhood and the growing labour market participation by women (Kim \& Choi, 2013; Brady \& Kall, 2008). Although some have argued for active citizenship and active labour market policies as the most effective way of combating poverty in post-industrialized countries (Rovny, 2014), others contend that the labor market and family structure have undergone significant changes which have weakened their role as welfare providers (Yang, 2014; Taylor-Gooby, 2004). Firstly, the quality of jobs in a neoliberal globalized labour market has deteriorated and well paying, unionized, permanent jobs, are being substituted with low paying, part-time, back breaking, precarious work (Chomsky, 1999; Dean, 2012; Pierson, et al, 
2014). Whereas job precarity enhances the risk of hidden homelessness, in a neoliberal environment, large corporations depend on these types of jobs to make huge profits. For example, in the introductory remarks of his ground-breaking seminal, Power Inc, Rothkarp (2012) describes corporations as "bodies without a soul, ...vampires [and]...squids" whose unquenchable thirst for money will stop at nothing even if it meant ruthlessly choking the whole country of its lifeline (p.12).

Secondly, job precarity in Canada disproportionately affects women. Various studies have revealed shown that women are more likely to have low wages and higher rates of unemployment as contributory factors to higher incidences of poverty and homelessness among this group (Anthias, 2014; Creese, 2011; Creese \& Wiebe, 2012; Cool, 2010; Daddley, 2017; Donnan, 2014; Gaetz et al., 2013, 2014; Klodawsky, 2006; 2015; Knight, 2016; Little, 2015; Trypuc \& Robinson, 2009; Walsh, et al, 2016; 2015; ; Watson, 2011). When it comes to promotion, women are often by-passed due to pregnancy and care giving hence they are over represented in low paying parttime jobs (Canadian Women's Foundation, 2017; OECD, 2014; 2012; UN, 2014). As a result, despite an increase of women in the workforce in most recent years, female employees, particularly in Canada, are greatly under-represented among top income earners, and over-represented in low paying jobs. (Fortin, Bell \& Böhm, 2017). In fact, the gender income gap in Canada continued to grow to a point where Canada was rated 29 out of 34 OECD countries, and is lagging behind its counterparts, Australia, Germany, the United Kingdom, and the United States of America (OECD, 2017).

While some studies have focused on the impact of neoliberal policies on women, others drew attention to multiple forms of oppressions experienced by immigrant women of colour in the Canadian labour market (Creese \& Wiebe, 2012 and Man, 2004; Gupta, 1999; Lui, 2000). Of particular concern is the deskilling of immigrant women. Although the Canadian immigration laws 
target highly skilled immigrants, based on the state's assumption that highly skilled jobs are in demand in the new economic order (Shields, 1995), the deskilling of immigrant women on the Canadian labour market renders them vulnerable to episodic homelessness (Klowdasky et al, 2015; Christine et al, 2015). Despite being highly educated and skilled professionals, immigrant women encountered several barriers to finding employment that is proportionate to their qualifications. Moreover, the devaluing of international credentials and the call for Canadian experience has been viewed by some as engrained in the nature of neoliberal capitalistic values and therefore an assault to citizenry (Mojab, 2000; Shields, 1996). For example, Man (2004), discovered that despite being highly educated and experienced, women immigrants are viewed and treated as a cheap source of labour and are relegated to back-breaking, part-time menial work with no security, benefits or flexible hours.

The institutionalization of job precarity extends to transnational organizations who appear to wield unbridled power to direct government agenda on the labour market. Rothkopf, 2012 makes a case that politicians and policy-makers often fear that too much regulation of the labour market will push transnational corporations elsewhere in a globalized world, resulting in job shortages. Furthermore, Lindblom (1982) argues that the public sector has been captured and that governments, particularly in Western countries, have become prisoners of the market, often resulting in policy inertia and social stagnation. Likewise, some studies (Brodie \& Baker, 2011; Thomas, 2010), have shed light on the negative impact of neoliberal policies on women, and put forward that both the federal and provincial governments were prioritizing corporate loopholes and fiscal health at the expense of the wellbeing of women through regressive policies such as:

(a) Changes in EI resulting in reduced benefits and fewer women qualifying to receive benefits (Townson \& Hayes, 2007); 
(b) The introduction of Ontario Bill 47 which freezes minimum wage in Ontario, at \$14.00/hour from 2018 to 2020, below livable wage (Di Cesare, Simon, \& O’Ferrall, 2018; Global News, 2018; );

(c) De-regulation of labour laws through Bill, 7; Bill 49 and Bill 147 between 1995 - 2001, to make Ontario “open for business” and to create labour flexibility for employers while exposing low-income earners to market forces (Brodie \& Baker, 2011).

Beyond discriminatory practices in the labour market and the weak labour laws, the devaluing of feminist knowledge has been raised by some scholars who contend that the politics of exclusion in public policy operates through (i) the silencing of women and marginalized groups, (ii) uneven allocation of resources, and (iii) secrecy and unilateral decision making (Brodie, 2011; Scala, 2008). Others have concluded that reforms within public institutions, fail to meet the needs of women because politics, policies, and programs ignore, minimize and view with contempt, feminist discourse and adopt policies that reflect male norms and values (McPhail, 2003; Marshall, 1999; Hindman, 1990). In this regard, some are calling for a more coherent and integrative approach to homelessness that takes into account, both, the individual and structural risk factors influencing homelessness.

\subsection{An Intersectional Discourse: Structural and Individual Risks}

In moving towards an integrative approach to housing and homelessness, Anauchi (2005) and Donnan (2014) have raised concern over scholars that get fixated on either individual or structural determinants of homelessness, and they argue for an intersectional analysis, noting that individual choices and personal circumstances intersect with systemic barriers, including inadequate distribution of resources, racism and other forms of discrimination that perpetuate homelessness. As such, according to Anauchi (2005) and Donnan (2014), an intersectional 
analysis ${ }^{10}$ of homelessness should include individual and structural risk factors. Several feminist studies have used an intersectional gender-based approach to better understand the socioeconomic conditions that contribute to experiences of homelessness among diverse groups of women (Baker, et al, 2010; Donley \& Wright, 2012; Drabble, 2017; Duchesne, 2015; Gaetz, Gulliver \& Richter, 2014; Huey \& Berndt, 2008; Klowdawsky, 2015; 2006; Laird, 2007; Verloo, 2016; Walsh, 2016; 2015; Whitzman, 2006). These studies concluded that, whereas current policies and programs are inadequate and there is growing evidence pointing to the feminization of homelessness, this alone, cannot completely account for hidden forms of homelessness. Rather the intersections of gender, with systemic forms of discrimination and gaps in policy, coupled with individual risk factors associated with domestic violence, single motherhood, immigrant status, level of education and the availability of a strong support system, all come together in the creation of hidden homelessness among women.

It should however be noted here, that while acknowledging the intersectionality of personal, interpersonal and structural risks in the creation of hidden homelessness among women, there is no denying that structural factors are by far, the most dominant of them all. For example, several feminist studies have connected the feminization of hidden homelessness to violence against women. Inadequately housed women are left with no choice but to remain in abusive relationships, exchange sex for shelter, live at the mercy of slumlords and/or stay in unsafe, over-crowded conditions, out of fear of becoming homeless with their children (Dewey, Hankel, \& Brown, 2017; Donnan, 2014; Drabble, 2017, Little, 2015; Muzorewa, 2014; Oliver, 2013; Price 2012; Watson, 2011). As such, some feminist scholars have put forward that homelessness should be viewed as a

\footnotetext{
${ }^{10}$ Intersectional analysis of homeless focuses on the fluidity of homelessness and the diversity of risk factors that result in experiences of homelessness, from systemic factors, such as a lack of affordable housing, racism and discrimination; to the individual/household's risks associated with financial, mental, cognitive, behavioral or physical challenges, gender and ethnic identities (Canadian Observatory on Homelessness, "Canadian Definition of Homelessness", 2012. Homeless Hub: www.homelesshub.ca/homelessdefinition/).
} 
form of structural violence against women, noting that violence that result from the feminization and racialization of poverty, hunger and homelessness have far reaching negative impact on women's health and wellbeing than violence that happens in interpersonal altercations (Donnan, 2014; Muzorewa, 2014; Oliver, 2013; Price 2012).

To better understand the phenomenon of hidden homelessness among women in Toronto and Barrie and examine policy gaps, power dynamics and structures of domination influencing this phenomenon, the next chapter will explore the conceptual framework guiding this study. I have integrated the Feminist Critical Policy Analysis (FCPA), with the concept of gender mainstreaming and intersectionality, to allow me to come up with a coherent model that will help to uncover underlying dynamics that influences policy processes. 


\section{CHAPTER 3}

\section{An Integrative Approach}

Gender mainstreaming is the (re)organisation, improvement, development and evaluation of policy processes, so that a gender equality perspective is incorporated in all policies at all levels and at all stages, by the actors normally involved in policymaking.

(Council of Europe, 1998 p.12)

\subsection{Introduction: Feminist Critical Policy Analysis}

The shift towards neoliberal forms of governance, the shrinking welfare state, and the devaluing of feminist knowledge, coupled with lack of a coherent public policy theory that focuses on women's issues, led to the emergence of the Feminist Critical Policy Analysis (FCPA) in the 1990s. This concept was first introduced by Catherine Marshall in her examination of education policies and programs (Marshall, 1997a; 1997b; 1999). The FCPA questions the silencing of women's voices within new forms of governance, and queries why women's issues and concerns are "declared irrelevant, postponed, co-opted, put on the back-burner, assigned responsibilities with no training, budget personnel, or time, or otherwise ignored" (Marshall, 1997, p. ix). This model incorporates critical theory with feminism in ways that challenge traditional ways of knowing in policy analysis. For instance, Marshall (1999) and Shaw (2004) critique of education in the USA, revealed how policies and broader structures within colleges and universities operate as barriers to higher education for women.

Given that society is organized around gender, proponents of FCPA challenge the notion of gender neutrality in decision making and put forward that gender neutrality in public policy only serve to reinforce gender inequalities (Borchorst, 2008; Brodie, 2011; Hernes 1987); Marshall, 1999; Scala, 2008; Shaw, 2004). They argue that gender should not be considered as an aftermath 
of policy but rather, should be incorporated throughout the policy process to determine the perceived impact of a policy on women and other vulnerable groups. The FCPA approach is tied to the concept of state feminism whose focus is to ensure that governments come up with womenfriendly policies. Hernes (1987) coined the idea of a women-friendly state and defines it as:

"A woman-friendly state would enable women to have a natural relationship to their children, their work and public life ... A woman-friendly state would not force harder choices on women than on men, or permit unjust treatment on the basis of sex. In a woman-friendly state women will continue to have children, yet there will also be other roads to self-realization open to them. In such a state women will not have to choose futures that demand greater sacrifices from them than are expected of men." (p. 15)

Beyond women friendly policies in the public sector, the FCPA calls for women friendly policies in the private market. Although negotiating and enforcing gender equity policies in a capitalistic, profit-driven environment can prove to be an uphill battle, in recent years, the Scandinavian gender equality model has been rather successful in renegotiating the private-public split in ways that encourage women-friendly policies all round (Borchorst, 2008). A strong focus on state feminism by Scandinavian countries enables greater political participation and representation of women in positions of power, who in turn are able to influence gender equity policies (Borchorst, 2008). Although the current Liberal Government of Justin Trudeau has managed to achieve a more gender inclusive government, this has not yet translated to policy gains in the area of housing, with the exception for the recently announced National Housing strategy.

\subsection{The Challenges of Feminist-Based Policy Analysis}

Although the FCPA has made strides in pushing for women's friendly policies, there appears to be a disconnection between acknowledging gender inequality and implementing policies that, in fact, narrow the gender gap. Some have argued that even though formally speaking gender 
equality is (a) universally embraced by the international community, (b) enshrined in national constitutions, and $(c)$ identified as an important element in international human rights agreements, to which most countries are signatories to, in practice gender-based inequalities are not readily acknowledged (Ackerly, 2009; Pew Research Center, 2010). Hence gender-based inequalities and remain entrenched within societies

One of the greatest constraints in implementing gender friendly policies is the lack of understanding of how gender perspectives can be identified, highlighted, and addressed through policy formulation and program development (United Nations, 2002). Moreover, although there is no denying that the FCPA has come a long way in raising women's issues and concern at the policy level, it is often met with resistance and scepticism as it is viewed as being anti-men.

Some point out that failure to incorporate gender perspectives in policy, and the undervaluing of feminist research at planning tables that inform resource allocation, is reflected in gender neutral budgets (Women's Budget Group, 2013; Knight, \& Rodgers, 2012; Scala, 2008; Broddie \& Bakker, 2008), and colour-blind budgets (Sandhu \& Stephenson, 2015). Moreover, bureaucratic attitudes towards gender equality have remained underdeveloped. As well, with the emergence of the New Public Management (NPM), state feminism is not adequately equipped to address new realities associated with market-based policies. Specifically, femocrats ${ }^{11}$ and feminist advocates have not been able to capture the complexity of new forms of governance as it relates to the welfare state retrenchment, neoliberalism and globalization (Knight, \& Rodgers, 2012; Kantola \& Squires, 2012). Moreover, in a neo-liberal environment, constant underfunding of organizations representing women coupled with negative bureaucratic attitudes towards femocrats, slow down feminist activities within government departments and hinders positive responses towards gender equality (Hankivsky, 2013; Knight, \& Rodgers, 2012; Rodgers \& Knight, 2011).

\footnotetext{
${ }^{11}$ A femocrat is a female bureaucrat in an agency or government department dealing with women's issues.
} 
Without the acknowledgement of hegemonic masculinity in power relations that shape social structures (Gramsci, 1971; Bourdieu, 1991), policies and programs create, legitimize, and justify, the subordination of women in society. It is not surprising that feminist advocates are calling for the re-evaluation of the underlying nuances and power dynamics (both visible and invisible), that shape budget allocation and policy formulation, and therefore, hinder the achievement of equity and social justice for women and racialized groups (Beaumont, 2016; Sandhu \& Stephenson, 2015; Scala, 2010; Broddie \& Bakker, 2008).

Whereas the need to account for gender in policy formulation has been raised by many scholars as a matter of social justice, what is missing is an effective model to guide the course of action in a way that is acceptable to various constituencies, including both men and women. Hence, the stubborn persistence of gender inequality calls for the broadening of the FCPA, to include strategies that go beyond critiquing the wrongs of patriarchy, to revamping its enduring hegemonic structures that limit human potential.

As such, this study seeks to broaden the FCPA by integrating the concept of gender mainstreaming (GM), to address the various conceptual gaps mentioned above and to better understand women's experiences with hidden homelessness and the policies meant to address this issue. As well, given the diverse nature of women experiencing hidden homelessness, the current study will also incorporate the theory of intersectionality to determine the extent to which the IH policy is meeting the needs of diverse groups of women in core housing needs.

\subsection{Integrating Gender Mainstreaming Strategy}

Gender mainstreaming (GM) is proving to be less threatening towards various constituencies and more effective in responding to current realities brought about by globalization and neoliberalism. This concept emerged out of the need to bring to bear a gender perspective in the 
decision making process and program formulation. GM is not only necessary in securing the rights of women, but also in securing the rights of men and ensuring social justice for all (United Nations, 2002). It exposes the urgent need for change in institutional and governmental goals, strategies and actions, to ensure that both genders benefit equally from proposed policies and programs. It broadens the feminist critical policy analysis in ways that attract less resistance from feminist detractors. Gender mainstreaming is not a new concept, rather, it builds on previous feminist efforts aimed at making gender central in policies and programs. It was first highlighted at the United Nations women's conference in Beijing in 1995, and was further expounded by the United Nations (UN) Economic and Social Council (ECOSOC) in 1997 (United Nations 2002).

In laying out the overall principles of this concept, the UN ECOSOC agreed conclusions, defines gender mainstreaming as:

...the process of assessing the implications for women and men of any planned action, including legislation, policies or programmes, in all areas and at all levels. It is a strategy for making women's as well as men's concerns and experiences an integral dimension of the design, implementation, monitoring and evaluation of policies and programmes in all political, economic and societal spheres so that women and men benefit equally and inequality is not perpetuated. The ultimate goal is to achieve gender equality. (United Nations ECOSOC, 1997 p.3).

The concept of gender mainstreaming (GM) is now viewed as a global strategy for achieving gender equality. It is increasingly gaining popularity in the socioeconomic and political agenda of global governance institutions such as, the United Nations (UN) and the Organization for Economic Cooperation and Development (OECD), as well as "regional supra-state bodies such as the European Union, the Nordic Council of Ministers, the Organization of American States" and the Council of Europe (True, 2003 p.369).

Individual governments, member states and various agencies associated with these organizations have shown an ongoing commitment to gender mainstreaming, as outlined in various 
national policy documents. In further articulating GM, the Council of Europe (1998) put forward that rather than viewing gender mainstreaming as a goal, it should be viewed as a strategy or a process, used to achieve equality, by demanding that policy actors integrate gender-equality issues and concerns throughout the decision making process, and evaluation of policies and programs. In this regard, policy actors are to analyze the impacts of an intended action/inaction on both men and women, before, during, and after implementation.

Gender mainstreaming sorts through, $(a)$ the conceptual confusion; $(b)$ the lack of understanding on how to apply gender perspectives in decision making, and $(c)$ the undervaluing of feminist knowledge. Mainstreaming policy is a top-down approach that demands a renewed commitment from political and bureaucratic leadership and private corporate elites on issues of gender. The expectation here is that gender should not be viewed as an afterthought in policy formulation, but rather, an important aspect throughout the decision making process. The Council of Europe lays out gender mainstreaming strategy as;

the (re)organisation, improvement, development and evaluation of policy processes, so that a gender equality perspective is incorporated in all policies at all levels and at all stages, by the actors normally involved in policymaking. (Council of Europe, 1998 p.12).

This conceptualization of gender mainstreaming brings to light the urgent need for public administrators, civil servants, politicians, and the corporate elite, to take up an active role in ensuring that societal gains and burdens are equally distributed to citizens regardless of gender. Yet the above literature review has shown that there is gap in the housing sector, in that the burden of housing affordability disproportionately affects women, who are also lagging behind in socioeconomic gains offered under capitalism and globalization. 
GM reduces the rhetoric that radical feminism or socialist feminism creates male-bashing and fuels reverse sexism. There is no denying that such rhetoric has influenced the way politicians and civil servants have framed policy in a rather gender neutral way. Gender mainstreaming is aimed at ensuring that both women and men are in practice treated fairly, by taking into account gender-based differences in the lived experiences of women and men, and assessing how policies affect women and men differently.

\subsection{Instrumentation and Best Practices of Gender Mainstreaming}

Over the years, various instruments have been used in gender analysis, notably, genderbased impact assessment guides, good practices series, follow-up sheets scoreboards and interservice groups with gender-trained officials, to coordinate and supervise the implementation of gender mainstreaming within supra-organizations and government departments (Jacquot, 2010). Whereas there is no unified implementation strategy for GM, given GM varies according to context, policy area, and usage by various actors, GM tools can be broken down into three main categories namely; $(a)$ analysis tools, $(b)$ awareness-raising tools and (c) organizational tools (Jacquot, 2010). ${ }^{12}$ These tools can form the guiding principles in mainstreaming policy and ensuring that both women and men's needs are accounted for in the decision-making process.

In exploring best practices for the application of GM, the European Institute for Gender Equity (2013) put forward that GM should be done in a systematic way that honours "the conditions, situations and needs of women and men, the relations existing between them, and the differentiated policy impact on the concrete lives of women and/or men" (European Institute for Gender Equity (EIGE), 2013, p.10). As such, Gender Mainstreaming (GM) situates policy analysis within contextual and systemic conditions which influences policy.

\footnotetext{
${ }^{12}$ See Table 1: Gender mainstreaming tools
} 
In creating women-friendly policies, gender segregated statistics and indicators need to be incorporated in policy formulation, program implementation and budget analysis. The underlying belief here is that, filtering public data by government institutions only serves a political purpose in that it takes away accountability, transparency and good governance, expected from politicians and public administrators. Gender segregated statistics can therefore be used to expose the underlying nuances that result in experiences of poverty, homelessness and criminal behaviours among women. For example, in calling for gender responsive correctional programs and policies for women, Wattanaporn (2014) proposed a feminist pathway-based analysis in which juvenile delinquency, adult offending, and adult victimization among women was linked to the high prevalence of childhood abuse, intimate partner violence, and economic marginalization. Other feminist scholars are also calling for women-friendly housing policies in Canada, that respond to the gendered risk of homelessness among women (Drabble, 2017; Donley \& Wright, 2012; Baker, et al, 2010; Laird, 2007; Whitzman, 2006; Klowdawsky, 2006).

GM accounts for the heightened risks for women experiencing homeless and perhaps the most outstanding GM analysis tool is the REFLEX tool, which was developed in Sweden to gender proof all public policy and strategies (Reeves, 2002; ENGENDER, 1998). It puts forward that in assessing any public policy, the following should be done:

(1) Relevant gendered information needs to be collected;

(2) Women and men need to be represented on decision making bodies;

(3) Policies need to reflect different needs; and

(4) Measurable goals and outcomes need to be established.

Whereas GM is a newer approach to public policy, it provides a blueprint on how and when policy analysis is to be made, for what and by whom (Paterson, 2010). It creates room for ex-ante 
evaluation ${ }^{13}$ thereby allowing the scrutiny of broader policy agendas and neoliberal agendas in the creation of policy (Bacchi \& Eveline, 2004). Subsequently, GM calls for policy actors to integrate gender equity concerns in the planning, implementation, monitoring and evaluation of all policies, programmes and activities (EIGE, 2013; UN, 2002; Beveridge, Nott, \& Stephen 2000). This approach is progressive rather than regressive, in that rather than react to unintended consequences of policy after the fact, incorporating a gendered lens throughout the policy process results in the rejection of unfair policies before they are implemented.

\subsection{Assessing Measurability of Gender Mainstreaming}

In assessing measurability of GM, there is no denying that this is a highly contested concept of public policy. Whereas some see great potential in how gender-based analysis can engender better policies, and transform gender relations in ways that enhance gender equity (Council of Europe, 1998; EIGE, 2013; UN, 2002), others have mixed feelings regarding the transformative nature of GM given opposing institutional goals and threats to the democratic citizenship (Benschop \& Verloo, 2006; Grace, 1997; Verloo, 2016). Yet still, others argue that the coercive nature of emerging concepts pushing for equality, especially in the housing market, may very well lead to group conflict when individual liberties are threatened within a democracy (King, 2000).

Moreover, GM is packed with contextual and conceptual issues that limit its transformative potential, for example, there is no clear definition of what constitutes gender equality and gender mainstreaming itself, as a result different policy actors interpret it differently (Caglar, 2013; Grace 1997; Paterson, 2010). Others use the name GM and policy agencies interchangeably (Teghtsoonian, 2004) while, in Canada, GM is best known as gender-based analysis (Paterson,

\footnotetext{
${ }^{13}$ Ex-ante is an evaluation of a policy before it is implemented, to examine its objectives and determine its feasibility and potential impact on the community and various groups. Also see https://www.jica.go.jp/english/our_work/evaluation/tech_and_grant/guides/pdf/guideline03-02.pdf
} 
2010). As well, some have raised concern about situating women's agency organizations within government departments, noting that limited resources awarded to femocrats limit their ability to effectively lead gender-analysis aimed at reducing gender inequality. (Knight, \& Rodgers, 2012; Rodgers \& Knight, 2011; True \& Mintrom, 2001; True, 2003; Grace, 1997). In addition, others worry that GM simply adds women's issues to existing policies without necessarily incorporating feminist values and standpoint (True \& Parisi, 2013).

However, despite the scepticism regarding the transformative nature of GM, and confusion surrounding the conceptualization of GM, what is apparent is that the underlying principles of GM are grounded in feminist ideals, given that historically and contemporary, women are disadvantaged. Yet although GM is closely tied to state feminism and women's agency policies (True \& Mintrom, 2001; True, 2003), it is not intended to disadvantage men. Rather, the goal of GM is to create a just society where both women and men can have equal access to societal gains, and share societal burdens in ways that do not disadvantage individuals because of their gender.

Some scholars contend that GM is yet another capitalistic-neoliberal instrument created by the elite to dismantle years of feminist gains, through gender expert advice, while closing political space for debate and worsening the material condition of women (Alvarez, 1997; 1999; Bachi \& Eveline, 2004; Eschle, 2000; Paterson, 2010;Teghtsoonian, 2005) and limiting work-life balance (Stratigaki, 2005; Wo"hl, 2007). Others fear that femocrats and feminist researchers in a neoliberal environment remain outsiders while mainstream civil servants continue to hold power to direct policy agenda, often in a gender neutral way (Benschop \& Veloo, 2006; Rodgers \& Knight, 2011).

GM is flexible enough to adapt, to the shift towards a globalized world and the spread of new rightwing ideals (Kantola, \& Squires, 2012; Jacquot, 2006). In particular, GM is a noncoercive approach that appeals to a broader constituency in a highly politicized neoliberal environment (Jacquot, 2010). Moreover, far from being a negative, the top down approach of GM 
pushes the corporate elites, public administrators, civil servants and other bureaucratic leadership, to reorganize and reject policies and procedures that propagate gender inequality. Whereas previous gender-based reforms sought after sameness or equality of treatment, in which women are fit into a men's world, GM thrives on the politics of difference within structures of domination and seeks to transform institutions in ways that enable both women and men to flourish (Bacchi \& Eveline, 2004; Council of Europe, 1998; Reeves, 2002; True, 2003). As such, in pushing for gendersensitive policies, some scholars have demanded that gender expertise be a requirement for all policymakers to enhance gender capacity, competency and accountability within the public and private sectors (Caglar, 2013; Clougherty, 2010; 2003; Council of Europe,1998; Rai, 2013; Stratigaki, 2005).

GM has had political effects that surpass academic and feminist communities (Gulay, 2013; Escott \& Punn, 2006; True, 2003; UN, 2002). In recent years, feminist researchers, policymakers and advocates have worked together in making gender analysis an integral part of the regular routine and practice of global governance (True, 2003). Despite its soft nature, GM has perhaps, managed to achieve greater results in promoting gender equity in Europe than any other policy (Jacquot, 2010). In this regard, there is need to understand, from a woman's standpoint, if the IH policy is meeting the needs of low-income women.

\subsection{Limitations of Gender Mainstreaming}

Whereas GM views the integration of gender differences between men and women, as integral in achieving gender equality, it is silent on women's differences and how various women are impacted differently by policies. The dichotomous principles of GM ignores the ways in which gender inequality intersects with other forms of inequalities, such as class, race, ethnicity, and sexual orientation (True \& Parisi, 2013) to further alienate diverse women. Access to affordable 
housing and therefore the successful integration of new immigrants can be hindered by discriminatory practices of public gatekeepers and urban gatekeepers such as landlords, mortgage lenders and real estate agents (Teixera, 2011). Whereas the emergence of GM parallels the third wave of feminism and the integration of Black Feminism in the mainstream, it has failed to produce principles of social justice that honour the diversity of women and the barriers faced by women from different backgrounds.

Failure to integrate the multiplicity of oppression as part of its guiding principles slows down the transformative nature of GM. Consequently, gender equality laws that seek to narrow the gender gap and discriminatory practices within government departments, have been done in a Eurocentric manner that does not sufficiently recognize the views of racialized groups. Moreover, government departments rarely take Equality Act seriously hence GM has not yielded meaningful gains for racialized women when it comes to housing and homelessness. Evidence show that racialized women are hit the hardest with budget cuts and policies aimed at cutbacks and clawbacks (Sandhu \& Stephenson, 2015; Anthia, 2014; Brodie \& Bakker, 2008). To this end, some are beginning to push for an integrative approach to gender analysis in the Canadian housing policy (Little, 2015; Donnan, 2014; Whitzman, 2006;) and elsewhere (Anthias, 2014).

\subsection{Integrating Intersectionality}

Black feminists have pointed out the need to recognize policy gaps resulting from differences that go beyond gender and address them through diversity and inclusionary policies (Collins, 2000; Crenshaw, 1989). For example, in laying out some of the barriers faced by Black women, Sterling (2015) points out that:

It is not possible for Blacks as a group to attain the positive qualities associated with Whiteness, and individual Blacks will be prejudged to not have these qualities and must prove otherwise. Some of these positive, if somewhat subjective, qualities 
are closely associated with academia: intelligence and educational attainment, middle-to-upper-class values, achievement, rationality, honesty, and objectivity. Not coincidentally, many of these values are also associated with masculinity. Blackness and Brownness are constructed as having the opposites of these values; in reconstructing the past, Blackness and Brownness are associated with primitiveness and backwardness. (Sterling, 1997, p.97).

In trying to narrow the inequality gap in some countries, such as the UK, it was hoped that by merging various equality 'strands' under a single piece of legislation, it would help address 'multiple inequalities' (Squires, 2009), and help move the country towards inclusiveness, integration, and intersectionality (Dickens, 2007). However, the dilemma with this approach is that civil servants tend to focus on one particular strand of oppression at a time, such as gender, race, disability, etc, while ignoring other forms of oppression (Sandhu \& Stephenson, 2015). As such, incorporating intersectionality can enhance GM in ways that give a voice to the diverse groups of women.

Kimberlé Crenshaw first coined the concept of intersectionality in 1989 and it raises awareness of the multiplicity of oppression. Crenshaw (1989) observed the allocation of societal burdens and concluded that, whereas these burdens are by far the result of gender and class oppression, they are exacerbated by the racially discriminatory employment and housing practices women of color often face. This concept was further advanced by other feminist scholars who introduced various concepts that give voice to diverse women's lived experiences. Patricia Colin Hill introduced the Matrix of Domination (2000); and Sandra Harding put forward the Feminist Standpoint theory $(1986 ; 1987 ; 1993)$. These perspectives argue that women should not be considered as a homogenous group, and point to the need to account for diversity and inclusion in public policy.

Whereas the concept of intersectionality is highly contestable, Dhamoon (2011) revealed that intersectionality has generally centred around: $(a)$ identities (e.g., Black); $(b)$ categories of 
difference (e.g., race); (c) processes of differentiation/social differences (racialization); and $(d)$ systems of domination (e.g., racism, colonialism and patriarchy). Various studies have shown how the intersections of race, class, gender, and sexuality disadvantage racialized women in business (Anthias, 2014; Knight, 2016) and on the job market (Creese, 2011; Creese \& Wiebe, 2012), thereby rendering them economically vulnerable. Moreover, other studies have discovered how these hegemonic processes and systems of domination result in high incidences of homelessness among new immigrant women (Hyndaman, Fielder, et al, 2006; Keung, 2012; Walsh, et al., 2016;) and racialized women (Sagha, et al, 2012).

In this regard, this study sought to integrate concepts from intersectionality and concepts from gender-mainstreaming, to strengthen the Feminist Critical Policy Analysis. This integration brought forth an intersectional gender-based analysis, which I used to evaluate perceptions of the implementation of the inclusionary housing policy as it relates to diverse groups of low-income women.

\subsection{Intersectional Gender-Based Analysis}

An intersectional gender-based analysis (IGBA) incorporates the concepts of gender mainstreaming and intersectionality into the feminist critical policy analysis, to bring out a holistic tool that can be used in guiding policy formulation, implementation and evaluation. This integration is essential because it can be used to expose the multiple forms of oppression that intersect with gender to render women powerless and susceptible, to experiences of poverty and homelessness. Moreover, the IGBA goes beyond gender issues, to bring attention to how issues stemming from racism, xenophobia, homophobia and ageism perpetuate and maintains homelessness among women. In this regard, the IGBA calls for policy-making processes that take into account issues of gender, race, ethnicity, immigrant status, sexuality and age, in addressing social problems such as 
housing and homelessness. Ultimately, by acknowledging the politics of difference, the IGBA is able to encourage issues of social justice that go beyond gender equality.

\subsection{Conceptual Gaps in Literature}

Although various feminist scholars have used critical feminist policy analysis to explore the problem of hidden homelessness among women in Canada and have called for women friendly policies, only a few studies incorporated intersectional gender-based analysis to account for the multiple identities of women experiencing homelessness (Donnan, 2014; Little, 2015; Whitzman, 2006) in Canada and elsewhere (Anthias, 2014). As well, when it comes to the IH policy in Canada, there is a glaring gap in literature. First, studies on IH policy in Canada are sparse (Balfour, 2010; Mah, 2009; Mah \& Hackworth 2011). Second whereas a few studies in the United States of America (Pogliani, 2012; Schuetz, Meltzer \& Been 2009) and Canada (Balfour, 2010; Mah, 2009) have sought to understand the effect of this policy on affordable housing stock, none used a gendered lens and findings in Canada were inconclusive.

This study seeks to address these gaps by exploring how the Cities of Toronto and Barrie have used IH policy, in the aftermath of devolution, to address the issue of hidden homelessness among low-income women. I chose the City of Toronto and Barrie because current indicators show that they are the most expensive cities to purchase or rent a house in Canada, apart from Vancouver, yet not much has been written about affordability issues in these two cities, in particular as it relates to women in core housing need.

In the following chapter (4) I detail my methodology and ethical challenges in answering the question, how do low-income women in Toronto and Barrie experience hidden homelessness? 


\section{CHAPTER 4}

\section{A Qualitative Case Study}

[Case Studies are employed] for both their uniqueness and commonality. We would like to hear their [participant's] stories. We may have reservations about some things the people tell us, just as they will question some of the things we will tell about them. But we enter the scene with a sincere interest in learning how they function in their ordinary pursuits and milieus and with a willingness to put aside many presumptions while we learn

(Stake (1995, p.1).

\subsection{Introduction:}

In planning for this study, I considered three major research designs, (a) Qualitative, Quantitative and Mixed methods as outlined by Creswell (2009). Traditionally, quantitative methods dominated the social sciences from the 19th century through the mid-20th century, at which point social scientists became more interested with qualitative and mixed methods (Creswell, 2009, p.4). The differences between qualitative studies and quantitative research designs stem from: ontological assumptions (the nature of reality), epistemological assumptions (the association between the researcher and what is being studied), axiological assumptions (the ideals or beliefs held by the researcher), rhetoric (the language of the research), and methodological assumptions (the guiding procedures and processes used to collect the data) (Creswell, 2007). The choices made by the researcher based on these assumptions are key determinants in the research design and conduct of the study. Whereas there is no hierarchy between quantitative, qualitative and mixed methods, the selection of an appropriate research design is closely tied to the purpose of the study and the type of data that must be collected (Creswell, 2009). Quantitative research designs are based on positivism and are more structured and controlled, while qualitative research designs are 
underpinned by constructivist philosophical assumptions and are flexible and less structured (Creswell, 2009; Guba, 1990).

I required a method that would provide the data I needed to answer the research question, "How do low-income women in Toronto and Barrie experience hidden homelessness? How do their experiences expand or challenge the established definition of hidden homelessness?" In addition, I needed to choose a research design that is less structured and that would allow me to elucidate the voice of participants in their natural environment.

\subsection{Qualitative Methods}

As a feminist researcher, I believe data is socially constructed based on participants' and researcher's worldviews, lived experiences and backgrounds. As such, I chose a research design that embodied a feminist, anti-oppression framework in guiding this study. Creswell (2009) talks about the intersection of philosophical worldview, research design, and specific research methods. A philosophical world view is a basic set of beliefs used to guide the action of a researcher (Guba, 1990, p.17), from the choice of the research method and design up to data analysis (p.5). Creswell (2009) mentions four philosophical worldviews: (a) the post-positivist, (b) constructivist, (c)

transformative and (d) pragmatic. Post-positivism is associated with quantitative research methods which calls for objectivity and causal effects (p.6-7). Qualitative research methods are closely associated with constructivist and transformative worldviews.

I chose the constructivist worldview because I was not seeking for an objective reality, but rather a reality that is socially constructed through participants' lived experiences, historical, and social perspectives that frame those experiences. This philosophical foundation led me to choose qualitative methods of inquiry as set out by Creswell (2009), Bryman, Teevan \& Bell (2009), and Denzin \& Lincoln (2005). Qualitative methodology allowed me to gain a deeper understanding of 
the meanings women and policy actors attach to the phenomenon of hidden homelessness in Toronto and Barrie. Its interpretive nature also allowed me to make inferences regarding policy responses to gendered homelessness, based on my own observations and interpretations as a feminist researcher and a woman of colour. In this study, much was learned from talking directly with the women experiencing hidden homelessness and allowing them to narrate their experiences in their own natural setting and within the communities they live, without the restriction of a controlled environment.

As well, I chose qualitative research methodology because at the centre of feminist research is a strong belief that traditional scientific methods of inquiry are carried out within a maledominated paradigm, which reproduces endocentric biases (Griengeril et. al, 2010). In particular the hegemonic nature of quantitative research methods isolates participants from everyday processes (Liamputtong, 2007) and dulls down the "localized and personal knowledge of research participants," (Gergen, 2001, p. 21) thereby silencing participants standpoint. Moreover, the standardized nature of positivistic research methods fail to capture much of what transpires during research and this information remains unspoken and unexamined (Allen \& Walkers, 1992).

The choice of an appropriate research method is dependent on the purpose and nature of the study. Given that I was not seeking to determine causal effects and outcomes, and that my focus was to understand policy processes and how women experience hidden homelessness, qualitative method was most ideal. Liamputton (2007) argues that while it is possible to carry out feminist research within quantitative and mixed methodologies, qualitative methods are best suited because they are less structured and more flexible. Feminist researchers tend to lean more towards qualitative methods because they adapt to the needs of participants and allow researchers to construct knowledge based on participants' lived experiences and researcher's own interpretation of what was observed in the field (Liamputton, 2007). 
I chose qualitative methods because they are more responsive to natural settings, local conditions, and issues that arise during the research process, even if it requires a shift in the focus of the study (Dillman, 2000). I also chose qualitative design because it allowed me to situate participants within the context in which they live and work so that I could access rich thick description of women's experiences with hidden homelessness and policy makers' and stakeholders' responses therefore (Creswell, 2007). In addition, qualitative research methods allowed me the flexibility to utilize multiple data sources and a variety of techniques and procedures from an "insider's point of view while maintaining the analytical perspective and distance of an outsider" (Grinnel, Williams, \& Unrau, 2012, p. 137).

\subsection{Limitations of Qualitative Methods}

Although qualitative research methods are flexible, less structured and provides depth and meaning to participants' attitudes, feelings and behaviours, the use of smaller sample sizes compared to other research methods, bring into question certain inherent weaknesses. First, it has been argued that qualitative methods lack in external validity because it is heavily dependent on the skills of the researcher and it is difficult to generalize or make inferences from a small sample that may be anecdotal (Creswell, 2009; Yin, 2009). Second, because policy makers and public administrators cannot draw quantitative predictions from qualitative methods, findings from qualitative studies may be viewed as less reliable and flawed (Creswell, 2009). Last, the issue of subjectivity in qualitative studies cannot be downplayed or ignored. As a woman of color and a recent immigrant in Canada, I may hold certain values and beliefs that may influence the direction of the study and its conclusions.

To mitigate these biases and prejudices and to ensure the credibility of this study, I have endeavoured to be truthful, consistent, and honest about how my personal beliefs and values can 
cloud researcher independence. I engaged in constant self reflexivity to keep my biases in check and was open to opposing evidence from other studies that were inconsistent with my preliminary position. Further, Creswell (2009) and Patton (2002) suggested peer review, of which I did with my peers and doctoral committee. As well, I used the research participants to validate and clarify some of the direct quotes, and to confirm or disconfirm data from in-depth interviews, a process referred to as member checking (Creswell, 2007). This was particularly important as it enabled me to clarify areas that were unclear and to ensure that participants' views were being well represented in this study.

\subsection{Case Study Approach:}

Cresswell, (2009) talks about "five strategies of inquiry in qualitative methods," that can be used to guide a qualitative researcher namely: ethnography, grounded theory, phenomenology, narrative and case study (p.11). The choice of the appropriate approach is dependent on the nature of the research problem, the purpose of the study, the research questions, personal experiences of the researcher, and the target audience (Creswell, 2013). Moreover, it has been suggested that when dealing with a "contemporary issue within a real life context" a case study is most appropriate (Yin, 2009).

Given that the major purpose of this research study was to explore the prevailing problem of hidden homelessness among low-income women in Toronto and Barrie and the effect of the IH policy, I chose a case study approach. According to Stake (1995) and Yin (2009), the case study approach is conceptualized within a social constructivist paradigm which fits well with qualitative methodology. Creswell (2009) suggested that the social constructivist worldview allows researchers to rely on the participants' own perception of the situation under study. To sum up, the benefits of social constructivism, Stake (1995) put forward that: 
[Case studies are employed]for both their uniqueness and commonality. We would like to hear their [participant's] stories. We may have reservations about some things the people tell us, just as they will question some of the things we will tell about them. But we enter the scene with a sincere interest in learning how they function in their ordinary pursuits and milieus and with a willingness to put aside many presumptions while we learn (Stake (1995, p.1).

I also chose a case study approach because a case study is more ideal (a) when the objective of the study is to explore the how and why queries, (b) when there is a well formulated theory guiding the research and (c) when there are clear boundaries that can be identified based on space and time (Yin, 2009). The case study approach enabled me to explore how and why women experience hidden homelessness, by situating them within the prevailing neoliberal driven policy environment, in which they work and live. As well, given that this study is guided by the intersectional gender-based analysis, and is limited to the implementation of the IH policy in Toronto and Barrie, in the past 15 years, a case study approach was most appropriate.

Yin (2009) further identifies single case study and multiple case study approach. I chose a single case study because it is more desirable when there are no logical subunits that can be identified (Yin, 2009). All participants in this study were treated as one case where interviews were conducted with women, policy makers, private developers and community stakeholders in two different cities, Toronto and Barrie. Toronto was treated as a representative sample of the housing dynamics in cities attempting inclusive housing policies in large diverse metropolitan city. Barrie, was treated as a representative of many cities on the outskirts of larger metropolitan cities were also attempting IH policies. These metropolitan cities often experience rapid rise in population, cost of living and housing affordability and transit issues. 


\subsection{Limitations of Case Studies}

Notwithstanding the visible advantages of a case study approach, case study research depends on the researcher's construal ${ }^{14}$ of data and is often viewed as rather one sided and biased in its production, execution and evaluation of data. Case studies have often been viewed as pseudoscientific and, lacking in scientific rigor, generalizability and validity (Padgett, 2008). As a result, case studies are often viewed as a "weak sibling among social science methods," and researchers, who utilize this approach have often been criticized for "having deviated from their academic disciplines," and their work is viewed as insufficient and lacking precision that is quantifiable, objective, and rigorous (Yin, 1994 as cited in Pealo, 2005, p. 1). Consequently, case studies have been criticized for inability to offer any meaningful remedy and researchers have been cautioned that, over dependence on a limited number of cases as the source of generalization creates the risk of making assumptions based on anecdotal evidence (Yin, 2009).

Notwithstanding the various contentions with case studies mentioned here, this approach is increasingly becoming popular among researchers (Gustafsson, 2017; Hyett, Kenny \& DicksonSwift, 2014; Thomas, 2011). First, it should be noted that the essence of this case study was not to generalize, but to situate low-income women within the context of the contemporary housing policies and get a rich, thick, description of their experiences with inadequate housing. However, whereas the main objective of this qualitative case study was not to generalize to theoretical propositions or general populations (Yin, 2009), by, (a) identifying and conducting indepth interviews with critical cases; (b) keeping an audit trail; (c) engaging in constant selfreflexivity; (d) memoing; and (e) member checking, findings from this study is most likely a good representation of how women experience hidden homelessness, and how policy makers,

\footnotetext{
${ }^{14}$ In social science, construals are how individuals perceive, comprehend, and interpret the world around them, particularly the behavior or action of others.
} 
community stakeholders and private developers, are using the IH policy to ease the housing affordability problems in Toronto and Barrie. As well, to enhance external validity of data, a case study utilizes multiple data sources from in-depth interviews, newspaper, academic journals and policy documents. The use of multiple data sources makes it possible to replicate research within a real life context and capture similarities and contrasts in the findings (Vannoni, 2014; 2015; Yin, 2009).

Another issue with case studies is that the process is excessively long, time consuming, and may result in "massive, unreadable documents" (Yin, 2009, p. 15). However, Yin (2009) argued that while this may have been true in the past, there is no need for case studies to be prolonged because a case study relies on multiple data sources and can be conducted without even going out into the field, depending on the topic of study (Yin, 2009).

I focussed on two cities, Toronto-Barrie and conducted in-depth interviews with women, policy-makers, community stake holders and private developers, as I sought to answer the core question:

How do low-income women experience hidden homelessness in Toronto and Barrie and how do their experiences expand or challenge the established definition of hidden homelessness?

To answer this question, I endeavoured to address the following sub questions:

1. How have service managers in Toronto and Barrie used the Inclusionary Housing policy to address housing affordability issues in their jurisdiction?

2. How do inclusive housing policies relate to the experiences of low-income women in Ontario?

3. What data needs to be collected or incorporated to inform levels of success of inclusionary housing policies in general, and specifically to include women's experience? 


\subsection{Delineation of Methods and Procedures:}

\section{Site selection:}

Creswell (2009) puts forward that qualitative researchers seek to understand the setting of the participants or the context in which the phenomena is experienced, through visiting these sites and gathering information personally. The broader the breadth of the area covered in data collection, the wider view a researcher will have on issues affecting individuals under study (Creswell, 2009). The current study was delineated to the City of Toronto and Barrie due to the prevailing housing affordability crisis in these two cities, and the lack of studies highlighting the plight of women experiencing hidden homelessness and the extent to which IZ policy has been used to affect change in these areas.

Toronto is Canada's largest city and is home to a diverse population of about 2.8 million people (City of Toronto, 2017). Beside Vancouver, Toronto has been rated the most expensive place to buy a house in Canada (Toronto Foundation, 2016) and has the second lowest vacancy rate (Toronto Foundation, 2018). Barrie is a smaller city within the County of Simcoe, with a population of 197,059 residents (City of Barrie, 2017). The City of Barrie is surrounded by mostly farms and rural area, and has remained conservative and less diverse compared to metropolitan Toronto. The City of Barrie has been "a magnet for those looking for lower housing costs", as such it has grown by over $560 \%$, in the past 40 years (City of Barrie, 2017) thereby pushing down the vacancy rate and pushing up prices in the rental market. Barrie was recently rated as having the third most expensive rental market in Canada, after Vancouver and Toronto (CBC News, 2018; CTV Barrie, 2017).

\subsection{Purposive Sampling Techniques:}


Given the fact that this study is concerned about finding deep meanings that participants attach to their experiences with hidden homelessness and housing policy processes in Toronto and Barrie, I chose non-probability sampling techniques in general, and in particular purposive sampling. Purposive sampling enabled me to target specific groups of people, with characteristics that would help me to advance my research on the IH policy as it relates to women experiencing hidden forms of homelessness. Purposive sampling approach is flexible and encompasses a variety of techniques such as expert sampling, which is especially useful in policy evaluation research, as it includes identifying major experts or stakeholders involved in the designing, implementation and monitoring of a policy or program under review (Palys, 2008). Expert sampling enabled me to target major policy actors and stakeholders in the field of housing and homelessness, whose expert opinion helped to shed light on the IH policy process as it relates to the issue of hidden homelessness among women.

\subsection{Limitations of Purposive Sampling Techniques}

Given that this study utilized purposeful sampling to identify cases for data collection, the quality of the findings was dependent on locating an appropriate number of the right participants from which conclusions could be drawn with some confidence (Creswell, 2009). Creswell (2007) argued that the inquirer must carefully, with a purpose, "select individuals and sites for study because they can purposefully inform an understanding of the research problem and central phenomenon of the study" (p. 125). Therefore, I relied on my intimate knowledge of the target population, stemming from my professional background as a social worker and having worked as a frontline worker in various community organizations. I purposefully chose women who met the criteria of hidden homelessness according to my definition for this study, and I targeted various stakeholders involved in the formulation, implementation and sustenance of the IH policy. Given 
that women are a hard-to-reach population and that there was the problem of gate-keepers with policy makers, I also utilized snowball sampling techniques, where participants and informants referred me to their colleagues and peers.

\subsection{Target Population}

\section{Women}

The target population for this study consisted of women living in Toronto or Barrie, who had experienced or are experiencing chronic hidden homelessness lasting for more than 6 months, between the ages of 20 to 65 , who are single or married, from any racial or ethnic background, who are working or are on government income support, with an income of less than $\$ 60,000^{15}$ and are currently spending $30 \%$ or more of their income on rent; and are living with friends, relatives, partners or in overcrowded and/or rundown dwellings due to affordability issues. This target population enabled me to develop an in-depth understanding of the issue of under-housing among women in Toronto and Barrie.

\section{Policy Experts and Stakeholders}

To gain an in-depth understanding of the IH policy as it relates to women's experiences of hidden homeless, I targeted policy experts, housing developers and community organizations/advocates in the field of housing and homelessness in Toronto and Barrie. Policy experts from Barrie included the Mayor of Barrie or his designate, the Chairperson of the Simcoe County Alliance to End Homelessness, SCATEH, and the Manager, Social Policy and Planning Simcoe County. Policy experts in Toronto included the Mayor of Toronto or Director - Affordable Housing Division or a designate, the Manager - Affordable Housing Development Division, and The Lead - Toronto Housing Task Force. Other community organizations and frontline workers

\footnotetext{
15 The cut-off of $\$ 60,000$ for low-income was based on the livable wage for the City of Toronto and Barrie. This would allow participants to pay housing costs and still afford food, transport, clothing and other basic necessities.
} 
dealing with the issue of housing and homelessness included Ontario Association of Municipalities, Ontario Home Builders Association, Habitat for Humanity, and caseworkers from Massey Centre for Women, New Beginning Program, East York Housing Help Centre.

\subsection{Sample Size}

"Case studies are among the most difficult types of qualitative research to classify" (Marshall, 2013 p.13) and there is no clear guideline as to how many individual cases should be used in a case study. Moreover, given that qualitative research is focused on meaning making rather than generalizability, there are no clear guidelines or consensus as to how big a sample size should be. However, given the breadth of the area under study and the evaluative purpose of this project, the sample for this study, consisted of 23 participants as follows; 11 Women (6 Barrie, 5 Toronto), 5 Policy Experts (3 Barrie, 2 Toronto), 8 Community Stakeholders, (3 Barrie, 2 Toronto) and 2 Private Developers (1 Barrie, 1 Toronto).

\subsection{Accessibility to Target Population:}

I considered the issue of accessibility when sampling participants. Women experiencing hidden homelessness are hidden and most likely to avoid homelessness by staying with abusive partners, friends, relatives and strangers for short or extended periods of time. Some avoid absolute homelessness by working two jobs or overtime, with limited or no free time at all. Yet still, some women may be hidden in various institutions such as hospitals or rehab centres, yet do not have anywhere to go upon being released. Liamputtong (2007) refers to this vulnerable group as a hardto-reach population and suggests that snowball sampling techniques and use of informants or referrals is most appropriate. As well, I considered barriers to accessing policy experts and community stakeholder, given their busy schedules and gatekeepers. 
In this study, I used a combination of snowball sampling techniques, informants and other forms of referrals. For example, informants connected me to policy experts, policy experts connected me with developers and women referred other women to me, with similar lived experiences. I sent e-mails and/or letters, addressed directly to the bureaucrats and made followups. I also requested to speak to their designate, if they were unavailable or unable to engage in the interview process.

However, whereas I had sought out to interview four policy-makers in Toronto, the issue of accessibility was a challenge. First, I could not get a response from the office of the Mayor of Toronto despite sending three emails and making several follow-up phone calls (a problem with gatekeepers). Second, after interviewing the Director of Housing - Affordable Housing Division, for the City of Toronto, a lower level manager dealing with housing issues within the City, felt he did not have anything else to add to what the Director of Housing had already said. Nonetheless, despite accessibility challenges, the actual sample size was determined by data saturation. As such, whereas I initially sought to interview 36 participants (consisting of 16 women, 8 Policy-makers, and 8 Stakeholders), I stopped conducting interviews after interviewing only 23 participants, (consisting of 11 women, 5 policy-makers and 7 stakeholders), when it became evident that further sampling could no longer yield any new information to develop new codes, categories or themes.

\subsection{Participants' Profile:}

I collected data regarding participant's histories and backgrounds, to help me unpack power dynamics that may influence women's stories and experiences with hidden homelessness. This approach aligns well with feminist research which seeks to construct knowledge based on participants' lived experiences and researcher's own interpretation of what was observed in the 
field (Liamputton (2007). As a result, I take time, here, to describe the profiles of participants, prior to discussing emerging data that came out from in-depth interviews and other sources.

\subsubsection{Women's profile:}

A total of eleven (11) women were interviewed, seven of whom were from Barrie, namely: Elaine, Sophia, Elizabeth, Lily, Cindy, Pat and Katie, and five were from Toronto, Abigal, Yolanda, Daisy, Lisa and Melissa. The demographics of these women was diverse and there were visible differences, between participants from Barrie versus participants from Toronto. These differences centred on participant's age, ethnicity, racial, immigrant and employment status, as well as educational background. First, while Barrie women consisted of mostly older women above 55 and only two younger women below 35, Toronto women were mostly middle age of between 35 to 45. Second, while Barrie women were all Canadians of European descent, Toronto women were diverse, having two Canadians of European decent and three new immigrants, two of African descent and one of Pilipino descent. Third, all women were single except for one woman in Toronto, Daisy, who was married. As well, none of the Barrie women reported living with children, while all Toronto women had younger children living at home.

Fourth, there were more women working in Toronto, with a college degree or diploma, than in Barrie. For example, Abigal, a Toronto woman, had a master's degree and worked as a part-time research assistant at a large university in Toronto, while Yolanda, held a college degree and worked full time as a Senior Certification Consultant with a large company in Toronto. The remaining Toronto women, Daisy and Lisa had college diplomas and were employed full time, in the healthcare, while Melissa worked in retail. Only two Barrie women were working minimum wages jobs at Tim Hortons and in a long term care facility as a personal support worker. The rest of the women from Barrie were on government income supports; three were on Canada Pension Plan 
(CPP) Disability, two were on Ontario Disability Support Program (ODSP) and earned between

$\$ 800$ and $\$ 1,200$ per month. The average annual income for Toronto women was $\$ 55,000$

compared to a $\$ 15,000$ average income for Barrie women

To qualify for this study, I targeted low-income earners with a household income of $\$ 60,000$

or below, who reported their dwellings as inadequate, unsuitable and unaffordable, based on the

operational definition for hidden homelessness in this study ${ }^{16}$ were inadequately housed, or lived in

unaffordable housing reported their dwellings as run down and requiring major service

Secondly, women in this study qualified as low-income because their income fell way

below the median wage as set out by Statistics Canada in 2017. According to Statistics Canada, in

2017, the median after-tax income that would allow families or individuals to live out of poverty

was $\$ 59,800$ (Statistics Canada, 2017). Beside, women in this study fell way below the livable

wage standards that allow a household to meet its basic needs, after government transfers have been

added and tax deductions have been made (Ontario Living Wage, 2018). In fact according to a

report by the Canadian Centre for Policy Alternatives, Making ends need: Toronto's 2015 Living

Wage, Toronto has become so expensive that Canadian Centre for Policy Alternatives, the cost of

living in Toronto is now so high that a household would require $\$ 72,241.55$, or an hourly rate of

$\$ 18.52$ after tax deductions, in order to afford the basics in life such as rent, food, transportation

and childcare. The hourly livable wage for both Toronto and Barrie, has increased since 2015 and is

not sitting at \$21.75 for Toronto and \$18.01 for Barrie. As such when we factor in tax deduction, all

\footnotetext{
${ }^{16}$ As mentioned earlier, hidden homelessness in this study is based on low-income women's experiences with lack of affordable housing and the subsequent segregation into rough neighbourhoods, coupled with the violence women face within shared spaces or at the hands or intimate partners and slumlords whom they depend on for housing. In addition, hidden homelessness in this study is based on CMHC's definition of core housing need, which takes into account housing adequacy, affordability and suitability. Ultimately, according to this study women experiencing hidden homelessness are low-income women whose earnings of $\$ 60,000$ or below is unable to afford them decent accommodation in Toronto or Barrie, hence are either forced to; (a) live in unsafe but cheaper neighbourhoods where they are often exposed to violence (related to drugs, guns, burlary); (b) live in cheaper housing that need major repairs and are often exposed to major health hazards (such as black mould, elements and/or insect infestation); (c) live with abusive males partners to remain housed; (d) live in shared spaces with relatives, friends and strangers, often in unsanitary and overcrowded conditions, lacking enough bedrooms, kitchen, toilet and shower for the size of the household, or (e) live in housing they cannot afford and spend more than $30 \%$ of total before-tax household income on rent.
} 
women including Yolanda whose gross income was $\$ 60,000$ and net income $\$ 49,972.97$, fell below the Canadian median income standards and livable wage standards. In addition, when we consider the context, Yolanda was situated in a high rental market in Toronto and she struggled paying her rent for a tiny one-bedroom condo that she lived with her mother and son. As such she qualified for hidden homelessness because she did not meet the affordability and suitability aspects that would allow her to maintain her dignity, health and wellbeing. The majority of women had a history of surf couching with friends and relatives and were inadequately housed in dwellings needing major repairs, or are living in unsuitable overcrowded conditions and having to share a bedroom, bathroom and/or kitchen with several other people or are living in unaffordable housing w without proper currently experiencing hidden homelessness or with a history of hidden homelessness.

When it comes to housing, all women in Barrie and Toronto lived in private market rentals except for two participants in Toronto, who lived in municipal/co-op housing in Etobicoke and Scarborough, but were paying market rental. One woman in Toronto earned $\$ 60,000^{17}$ and lived in an upmarket condo in Etobicoke, she was spending over $42 \%$ of her gross income on rent. The remaining two Toronto women lived in "tiny", "rundown", apartments in the Parkdale area, downtown Toronto. Only, two women in Barrie received subsidy and lived in high raise apartment buildings. The rest of Barrie women lived in basement apartments and/or rooming houses. One Toronto woman was in the process of getting evicted by her landlord.

According to this study's definition for hidden homelessness, all women in this qualified as experiencing and/or having experienced hidden homelessness.

${ }^{17}$ This participant was included because of the high cost of living in Toronto and the higher rentals compared to Barrie. 74 
Table 1: Women's profille

\begin{tabular}{|c|c|c|}
\hline \multicolumn{3}{|c|}{ Women Participants } \\
\hline & Toronto & Barrie \\
\hline \# of participants & 5 & 6 \\
\hline Age range & $35-45$ & $45-65$ \\
\hline Marital Status & $\begin{array}{l}\text { 1 Married } \\
\text { 4 Single }\end{array}$ & Single \\
\hline Average Income & $\$ 55,000 /$ annum $^{18}$ & $\$ 15,000 /$ annum \\
\hline Highest level education & Master's Degree & High School Diploma \\
\hline Source of Income & Middle income jobs & \begin{tabular}{|l}
2 ODSP \\
2 CPP Disability \\
2 Min wage job
\end{tabular} \\
\hline Housing Status & $\begin{array}{l}1 \text { Upmarket Condo } \\
2 \text { Market-based apartments } \\
2 \text { Social housing but paying } \\
\text { market rent }\end{array}$ & $\begin{array}{l}2 \text { Subsidized market-based } \\
\text { apartments } \\
3 \text { Rooming houses } \\
1 \text { Basement apartment }\end{array}$ \\
\hline Race/Ethnicity & $\begin{array}{l}1 \text { White } \\
3 \text { Black } \\
1 \text { Filipino }\end{array}$ & All white \\
\hline
\end{tabular}

\subsubsection{Policy Experts' Profile:}

To discover how policy-makers' perception regarding gendered hidden homelessness and policy responses to this phenomenon, I targeted bureaucrats, directly responsible for the formulation, implementation and maintenance of housing policies in Toronto and Barrie. Housing policy in Ontario is implemented through the 47 service managers (municipalities and district social services administration boards) designated under the Social Housing Reform Act, 2000 to manage social housing programs across the province (Ministry of Municipal Affairs \& Housing, 2017).

\footnotetext{
${ }^{18}$ The average income in Toronto was higher because of the demographic of younger working women, better paying jobs and the higher rentals in Toronto compared to Barrie.
} 
Whereas Toronto is one of the 47 Service Managers directly responsible for the implementation of homelessness and housing policies in Toronto, Barrie's policy process is two tiered, with the County of Simcoe acting as the Service Manager for several smaller municipalities in the County, including the City of Barrie. Nonetheless, the City of Barrie has authority within its jurisdiction, to formulate housing policies in collaboration with the County. With this in mind, I interviewed both the Mayor of Barrie, Honourable Jeff Lehman, and two representatives from the County of Simcoe (a public administrator and a top level manager responsible for social policy implementation) ${ }^{19}$.

I did not get a response from the office of Mayor Tory, but Sean Gordon, the Director of Housing for the City of Toronto, accepted to participate in this study. However, the Manager Policy and Partnerships for the City of Toronto, declined to be interviewed, citing that he had nothing to add to the perspectives of the Director of Housing. As such I interviewed Sean Godon, who is directly responsible for the formulation and implementation of housing policies in Toronto and he heads a team of policy-makers, which includes the previously targeted lower-level manager, responsible for housing and homelessness in Toronto.

Moreover, given that City officials may be biased because they are responsible for municipal housing and homelessness policies, I also targeted independent policy entrepreneurs with expert knowledge of the IH policy as it relates to women. I also interviewed, Dr. Emily Pardis, a housing expert and senior researcher at the University of Toronto. For the past twenty five years, Emily has been an avid activist, advocate and policy entrepreneur, with a focus on women facing homelessness. As a researcher, her scholarly work centres around homelessness among women and families, human rights dimensions of homelessness and housing, as well as community-based

\footnotetext{
${ }^{19}$ Due to the limited number of top-level managers at Simcoe Country, I cannot provide further demographic or personal information, without exposing participant's identities. As such to protect participants' rights to confidentiality, I used generic titles namely policy implementation manager and top level manager.
} 
research. Consequently, a total of five policy experts, were interviewed, three from Barrie-Simcoe County and two from Toronto.

Although this diverse group of policy experts enabled me to explore policy-makers' and policy entrepreneur's views and opinions regarding the IH policy as it relates to hidden homelessness among women, there was a huge gender disparity among the high-level policy experts, where 4 out of 5 policy experts interviewed for this study were male. In Toronto, the Mayor and the targeted lower level manager who declined to be interviewed for this study were also male. The only female policy expert was not directly responsible for policy implementation but rather advocates for policy change. It can be argued therefore, the highest levels of housing policy making in Toronto and Barrie is done from a patriarchal point of view, which may result in the silencing of women's perspectives.

\section{Table 2 Policy Experts’ Profile}

\begin{tabular}{|l|l|l|}
\hline \multicolumn{2}{|c|}{ POLICY EXPERTS } \\
\hline & Toronto & Barrie \\
\hline \# of participants & 2 & 3 \\
\hline Title & $\begin{array}{l}\text { - Director of Housing } \\
\text { - Housing Expert, Advocate and } \\
\text { Researcher }\end{array}$ & $\begin{array}{l}\text { - Policy Implementation Manager } \\
\text { - Manager of Social Policy and } \\
\text { Planning }\end{array}$ \\
\hline Organizations & $\begin{array}{l}\text { - City of Toronto } \\
\text { - University of Toronto }\end{array}$ & $\begin{array}{l}\text { - City of Barrie } \\
\text { - County of Simcoe }\end{array}$ \\
\hline Gender & $\begin{array}{l}\text { 1 Male } \\
\text { 1 Female }\end{array}$ & All male \\
\hline
\end{tabular}




\subsubsection{Community Stakeholders' Profile:}

To corroborate data from women and policy experts, I also interviewed five major stakeholders in the area of housing and homelessness in Toronto and Barrie. These stakeholders included community organizations, working directly with women experiencing housing problems. In Barrie, I managed to interview Danielle Gaucher, a transitional housing worker with Barrie Women's and Children Shelter. Danielle works with women fleeing abuse (with or without their children), to help them find safe, affordable housing in the community. I also interviewed frontline workers from Elizabeth Fry, namely, Meghan Chamber, the Director of Residential Programs, and Charlene Blanchard, a Mental Health Worker.

Whereas Barrie Women's and Children Shelter only works with women who are fleeing abuse, Elizabeth Fry works with high risk women, including women struggling with addiction and mental health issues, and women coming out of incarceration or rehabilitation, to help them find housing, access legal supports and other community services needed for them to reintegrate into the community and keep their housing. These organizations state that women living in abusive relationships, previously institutionalized women, and women struggling with mental health and addiction problems, are at high risk of experiencing hidden forms of homelessness, and they work with them to address various housing problems and barriers.

In Toronto, I interviewed the David Reycraft, the Director of Housing, Dixon Hall Neighbourhood Services. As the Director, Housing Services, David stated that his team advocates for the most vulnerable members of the community to address housing needs. Some of his service recipients include high-risk women living in poverty, and women with mental health and/or addiction problems. Beyond shelters, transitional housing and rentals, I also interviewed a Manager 
from Habitat for Humanity, an organization working to help low-income families achieve homeownership. Habitat for Humanity provides, no-interest, no-down payment mortgages to qualifying households.

These stakeholders work with developers and municipal/co-op housing to secure housing units for their clients.

Table 3: Community Stakeholders' profile

\begin{tabular}{|l|l|l|}
\hline \multicolumn{2}{|c|}{ COMMUNITY STAKEHOLDERS } \\
\hline & Toronto & Barrie \\
\hline \# of participants & 2 & 3 \\
\hline Title & $\begin{array}{l}\text { - Director of Housing Services } \\
\text { - Communications Manager }\end{array}$ & $\begin{array}{l}\text { - Housing Outreach worker } \\
\text { - Mental Health Worker }\end{array}$ \\
\hline Organizations & $\begin{array}{l}\text { - Dixon Hall Neighbourhood } \\
\text { Services } \\
\text { - Habitat for Humanity GTA }\end{array}$ & $\begin{array}{l}\text { - Barrie Women \& Children's } \\
\text { - Elizabeth Fry }\end{array}$ \\
\hline Gender & All Male & All female \\
\hline
\end{tabular}

\subsubsection{Private Developers' Profile:}

I interviewed two private developers for this study ${ }^{20}$. First, Laurie Payne was the Vice President of Development - Diamond Corp in Toronto. Diamond Corp is a private real estate development company whose main focus urban development, in particular creating innovative high density and mixed-use developments in urban areas. Diamond Corp works closely with the City of Toronto, other developers, co-ops and community stakeholders to bring affordable housing units to low-income households in Toronto.

\footnotetext{
${ }^{20}$ Although saturation was not reached here, the two private developers were referred by policy makers in both cities and were viewed as major players in the implementation of IZ practices and were meant to add a rich thick description of private developer's perspectives in the analysis of the inclusionary housing policy in Toronto and Barrie.
} 
Second, I interviewed Rhonda Kent, who is the Co-owner of Redwood Park Community Park, in Barrie. Rhonda Kent noted that, she and her husband Tim, who is a builder by profession, "saw the need for housing [in Barrie] and Tim knew he had a skill in building housing ... and we wanted to make a difference with the need for housing." As such, they began by renovating an old abandoned building in downtown Barrie, to provide affordable, fully furnished transitional housing units for women fleeing abuse. According to Rhonda, Redwood Park Communities works with the City of Barrie, the County of Simcoe, and Barrie Women's shelter, to provide affordable units and to "fill the gap between when women leave the women's shelter here in Barrie and when they get their Ontario Housing."

\section{Table 4: Private Developers' profile}

\begin{tabular}{|l|l|l|}
\hline \multicolumn{2}{|c|}{ PRIVATE DEVELOPERS } \\
\hline & Toronto & Barrie \\
\hline \# of participants & 1 & 1 \\
\hline Title & Vice President of Development & Co-owner \\
\hline Organizations & Diamond Co-op & Redwood Park Communities \\
\hline Gender & Female & Female \\
\hline
\end{tabular}

\subsection{Strategies of Inquiry:}

\section{Data collection: In-depth interviewing techniques:}

The main instrument of measure was semi-structured in-depth interviews. In-depth interviewing techniques are helpful for understanding interventions, perceptions and experiences, and are more desirable in evaluation research, as they enable researchers to collect detailed information about participant's thoughts and actions regarding a program or policy issue under review (Boyce \& Neale, 2006). In this study, use of in-depth interviewing techniques enabled me 
to gain a better understanding of the meanings that women attach to their experiences with hidden homelessness and policy-makers' and stakeholders' thoughts and actions in working to address housing issues in Toronto and Barrie.

Using in-depth interviewing techniques, I asked open-ended questions and actively engaged in probing, clarifying, paraphrasing, summarizing and follow-up questioning. For example, an opened ended question such as "In your opinion, what will it take to end hidden homelessness in Ontario," was followed up with questions such as "can you elaborate more on that idea, what else would you like to say about that? Could you explain further, is there anything else you would like to talk about regarding this issue?" As well, in seeking for clarification, I asked participants questions such as, "I am not sure I understand what you just said, would you like to clarify that for me?" Furthermore, follow-up questions enabled me to discover in-depth knowledge regarding participant's understanding of the phenomenon of hidden homelessness or policy response herewith. For example, “what does it mean when you say, I just don't have a choice?” or “you have just told me that, ending homelessness begins with political will, what do you mean by that?" This approach is especially relevant to the current study because it is in line with qualitative research methods and feminist worldview. Qualitative approaches are especially responsive to local conditions, situations and, the needs of participants (Creswell, 2009). As such feminist research begins with an acknowledgement that research is a collective process that cannot be achieved by researchers working alone (Zavos \& Biglia, 2009), but through close collaboration with participants, to reduce power imbalances and avoid further marginalization of vulnerable populations.

In this regard, I conducted in-depth interviews with participants in their naturalistic settings, between the period of November 2017 and February, 2018. I visited women participants in their local communities and carried out in-depth interviews using semi structured, opened ended 
questions. These meetings were carried out in private rooms within public places like public libraries and community recreational centres. I also visited policy experts and stakeholders in their offices or boardrooms, or scheduled teleconference for interviewing purposes.

Whereas I used a semi-structure interview $\operatorname{protocol}^{21}$, with general guidelines of questions to guide the interview process with women, policy-makers and major stakeholders, these questions shifted as new themes came up during the interviews. During these interviews, I paid close attention to verbal and non-verbal cues from participants and the meanings that they attach to their stories. For example, I asked women the following open-ended questions:

a) How would you describe housing affordability in Toronto (Barrie)?

b) What has been your experience in accessing social housing?

c) How would you describe your current living arrangement and your experience living there? ${ }^{22}$

As well, policy experts and stake holders where asked the following open-ended questions:

a) How has your organization used the inclusionary housing policy to address the issue of hidden homelessness among women, in your area?

b) What are the challenges of implementing the inclusionary housing strategy?

c) In your opinion, to what extent has the inclusionary housing policy contributed to an increase in affordable housing stock in Toronto (Barrie)?

\section{Instrumentation:}

I purchased a digital recorder to record the interviews for later transcription. I also acquired a computer, electronic storage devises as well as paper journals and pens, to record field notes and to transcribe and store the electronic transcripts.

\footnotetext{
${ }^{21}$ Appendices I and $\mathbf{J}$

${ }^{22}$ Past experiences with hidden homelessness were reflected in lengthy interviews and will be discussed in the results chapters.
} 


\subsection{Ethical Considerations:}

Researchers working with human subjects need to take into account some practical ethical considerations to minimize harm to participants. As such, before interviewing participants, I sought permission from the Ryerson Research Ethics Board (REB), to ensure the safety of participants in this study. Moreover, given that participants experiencing hidden homelessness may have multiple layers of trauma and victimization, I put together a list of counselling resources that woman could access, in case of triggers while narrating their experiences with hidden homelessness and I also put together a list of community resources ${ }^{23}$ that deal with housing, income supports and other services. As such participants were offered these resources prior to the study and were informed of their right to withdraw from the study at any given time, before, or during the study, without losing their honorarium.

It should, however, be noted here that, apart from minor emotional and psychological discomfort, this study posed no serious harm to participants. Moreover, feminist research is done with an action agenda to change the lives of participants, reform institutions in which they live and work, or even change the researchers' lives (Huey et al 2012; Liamputtong, 2007; Richards, et al., 2010; Zavos \& Biglia, 2009). As such, the benefits of highlighting the plight of women experiencing hidden homelessness at policy level, far outweighs the minor discomfort that participants may have experienced.

Issues of safety and confidentiality are at the centre of feminist research, noting that participants face the risk of having intimate details about their lives exposed and a research study may be hampered if data is lost or tampered with. In particular, Creswell (2007) warns that due to the extensive use of computers in qualitative research, particular attention should be given to how

${ }^{23}$ See Appendices $\mathrm{G}$ and $\mathrm{H}$ 
qualitative data is organized and stored. In this regard, I endeavoured to protect the confidentiality of participants and the credibility of this study by: (a) using pseudonyms in data analysis and final report, (b) following safe storage of data protocols by using a password controlled computer and creating a password protected archive file containing original copies of the transcripts, $(c)$ securely locking away my laptop, backup sticks and all the documents including daily written transcripts, journals and all rough notes related to this project, in particular those with identifiers, when not in use by this researcher.

I obtained Ryerson Ethics Board approval for this project. Regarding the identification of names, I agreed to respect confidentiality and anonymity of participants by not disclosing their names. Although participants were debriefed on issues of confidentiality, and were given an option to remain anonymous, the majority of policy-makers and stakeholders wanted their names and professions included in the study. In Barrie, policy experts and stakeholders who wanted their real names included in this study were, the Mayor of Barrie, Mayor Jeff Lehman, a housing developer Rhonda Kent from Redwood Park Communities, and Housing Outreach worker from Barrie Women's Shelter, Danielle. In Toronto, the Director of Housing for City of Toronto, Sean Gadon and Policy Expert from University of Toronto, Dr. Emily Paradis, as well as the Director for Housing with Dixon Hall Neighbourhoods, David Reycraft, also preferred to have their identity included in data analysis and in the final report. Further, although I offered to use pseudonyms to protect women, during data analysis and in the final report, two women from Barrie, Elaine and Elizabeth, wanted their names used as they felt it was empowering. In fact Elaine pointed out that “finally I can have my voice heard”. Consequently, unless given consent, in writing, verbally or electronically via email, all participants remained anonymous.

Beyond confidentiality issues during this study, I also considered breach of confidentiality after the completion of this study. In particular, continued storage of confidential data increases the 
risk of possible violation to confidentiality through extraction or reconstruction of the raw data. In this regard, appropriate steps were taken, to thoroughly, and completely destroy all raw data, once my dissertation was complete and approved.

This case study was voluntary and I endeavoured to provide a full disclosure regarding the purpose of my study. Women participants were debriefed about the research through a recruitment poster (Appendix A), and policy experts/stakeholders through invitation letters (Appendix B).

Before the actual in-depth interview, participants were provided with a debriefing letter (Appendices D and F) and were asked to sign a voluntary consent (Appendix C and E), to participate in the study, in which they were advised of their right to withdraw participation at any given time.

Whereas participants were not offered any compensation for participating in this study, bus coupons were made available to low-income women who could not afford transport. However, given that interviews were conducted in participants' communities or over-the-phone, none of the participants requested for bus tokens. I however provided a small token of appreciation to all participants, in the form of \$20.00 Tim Hortons Gift Card. Participants were notified that, should they choose to withdraw from this study at any given time, this token of appreciation would not be impacted by their withdrawal.

\subsection{Validation of Data:}

To enhance the validity of this study, I used the standards of validation developed by Guba and Lincoln (1981) in which they addressed issues of reliability and validity by introducing the concept of "trustworthiness" and using four aspects to judge the soundness of a study, namely credibility, transferability, dependability, and conformability (Guba \& Lincoln, 1981). According to Guba and Lincoln (1981), to demonstrate qualitative rigor that will enhance the trustworthiness of a 
study, a researcher may use audit trail, peer debriefing, member checks or confirming results with participants. I, therefore, followed similar processes and procedures throughout this case study of the IH policy as it relates to the problem of hidden homelessness among women.

For example, credibility in this study was be achieved by maintaining an audit trail in which I kept a record of research activities and coding processes, including date, time and venue of interviews, interview notes, coded transcripts and a coding book. I also used self-reflexivity, daily journaling and peer debriefing, to enhance the credibility of the research process. I was careful to check my own biases and look for disconfirming evidence or outliers that did not fit the perspective of the majority. To enhance the dependability of results, I elucidated the voice of the participants in data analysis, by including words, phrases and long quotes from interview transcripts. Only rich, thick descriptions or verbatim words of participants where used to describe participants' experiences with inadequate housing and policy responses.

Moreover, credibility of this study was achieved by using the triangulation of data sources, to understand the phenomenon of gendered hidden homelessness and the effect of the IH policy, from different viewpoints. Triangulation of data sources has been found to enhance trustworthiness (Lincoln \& Guba, 1985; Creswell, 2009). In his book Case Study Research: Design and Methods, Robert Yin argues that "case studies need not be limited to a single source of evidence [as] some of the most well written case studies relied on a variety of sources" (Yin 2009, p.110). As such, I used transcript data from women to corroborate data from policy-makers and stakeholders in the area of housing and homelessness. I also analyzed various other forms of data from government policy documents, online newspapers, peer-reviewed journals, policy documents from Canadian Centre for Policy Alternatives, the Caledon Institute, and municipal websites, etc. Lastly, the rich, thick description of the target population, participant's stories and their setting, will enable the transferability of results of this study to similar populations and settings. 


\subsection{Approach to Data Analysis:}

\section{Unit of Analysis:}

The case study method "explores a real-life, contemporary bounded system (a case) or multiple bounded systems (cases) over time, through detailed, in-depth data collection involving multiple sources of information... and reports case description and case themes" (Creswell, 2013, p. 97). Although I reviewed policy documents related to housing and homelessness, my main unit of analysis was the $23^{24}$ transcripts from in-depth interviews with participants. Although each transcript constitutes a unit of analysis, data was organized around two cases, Toronto and Barrie, for comparative analysis across geographical areas. The first data set was from Toronto, and it consisted of transcripts from five women experiencing hidden homelessness, two policy experts, two community stakeholders and one private developer. The second data set was from Barrie, and it consisted of transcripts from six women experiencing hidden homelessness, four policy experts, three community stakeholders and one private developer. Each of these two data-sets was viewed as a whole and was clearly distinguished from the other data set.

Triangulation of data sources: Apart from the main unit of analysis (the transcripts from participants from Toronto and from Barrie), the current study triangulated data from various data sources, in its strategy of inquiry. The data included; peer review journal articles, policy documents within the public domain, related to the Long Term Affordable Housing Strategy 2010, National Housing Strategy 2017 and policy reports related to Bill 7 of the Affordable Housing Act 2016 and Fair Housing Plan 2017, as well as newspapers articles on housing and homelessness in Toronto and Barrie. This data was accessed through the Ryerson University multidisciplinary database,

\footnotetext{
${ }^{24}$ Saturation was reached when I could not find any more new information from women, stakeholders and frontline workers. When it comes to policy makers, I interviewed high-level policy experts directly responsible for housing policy in Toronto and Barrie. Junior level policy experts declined interviews stating they had nothing to add from what their senior would have said.
} 
federal and provincial government websites, municipal websites, policy institute websites such as the Canadian Centre for Policy Alternatives and Caledon Institute of Social Policy, activists, research think tanks and policy entrepreneurs' websites, and Google search. Furthermore, some of the data related to the IH policy and housing affordability issues, came from newspaper cuttings and online newspaper articles.

Thematic analysis: I began my data analysis by organizing raw data from in-depth interviews, field notes and self-reflexivity notes. I used applied thematic analysis (ATA), a bottomup approach to data inquiry, to enable me to build general themes or concepts from observations I made from transcripts, field notes and self-reflexivity notes. Creswell (2009) posit that researchers who engage in this form of inquiry, maintain a research style which honours individual meaning while trying to understand the complexity of a situation (Creswell, 2009). ATA draws from the grounded theory approach and it focuses on systemic data analysis involving constant comparative analysis of data (Charmaz 2006; Corbin \& Strauss 2008; Glaser and Srauss 1967), such as “incident to incident, incident to codes, codes to codes, codes to categories, and categories to categories" (Birks \& Mills, 2012 p.9). Every concept identified during initial coding earned its way up into a category by repeatedly being present in each transcript, document, or observation (Strauss \& Corbin, 1990). Themes emerged from relationships built through constant comparisons between codes and between categories. However, unlike grounded theory method, ATA is not preoccupied with building and assessing theoretical models, rather its primary focus is to summarize participant's perceptions and lived experiences as it relate to a particular research problem.

My initial coding began by reading and re-reading the 23 transcripts from participants from Toronto and Barrie, as well as field notes and self-reflexive notes, policy documents related to the Ontario's Long Term Affordable Housing Strategy 2010; National Housing Strategy 2017, Bill 7 of the Affordable housing Act 2016; and Fair Housing Plan, 2017, case notes, archives, reports and 
scholarly articles while counting the frequency of verbs used to describe, affordable housing, accessibility to affordable housing, housing stock, living conditions, intended and unintended consequences of the IH program. I then began assigning codes in the form of words and short phrases from the data. Through constant iterative of code to code, relationships were formed and themes began to emerge. Emerging themes from these words were summarized into categories and colour coded in MS word. For example, words such as, "mouldy," "small," "tiny," "cockroach infested," "broken," "rusty," "old," were used by women to describe their units and these earned their way to the theme of poor housing conditions. Every theme developed was assigned a colour in the coding book. I therefore used the colour red, to highlight all words and phrases depicting poor housing conditions in Toronto and Barrie.

Moreover, most themes were named after recurrent catchy phrases from participants, for example, a recurrent phrase of affordability crisis emerged into a theme and was coded green, following participant's description of housing in Toronto and Barrie as "unaffordable," “expensive," "out of reach," "all money goes to rent," "sky rocketing prices," "bidding wars," etc. As well, emerging theme of market pressures was coded yellow, following policy-makers' and stakeholders' description of various market forces influencing housing affordability in Toronto and Barrie. The theme finding a happy medium emerged following policy-makers' and private developers' description of the incentives and trade-offs used in negotiating IH strategies. This them was coded light purple, as illustrated in the colour coding book. Consequently, 16 themes came out from the data. 
Table 5: Coding Book

\begin{tabular}{|l|l|}
\hline \multicolumn{2}{|c|}{ OPEN CODING: } \\
\hline Market pressures & "Poor" Housing Conditions \\
\hline "Affordability Crisis" & Current homelessness prevention strategies \\
\hline Paradoxes and choices & Finding "a happy medium" \\
\hline Creation of Big Society & Structure and tenor of IH housing Units \\
\hline IH Policy Perceived Outcomes & Implementation gaps \\
\hline Top down-approach & $\begin{array}{l}\text { Poor Conceptualization of hidden } \\
\text { homelessness }\end{array}$ \\
\hline An integrative approach & Alternative Policies \\
\hline Feminist Advocacy & Ending homelessness \\
\hline
\end{tabular}

Identifying possible themes and associations between the codes and between the themes, was done through constant comparing, contrasting, connecting and merging like codes into themes, and like themes into categories (Guest, MacQueen \& Namey 2005). For example, I compared Barrie women's responses, when describing the condition of housing in Barrie, against Toronto women's responses to determine similarities and differences. I also compared women's responses regarding housing conditions in Toronto and Barrie, to responses from policy-makers' and stakeholders. Moreover, I compared policy-makers' opinions regarding policy responses to the housing affordability crisis to stakeholder's opinions. This helped me to understand how each participant viewed the issue of hidden homeless in their jurisdiction and how various policy actors and community organizations view policy responses, particularly, the IH policy, as it relates to hidden homelessness among women.

Saturation was reached when no new themes or categories could be found anymore. At this point, I began interpreting the data using the feminist critical policy analysis and the concepts of gender mainstreaming and intersectionality. The 16 themes that came out of the data, were further 
placed in into 4 major categories which constitute the next few chapters of this study, namely: (i) hidden homelessness daily survival and vigilance; , ii) factors influencing hidden homelessness, iii) the marketization of housing, and, iv) Way forward: An integrative approach.

The first major category, 'hidden homelessness daily survival and vigilance,' focused on unpacking women's experiences with hidden homelessness from their standpoint and from the opinions of policy-makers and stakeholders. The second major section, sought to uncover, from data, factors influencing women's experiences with hidden homelessness. In particular, this section of the study endeavoured to examine how policy-makers and stakeholders perceive, conceptualize and respond to the issue of hidden homelessness among women, at a policy level. Particular attention was given to existing policies, programs and strategies, as it relates to women. It should be noted here that perhaps, one of the greatest institutional changes witnessed in the 1980's to 1990 's in Western countries was the move towards new forms of governance, which began with the diffusion of power to lower levels of government and the creation of a big society. As such, in the third major category, I attempted to understand the move towards new forms of governance in particular the marketization of social housing, the creation of a big society and the subsequent introduction of the IH policy. In a big society, the welfare of citizens is no longer the primary responsibility of the government but of families, local communities, non-governmental organizations, charitable organizations, individual philanthropists and private businesses (Alcock, 2014). It has been argued that the establishment of the big society is closely tied to welfare retrenchments and the commodification of social services (Dean, 2012; Jones, 2012; Joy \& Sheilds, 2013; Prince 2014). In particular, Joy and Shields (2013) explored the characteristics of the welfare state in a big society and make a case that the main focus of the government in a big society is devolution, outsourcing of services to the private sector, tax-breaks to charities to encourage philanthropic activities, and reduction in government spending on social services. It should 
however be noted that the key elements of public management in a big society, is the privatization of state assets and marketization of public services.

Particular attention was given to how policy-makers have attempted to use the inclusionary policy to address housing problems in Toronto and Barrie and the perceived outcomes of the implementation of this policy. Lastly, in the fourth and final major category, I endeavoured to articulate the way forward, from an integrative gender-based approach and participants' views and my own observations from the field.

Feminist critical policy analysis seeks to evaluate how policies and broader structures act as barriers, (Marshall, 1997) to women's inherent right to a decent standard of living as citizens. At this point, in the study, I sought to explore the positions of women in the Canadian housing landscape and their experiences with hidden forms of homelessness in Toronto and Barrie. Particular attention was given to women's responses as it relates to their lived experiences with housing affordability issues, their living conditions and the physical condition of their built-forms. Furthermore, attention was given to how policy-makers and stakeholders perceive women's experiences with hidden homeless and their opinions regarding the condition of housing in Toronto and Barrie. As such, the next few chapters of this study will focus on findings grounded in the data from participants as well as policy documents, field notes and my own reflexivity process throughout this study. 


\section{CHAPTER 5}

\section{Hidden Homelessness, Daily Survival and Vigilance}

A woman-friendly state would not force harder choices on women than on men, or permit unjust treatment on the basis of sex. ... In such a state women will not have to choose futures that demand greater sacrifices from them than are expected of men.

(Hernes 1987, p.15).

\subsection{Poor Housing Conditions}

In a woman friendly state, women would not be forced to bear the burden of housing affordability. Yet emerging data revealed that women in Toronto and Barrie were situated within an outrageously high private market where they described only being able to "afford crap." They described the built-form of their units as small, tiny, mouldy rusty, broken and in need of repairs. Five out of seven women in Barrie lived in shared spaces that they described as unbearable due to the overcrowded nature of the environments and the violence they experienced in those shared spaces. Elaine lived in the basement of a rooming house, and she narrated sharing the house with up to 14 other people and sharing one bathroom with seven people. She described her living condition as unsanitary, noting, "the bathroom is always dirty" and "occupied." Elizabeth, another Barrie woman living in a boarding house, concurred with Elaine's assertion, and added that she hardly has access to the kitchen because it "is always messy and full of people."

Besides the overcrowding and unsanitary conditions in rooming houses, the violence experienced by Barrie women in those shared spaces was explored. For example, Elaine, who lived in a basement apartment of a rooming house, narrates feeling unsafe and living in a state of hyper vigilance due to the presence of several "strange men" and "druggies," who had a habit of loitering around her unit. In addition, Sophia and Elizabeth, described the verbal, psychological and 
emotional abuse they experienced due to their living arrangement. At the time of the interview, Sophia lived with an abusive brother while Elizabeth lived in with an abusive ex-husband. Both women narrated constant exposure to "ridiculing," "sarcasm," "yelling," "profanity," "name calling," "belittling" and "controlling," behaviours from the abusive brother and abusive exhusband.

Moreover, Sophia and Elizabeth were denied their right to freedom of religious expression as they were constantly challenged, mocked and ridiculed for their spiritual beliefs. For example, Elizabeth's abusive ex-husband taunted her about her Christian values and beliefs, while Sophia's abusive brother, belittled her and called her "crazy", because of her "strong belief in the Esoteric Law of Attraction.” In narrating their struggles in rooming houses, Sophia and Elizabeth revealed that they were living in a state of hyper-arousal due to the verbal abuse they experienced at the hands of their abusers. They particularly felt unease with the "profane words" noting that it goes against their spiritual beliefs. However, whereas Elaine, Sophia and Elizabeth wanted out of their current situation, yet they felt stuck because that is all they could afford on CPP disability. Elizabeth pointed out that "I don't like living with my ex-husband, but I am on a fixed income, on CPP disability, that is all I can afford here in Barrie."

Whereas some women in Barrie narrated their experiences with violence in the shared spaces they lived, none of the women in Toronto was currently living in a shared space. However, women in Toronto, particularly single and racialized women, were segregated into less desirable, poor and unsafe neighbourhoods. For example, Abigal, a single mother of two, was living in the less desirable pocket of Parkdale Community neighbourhood. However, she revealed a long history of hidden homelessness in Toronto, during which time she had lived in "a crack house," "a prostitution house" and "a sex house," with her two children. Whereas she acknowledged that "it was not the safest housing, I can tell you that," yet she pointed out that she could not afford any 
other place in Toronto. Moreover, two racialized women, Daisy and Melissa, lived in public housing, in the marginalized pockets of Rexdale and Scarborough Communities. These women described their neighbourhoods as "rough" and "downright dangerous." They worried about regular exposure to gun violence, drug-related crimes, gang-violence, burglaries and other criminal activities.

In attempting to escape, the systemic segregation of low-income women into rough neighbourhoods, Yolanda, a single mother of a teenage boy, was currently renting a "tiny" but upmarket condominium unit in Etobicoke that she could not afford. She revealed that that the city of Toronto had become very expensive, such that, "it is almost impossible to find a 2-bedroom apartment in a good neighbourhood, with good schools," at an affordable rate. However, her decision to spend $42 \%$ of her income on rent was driven by her desire to give her son a chance at life; to be safe and to access good schools. However, whereas Yolanda was "willing to trade-off housing affordability to live in a safer location, with a good school for [her] son," regrettably, that was not an option for the all the other low-income women in this study. In fact, with the exception of Yolanda, all low-income women in this study had a history of living in poor, segregated communities, due to housing affordability issues in Toronto and Barrie.

Despite the visible differences in the built-forms ${ }^{25}$, the narratives of Toronto women, regarding poor housing conditions, closely mirrored those from Barrie women. For example, in describing her housing problems in Toronto, Melissa, a recent immigrant from the Philippines, pointed out that she lived in a "very small apartment" with a "leaking wall" and "everything broken." Prior to settling down in her current unit, she lived in an old downtown apartment with "broken windows," and "a tiny heater," she "almost froze in the middle of winter." As well, Abigal,

\footnotetext{
${ }^{25}$ Barrie women mostly lived in shared spaces within private homes, Toronto women lived in high-rise apartments and/or condominium units.
} 
a single mother, who had recently been served with an eviction notice, described being overcharged for substandard housing in Toronto. She pointed out that she once "paid \$550 per month for a room in a prostitution house" that she described as tiny and disgusting. She was currently paying $\$ 1000.00$ per month, for an apartment she describes as "a garbage apartment," full of "cockroach infestation" and "black mould." In detailing her experiences living in this apartment in Toronto, Abigal revealed that:

It is extremely difficult, I have cockroaches all over my apartment, they are everywhere, in the cupboards, underneath my table; they are always crawling all over my food, jackets and coffee. It is so frustrating, I have to cover everything. I feel sick in my stomach (Abigal, personal communication, Toronto, February, 4, 2018).

While landlords benefited from collecting rental every month, the daily struggle faced by women in their rental units is an indicator that that those with resources and proximity to power, make decisions, and set the pace and environment in which women are forced to survive. There is a casting out of citizenry, a concept related to social exclusion. According to Galabuzi (2007), social exclusion is a form of alienation and denial of full citizenship experienced by particular groups of individuals and communities. In industrialized societies, a key determinant of social exclusion is uneven access to the processes of production, wealth creation and power manifesting in the form of denial of access to social goods, such as housing, education and health care, and the opportunity to participate actively in society; that is, being excluded economically, politically and socially.

In addition, in trying to balance between the stressors of living on an inadequate fixedincome and the poor conditions of their units, the anxieties brought about by slumlords were a narrative that woman participants raised throughout the study. 


\subsection{Power and Greed: The Struggle with Slumlords}

The casting out of citizenry is a direct assault to women's rights ${ }^{26}$. Most notable is how the intersections of a weakened safety net, the affordability crisis, and the deregulation of the rental market, compound women's experiences with hidden homelessness. Particularly, in the absence of national housing standards, the line between what constitutes acceptable and unacceptable builtforms has become blurry. As a result, poor planning of built-forms, and overcrowding conditions in rooming houses, speaks to the ominous absence of federal leadership in setting national standards.

Given the feminization of poverty, and with limited stock of social housing, landlords appeared to take advantage of extremely vulnerable women, who were left with little options but to rent sub-standard housing within shared environments. For example, Cindy, a woman living in a basement apartment in Barrie, narrated harrowing stories of being exposed to constant "noise" "yelling" "fights" and "loud music", from the tenants upstairs such that she could hardly function at work. She pointed out that:

...living here, noise is the biggest problem, especially when I work mornings, ...I can't get enough sleep [because] ...the couple upstairs fight a lot, ..the man is verbally abusive, the things he says to her is very disrespectful, I just want to call the police, he shouldn't treat a lady like that. Their kids are always making noise I can't sleep. I have terrible headaches due to lack of sleep and its affecting my work at Tim Hortons. (Cindy, Barrie, October 23, 2017)

It should be noted here, that in a patriarchal capitalistic society, women's experiences with hidden homeless speaks to issues of power and greed and points to an endearing capitalistic culture, where maximizing profits from rentals supersedes the quality of built-forms and hampers landlords' commitment to providing adequate housing. For instance, despite the high rentals in Barrie, Cindy,

\footnotetext{
${ }^{26}$ According to the United Nations Human Rights Covenants to which Canada is signatory, every citizen has the right to access adequate and proper housing, healthcare and education. Also see: Report of the Special Rapporteur on adequate housing as a component of the right to an adequate standard of living, and on the right to non-discrimination in this context: Mission to Canada (PDF). C (Report) (A/HRC/10/7/Add.3) (United Nations). Retrieved November 5,2018
} 
Pat, Elaine and Elizabeth, did not have access to functional kitchens where they could prepare healthy meals. For example, while Cindy, could not cook actual meals because there was no stove, in her basement apartment, Pat did not have a kitchen in her basement apartment. As well, Elaine, an elderly woman in a rooming house, gave up cooking because it took her three flights of stairs to get to the kitchen. She goes on to say, "I can't do stairs, it gets harder and harder each day...but I cannot find a place getting $\$ 900$ only on disability.” Moreover, Elizabeth also faced barriers accessing the shared kitchen in her boarding housing, due to overcrowding issues, noting, "I can't cook in that kitchen, there are always too many people in the kitchen." Although these women tried to cope with housing precarity by substituting cooked meals with take-out, microwave meals and by utilizing crock pot, they admitted that they were not following proper diet resulting in poor health outcomes, which will be discussed in the next section of this chapter.

Apart from accessibility issues, it was apparent from this study and others (Edwards, 2018; The Guardian, 2018), that landlords acted with impunity in the face of deregulation and government's hands off policy, to the point of overcharging tenants for inadequate housing. For example, Yolanda, a Toronto woman living in a condo, revealed that she was being charged over $\$ 2,200.00$ plus condo fees, per month, for her unit, she described it as "tiny," she could hardly accommodate her family. She narrates feeling cheated, noting that although her condo building was "beautiful and well kempt, ...the owners passed off the unit as a 2-bedroom apartment, but it's not, the other room has no privacy at all, it's not a bedroom, it's just like a den." As a result, Yolanda was forced to "share [her] bedroom with her mom," while her "son sleeps on the couch." The deception and greed that women experienced in dealing with landlords was also brought into the open by Daisy, a woman of colour who lived in public housing in Toronto. She revealed that that her property manager is pre-occupied with maintaining the public areas inside and outside the apartment building, noting "they have well-manicured gardens, to make it look like heaven from 
the outside, but inside, it's a mess." Regrettably, the irony of hidden homelessness is that property managers are preoccupied with marketing their properties to the public and not with providing adequate housing.

In addition to overcharging for inadequate housing, perhaps one of the greatest challenges women in this study faced, was an expectation to give up their pets in order to find suitable accommodation. For example, although Elizabeth was having accessibility challenges in the boarding house she shared with an abusive ex-husband and other "strange men," she was finding it particularly difficult to find a place without stairs that can take a dog. However, although Elizabeth acknowledged that most places do not like dogs, she believed her dog carries her late daughter's spirit; as such it was a source of comfort and spiritual connection to her daughter. Likewise, Sophie avoided shelters and remained precariously housed with an abusive brother because, she was worried that her cats would not be allowed in the shelter.

Frontline workers confirmed that pets, particularly dogs, are often not allowed in shelters, transitional housing units and even in some permanent rental units. Although Ontario's Residential Tenancies Act, 2006 prohibits landlords from having a no-pet clause in the lease agreement (Ontario Government, 2018), it does not prohibit the landlord from refusing to rent their property to someone with a pet. As a result, women and frontline workers in this study noted that some landlords discriminated pet owners by using strict eligibility criterion to recruit tenants who had not pets. Furthermore, in addition to sanctions on what women can own, some landlords imposed sanctions and restrictions on women and limited what they can bring into their units. Tenant sanctioning is limiting and speaks to power imbalances and greed found in capitalistic, neoliberal societies, where greed and profits overrides our collective humanism.

Although women in this study appeared housed, they were unhappy with their living conditions. However, when asked if they had tried to look for alternative accommodation, they 
pointed out that lack of affordable housing and the limited housing choices awarded to them within the private rental market, forced them to stay put in their current residences. The low vacancy rates resulted in increased competition for housing in Toronto and Barrie. As such some women gave up searching for alternative accommodation and remained precariously housed in shared environments where they experienced abuse and violence. Others had no choice but to remain inadequately housed in substandard units that allow pets.

Women in this study were denied freedom of choice and access to adequate and affordable housing, which is a violation of basic human rights to housing, safety, self-determination, and decent standard of living (Galabuzi, 2009; United Nations Human Rights Committee, 2009). The consequences of such power imbalances amount to systemic violence against women in that it fuels housing insecurity and the interpersonal violence that women in this study experienced their shared spaces. In addition to poor built-forms, restrictions and sanctions imposed on precariously housed women, incidents of landlords exercising power over tenants and refusing to listen or act upon tenants' issues of concerns was a common theme raised by women in both private rentals, rentgeared to income rentals, as well as those in social housing.

Various incidents raised by women point to deeper systemic issues. Given that neoliberalism pushes for individual right of choice, and rather than provide affordable housing, low-income women are sometimes given a housing subsidy to 'choose' their own accommodation. However, the challenge of situating low-income women within the private market through the subsidy program is that tenants on government subsidy were treated differently compared to market-based tenants. For example, Lily, a Barrie woman in subsidized housing, noted that despite submitting several complaints to her landlord multiple structural and health-threatening problems in her apartment, the landlord continuously minimized and failed to act upon her concerns. In fact, 
according to Lily, preferential treatment was given to newer tenants who were not on rent-gearedincome:

When I first moved into this apartment 18 years ago, the carpet was dirty and over the years, the landlord has not been doing any renovations at all, ...two cupboard doors have been missing for four years, the stove has not been working for three weeks, ...the paint on the walls is peeling off, ...the bathroom sink shifts and move, ...there is rust and mould in the bath tab from a leaking tap along the wall, ...its eating the enamel, and there is sewage breaking up in my bathroom, I can smell it, I don't take a bath anymore. I reported all these problems to the landlord, but nothing has been done. Other apartments are renovated when new tenants come in, but not for me. I put in a request 12 years ago, and believe me Rosemary, I keep submitting these requests, but nothing has been done for me. A neighbour who moved here only 4 years ago had all her carpets ripped-out and new flooring put in, but nothing has been done here. I have a burnt counter and I get written up every year on the annual inspection. I have allergies but I live with mould and rust. They don't listen, they don't seem to care because I am on government subsidy, they just keep brushing me aside. They want to wait until it's so bad that I am gonna have to hurt myself (Lily, personal communication, Barrie, October 12, 2017)

Beyond challenges faced by women in rent-geared-to income housing, women in social housing also faced similar problems with landlords refusing to attend to various issues of concern. For instance, Daisy, a Toronto woman in social housing, pointed out that her property manager failed to do the necessary repairs, and failed to rid the apartment from cockroach infestation. She pointed out that despite paying her rent on time, her apartment was in a "mess", noting that "there are cockroaches everywhere ...the whole building is infested and it smells terrible." She narrates feeling "terrorized" by the infestation and the "terrible smells" in her apartment, yet despite raising these issues several times with her landlord, nothing had been done. Daisy remembers a particular incident involving the death of a neighbour her landlord's refusal to investigate the foul smell coming from the apartment. She noted that:

A neighbour died in my unit and for one week and there was a terrible smell from my apartment, but the landlord did not do anything until I called the police. After the corpse was finally removed, the landlord just did a little clean up and put another family in there immediately. They just don't care about your well-being. I feel unheard. It's a rip-off! I am 
one of the best tenants in this building, I pay my rent on time, I keep my apartment clean, but the landlord don't care about your wellbeing or your welfare (Daisy, personal communication, Toronto, November 17, 2017)

Daisy narrated feeling traumatized and horrified by the incident and like several women in this study, she tried to advocate for herself but felt as if she did not have a voice.

In addition to failing to maintain their rental properties, some have discovered that there are property managers who also place barriers on new immigrant's efforts to integrate in their communities and put behind the impacts of war and trauma from their countries of origin. For example, when Syrian refugee families in a high-rise apartment building in Hamilton, decided to break their lease because the landlord had failed to resolve the issue of bedbug infestation in their apartment, and the rental agency sued the families for unpaid rent, and refused to issue rental receipts that were crucial for the refugees and other low-income residents to apply for child tax credits (The Guardian, 2018). Whereas, the Landlord Tenant Board, can adjudicate issues of concern between landlords and the tenants, it has been argued that lack of understanding of tenants' rights, particularly among immigrant communities, coupled with language barriers and culture shock, highlights some of the challenges recent immigrants face in navigating the Canadian rental market (The Guardian, 2018). As such, the need to protect vulnerable tenants, particularly new immigrant women, from imminent abuse from landlords and other tenants can never be overemphasized.

Whereas it has been argued that the vicious cycle of homelessness continues to fester among immigrant communities because incidents of abuse are often underreported (The Guardian, 2018), yet some women in this study who attempted to report issues of concern related to their housing, were unsuccessful. In varying instances, landlords in this study failed to resolve apparent conflicts within shared spaces, and/or communities in which they live. For example, when Katie, a Barrie woman, reported incidences of harassment from the tenant downstairs, she felt "ignored". In 
detailing her struggles with this tenant and her landlord's response, Katie revealed that:

The lady who lives downstairs, ...curses at me, she swears at me, all day long. I am the last thing she thinks about at night and the first thing she thinks about in the morning. She has pulled out some of my flowers. I've involved the landlord, but as long as she is paying her rent, they have told me to ignore her. (Katie, personal communication, Barrie, November 4, 2017).

Nonetheless, the subtle yet deadly violence that women face at the hands slumlords amounts to systemic violence which requires the urgent attention of public administrators, politicians and research scientist. For instance, Pat was "left stranded" when her landlord decided to sell his property, rather than deal with an abusive neighbour. She pointed out that the neighbour constantly harassed her and even went as far as calling the police on her, "for no apparent reason." However the landlord did nothing and, instead sold her house leaving Pat to find another dwelling, in a very hot and competitive housing market. Like many other women in this study, Pat felt, "let down" insecure, powerless and defenseless, as a result of housing insecurity and challenges with landlords. Lily another Barrie woman whose landlord refused to do the necessary repairs in her apart, asked rhetorical questions such as, "What do I do? Do I move away from Barrie? Where do I go? It is very discouraging." Moreover, in addition to problems with slumlords, the racialization of hidden homelessness and heteronormative biases that exist in rooming houses, further worsened women's experiences with hidden homelessness.

\subsection{The Racialization of Hidden Homelessness and Heteronormative Biases}

In applying gender mainstreaming and intersectionality tools in this study, it was clear that gender intersects with race, immigrant status and heteronormativity to create layers of oppression in the lives of diverse groups of women experiencing hidden forms of homelessness. In particular, women experiencing hidden homelessness were grossly entrenched in the dichotomous roles and positions of, masculinity and femininity; deserving and undeserving; voice and neglect, which 
reflected power and privilege. First, the racialization of hidden homelessness was evident in the treatment of women of colour on the housing market in Toronto. Race was compounded by their immigration status, which was echoed by, Daisy, Lisa and Melissa, who were both racialized and recent immigrants living in Toronto. All women of colour in this study, apart from Yolanda, narrated experiences of racial discrimination and stereotypical attitudes at the hands of their landlords as well as prospective landlords. For instance, Melissa pointed out that finding adequate housing as a Pilipino immigrant woman, with an accent, was a challenge. She believed landlords looked at her "differently ... as if I cannot pay my rent," hence she was denied a residency in several buildings that were far much better than her current residence.

Even after becoming a tenant, women of colour narrated their experiences with racism and profiling in their rental units. For example, in describing how her family was "constantly targeted," by her property manager, Daisy a black immigrant women, revealed that "if anything bad happens in this building, they call me and ask if my son knows those people." It was obvious that the property manager's statements were laden with insinuations, accusations and innuendos that associate blackness with criminality and Daisy was aware that her son was being targeted "simply because he is black." Consequently, Daisy and her family lived in a constant fear because they would "never know when the next accusation was going to come." Moreover, in trying to protect her son and escape the "stigma associated with young black men in social housing," Yolanda, a single mom in Toronto, rented a condo unit that she could not afford. She argued that although she was spending more than $42 \%$ of her income on rent, she was happy "to live in a safe neighbourhood."

Racialized women in this study tied their experiences with hidden homelessness to racism on the housing market, job precarity and inadequate income supports. Daisy pointed out that the reason why her landlord did not pay attention to her complaints about "broken appliance, ...peeling 
paint, ...cockroach infestation and...the smell of a corpse next door," was because "the superintendent doesn't like people of colour... it's because I am Black.” As well, Lisa, also believed her housing problems were tied to racism and stated that her landlord "only help people of their own race." Whereas Melisa echoed similar sentiment as Daisy and Lisa, she also believed that her landlord was devoid of empathy for racialized people who were over represented in social housing. She pointed out that "I pay my rent every month, but the landlord does not listen ...they treat me differently from other tenants, it's because I am not white so they treat me differently." In addition to the stigma and discriminatory practices experienced by racialized women on the Toronto housing market, women of colour felt penalized for their work ethics, by being denied housing subsidy even though they were not making enough to cover rent. Melissa pointed out that "rent keeps going up," and "parking is very expensive," such that it was difficult to put food on the table for her and her family.

The experiences of hidden homeless by racialized women in Toronto were compounded by the fact that they were also new immigrants to Canada. They believed their housing situation was worse than being on the streets in Canada, and compared the condition of the units to that of third world countries where they came from. Whereas they had all imagined coming to Canada and living a 'Canadian Dream' yet they narrated their nightmare, with the poor living conditions in which they lived. Daisy, who lived in social housing in Etobicoke, struggled with trying to understand how a wealthy country like Canada would have living conditions "worse than the living conditions back home.” Moreover, Melissa, who lived in social housing in Scarborough, echoed similar sentiments, pointed out that: "I never saw such a big cockroach in my life, until I came to Canada and started living here, I just don't understand, because this is supposed to be a good country, you know."

Narratives from racialized women pointed to the segregation of immigrants and individuals 
of colour, into the less desirable neighbourhoods of Toronto. In fact, Abigal, a white Canadian experiencing hidden homelessness in Toronto’s Parkdale area, corroborated Daisy, Lisa and Melissa's stories. She articulated her own experiences living in a predominately Black immigrant community in Parkdale, saying "I witnessed the racialization and marginalization of these communities, I saw people go hungry, ... alcohol and drug addictions, ...guns and violence, I had to ask myself am I in Canada? ...We created these racialized communities.” (Abigal, Toronto, October $22,2018)$. Whereas the issue of race has been acknowledged at policy level, as it relates to the over representation of Indigenous women in poverty, the issue of race and gender within debates on housing is still under-researched. According to the NHS policy document, more research is needed in Canada to enhance our understanding on how issues of gender, race and ethnicity, play out in the making of gender-based homelessness (Government of Canada, 2017).

Although none of the women in Barrie were part of the visible minority groups, the heteronormative bias that exists in shared quarters was a cause for concern. Most visible was the belief that men and women ought to fall into natural roles of male and female, and adopt heterosexual norms and values in rooming houses in Barrie. Hence women in these shared spaces were expected to "clean after men" in "dirty kitchens" and "filthy bathrooms." (Elizabeth, Barrie, October 24, 2017; Elaine, Barrie, November 23, 2017). As well, Elizabeth, who identified herself as "lesbian," pointed out that she was expected to adhere to strict norms and values regarding her sexuality or risk being shunned. These norms and values were first enforced by the normalization of heterosexual relationships, particularly in older couples, no matter how dysfunctional or abusive the relationship, and were further reinforced by the lack of privacy in rooming houses. Being an older, lesbian woman, Elizabeth did not feel safe to disclose her sexuality in the rooming house she lived with an abusive ex-husband, out of fear of reprisals from her roommates in the boarding housing. She pointed out that "if they get to know that, I am gay, at this age, I will be shunned." 
Yet living with an abusive ex-husband was never questioned and considered normal, in the rooming house. As such, because of her living arrangement and her age, she was not able to have a partner of her choice due to lack of privacy and the sanctions associated with being anything other than heterosexual. The multiple layers of oppression, based on gender, age and sexuality, exacerbated this woman's experience with hidden homelessness, as she narrates keeping to herself and "feeling trapped.” (Elizabeth, Barrie, October 24, 2017).

\subsection{Internal Displacement}

The issue of internal displacement was evident in the lives of women experiencing hiddenhomelessness and housing insecurity. For example, when asked how long they had stayed in their current residences, only two women in Barrie and one woman in Toronto had lived in their current residence for long periods of time. However, despite staying in their current residences for long periods of time, they all narrated a history of being inadequately housed and expressed dissatisfaction with their current living arrangements. For example, Lily, stated that it took her a long time to find housing that she could afford in Barrie, to the point that she had to move-in with her mom who was verbally and physically abusive. She recalled incidences in which she was "punched in the stomach" when she was pregnant, noting, "so I moved in with my dad and stayed

there for a year, but there was no elevator...it was hard with a baby, a toddler and a stroller...I had to carry one child at a time, then the stroller". (Lily, Barrie, October 12, 2017). Moreover, Lily states that she "had to fight hard for ODSP" before she finally got into her current apartment. Despite her dissatisfaction with her current apartment for 18 years, she feels secure and is fearful of losing that housing security. Consequently, she has learnt to tolerate her slumlord. 
Several Barrie women also narrated their struggles with finding adequate, affordable, safe

housing, in Barrie, such that they had to constantly move. Katie, noted that she "moved 23 times in the last 5 years" before settling into her " 2 bedroom apartment ...2 years ago." She states that:

At one point I moved in with an alcoholic friend. She was a heavy drinker and she didn't want my dog, so I left after only two weeks. I stayed with my niece and my family for a while, then I moved into a rooming house, where I lived with a guy who was alcoholic, and a drug dealer. He watches TV till 6 am and has weird people coming into the house at odd hours. Look it doesn't help you know, they can walk into your room. I was scared...the doctor said you've picked a dangerous place to live. I moved and rented a room with a woman who had seizures. It was brutal, really brutal. It terrified me. I could not cope with her illness. So I moved into a basement apartment in St. Vincent Street. The landlord was good but the neighbours were horrible. They tried to get me arrested for something I didn't do. They accused me of breaking into a neighbour's house. The landlord sold his house to get away from the horrible neighbours. I finally got this apartment, but I am not happy where I am right now. ....I am not coping well but I will never move again. I will stay put. I have been here for 2 years. I am not going anywhere. (Katie, personal communication, Barrie, November 4, 2017)

Whereas the displacement of Katie was closely tied to lack of adequate and suitable affordable housing, the violence that happens in interpersonal relationships also exacerbate the internal displacement of women. For example, in narrating Elizabeth, a Barrie woman, started experiencing housing problems after she left her abusive husband and moved from Barrie to Collingwood because, she wanted a distance between her and her abuser. However, she could not find a cheaper place to rent, therefore she moved back to Barrie. She then lived in various rooming houses for 10 years, before moving back in with her abusive husband. In addition to the housing insecurity and constant internal displacement, Elizabeth's vulnerability was worsened by other traumatic events in her life. First, her daughter passed away, second, she found herself unable to work after she "hurt [her] back at Maxi convenient store, unloading a truck." Desperate, overwhelmed and unable to afford rent on her own, Elizabeth states that "I moved back to Barrie with my abusive ex-husband, Rob, while waiting for my sick benefits." Although she was not 
happy living with her abusive ex-husband, at the time of the interview, she pointed out that moving out was not an option due to affordability issues.

Stories of internal displacement were also prevalent in Toronto where participants narrated ongoing housing insecurity. For instance, Abigal, who recently graduated with a Masters' Degree, pointed out that she started experiencing hidden homelessness at the age of 16 when she had "run away from home." Since then, she was constantly moving from one place to another and over the years she lived in "basement apartments with broken windows," "a crack house," "a prostitution house" and "a sex house," because of housing affordability issues. At the time of the interview, she was undergoing an eviction process due to non-payment of rent. Moreover, Yolanda, another Toronto woman experiencing hidden homeless, had recently been forced out of her condo unit in downtown Toronto to Etobicoke, because "the property managers kept increasing the rent."

\subsection{The Paradoxes of Hidden Homelessness: Making Tough Decisions to Survive}

Gender mainstreaming posits that "a woman-friendly state would not force harder choices on women than on men, or permit unjust treatment on the basis of sex... In such a state women will not have to choose futures that demand greater sacrifices from them than are expected of men." (Hernes 1987 p.15). Yet emerging evidence in this study reveals that women experiencing hidden homelessness were forced to make tough choices to remain housed. For example, Abigal had a history of living in dangerous neighbourhoods with her children, while several Barrie women, particularly Elaine, Sophia, Elizabeth, Cindy, Pat and Katie, lived in shared environments with abusive males, drug dealers and drug abusers. Notwithstanding that women in this study feared for their safety and the safety of their children, in these shared environments yet lack of affordable housing, left them with limited choice. Hence, although Abigal, admits that her decision to, "move into a crack-house, ... a prostitution house [and] ...a racialized community" with gun violence, with 
her kids, was "not the greatest thing to do," yet she felt that she had "no choice, because that's all I could afford. I paid \$550 for a room.” (Abigal, Toronto, February, 4, 2018).

The struggle to survival in a hot and competitive housing market was further echoed by a manager from Habitat for Humanity (GTA). He revealed that whereas his "clientele" feared for the safety of their children in the unsafe, over-crowed neighbourhoods in which they lived, and were eager to change their living conditions, it was "extremely hard to get affordable rental" in Toronto. He notes that:

Our clientele are working low-income families ...coming from sub-standard, over-crowded living situations. A family of five, renting a one or two bedroom apartment ... in unsafe neighbourhoods ... because that is all they could afford. ...Often we hear from our families why they want to change their current situation, ...they are afraid for their children's safety, there are acts of violence in the community and neighbourhood and there is fear for the safety of their children at the end of the day. (Manager, Habitat for Humanity, GTA, personal communication, December 6, 2017)

One of the greatest dilemma of hidden homelessness is that women are being forced to choose between rent and food, homelessness and abuse, family and work, housing and lack of dignity, in order to survive. Abigal articulated this dilemma by pointing out that:

It's so difficult for us women. Rent here is very expensive, I have to work two jobs, I have no time for my family, no time to go to church, ...women we suffer you know, some of us end up committing crimes you know. I know of a women who ended up prostituting themselves to help cut the cost of rent. Some women have given up housing altogether and they baby-sit houses, or become live-in baby-sitters, not by choice, but because they can't afford to rent their own place. (Abigal, personal communication, Toronto, February, 4, 2018)

Moreover, in trying to survive experiences of hidden homelessness, several women in this study were forced to normalize their poor living conditions and tolerate slumlords despite feeling unheard. For example, women in rooming houses normalized the absence of kitchens or inaccessibility to kitchens by ordering in or using the microwave, or crock-pot to prepare meals. 
Cindy, a racialized woman experiencing hidden homelessness in Toronto pointed out: "when you've been abused so much, you just think it's normal you know, and if it comes easy, I have to question, why? I just have to be strong, as a woman of colour I have to be strong."

Beyond being forced to tolerate slumlords, racialized women in Toronto women were also forced to tolerate discriminatory attitudes from landlord, noting that despite being, "targeted," "stereotype[d]" and "ignored," by their landlords," they were forced to stay in run-down, cockroach-infested apartments, for long periods of time, due to the affordability crisis in Toronto (Abigal, February 4, 2018; Lisa, January 17, 2018; Daisy, November 17, 2017). For example, Daisy revealed that she had continued to live in her social housing apartment for 12 years because she felt she had "no choice, it is too expensive out there, affordability is horrible." Whereas the conscious desire to be adequately housed was there, yet the unconscious familiarity with what was considered affordable housing, resulted in the normalization of the poor quality of the housing.

Paradoxically, women took pride in keeping their living space clean and organized, despite their frustrations with the poor condition of housing. In fact, they tried to rectify the problems in their units and keep their apartments "very clean," "wash walls," "paint" and "spray chemicals" frequently "to get rid of cockroaches." For example, Lily focussed on "vacuuming once per week," "dusting every day," and "half washing the walls," because if she washes them completely, "paint comes out and you get written up." As well Daisy's husband had tried to deal with the cockroach infestation by constantly "spraying chemicals around the house."

The dilemma that women faced in their struggle with hidden homelessness, was further corroborated by frontline workers working with women to end homelessness. For example, Danielle a frontline worker in Barrie, pointed out that:

Women tolerate landlords who are almost like slumlords because our housing market is what it is right now. In particular, it is a real struggle for women on assistance and many ...women in our community will put 
up with substandard conditions because the alternative is living in unaffordable housing. (Danielle, personal communication, Barrie, November 9, 2017)

Consequently, while women dutifully paid their rent each month, slumlords continued to be rewarded for inadequate housing. Yet the visible impact of hidden homelessness and the invisible pain associated with it was well articulated by all participants in this study.

\subsection{Impact of Hidden Homelessness: Women are "Emotionally Tossed!"}

Housing is viewed as one of the major social determinants of health. It has been argued that Canadian governments are not taking seriously the role that housing policies play in fueling housing inequalities in Canada (Bryant, 2009). Some have made a connection between hidden homelessness and poor access to health and social services and concluded that for the most part, resources were not being allocated to individuals experiencing hidden homelessness because they are invisible and difficult to access (Crawley, et al, 2013). However, whereas Crawley and colleagues concluded that compared to accessing health and social services, housing was not a priority for individuals in their study, several studies have noted that lack of adequate, safe, secure and affordable housing reduces quality of life and increases the risk of sickness and diseases (Bryant, 2009; Mikkonen \& Raphael, 2010; Rapheal, 2009).

From the narratives of women in this study, hidden homelessness was more than just a lack a basic physical necessity; it affected them in critical dimensions of health and wellbeing - notably physical, mental, emotional, and spiritual wellbeing. For example, all women narrated feeling "stuck" "hammed in" with "no choice," "terrorized," "harassed" "tormented" "frustrated," "angry," "sad," "unhappy" and "depressed," most of the time. Some women pointed out that they had gained a lot of weight as a result of of stress. (Elizabeth, Barrie, October 24, 2017; Elaine, Barrie, November 23, 2017). These two women reported engaging in comfort eating, particularly eating 
junk food either to cope and/or because they could not access kitchens. Some of these women complained about back problems as a result of the weight gain. In addition, other women described their housing situation as toxic and unbearable and mentioned undergoing psychological and emotional trauma as a result of their living conditions that they." (Abigal, Toronto, February, 4, 2018; Cindy, Barrie, October 23, 2017; Lisa, Toronto, January, 17, 2018; Sophia, Barrie, October $12,2017)$.

Yet still, some women struggled with physical ailments that they connected to inadequate housing. Sophia and Cindy, reported suffering from constant migraine headaches as a result of housing insecurity and ongoing exposure to abuse, noise, worry, sleep deprivation and anxiety in shared housing. Abigal, a Toronto woman, served with an eviction notice, described her struggles with "a lot of migraine headaches, ... at least twice per week," and she narrated "throwing-up regularly," as a result of the headaches. She further revealed her experiences with "frequent panic attacks" and having an overwhelming "sense of being in danger all the time." Similarly, Sophia, a Barrie woman also pointed out that that because of her living arrangement with her "abusive brother" and "abusive slumlord," her pre-existing conditions had worsened over the years, particularly, the impacts from childhood trauma and fibromyalgia. She stated that:

Living here with my brother is a nightmare, its toxic. He is always yelling at me, putting me down, and making me think I am crazy. This landlord too, he is a slumlord, you know. The other day he walked into the house unannounced and removed the washer and dryer, now I have to do my laundry by hand, I cannot afford Laundromat. He refused to turn on the air conditioner during a heat wave. If I have a visitor, he threatens to up the rent. I have had several fights with him. I feel alone, all my friends are out West. I don't feel safe here. I get triggered easily you know, from my childhood, I have childhood trauma, my brother and my landlord makes it worse. Living here is very stressful, I am always anxious and my fibromyalgia flares-up all the time and the pain is unbearable. I feel exhausted; I have migraine headaches because of all the yelling. And when I get these headaches, I throw up and I lose appetite. I have not been eating and all my food go bad. I don't have money to buy more food, but how can you eat when someone is yelling at you? I am emotionally distraught, I cannot stay calm, I slip in and out of depression all the time, but the doctor has no clue because I cannot get there to 
see him, I don't have a vehicle, I have not bus money. I have to ask my brother for his car, he gives it to me sometimes to do grocery, only if he is in a good mood. My depression is worsening, I feel angry all the time. I feel as if I am stuck between a rock and a hard place, there is no solution, there is nothing out there that's affordable, that's within my budget. I just feel helpless and suicidal. I have no stamina to take care of things. I haven't done my taxes in 3 years and I have not received any tax rebate. To be honest with you, I am not coping well with this housing situation, I just use pot, you know, cannabis, it helps me with my pain, but I don't always have money to buy it, so I just suffer, because pain killers don't work. Maybe I should just leave Barrie and go out West (Sophia, personal communication, Barrie, October 11, 2017)

Other women used sarcasm to cope with their poor housing conditions. For example, at the end of her interview, Daisy, a Toronto woman grappling with cockroach infestation in social housing, retorted that, "You know what, I am okay, weather I complain or not, it's just the same thing, nothing gets done, nothing changes. So I am okay. I just have to be strong." A few women narrated numbing out. For instance, Mia, another Toronto woman with a long history of hidden homelessness, revealed that, “I don’t know what happened to my heart, I numbed out, I stopped feeling."

Hidden homelessness can be alienating, as it can push women to shutdown and isolate. For instances, in trying to survive experiences of hidden homelessness in a rooming house in Barrie Elaine revealed that, "I just keep to myself." Elizabeth, another Barrie women coping with hidden homelessness in a rooming house, also noted that, "I stay in my room all the time, I can't invite friends over because of the way my abusive ex-husband is... it is very isolating." As a result, Elizabeth reports "losing self-pride and self-respect," because of her living arrangement with her abusive ex-husband. Whereas she is constantly thinking of how to get out, she feels stuck and helpless. In the same manner several women revealed that the burden of poor housing, housing affordability and housing insecurity weighed heavily on them such that they were constantly thinking of a way out, of unsafe housing, given that there is no safety net to fall back on. 
When asked to give their views regarding hidden homelessness among women, policymakers in Barrie and in Toronto admitted that low-income families in their jurisdictions are struggling from various impacts of housing insecurity. For example, Mayor Lehman raised the issue of food insecurity among low-income women experiencing hidden homelessness and articulated the tough decisions woman have to make, in order to survive with their children. $\mathrm{He}$ stated that:

Food insecurity is very common and pervasive, so that part of hidden homelessness, I am very much aware of it. And you know many women will say to me 'if it's a choice between my kids or me eating a meal, it's me who is not gonna eat, I am gonna have to pay the rent, or if I have some shelter cost, that comes before the food.' So you know that piece of hidden homelessness is particularly devastating and I think the long term health impact and mental health impacts of food insecurity is very severe. That's out there for sure (Mayor J. Lehman, personal communication, Barrie, November 7, 2017).

In addition, Sean Gadon, the Director of Housing - City of Toronto, revealed that because "housing has eaten up more disposable income people are struggling around the choices they make around where their disposable income goes." Sean further pointed out that, despite being a "caroriented society," some low-income households are being forced to either "give up their cars and use public transit" or "move closer to where one works." In fact, according to Sean, "it's either that or it's a challenge for families to put food on the table" hence the emerging "new phenomenon in ...North America is pay the rent or fix the car." Although Sean Gadon, suggests that there has been an increase in the use of food bank, rent bank and clothing bank, only one woman in Toronto reported accessing these services, and only two women in Barrie acknowledged using food banks.

The majority of women in this study cited transport problems, poor quality of food, strict eligibility criteria and restrictions on food quantities, as the reason why they did not access foodbanks. For example, Melissa, a Toronto woman struggling with food insecurity, pointed out that that, "I don't use foodbanks, ... it's a waste of time. Their food is junk food. They don't give 
fruits and vegetables, just expired can food." In addition, Pat, a Barrie woman also struggling with severe food insecurity, revealed that she has not been able to access any foodbank in Barrie because “it is too hard, they want me to bring too many documents. I don't have anything showing my address right now. But I heard the food is not enough, anyways ...they only allow you to get food once per month. So I don't bother going to the foodbank." Other studies have also discovered that foodbanks in Canada do not provide adequate food to address food insecurity among low-income families (Loopstra, \& Tarasuk, 2012; Tarusk, Dachner \& Loopstra, 2014).

Several women in this study felt de-humanized, disappointed and let down by the system, in general, and most specifically by their Members of Parliament and Mayors. For example whereas Elaine, a Barrie women living in a rooming housing, pointed out that, "just because you are lowincome does not mean your dignity should be taken away," Elizabeth, another Barrie women living in a boarding house, also noted that, "they should treat us like human beings [and] think about us like their mother or sister." It goes without saying that having a home goes beyond brick and mortar to encompasses quality of life and the basic rights associated with being human, particularly the right to safety, decent shelter and good health.

\subsection{Conclusion:}

This chapter explored women's experiences with hidden homelessness in Toronto and Barrie, and the challenges they faced in coping with substandard housing and slumlords refusing to make necessary repairs. Emerging evidence points to a gross violation of basic rights to safety and adequate housing for women and their children. The daily stressors brought about by daily experiences of hidden homelessness were examined, with particular attention being given to the stressors brought about by the constant internal displacement of women due to housing insecurity, and the systemic segregation of low-income women into poor, dangerous neighbourhoods and 
unsafe share spaces. Moreover, this chapter unpacks how racialized women and a woman from the LGBTQ community, experienced hidden homelessness, and discovered that the racialization of hidden homelessness and the heteronormative biases that exist in rooming houses, exacerbate women's experiences with hidden homelessness. In addition, this chapter reveals how women are forced to make tough decisions to remain housed, while losing their sense of dignity and wellbeing. The next chapter focuses on factors influencing women's experiences with hidden homelessness, from the personal, interpersonal and systemic factors. While acknowledging the multi dimensional factors that shape experiences of hidden homelessness, major focus will be centred around systems of domination that render women powerless. 


\section{CHAPTER 6}

\section{Factors Influencing Women's Experience with Hidden Homelessness}

Affordability with respect to market rent in Barrie just doesn't match what women are given by OW. Whether it's a single woman or a woman with one, two, three, or four children, the housing allowance from OW, just doesn't match, it's not enough. It's not enough money to pay their rent. Not only does it not pay their rent, let alone food, transportation and clothing for their children. I believe women, on disability ...have more income but they also have more needs that require the use of their money. So it is a real struggle for women on assistance.

(Danielle, personal communications,

November 9, 2017)

\subsection{The Housing Affordability Crisis}

Emerging data from this study revealed that there are multiple factors influencing women's experiences with hidden homelessness, from the personal and interpersonal, to broader systemic issues $^{27}$. However, this chapter examines the bureaucratic elements of housing that push women into hidden homelessness. Significant issues include housing affordability and the rental trap, low wages, difficulties accessing housing and income supports, shortage of shelter space and long wait time. I end the chapter briefly discussing women's perception of these bureaucratic elements, which ultimately have left them jaded with the shelter system.

In exploring factors influencing hidden homelessness in Toronto and Barrie, all policymakers, housing workers and private developers corroborated women's narratives regarding the lack of affordable housing as one of the greatest barriers to overcoming hidden homelessness among women. The Mayor of Barrie and the Director of Housing for the City of Toronto described the housing market in their jurisdictions as very expensive, unaffordable, and "at an all-time high." In fact several policy-makers and stakeholders, went as far declaring a housing "affordability crisis"

\footnotetext{
${ }^{27}$ See Figure 1: Factors influencing women's experiences with hidden homeless (in participants' own words).
} 
in Toronto and Barrie, noting that the housing market is "hot", "difficult", "complex", "challenging", "worrisome", "tight", "closed" and "unhealthy" such that low-income families are struggling to make ends meet within the rental and homeownership side. In addition, policy-makers revealed that in most recent years, the burden of housing affordability in the rental market had expanded to include middle-income households. Emily, a housing advocate and policy entrepreneur ${ }^{28}$ in Toronto, articulated this new phenomenon and argued that the "middle income households are increasingly having difficulties finding rental housing that they can afford and, households with moderate or low-income find it almost impossible." The housing affordability issue in Toronto was rather worrisome such that, Sean, the Director of Housing with the City of Toronto, went as far as situating the "housing crisis that the city is facing, ... on a worldwide scale, ...in the range of New York, Los Angeles and Vancouver." He put forward that "individuals and families are spending well in excess of $30 \%$ of their income on rent and are living paycheck to paycheck."

Despite being a smaller city, the housing market in Barrie, closely mirrored that of Toronto. A Public Administrator from the County of Simcoe pointed out that "housing affordability is at an all-time-high" particularly with the "huge spike in prices" in Barrie. Although Mayor Lehman was in agreement with his fellow Public Administrator at the County, regarding the affordability crisis in Barrie, he appeared boggled by the extent to the City of Barrie had recently taken a centre stage at national and provincial levels, such that the city's housing crisis was now comparable to larger cities like Toronto and Vancouver. He further articulated how the affordability crisis is closely linked to hidden homelessness, noting:

\footnotetext{
${ }^{28}$ The term policy entrepreneur was first coined by American political scientist John W. Kingdon in his seminal work Agendas, Alternatives and Public Policies published in 1995. It refers to an individual who takes advantage of windows of opportunity to influence policy outcomes and brings awareness of issues of public concern, to the agenda table.
} 
It's terrible! So we have a very odd situation here. First of all, the Barrie Metropolitan area has the $3^{\text {rd }}$ highest average rent in the country, which is just astonishing, and it is Toronto, Vancouver and then Barrie. And if you sort of think of that, you know, it surprises just about everybody who sees that number, ....it is so difficult for people at the lowest level of income because ...it's just not possible, if you are a person on Ontario Works to rent an apartment here [in Barrie]. I mean, maybe you can get a rooming house. If you team up with a bunch of other people, you might be able to afford something. It is so difficult for people at the lowest level of income because the community is no longer affordable at all. (Mayor Lehman, Barrie, November $7^{\text {th }}, 2017$ )

Beyond the glaring "affordability crisis" on the rental market, policy-makers and stakeholders from both cities opened up about the growing cost of owning a house in Toronto and Barrie. A policy implementation manager with the County of Simcoe pointed out that "in terms of the homeownership .... lot of the GTA housing prices keep going up [and] ...in Barrie, this spring there was a huge spike in prices in Barrie, [such that] there were bidding wars on houses [and] people were overpaying on houses for sale." Mayor Lehman concurred and further articulated that "the community is no longer affordable at all ...not only in rental, the flip side of that is the ownership, ...the average cost of housing in Barrie has doubled in the last three years, from three hundred thousand dollars $(\$ 300,000)$ to six hundred thousand dollars $(\$ 600,000)$.

The unhealthy condition of the homeownership market has led to the squeezing out of middle-income families who in turn crowd-up the rental market leading to the squeezing out of low-income families from the rental market. This vicious cycle was well articulated by a manager from Habitat for Humanity GTA, who noted that:

....it is tough to own a home in the GTA, particularly Toronto and because the entry into the ownership in the Toronto makes it so difficult, younger professionals like myself are finding it increasingly difficult to enter into the ownership market, let alone those on low-income individuals. (Manager, Habitat for Humanity GTA, December 6, 2017) 
The housing affordability crisis is therefore a systemic problem which cannot be overlooked. It renders women vulnerable to experiences of hidden homelessness in the private market in which they are situated.

\subsection{Market Pressures}

In a healthy housing market, low-income earners and young professionals often follow a pattern which goes from renting to homeownership. However, the high cost of buying a house in Toronto and Barrie, coupled with persistent failed attempts to succeed even in the rental market, has created a housing trap for low-income women, particularly single women, older women and new immigrants, who often find themselves stuck in the rental market with no prospect of progressing into home ownership. It is not surprising that despite being precariously housed on the rental market, women did not raise the issue of home ownership, serve for one woman in Toronto, who was living in a condo and spending over $40 \%$ of her income on rent. Yet despite earning a decent income compared to all women in this study, Yolanda felt trapped in the rental market and did not see herself moving into homeownership in Toronto. She points out that "the Toronto market makes it difficult to buy a house, particularly if you are a single income earner, you just don't have extra money to save for a huge deposit" Some Policy-makers appeared to agree with Yolanda regarding the challenges women face in penetrating the homeownership market. They suggested that banks are making it difficult to borrow, such that middle income earners and first home buyers, are finding it hard to achieve homeownership. As a result, less people are moving from rental to homeownership, and this is putting a strain on the rental market in Barrie and in Toronto.

While some policy-makers raised issue with bankers for placing barriers to the cities' commitment to establish a healthy housing market, others pointed towards private developers who 
are failing to meet the high demand for affordable housing. A Public Administrator from the County of Simcoe, charged that because developers are increasingly looking for incentives to build "they may sit on land until the right time comes, or may choose to build home ownership instead of rental, " further offsetting the housing market. Mayor Lehman, concurred, and added that in the past twenty years, private developers in Barrie have not been keen on building rental units, opting instead for homeownership or building condos because it's easier to make a quick return on their investments. Laurie, a private developer in Toronto, agreed with Mayor Lehman and added that although cities in the USA still build mostly rentals, there are very limited affordable rental units being built in Toronto because developers in Toronto mostly build condos. Consequently, the vacancy rates are low and the affordability and suitability of the units is not adequate for women experiencing hidden homelessness.

The issue of availability, suitability and affordability when it comes to housing women requires attention. Emily, a housing advocate and researcher with the University of Toronto, was concerned that, "there are more luxurious apartments compared to high-rise rentals" that woman can afford. Furthermore, Sean, the direct of housing from the City of Toronto also raised the issue of availability, and revealed that:

The vacancy rate in Toronto is measured at $1.3 \%$ which is considered in the housing economics as being an unhealthy market. And equally the type of housing that is available is not necessarily suitable because we lack a large portion of family housing. Also most the housing being built today, is in the form of one or two bedroomed condominiums units. While they are rentable, for a family of four or five that's not suitable housing, so you end up then with overcrowding. That is one of the problems we face in the city, finding a suitable and affordable place amidst a very tight and what's referred to as a very hot market. (Emily, personal Toronto, November 30, 2017)

Subsequently, both policy-makers and women in this study directly linked the low vacancy rates to high market rentals in Toronto and Barrie. A top level manager, at the County of Simcoe added that on the rental side "lower vacancy rates ...usually means the rents keep going upwards" 
and on the home ownership side, he pointed out that demand was greater than supply, hence the huge spike in prices and bidding war on houses that have been witnessed in Barrie and the Greater Toronto Area. His views were further echoed by women who also believed that the low vacancy rate was pushing rental prices up and forcing them to move into less desirable neighbourhoods. For example, Yolanda, a Toronto woman, pointed out that, it took her a long time to find an apartment when she decided to move. She points out that "regardless of income level, it is difficult to find an affordable apartment in Toronto because the vacancy rate is so low." She had to move from downtown Toronto to Etobicoke, yet still her unit was the only rental available in the entire building. Conversely, despite being unhappy with their current housing situation, several women in Toronto and in Barrie, indicated that they were fearful of moving from their current residence, because they felt "there is nothing out there that is available" and "affordable". Consequently women experiencing housing affordability issues were systemically immobilized and rendered powerless to the point that despite their dissatisfaction with their housing conditions, they moved from their residence only as a last resort or when forced to move due to an eviction notice or affordability issues.

However, whereas the majority of women participants in Toronto and Barrie believed that the low vacancy rate was pushing up the prices of housing in the two cities. Abigal, argued that the gentrification of downtown Toronto, is directly responsible for rent increases, in that city. She points out that "even in the worst neighbourhoods, the landlords will serve you with an eviction notice and they just clean up the unit and increase the rent." In fact, at the time of the interview, Abigal stated that she had been given an N8 eviction notice because she was slightly late with rent. However, she believed her eviction was driven by her landlord's desire to increase the rent. 
Ultimately, according to Abigal, the gentrification ${ }^{29}$ of Toronto is directly responsible for driving out low-income households from downtown Toronto.

While women spoke about low vacancy rates and gentrification as pushing the housing prices up, policy-makers pointed to rural-urban migration. They revealed that in most recent years Barrie had witnessed unprecedented market pressure stemming from rural-urban migration and other forms of migration. Sean, a Toronto policy-maker, argued that this phenomenon has been happening at a global scale, noting that "more people worldwide are moving to cities, [and] it is predicated that by $2050,90 \%$ of the population will live in Cities and influence demand for housing." He went on to allude that in the past few decades, Toronto has had its share of urban pressure because "people are seeking after urban experience" and, more and more people want to live near their jobs to cut transport costs. Moreover, recent immigrants to Canada, tend to settle in large cities like Toronto. Yet despite being a smaller City, Barrie appeared to bear a larger burden of market instability associated with migration and the substantive huge population growth.

Perhaps one of the most important discoveries in this study was how the housing crisis in Toronto, and elsewhere, has put an enormous pressure on the Barrie housing market. The mayor of Barrie and a Senior Manager from the County of Simcoe revealed that in most recent years, Barrie has been bombarded with people coming from Toronto because Barrie is still considered relatively cheap compared to Toronto. Whereas Mayor Lehman argued that "people want to live here [because] the economy of the city is doing very well," the Senior Manager from the County of Simcoe added that, lack of Indigenous women's housing in the North, had also fueled substantive

\footnotetext{
${ }^{29}$ Gentrification is a process of renovating deteriorated urban neighborhoods and encouraging the influx of more affluent residents. In most recent years, the gentrification of Toronto's Regent Park area has been a controversial topic in public media, politics and in urban planning, with some arguing that although the revitalization of this neighbourhood can lead to the reduction of crime and poor housing conditions, most affordable housing is being replaced by expensive condominiums and town homes that low-income families cannot afford. See https://www.thestar.com/news/gta/2010/09/12/regent_park_revitalization_or_gentrification.html
} 
migration of Indigenous women from Northern Ontario to Orillia and Barrie, North of Toronto. As a result, Barrie had grown tremendously over the past few years.

Mayor Lehman was concerned about the impact of migration on the City's infrastructure and social services. He noted that the high demand for housing had resulted in "the polarization of shelter in Barrie, such that people who could at least have gotten by a few years ago, can't even get by." In addition, he charged that the polarization of shelter in Barrie was putting pressure on the safety net and much more importantly had a very real human cost. He went on to reveal that, "the math just doesn't add up, women are working ... and ... are either not getting enough hours or a high enough wage to even pay the cost of their childcare, on top of their basic need," let alone market rentals.

However, Laurie, a developer in Toronto, disagreed with policy-makers' assertions that urban migration had a considerable influence in the state of the housing market in Toronto and elsewhere. Instead she pointed to the reality of the complex market forces, the high development costs charged by the City, and the slow bureaucratic processes in approving plans, are directly responsible for slowing down development of houses, thereby affecting supply and demand and resulting in too much competition for very few houses. According to her, this accounted for the sky rocketing of prices for housing in Toronto and elsewhere. Moreover, Rhonda, a private developer in Barrie, argued that the underfunding of public housing and the long waitlist for affordable housing had heightened the demand for affordable housing within the private market, thereby making it very competitive.

Mayor Lehman admitted that in a competitive market like Barrie, the odds of getting adequate housing were stacked up against low-income women. Danielle, a housing worker with the Barrie Women and Children's Shelter, agreed with Mayor Lehman's assertions and further 
suggested that with the housing market heating up in Barrie, women are increasingly finding it difficult to access affordable housing within the private market. She pointed out that:

If one is a single women, in a housing market as competitive as Barrie, the landlord is most likely to choose two working parents ... with cash in hand, first and last rent, and they are less likely to choose a woman on social assistance, a single woman with children, a woman with bad credit or a woman with no address to give for a reference. (Danielle, Barrie, November 9, 2017).

Notwithstanding the increased vulnerability of women to homelessness as a result of the various market pressures and other systemic issues mentioned here, homelessness among women in Canada is not yet well understood (Collins, 2010; Gaetz et al, 2014; Klawdosky, 2009; NHS, 2017). Not much research has focussed on hidden population among women..

\subsection{Low Wages and a Weakened Safety Net:}

However, policy-makers did not view bureaucratic processes or the dwindling social housing stock, as the biggest factors offsetting demand and supply of housing. They suggested other systemic and individual risk factors that influence women's experiences with hidden homelessness. For example, whereas Mayor Lehman was happy about the low "unemployment rate in Barrie, ...sitting at 4.4\%, ... way below the national (5.8\%) and Ontario (5.6\%)," he cautioned that there are various market forces that are putting enormous pressure on low-income families trying to access adequate housing.

Although policy-makers raised concern over growing issues of poverty and homelessness and suggested that, an inability to earn a decent income, relationship breakdowns, and lack of a stable wider family network to turn to when one is in crisis, exacerbate women's vulnerability to hidden homelessness. The dwindling supply of social housing and gaps in housing income supports outweighs individual and interpersonal risk factors associated with hidden homelessness. A Senior 
Manager from the County of Simcoe Country suggested that, whereas people fall onto public services to cushion them in times of hardship, the welfare system "is often lacking particularly when it comes to the issue of rent supplement" and other income supports. He went on to argue that "when you need to enter the welfare system for income, it is not always available at the time when you need it [and], it's not as responsive as you need it to be, because there is limited supply of subsidized units." Moreover, not only did income-based responses fall short in meeting the housing needs of women, access to social housing itself is but also the strict eligibility criteria used to determine the deserving and undeserving for societal benefits, often fail to assist those deserving of support.

\subsubsection{Strict Eligibility Criterion: Deserving and Undeserving}

Emerging data revealed that the contemporary welfare system is set up to fail the majority of women and to only minimally benefit the most vulnerable individuals within our social system. For example, although the rent supplement is a good source of affordable housing and can assist in narrowing the gender income gap, frontline workers and women revealed that there are many barriers to accessing Rent-Geared-to-Income (RGI) for low-income women. In as much as the provincial government has mandated the 47 local service managers to determine eligibility criterion for social benefits based on gross income and assets (Ontario Government, 2015), both Toronto and Barrie's eligibility criterion is rather strict and only caters to the most vulnerable. For instance, in Barrie, one must have a net worth of "less than $\$ 50,000$ in income and assets" to qualify to rentgeared-to income. Danielle, a housing worker explained a major policy gap in RGI, noting that a woman fleeing abuse with her name still attached to the family home or family vehicle would automatically be disqualified from rent-geared to income, thereby making it difficult for women to break away from abuse. Moreover, whereas a single woman may require a vehicle to access 
employment, however owning a vehicle may increase her net worth hence prompting disqualification of the working poor from accessing societal benefits.

It is not surprising that all working women in Toronto and one working woman in Barrie were disqualified from accessing RGI because of their work activities. However, they pointed out that they were not making enough to cover rent. Daisy explained that "if you have a full-time job, the system will not give you any welfare assistance." In fact, Daisy, Melissa and Lisa, had never received government assistance because they were working two jobs to pay rent. In addition, participants at all levels and in both jurisdictions argued that the gender-income gap stemming from a labour market beset with low wages, and part-time jobs, coupled with strict eligibility criterion used to determine the deserving and undeserving to receive government assistance, exacerbates women's experiences with hidden homelessness. In particular, David, the Director of Housing, Dixon Hall Neighbourhood Services in Toronto, expressed concern over the impact of genderincome gap on women's ability to access adequate housing. He pointed out that "affordability is always an issue, in Toronto [because] women's salaries are not keeping pace with men's," noting, "I often think about the number of women who are working minimum wage paying jobs, who live in Malvern or one of the priority neighbourhoods outside the core of the city, and the distances that they have to travel in order to make it to their low paying jobs in the core of the city."

Women participants in Barrie described their struggles with paying rent in the face of rampant unemployment and low wages. They revealed that, although they would like to work, there were no good jobs in Barrie. Mayor Lehman concurred, and added that although "companies are doing well, [and] the economy is doing well [in Barrie] ...wages just aren't growing." As a result, women "are chasing a cost of living that gets ever higher and ever out of reach." Moreover, according to Danielle, a housing worker, the dilemma of a low-income woman is that "she is one paycheck away from paying her rent, and if she loses her job, she cannot pay her rent, and has to 
move. But then, she has nowhere to go and certainly does not have first and last month's rent."

\subsubsection{Inadequate Income Supports}

Although Ontario Works (OW), Ontario Disability Support Program (ODSP), Rent Geared to Income Supports, and Child Tax Benefit (CTB), are all crucial in cushioning women when they fall on hard times, they are often insufficient and unable to address the diverse needs of women experiencing hidden homelessness. In fact, David, the Director of Housing, Dixon Hall Neighbourhood Services, pointed out that whereas the "City [of Toronto] has made some adjustments with housing allowance and housing subsidies, ...those allowances are not enough to make the units affordable for the people we serve in the Dixon Community." His sentiments were further echoed by, Danielle, a housing worker in Barrie, who revealed that women on government income supports are paying market rent and are barely making ends meet. She noted:

Affordability with respect to market rent in Barrie just doesn't match what women are given by OW. Whether it's a single woman or a woman with one, two, three, or four children, the housing allowance from OW, just doesn't match, it's not enough. It's not enough money to pay their rent. Not only does it not pay their rent, let alone food, transportation and clothing for their children. I believe women, on disability ...have more income but they also have more needs that require the use of their money. So it is a real struggle for women on assistance. (Danielle, Barrie, November 9, 2017).

David and Danielle's assertions were confirmed by several women on ODSP, and OW who were paying market rent and were struggling to keep up with the housing affordability crisis. For instance, Elaine, a single woman in Barrie, pointed out that she only receives \$1,200 from ODSP, and was having a hard time paying rent and meeting her basic needs such as food. As such, despite being diabetic she had resorted to forgoing fresh meat, fruit and vegetables, so she can afford a room in a boarding house with, in her words, "drugs," "bugs" and "violence." 
Furthermore, Abigal, a Toronto woman who depends on Ontario Works and Child Tax

Benefit narrated feeling stuck and struggling with a housing trap because income supports, were not enough for her and her children she had "no support network," to fall on. As a result, she had resorted to complementing her income supports by accessing the rent bank and staying in school for Ontario Student Assistance Program (OSAP). Consequently, instead of graduating and pursuing a career, she had been in school for the past 10 years. Although, at the time of the interview she had graduated with her Masters' degree, she was applying into a PhD program. However, she had exhausted her OSAP and had just started working a part-time job as a research assistant.

Nonetheless, the vicious cycle of hidden homelessness continued, as she reported struggling to pay back her tuition and other debts and also pay for her rent, while supporting her children. As a result, she had been served with an eviction notice, and was looking for alternative accommodation at the time of the interview. Nonetheless, Abigal opened up about her anxieties was anxious about the high rentals in Toronto and the low vacancy rates.

\subsubsection{Shortage of Shelter Space and Permanent Affordable Housing}

Furthermore, apart from low wages and inadequate income supports for women, women fleeing abuse are finding it increasingly difficult to find safe housing because meeting the criteria for priority housing can be traumatizing, complicated, intimidating and cumbersome. For example, in order to qualify for priority housing, Danielle, a frontline worker with Barrie Women's and Children's Shelter, revealed that women leaving abusive relationships are required to "produce proof of cohabitation" with an abuser and "reveal intimate details of the abuse," which can lead to the re-traumatization of the woman. Although she was quick to add that "allowing women to tell their stories can be empowering," she also noted that it can be difficult and traumatizing for women, having to relive the abuse. In fact, Rhonda, a developer working with women in Barrie, 
corroborated Danielle assertions and added that while a woman leaving an abusive situation may own a home or even a vehicle, more often than not, "her well-being is tied up to the man or husband who controls the family's means of income." As well, a woman fleeing abuse "may have chosen to stay at home with children and relay on a partner for income." As such she suggested that part of the transition into independence for women should encompasses, adequate income supports, transitional housing, education supports, counselling, job search skills, and ultimately permanent housing.

However, whereas Rhonda, proposed wrap around services for women fleeing abuse, Danielle, a frontline worker argued that the strict eligibility criteria, used for priority housing places a huge barrier to women leaving violent relationships and in need of a safety net. Danielle, revealed her dilemma with inadequate housing supports, noting that, despite her best efforts to advocate for women she has witnessed women falling through the cracks, disqualified and penalized by the system. For example, women fleeing abuse can be disqualified from priority housing "if they fail to submit their application for priority housing within 3 months of leaving the abusive partner." However, more often than not, meeting these strict deadlines can be challenging for victims in need of support because sometimes women fleeing abuse may have "chosen to move in with friends or relatives for comfort and safety" and/or "they were unaware of the service."

In addition, Danielle argued that women are not moving into affordable housing at a rate that will allow women's shelters to create space for more women leaving abusive partners. Frontline workers expressed major concern over limited shelter space in Barrie. They pointed out that there are only two women's shelters in Barrie, namely, Barrie Women's and Children's Shelter and Elizabeth Fry. Whereas Barrie Women's and Children's shelter only has 14 beds to house women and children fleeing abuse, frontline workers pointed out that Elizabeth Fry's Joyce Kope House has "25 beds" for all single women experiencing any form of homelessness and housing 
problems. Regrettably, because of the limited shelter space, the pressure to create room for other women experiencing homelessness is placed on women. First, shelters limit the duration of the stay. For example, women fleeing abuse are only allowed to say at the Barrie Women's and Children's shelter for a maximum of 8 weeks. Second, women in shelters are expected to engage in daily active house hunting, in spite of recent trauma, tiredness, or sickness. Yet finding permanent, adequate, housing in Barrie is a challenge due to lack of affordable house. As a result, according to Danielle, a Transitional Housing Worker from Barrie Women and Children's Shelter, instead of going directly into permanent housing, women are often "placed into transitional housing, which is

temporary and strictly speaking, just another form of hidden homelessness." She also suggested that other women fleeing abuse go back to the abuser because that is the only other seemingly reasonable alternative. David, the Director of Housing from Dixon Hall Neighbourhood, agreed Danielle and pointed out that, "there are a lot of women staying in relationships that they would rather not because they don't feel safe enough to leave" due to lack of affordable housing. Moreover, Rhonda, a private developer from Barrie, further suggested that due to lack of shelter space, some women remain hidden, "sleeping in their cars," or "living with relatives and friends because they have nowhere else to go." This gap in housing, fuels the persistence of hidden homelessness among women.

\subsubsection{Neglect and Underfunding of Social Housing}

Whereas all policy-makers in this study agreed that adequate housing should include various aspects of affordability, availability and condition of built-form, they pointed out that Toronto and Barrie were lacking in all three aspects. Notwithstanding that the demand for affordable housing has increased in the past 30 years, social housing stock has remained stagnant and the wait time for social housing has sky rocketed (Gaetz et al., 2014; Ministry of Municipal Affairs, 2014). Mayor 
Lehman, City of Barrie and Sean Gadon, The Director of Housing, City of Toronto, were in agreement that lack of affordable housing is such a huge challenge in Barrie and in Toronto, and the sheer amount of families needing decent affordable housing, on the rental or ownership side is huge. As a result, according to Mayor Lehman and Sean Gadon, families are waiting eight plus years to get social housing in Toronto and up to nine years in Barrie, unless if a woman is fleeing abuse.

Whereas social housing used to be reserved for the most vulnerable in our society, evidence in this study suggest that even the most vulnerable individuals and families are falling through the cracks. For example, those with mental health and addictions problems are also grappling with long wait times. David, the housing stakeholder working the poor communities of Toronto:

The city of Toronto is facing some real challenges around the availability of social housing. The waitlist is approaching a hundred thousand $(100,000)$ right now, for community housing, and for access point, which is for people living with mental health problems, it's about 5 years long. Quite frankly... there is just not enough of it, there is just not enough of it! (D. Reycraft, personal communication, Toronto, December 10, 2017).

Furthermore, Danielle, a Transitional Housing Worker in Barrie, also revealed that "even for priority housing," for a woman fleeing abuse with her children, it can take "up to nine (9) months" to get into social housing and up to "one (1) year for a single woman fleeing abuse," Moreover, it takes longer for women who are not fleeing abuse. For instance, Pat, a Barrie woman who was not fleeing abuse revealed that that she had been sitting on the waiting list for 5 years. As well, although Lily, another Barrie woman, was currently in a RGI unit, she revealed that she knew of "friends who had been sitting on the waitlist for social housing for up to 10 years now."

Beside the long wait-time for social housing, policy-makers and stakeholders in Toronto expressed concern over a long history of neglect and underfunding of social housing in Toronto. The all pointed out that the buildings are inadequate and in desperate need of renovation. In 
particular, Sean, the Director of Housing, mentioned that whereas Toronto has "a wonderful legacy" in that it has "about a hundred thousand $(100,000)$ social homes ...developed over the last 50 years ago, that residents are still residing, ... at the same time, social housing is in need of revitalization and repair." Yet lack of federal and provincial government's commitment to addressing an eminent crisis resulting from the poor condition of social housing is a cause for concern as articulated by Emily, a Toronto housing advocate, noting:

Social housing in Toronto is in deplorable condition. ... The city and province, and federal government, have not invested appropriately in the upkeep of these units. They have been allowed to deteriorate to a great extent, in fact, to the extent that we are seeing units being closed because the physical condition can no longer safely house people. Tenants are living in poor conditions with pests and with moulds. Just generally, the buildings have deteriorated, these are old buildings, old stock. No new social housing has been built, for over 20 years, except for the revitalization projects. (Emily, personal communication, Toronto, November 30, 2017)

However, unlike Toronto, social housing in Barrie was said to be in "fairly good condition." Frontline workers in Barrie indicated that for the most part, the buildings are in pretty good shape and there are very limited calls of complaints from women living in social housing. However, both frontline workers and Mayor Lehman were quick to add that whereas the built-form is good, social housing in Barrie is unavailable and there are many barriers to accessing social housing in that City. Danielle, a transitional housing worker, cited the long wait times and bureaucratic procedures and processes which disqualify women from accessing social housing, particularly working women, further perpetuating experiences of hidden homelessness.

In addition, to the neglect and underfunding of social housing, the systemic criminalization of women was raised by Meghan Chamber, the Director of Residential Programs, Elizabeth Fry in Barrie. She pointed out that women are penalized and charged with fraud for failing to report that a partner moved in with her. However, Meghan pointed out that a woman would avoid reporting co- 
habitation, "because she may want to remain independent and not dependent on a partner for her and her children's sake."

\subsection{Negative Perception of Community Services}

The affordability crisis coupled with various market pressures, a weakened safety net, neglect and underfunding of social housing, evidently contributes to the violence that women experience at the personal level. Charlene, the Director of Residential Programs, explained that whereas Elizabeth Fry was developed for women leaving incarceration or drug rehab centres, the agency provides a whole array of services for women within the community. However, notwithstanding the diverse services offered by Elizabeth Fry30, the negative perceptions by women places barriers to accessing services from this organization. One Barrie woman went as far as declaring that she would rather "sleep in the park" or "live with an abuser" rather than getting "lumped up with criminals and druggies." (Sophia, October 11, 2017). Danielle a Housing Worker in Barrie, confirmed women's negative perception about Elizabeth Fry and added that "some single women that are living with an abusive partner, often don't feel as comfortable going into a shelter that is providing for the needs of so many different women." She was, however, pointed out that Elizabeth Fry was "the only other shelter for single women in Simcoe County."

Besides the stigma associated with shelters, lack of trust also places barriers to accessing community services by some women in Barrie. Pat, a Barrie women felt infantilized and she believed that human service organizations purport to serve vulnerable populations when in fact they are set up to protect jobs for bureaucrats. Pat, one of the women in Barrie expressed that belief in the following sentence:

All I am seeing is job security, the Busby Centre could do better, Barrie

\footnotetext{
${ }^{30}$ Information from their website reveals that Elizabeth Fry doubles as the only Half-Way House for federally and provincially sentenced women in Ontario, north of Toronto, and a Transitional Shelter for women discharged from mental health facilities and addictions treatment centres, single women seeking safety from an abusive partner, seniors without housing, and women living on the streets.
} 
Municipal Housing could do better, but it's all about job security you know, ...like there is this housing expert \{name provided\}, who is getting paid just to sit and pull houses off the internet, and I am like what? Anyone can do that! (Pat, personal communication, Barrie, December 7, 2017).

The cynicism associated with community resources create barriers to women's ability to access the help they need and to move swiftly through the process of re-housing. Yet when the system fails to deliver on its promises due to underfunding and budget cuts, it is hard to remove the distrust and scepticism associated with community services.

The indicators and facts identified in this chapter and previous chapters are powerful sources of information that warrant the attention of policy-makers and suggest areas in need of policy change. Yet the persistence of housing problems in Ontario in general, and Toronto and Barrie, point to underlying complexities in policy-making and agenda setting around affordable housing, which will be discussed in the next chapter. 


\section{CHAPTER 7}

\section{The Concealed Tentacles of Hidden Homelessness: Perceptions from City Policy Experts and Private Developers of the Inclusionary Housing Policy}

So the priority of the City Mayor and the government has been 'let's make Barrie attractive to city people ... because to buy a house in Toronto, you need a million dollars but to buy a house in Barrie, you only need $\$ 600,000$. To rent an apartment in Toronto, you need $\$ 2000.00$ but to rent an apartment in Barrie you need $\$ 1,500.00$. [So,] we are having so many city people move here. ...So I would say, the city does not care about poor people, they should consider the dignity of poor people, ... but they want people who can pay taxes, that's the way I see it.

(Elizabeth, personal communication, Barrie, October 24, 2017).

The will has to be there to do it, [but] it's politically difficult, it doesn't sound like it should be, because you would think that combating homelessness by having a proper range of housing in our communities would be something that just about everyone would agree to, and they do, but fiscal resources are limited, there is lots of call for capital dollars for different other infrastructure projects. As a result Barrie never built the stock of rental apartments ...needed just for the existing populations, and then of cause, [the city] ...grew, very quickly ... so, it's a combination of very tight supply and very high demand, [such that] rents have gone through the roof.

(Mayor J. Lehman, City of Barrie, personal communication, November 7, 2017).

\subsection{Introduction}

This chapter, through interviews with city policy experts and private developers, explores the poor conceptualization of hidden homelessness in Canada and suggests that a lack of understanding as to what constitutes hidden homelessness among women is problematic. First, I discuss how the absence of a clear definition of hidden homelessness in Canada often results in policy metrics and housing initiatives that fail to capture the heightened vulnerability of women to this problem.

Second, I explore how an attempt to conceal women's experiences and mask the subtle yet 
insidious, relationship between housing precarity and poor health outcomes, is done through political correctness and gender neutrality in the framing of housing policies. Lastly, I put forward that a lack of consensus as to what constitutes affordable housing contributes to poorly crafted, and badly executed housing policies that fail to address the feminization and racialization of poverty among diverse groups of women.

\subsection{Poor Conceptualization of Hidden Homelessness}

There appeared to be a disconnection between the needs of women in this study and policy responses to housing and homelessness, due to poor conceptualization of hidden homelessness by public administrators. According to the $\mathrm{COH}$ (2012) definition of hidden homelessness, one has to be temporarily housed without paying rent, to be considered in the category of hidden homelessness. As mentioned earlier in Chapter One of this study, this definition is limiting, as it fails to capture the full spectrum of women experiencing hidden homelessness, particularly those that appeared housed yet are living with abusive partners or segregated in rough neighbourhoods due to poverty and housing affordability issue. Notwithstanding the narrow definition of hidden homelessness in Canada, policy makers and stakeholders in this study did not seem to understand the full spectrum of women experiencing hidden homelessness as well.

Laurie Payne, a Toronto property developer suggested that, failure to understand the "spectrum of women" experiencing homelessness has resulted in policy responses that are only "targeted towards a level of affordability that is just below market." Particularly the lack of a clear national standard to guide levels of housing affordability throughout Canada has led to varying definitions of affordable housing. For example, affordability measures based on CMHC's Average Market Rent (AMR), leaves it to municipalities to decide the degree of affordability. Consequently, variations in levels of affordability were visible from policy makers and stakeholders in this study. 
Whereas Mayor Lehman defined housing affordability in Barrie as 10\% below market, David, the Director of Housing, Dixon Hall Neighbourhood Services in Toronto, talked about 20\% below market rent. He however raised issue over the use of AMR as a measure of affordability and put forward that it is not effective enough to stimulate deeply affordable housing that women can afford. He pointed out that:

Affordable housing in Toronto is defined by Canada Mortgage and Housing Corporation as $80 \%$ of market rent, which we all know that market rent in Toronto is high and $80 \%$ of expensive is still too expensive for other people. (D. Reycraft, Personal Communication, Toronto, December 10, 2017).

Besides the variations in the definition of housing affordability by policy experts and stakeholders in this study, there appears to be some discrepancies in the provincial and federal definition of affordable housing. While the province, through CMHC defines housing affordability as a percentage of the market rent, the province of Ontario defines housing affordability for Rent Geared to Income (RGI) recipients, as $30 \%$ of household income, the. So if we take the province's definition of affordability, a rental of $\$ 1,250$ per month would be considered affordable for a household income of $\$ 50,000$ in Toronto. However, if we use CMHC's definition of affordability and discount $10 \%$ of the average market rent of $\$ 2,550^{31}$, affordability for the same household would be $\$ 2,295$.

Policy-makers in both cities admitted that the phantom numbers by CMHC are just not adding up. Mayor Lehman argued that the average monthly income in Barrie falls way below CMHC's definition of housing affordability, noting:

We have a housing affordability definition by $\mathrm{CMHC}$ which is $10 \%$ below market rent. So we take the average market rent, which in Barrie, CMHC claims is about $\$ 1,450.00$ and we knock off $10 \%$ of that, which is about $\$ 150.00$, so $\$ 1,300.00$ is now considered affordable for a two bedroom

\footnotetext{
${ }^{31}$ Toronto's average rent for a two-bedroom apartment increase by $1.2 \%$ to reach $\$ 2,550$. See https://www.blogto.com/city/2018/02/average-renttwo-bedroom-apartment-toronto-passes-2500/
} 
apartment, which off cause is not affordable for low-income households

with an average monthly income of $\$ 1,200.00$ (Mayor J. Lehman, personal communication, Barrie, November 7, 2017).

The lack of consensus as to what constitutes affordable housing contributes to poorly crafted housing policies, creating high levels of precarity and disastrous effects for women ultimately pushing them into hidden homelessness.

Whereas the structural conditions that impose limits on women trying to survive in a big city like Toronto and a smaller city like Barrie should not be overlooked, policy-makers also cited, individual and interpersonal risk factors associated with lack of family support, and increase in single female-led households, as being directly responsible for the persistence of hidden homelessness among women. Hence, there is a pressing need for public administrators to acknowledge the politics of differences and explore how underlying issues of gender, race, immigrant status and sexuality in the lives of diverse groups of women experiencing hidden homelessness. As such in applying an intersectional gender-based analysis of the housing policy, I was particularly attentive to the language used by public administrators in describing the issue of housing issues in their jurisdictions.

\subsection{Political Correctness and the De-gendering of Hidden Homelessness}

An intersectional gender-based analysis of policy posits that issues of gender, race, age, sexuality and ableism, should not be viewed as an after-thought. Rather, these issues should be considered and incorporated throughout the policy process, from problem identification and agenda setting, to policy implementation and evaluation.

When conducting interview with public administrators, it became evident that unless prompted to talk about women, predominately male public administrators and a few male stakeholders used gender-neutral, colour-blind language to describe the spectrum of people affected 
by the current condition of the market. For example, in identifying the disadvantaged groups affected by the housing affordability crisis, male policy-makers in Simcoe County and Barrie, mentioned "a person on Ontario Works," "people at the lowest level of income," and "people ...overpaying on houses," while male policy-makers and stakeholders in Toronto talked about "individuals and families," "middle income households," "average households," "low to moderate income households" and "young professionals." Consequently, in the initial stages of the interview, there was no mention of how the intersections of gender, sexual orientation, race or immigrant status further compounded the housing affordability crisis in the lives of marginalized groups, until the interviewer asked specific questions about women.

However, while predominately male policy-makers did not discuss gender in the initial stages of the interviews, predominately female frontline workers and female stakeholders began the interview by arguing that women are hit the hardest by the current housing affordability crisis. Danielle, a Transitional Housing Worker in Barrie, narrated how women, particularly single women on government income supports, and those working minimum wage are struggling to keep up with the "incredibly high ...rents in our community," and the poor condition of housing. As well, Charlene, a Mental Health Marker with Elizabeth Fry, charged that much of women's stressors and anxieties are centred on being forced to make tough choices to remain housed in a rather harsh market environment.

When it comes to the perspectives from private developers, they believed that there are limited housing options for low-income-women. For example, Laurie, a private developer with Diamond Corp, Toronto, believed that although Toronto is still "successful ... as a city region because generally there are good housing options," however "there is limited affordable housing options being build and it's becoming much more difficult to ensure that everyone has access to good affordable housing," Similarly, Rhonda, a private developer with Redhood Park 
Communities, Barrie, was concerned about the limited housing options awarded to women fleeing abuse. She affirmed that;

A woman leaving an abusive partner who has control of finances, cannot afford a 2-bedroom apartment of up to $\$ 2000$, on $\$ 662$ Ontario Works, and it becomes a choice between unaffordable rent and abuse, and women are returning to the abuser. (R. Kent, personal communication, Barrie, November 10, 2017)

Stakeholders in both cities appeared to agree private developers, that there are limited housing options for women on the private market. Emily, a Housing Advocate in Toronto, expressed concern that there appears to be more condos being built in Toronto than affordable housing," leaving low-income households with rather limited housing options.

Meaghan, the Director of Residential Programs at Elizabeth Fry, in Barrie, revealed how the limited options awarded to women on the private market is directly linked to the violence that women experience in their lives. She pointed out that, given that the "rental market had skyrocketed over the past two years, ...female trauma survivors are living in unsafe housing with friends and relatives or are living on the street, but hiding in cars" and such living conditions often led to the re-traumatization of women at the hands of abusive partners, relatives, landlords or roommates. A case in point is Sophie, who lived with an abusive brother and Elizabeth who lived with an abusive ex-husband.

It was however clear in this study, that the institutional mandate on budget cuts, often do not align with the feminist drive to provide affordable housing and other programs to meet the urgent needs of women. Danielle, a Transitional Housing Worker in Barrie, felt constrained as she pointed out that, although she is constantly trying to advocate for women, to help them access safe and affordable housing, as quickly and as efficiently as possible, the long wait-times for affordable housing often hinder her efforts. It has been argued that the duality of power dynamics that exist between organizational needs and feminist goals often hamper the implementation of gender-based 
policies (Benschop \& Verloo, 2006). As a result, femocrats in a neoliberal environment have often remained as outsiders while civil servants continue to hold power to direct policy agenda, often in a seemingly gender neutral way (Rodgers \& Knight, 2011; Benschop \& Veloo, 2006).

Given that the experiences of women and men are different and cannot be viewed in unison, a gendered lens is required throughout the policy-making process. Avoiding issues of gender on the housing landscape, or narrowing it down to women fleeing abuse is tantamount to denial of gender-equity. Yet, only female frontline workers easily articulated women's challenges with hidden homelessness, without being prompted. The hypocrisy of acknowledging and addressing gender discrepancies and racial discrimination on the labour market through equity laws, while ignoring similar issues on the housing marketing, speaks to the double standards found in neoliberal societies, and only serve to propagate a false sense of equality on the housing market.

Moreover, the failure to incorporate gender perspectives at policy level and the undervaluing of feminist research at planning tables that inform resource allocation, is often reflected in gender neutral budgets (Broddie \& Bakker, 2008; Knight, \& Rodgers, 2012; Scala, 2008; Women's Budget Group, 2013;), and colour-blind budgets (Sandhu \& Stephenson, 2015), resulting in the further marginalization of vulnerable populations. Budgets that do not reflect the condition of the housing market is evidenced by the underfunding of the construction of new affordable market housing and lack of investment in the maintenance of pre-existing public housing. This speaks to a major disconnect between public administrators and marginalized communities.

\subsection{Lack of Political Will to End Homelessness:}

Although the invisibility of women experiencing homelessness provide a degree of insight into the discourse of hidden homelessness in Canada, and the challenges faced by politicians in 
trying to access this population, yet resistance to institutional change, driven by a lack of political will to end homeless, was raised by both women and policy-makers in this study. Women in this study were rather cynical and sceptical about their public administrators' ability or willingness to address hidden homelessness. Several women believed their mayors and members of parliament lacked the political will needed to deal with housing problems for people like them (Abigal, Toronto, 2018; Daisy, Toronto, 2017, Elaine, Barrie, 2017; Elizabeth, Barrie, 2017; Katie, Barrie, 2017; Lisa, Toronto, 2017, Pat, Barrie, 2017; Sophia,October 2017) . The only public

administrator that women in Toronto believed cared enough to resolve their housing issues was the late Mayor Rob Ford. In fact two racialized women, Daisy and Lisa, narrated their struggles with poor housing conditions in social housing and lamented the passing on of Mayor Ford and pointed out that Rob Ford was an avid advocate for women and visible minorities and was outspoken against "slumlords." In fact, Daisy sobbed uncontrollably as she recounted how Mayor Ford had assisted her and other tenants in her building, in addressing issues of bug infestation and repairs that needed to be done. She pointed out:

When Rob Ford was alive, he would come and help us. Unfortunately he is dead now, but he was a people-person. I don't know about Tory, but I miss Rob Ford (sobbing). If only Mayor Rob Ford was alive, he would listen to us ...he made life better for us in this apartment ... I don't know about Tory. (Daisy, Toronto, November 17, 2017)

Aside from the visible admiration of the late Mayor Ford, others point to the hypocrisy of politicians and argued that although Mayor Ford was a "champion of community housing [who] famously tours blighted apartment buildings and visits with needy tenants, extending his personal promise to get fridges fixed, patch holes in the walls or get rid of bedbugs", the reality was that the housing in Toronto went from bad to worse on his watch (Now Toronto, 2014). They revealed that the back log for the repair of community housing in Toronto increased by $\$ 215$ million, and the 
wait time for social housing increased by $17.5 \%$ during his time in office.

Similarly, Barrie women did not consider the Mayor as serving their best interest. Notably, Pat, a woman with a long history of hidden homelessness, strongly believed that the Mayor of Barrie and the government "only give preferential treatment to rich people who can pay taxes [and] will not listen to poor people like me." In addition Elaine, a precariously housed women in a rooming house, was convinced that her experiences with hidden homelessness were closely tied to "the Mayor's plan to continue to grow the city to accommodate people coming from Toronto," at the expense of low-income women in Barrie. Likewise, Elizabeth, another Barrie woman in a Boarding House, agreed with Elaine and pointed out that:

So the priority of the City Mayor and the government has been 'let's make Barrie attractive to city people ... because to buy a house in Toronto, you need a million dollars but to buy a house in Barrie, you only need $\$ 600,000$. To rent an apartment in Toronto, you need $\$ 2000.00$ but to rent an apartment in Barrie you need $\$ 1,500.00$. [So,] we are having so many city people move here. ... So I would say, the city does not care about poor people, they should consider the dignity of poor people, ... but they want people who can pay taxes, that's the way I see it. (Elizabeth, Barrie, October 24, 2017).

Elizabeth's views were echoed by Katie, another Barrie with a long history of hidden homelessness, charged that when it comes to women struggling with homelessness, "the Mayor's priority is off," because whereas "he has made the city too big by having people move from Toronto to Barrie, ...he has not fixed the Busby Centre," a shelter for women experiencing homelessness. As a result, several women in this study indicated that they would rather live with an abusive partner or relatives in rooming houses than to go to the Busby women's shelter because of the poor condition of the shelter.

Yet despite women's strong views about lack of political will to end hidden homelessness, Danielle, a frontline worker in Barrie, believed that the housing issue was "something that is on the forefront of our politician's minds" and she revealed that "there are some programs that are now in 
the works in Barrie," to address housing problems. However, she raised concern that, given that "the demand for affordable housing far outweighs the supply", Barrie had "a long way to go" when it comes to providing adequate housing for women. Mayor Lehman appeared to agree with Danielle, noting that in most recent years "the number of rental apartments as a percentage of housing stock in Barrie [had remained] much lower ...than in other cities". He commented on his dilemma with the housing situation in Barrie. He explained that while there is will to build affordable housing at the City level there is also the problems of a lack of funding by the Federal government, competition for limited capital dollars and he high demand for affordable housing, further exacerbating the housing crisis the City is currently facing. Moreover, he viewed the removal of CMHC as a major player in housing as another major obstacle to local governments' ability to effectively address the worsening housing situation across Canada. In particular, he points out that, whereas "CMHC was a major reason why so much social housing got built in the 1960s and 70s" it is also "the major reason why it didn't in the 1980 and 90s." He strongly believes that CMHC needs to "get back into the housing landscape." However, he also agreed with women that it takes a strong political will to make drastic shifts in policy that is required to end homelessness.

Nonetheless, the neoliberal context in which public administrators operate, often result in policy stagnation, such that although policy-makers, frontline workers and private developers, believed that the province is committed to addressing prevailing housing problems, they also acknowledged that there are fiscal challenges that limit the province's ability to do what they want to do. However, albeit, this acknowledgement, Mayor Lehman was quick to point out that "the province's fiscal challenges were nothing compared to ...fiscal challenges faced by municipalities." He revealed that "the challenge is always around budgets. Municipalities have no extra capital to tackle the housing crisis. [laughter] Come to think of it, we are not generating the kind of capital 
needed, even really to maintain our portfolio."

Moreover, given the sheer number of wicked problems crowding the agenda table and with limited funding from the province, policy-makers and politicians were grappling with how best to allocate resources, as articulated by Sean, the Director of Housing for the City of Toronto. Sean pointed out that, "with only so much money and so many needs, choosing between allocating money to affordable housing or other worthwhile initiatives, like investing in a new art centre, or in parks, can be a challenge." He feared that the issue of housing and homelessness was often lost in the mix. Mayor Lehman articulated the dilemma faced by public administrators, noting:

The will has to be there to do it, [but] its politically difficult, it doesn't sound like it should be, because you would think that combating homelessness by having a proper range of housing in our communities would be something that just about everyone would agree to - and they do- but fiscal resources are limited, there is lots of call for capital dollars for different other infrastructure projects. As a result Barrie never built the stock of rental apartments ...needed just for the existing populations, and then of cause, [the city] ...grew, very quickly,... so, it's a combination of very tight supply and very high demand, [such that] rents have gone through the roof. (Mayor J. Lehman, Barrie, November 7, 2017).

Whereas Emily, a housing Advocate in Toronto, and David, the Director of Housing, with Dixon Hall Neighbourhood communities, agreed with Mayor Lehman that the ongoing fiscal restraint and the sheer number of programs competing for a rather lean pool of capital funding dims down responses to housing and homelessness, yet they put forward that it is in fact the cities' priorities that were off. Emily pointed out that "up until recently, housing has not been a priority" at City Hall. Rather, according to David, what took precedence over affordable housing was the "expansion of the Toronto transit," and the "call for a greener Toronto" with several "parks and recreational centres." Emily, a housing advocate, charged that "if we spent as much money on affordable housing as we spend on roads, we wouldn't have as much problems."

Yet, the late Mayor Ford's inability to address the very problems he advocated for, speaks to 
the complexity of policy-making in a neoliberal environment. In particular the challenges of trying to balance organizational mandate on balancing budgets and the personal values held by politicians and bureaucrats. Consequently, the double standards that exist in a neoliberal environment and the lack of political will to address housing problem at all levels of government, speaks to deeper challenges in the policy-making process that I will now discuss in the next section of this chapter.

\subsection{Institutional Inertia and the Complexities of Policy-Making}

It has been argued that whereas policy-makers may want to address all issues at hand, the intractability of problems that crowd the agenda create "problem overload" for policy-makers and "reduce their ability to predict the issue's place on the agenda" (Zahariadis, 2003 p.714).

Moreover, with limited resources, policy-makers may choose to focus on problems that they know they can solve or problems carried over from previous policies (Kingdon 1984). Furthermore, in a politically charged environment, were evidence is often inconclusive, to remove uncertainty and ambiguity, persuasion and argument, not facts are the best tools to use in pushing for an agenda (Majone, 1989). Consequently, given that policy-making is a messy game (Lindblom, 1959), researchers and policy entrepreneurs have the taxing job of trying to frame problems in ways that reduce uncertainty, minimize ambiguity, and draw the attention of public administrators while inciting public interest (Zahariadis, 2014; Cairney, 2012).

Yet despite the complexities of policy-making, the idea of why and how policies change, with new ones being introduced and/or old ones being changed or phased out, is at the centre of all policy studies. In particular, the conundrum of how to provide adequate housing in an environment of austerity has baffled social scientists in most recent years. Policy-makers and public administrators continue with failed policies or have made very little inroads in changing current housing strategies to meet the new social risks associated with the changing housing market. 
One way of explaining why policies and institutional arrangements remain unchanged or undergo very little changes, is through path dependence. Path dependence is bounded by the rationality that historical settings and seemingly irreversible technocratic decisions from the past constrain and shape current institutional paths. Yet it has been argued that path dependence is in fact associated with the surge of new forms of governance where the choice of present policy is heavily dependent on the surge of new institutionalism (Torfing, 2009) and the neoliberal institutionalized legacies that structure our perceptions of problems and goals, define the range of feasible alternative solutions, and guide the cost-benefit analysis of any policy change (see Torfing 2001). The formal and informal rules and norms that guide institutional behaviors often go beyond rationality. For example, despite the increased need for affordable housing since the mid 1980's, Canadian governments have remained fixated on austerity measures to guide their policies. Hence, in an environment of fiscal restraint, the narrowing down the definition for hidden homelessness serves a purpose, in that restricts the down the number of people in need of government assistance.

Most recently, the multiple streams framework (MSF) became an effective tool in the study of public policy and can help us understand "how policies are made by government under conditions of ambiguity" (Zahariadi 2014: Kindle Locations 562). The MSF was first developed by John W. Kingdon's $(1984 ; 1995 ; 2010)$ and is well articulated in his book Agendas, Alternatives and Public Policies, first published in 1984, and was further advanced by Zahariadis (2003, 2014) and others. Kingdon describes policy formation as the result of three independent processes, or the flow of three 'streams', the problem stream, the policy stream and the politics stream (Kingdon 1984, p.174). Each of the stream is viewed as independent of the others yet at critical points in time, known as the "policy windows," the streams come together and creates a "tipping point," increasing the chances that an issue reaches the agenda table and a change in policy occurs (Zahariadis 2014, p.574-576). 
Nonetheless, despite the challenges in agenda setting, policy-makers and stakeholders from both cities pointed out that there a shift is underway [and] housing is getting more attention, partly because prices have gone up in the last two years, and partly due to change of governments both at the federal and provincial levels. For example, Sean, the Director of Housing with the City of Toronto, pointed out that most recently in Toronto, "affordable housing received much attention at policy level, [such that] the two major priorities and big items the city is dealing with right now are ...transit and affordable housing." However, whereas in the past, the return of war veterans, presented a tipping point for radical change on the housing landscape, yet the nationwide outcry to end homelessness, in the liberal welfare state, has not yielded much in the way of progress. In fact, in the past three decades, institutional inertia has remained visibly present on the Canadian housing landscape.

In most recent years, lack of consensus on the most viable response to housing problems has resulted in ad hoc and disjointed policy responses, with various policy entrepreneurs ${ }^{32}$, calling for various measures to address the housing affordability problems facing Canada. Some policy entrepreneurs have pushed for; the return of the National housing strategy, the expansion of funding for existing programs and the redefining of eligibility criteria to be more inclusive of mixed incomes households in core need (Association of Municipalities of Ontario (AMO), 2016; Ontario Non Profit Housing Association (ONPHA), 2016; Canadian Centre for Policy Alternatives (CCPA), 2015; Canadian Housing and Renewal Association (CHRA) 2016; Gaetz et al, 2016; Canada without Poverty 2013; Right to housing 2015; Housing Services Corporation (HSC), 2013; Wellesley Institute, 2012; 2010). Others have proposed raising minimum wages, fostering

\footnotetext{
${ }^{32}$ A person or organization that seeks to influence policy - they are not policy-makers as such rather they include consultants, think tanks (policy or research institutes) and advocacy or interest groups.
} 
investments in rental units and changes to taxation systems, to ease affordability for homeowners with second units and for new homeowners (CCPA 2015; TD 2017).

Although the return of the NHS with a gendered lens was a welcome step towards the right direction, yet the lack of national standards has resulted in provinces and municipalities running parallel housing policies across Canada. Most recently, the previous Ontario Liberal government proposed the 'Fair Housing Plan' - a broad set of policy actions that seek to address the housing affordability crisis by (a) bringing stability to the real estate market through the introduction of a $15 \%$ non-resident speculation tax; (b) regulating rent increases and restraining speculative practices; as well as (c) increasing the supply of housing units through rezoning practices and (d) provincial investment of $\$ 125$ million over five years for the construction of high rise affordable apartments (Royal Bank of Canada RBC, 2017).

Although the Fair Housing Plan is a noble idea, it does not seek to address the immediate needs of inadequately housed women because implementation is spread over 5 years. Moreover, with limited funding and the drive to reduce deficits by the province, it is less likely that the Fair Housing Act will have a significant impact on the affordable housing stock. In fact, the new government of Doug Ford has swiftly reversed aspects of the Fair Housing Plan that benefit lowincome groups, such as the removal of the $1.8 \%$ cap on rent increase (CBC, 2018). Furthermore whereas the province's Long Term Affordable Housing Strategy seeks to create more affordable housing opportunities, to end or prevent homelessness, previously stated indicators reveal that it has not made any visible impact in ending the growing affordability crisis in large Cities like Toronto and smaller Cities like Barrie.

Bureaucrats in this study pointed out that for any housing strategy to succeed there is need for the federal and provincial dollars to flow (Mayor Lehman, November 7, 2017; Sean Gadon, Toronto, November 23, 2017; Senior Manager, Simcoe County, October 23, 2017). Nonetheless, 
although Mayor Lehman believed the current federal government of Justin Trudeau and the former provincial government of Kathleen Wynne were "trying to pull their weight," to address housing problems, he pointed out that "the same cannot be said for previous governments, who didn't even try." As such, despite the growing affordability crisis, Canada remained "the only G8 country without a legislated national housing strategy or explicit laws to protect its citizens against inadequate housing" (United Nations, 2011 p.7). The previously tried and tested national housing strategy remained terminated while the condition of social housing in Toronto deteriorated drastically and, the housing affordability worsened in Vancouver, Toronto and Barrie.

The recent media coverage, highlighting the housing crisis in Toronto and Barrie (Global News, 2017; Toronto Star, 2017), brought about renewed interest in housing at the policy level and pushed housing issues to the top of the agenda, yet little immediate action was taken to address the affordability crisis. However, mounting pressure from media and housing advocates, coupled with the recent change of government from Steven Harper's Conservatives to Justin Trudeau's Liberal government has created a tipping point and opened a window of opportunity for the reintroduction of a gender-based NHS, with a promise of housing action, but only after the next federal election which will take place in late 2019.

Although policy-makers in this study believed that, with the recently introduced genderbased NHS, "the federal dollars are coming" to help boost affordable housing stock, yet the federal government is still not taking a leading role, as in the previous NHS. In fact, the success of this policy hinges on the degree of cooperation between the upper and lower levels of government in this cost sharing initiative. However, policy-makers were concerned that "it will take a long time to deploy the federal dollar," given that provinces/territories were yet to agree on the cost sharing initiative with the federal government. In the meantime, the move towards new public management and the introduction of the IH policy has taken root over the past few years. 
What remains to be discovered is how IH policy is being implemented and sustained in Ontario, and how effective it is in increasing affordable housing stock particularly for women experiencing hidden homelessness in Toronto and Barrie. As such, the next chapter will examine how the implementation and perceived effect of $\mathrm{IH}$ policy in Toronto and Barrie, as it relates to women experiencing hidden forms of homelessness. 


\section{CHAPTER 8}

\section{The Inclusionary Housing Policy \& the Marketization of Housing}

There is no housing that's been built in Toronto or across the country that does not involve the private sector. All of social housing has been built and delivered by the private sector. The government would contract non-profit organizations, but the people who built and delivered social housing made a profit. Again, there is no non-profit housing building corporation that I am aware of, that exist in Toronto, they all use private developers.

(S. Gadon, Director of Housing City of Toronto, personal communication, November 23, 2017)

\subsection{Introduction:}

In the face of federal and provincial claw-backs on social housing, and the growing number of families in need of affordable housing, the City of Toronto and Barrie sought for other means to improve the housing situation in their jurisdictions. In particular, they sought to share the burden of housing affordability with the private sector and the third sector, and a big society was formed through partnerships and collaborative relationships. The inclusionary Housing policy (IH) policy or inclusionary zoning (IZ) practice, is situated within this big society. The strengths and weaknesses of involving the private sector in the production of affordable housing is also explored in this chapter.

\subsection{New Public Management: Ontario's Big Society:}

In making a case for the creation of a big society ${ }^{33}$ in Toronto, Sean, the Director of Housing with the City of Toronto, argued that even the National Housing Strategy (NHS), announced by the federal government not so long ago, talks about partnership between the federal

\footnotetext{
${ }^{33}$ A big society in this study refers to the active engagement of all segments of civic society in the provision and administration of affordable housing through $\mathrm{IH}$ strategies.
} 
government, provincial government, municipalities, non-profit organizations and private

developers. He further pointed out that:

There is no housing that's been built in Toronto or across the country that does not involve the private sector. All of the social housing, has been built and delivered by the private sector. The government would contract non-profit organizations, but the people who built and delivered social housing made a profit. Again, there is no non-profit housing building corporation, that I am aware of, that exist in Toronto, they all use private developers. (S. Gadon, Toronto, November 23, 2017)

In fact, there appears to be a growing consensus among policy-makers and stakeholders that the issue of housing should not be the sole the responsibility of the government. As such in making a case for the IH policy, Mayor Lehman revealed that, in the past "Barrie was considered one of the cities that had an anti-affordable housing policy.” For example, according to Mayor Lehman, "you could not put in a basement apartment anywhere [in Barrie]. That was against our planning policies... there was a fatal fire in a basement apartment and ...the council of the day reacted by basically banning basement apartments and introducing strict fire codes." The problem with that was that it wiped out a good source of affordable housing noting that there are many single or detached homes in Barrie that could be turned into multi-dwellings to accommodate more households. Moreover, Mr. Lehman revealed that Barrie began to gain bad publicity to the point that "The Toronto Star gave us a 'D' because in Ontario, we were one of the worst offenders in that we had planning policies that prevented affordable housing."

Faced with limited capital investment for affordable housing and poor indicators showing Barrie as one of the Cities in Ontario with anti-affordable housing policies, Mayor Lehman revealed that the City's policy on affordable housing began to shift in the past 10 years. In fact, according to the Mayor, The City of Barrie "did what was considered unthinkable in that we permitted basement apartments everywhere by loosening the restrictions on basement apartments," within private homes. He revealed that the move to loosen restrictions on basement apartments, was 
viewed by some as too drastic and "was fiercely resisted by the politicians of the day," who viewed this approach as "a political third-rail and that it would be disastrous for politicians who stood up and said 'we need to do this'." However, Mayor Lehman was glad that his council voted unanimously for it and the City of Barrie began to move towards IH practices through community engagement and partnerships with private homeowners and private developers to build legal basement apartments known as "second suites" or "grannies apartments," within private residences to boast affordable rental.

Emphasis was placed on community engagement, partnership, collaboration and cooperation between the government, the private sector, NGOs and private citizens, in addressing the housing affordability problem. For example, Mayor Lehman pointed out that he city of Barrie proceeded to "actually engage with home builders" to create what is known as the "the Built-Form Taskforce, to look at innovative building forms for affordable houses. As such, laneway homes called granny flats, apartments over garages [and] container houses" were introduced in new developments, in a bid to boast affordable housing and improve the vacancy rate in Barrie. In addition, Toronto has a Planning Review Committee of 32 randomly selected Torontonians, who are tasked to provide recommendations to the City Planning Division, on major planning initiatives. In their most recent reflections on the IZ strategy, they recommended larger units and longer periods of affordability (City of Toronto, 2018).

In the same spirit of co-operation and partnership with the government, Rhonda, a private developer in Barrie, reports going into collaborative partnerships with the City of Barrie, Simcoe County, and the Barrie Women's Shelter, to house women fleeing abuse. She pointed out that her husband Tim, who is a professional builder, discovered that there was a gap in the housing sector that needed to be filled and he jumped in and put his skill to work while making a difference in the lives of women. Rhonda explained that as a private developer in Barrie, her Organization Redwood 
Community Parks receives government grants from Simcoe County to help homeowners create legal second suites, and they rent out the suites on behalf of the homeowner, at affordable rates, to women leaving the shelter and in need of affordable housing. Given the prevailing lack of affordable housing in Barrie, Redwood Community Park endeavoured to "fill in the gap between when women leave the women's shelter here in Barrie and when they get their Ontario Housing" (communications with R. Kent, Barrie, November 10, 2017). Rhonda further narrates working collaboratively with the Barrie Women and Children's shelter to assist women in transition and awaiting permanent social housing.

David, the Director of housing with Dixon Hall Neighbourhoods also pointed out that given the limited resources, his organizations has engaged a number of community partners that actually have housing, noting "we do not have housing but we have significant partners and other agencies who have housing." These community partners assist Dixon Hall Neighbourhood Services to provide seamless services to clients. Moreover, according to David, some of the community partners provide affordable units for his clients and these include agencies, such as, Mainstay Housing, Dixon Neighbourhood Homes, Christian Resource Centre and Loft Community Services. David also revealed that his organization has units scattered in Toronto Community Housing and they "work with the resources that ... are provided through the shelter support housing administration" noting "there are subsidies and housing allowances that we use to support men and women who are homeless, have a history of homelessness, or to support individuals who are at risk of losing their housing."

A Manager from Habitat for Humanity GTA also indicated that with the Inclusionary Zoning (IZ) and supports around that, Habitat for Humanity had partnered with a lot more developers in the residential development space in the GTA. Some of these partnerships had opened up more available units in mixed-income areas in new developments in the GTA. 
Developers put aside one or two units in a current development and were able to move families that qualified for homeownership program directly into those units. He went on to say, "it's been a positive impact for us in that regard, as it allowed us to put more families into their own homes."

\subsection{Implementation of IH Policy}

IH situates the production and provision of social housing, within the private market by requiring that a certain percentage of new builds to be deemed affordable, according to CMHC's or province's definition of housing affordability, that is: housing cost should either be; $(a) 80$ of or below CMHC's Average Market Rents $(\mathrm{AMR})^{34}$ or, (b) $30 \%$ or less of household income. According to policy-makers and stakeholders in this study, the implementation of IZ practices begins with submission of Requests for Proposals (RFPs) by the city or a submission of a project proposal or plans to build multiple dwellings, by private developers and/or housing corps, or private homeowners. Through various negotiations, incentives and trade-offs, the city may accelerate the plan approval process and award various incentives on condition that a certain percentage or all the housing, be donated to a community housing co-op or simply sold or rented out by the property owner, at an affordable rate. In this regard, emerging data from Toronto and Barrie revealed that IZ strategies used relate to planning and zoning measures, building measures and financial incentives (personal communications with S. Gadon, Toronto, November 23, 2017; Mayor J. Lehman, Barrie, November 7, 2017; Senior Manager, County of Simcoe, November 23, 2017). A Senior Manager from the County of Simcoe further detailed the following instruments used to implement the IH policy:

So, you can allow them [private developers] to build higher than they would otherwise be allowed to build, you could allow them to build smaller units than they would be otherwise allowed to build, maybe to increase the density, you can give them breaks on a whole range of fees, like development

\footnotetext{
${ }^{34}$ The Average Market Rents in Ontario are calculated at 20\% below the rentals being paid by http://www.mah.gov.on.ca/Page1117.aspx
} 
charges, building permit fees, planning application fees and parkland

dedication fees." (Senior Manager, County of Simcoe, personal

communication, October 23, 2017).

Other incentives offered to developers by both cities, were in the form of discounts on land or land donation by the city or a non-governmental organization concerned with housing issues.

In explaining the process of negotiating incentives and trade-offs between the local government and private developers, a Senior Manager responsible for policy implementation at the County of Simcoe explained that the planning staffconduct the IZ negotiations. He revealed that these negotiations are delivered and kept away from politicians who are ultimately the approval authority. As such, according to the Senior Manager, there is a separate negotiation that goes on between staff and the developer, as to what the bonus density is worth, and how they are going to provide it, and then there is the final approval process that goes on through the city council. Whereas IZ in Toronto happens at one level, IZ in Barrie is negotiated at a two-tier level, namely the municipal level and County level, but the City of Barrie is responsible implementing IZ practices.

\subsubsection{Finding a Happy Medium}

Despite the move towards a big society since the 1980s and the introduction of the IH policy, the Mayor of Barrie, Mayor Lehman opened up about the challenges of operating in a big society. Policy-makers believed that developers may be weary of the requirement to provide affordable housing in new developments because they are in business to make profit. A Senior Manager from the County of Simcoe suggested that, unless the city and the county help them, private developers might decide to build home ownership or sit on the land until the right time, or better still, "just keep building the products that can satisfy their bottom line reason, and that is homes for sale." As such, policy-makers believed they were not getting the collaboration and 
partnership they would have wanted to effectively deal with the housing crisis in their jurisdictions.

Notwithstanding the skepticism raised by policy makers, the two private developers interviewed in this study were in fact open to the creation of a big society, and the subsequent sharing of the burden of housing affordability. They acknowledged that the provision of affordable housing should be a societal burden and that it should fall on everyone, including the private sector, all levels of government and community leaders. However, despite their willingness to work with the local government to address the housing problems in Toronto and Barrie, developers were fearful of being asked to disproportionately carry the housing affordability burden. For example, Laurie, a private developer from Toronto, pointed out that there is no balance yet among stakeholders and "what people are figuring out is what is a reasonable amount of contribution [from private developers], so that you don't write-off the cost of housing generally, which can happen." Policy-makers in Toronto and Barrie agreed that there needed to be a balance. Specifically, Mayor Lehman noted that developers would be looking for something in return, such as increased height or density, or maybe a reduction of their development charges. He goes on to say, "they will likely argue that if you are making me give something up, or provide something such as affordable housing, then you can't expect me to bear the whole cost of that."

Subsequently, whereas the IH policy had been welcomed by many, policy-makers and private developers from both cities cautioned that the success of this policy in a big society, where there are many players, with different interests, hinges on consensus building and the ability to find a middle-ground or a happy medium. Hence, public administrators in this study were under pressure to offer more incentives and trade-offs to encourage the development of affordable housing within the private market. Mayor Lehman revealed that since the early 2000, local governments have been "trying to buy [a] way into the market," by utilizing IZ tools and offering various incentives and trade-offs, to encourage private developers to build affordable housing within new developments. 
However, the dilemma of balancing between the social responsibilities expected from the private sector, and what may appear as the use of public resources to boost profits for private businesses, was something public administrators were grappling with. In fact, Mayor Lehman articulated this dilemma noting:

I sympathize with them [public administrators], I do...people will say, look the developers are driving in their Mercedes Benz, they can afford to do it, ....I am sure they make good money but, the risk is that if you don't offer some kind of support, they just won't build, you can't force them to build. (Mayor J. Lehman, personal communications, Barrie, November 7, 2017).

A Senior Manager at the County of Simcoe concurred with Mayor Lehman and further suggested that "there is a recognition that, if you are going to impose something on developers, which is essentially what it is, saying that they must deliver certain percentage of affordable housing," then there is a "need to think of introducing some kind of incentives alongside that, some kind of support, whether that is through what is called the density bonusing, where you can allow for increased densities or heights, or waving development charges, that kind of thing" (communications with the Policy Implementation Manager, Simcoe County, November 9, 2017)

\subsubsection{Voluntary IZ Practices}

Policy-makers in Toronto, Barrie and The County of Simcoe, pointed out that whereas the provincial government had introduced Bill 7 of the Affordable Housing Act (AHA) that would permit the city to have IZ, the regulations in relation to that had not yet been released. As a result, the cities did not have a broad policy on IZ where affordable housing is required to be in new developments. However, Sean, the Director of Housing, City of Toronto, pointed out that "the City has a number of policies that support affordable housing in new developments." These policies 
enable voluntary negotiations or mandatory requirements for affordable housing in new or existing developments. Specifically, both cities utilize Section 37 of the Planning Act, to implement IH strategies. According to Sean, Section 37 is part of the Planning Act that allows municipalities to trade additional height and density for community benefits. Whereas transit, a library, daycare or recreational centre qualifies for community benefits, housing is a priority. Mayor Lehman suggested that voluntary negotiations carried out through section 37 of the Planning Act, include bonusing provisions that enables the city to "accept, and almost in all cases, a negotiation for higher density in exchange for affordable housing."

As well, the city of Barrie utilizes the City's 10-year Affordable Housing Strategy (AHS), to implement IH strategies. According to Mayor Lehman, the AHS include 14 different strategies that seek to "encourage, stimulate and increase the supply and range of affordable housing options to meet the needs of low-income households" in Barrie. Some of the voluntary IZ tools included in the AHS “relate to planning measures, building measures and financial incentives used to encourage the construction of affordable housing in new developments." For example, the Second Suites initiative, "is one of 14 of the recommendations in the Affordable Housing Strategy, called $A$ Place to Call Home," which seeks to encourage multiple dwellings on "single and detached homes." As well, the Community Improvement Plans (CIPs) requires that $10 \%$ of housing in new developments, be made affordable.

Likewise, Toronto utilizes Section 37, Community Benefits strategies to incentivize developers to produce affordable housing units through voluntary IZ strategies. Laurie, pointed out that Toronto's Community Benefits Policy is part of the planning approval process and is quite old, noting, "it's been in place for a while and its one of the cutting edges on how to do inclusionary type policies." According to Sean, this IZ practice is "negotiated and is voluntary," noting that, a developer who volunteers affordable rental or ownership housing in a new development can receive 
(a) credits towards developments charges, (b) exemption from certain planning fees, (c) density bonusing for no addition charge or (d) brownfield remediation grants. In fact Sean provided “one [such] example ...which is under construction at 10 York Street, which includes ten affordable units within a condominium." It should however be noted here that, whereas, capital investment in transit, libraries and recreational centres qualify as community-benefits, affordable housing also qualify as a priority for community-benefits.

Although some studies have raised issue with the voluntary, incentive-base IH approach and questioned its effectiveness (Karki, 2015; Armstrong et al, 2007; Lerman, 2006; Schueltz et al, 2009; Been, Meltzer \& Schuetz, 2007), policy-makers in Toronto and Barrie noted that despite challenges in negotiating a middle grounds, developers were quite open to working with municipalities to improve the housing situation. In fact, Mayor Jeff Lehman, from the City of Barrie, and Sean Gadon, the Director of Housing, City of Toronto, suggested that several developers have in fact taken the cities up on that and utilized IZ tools. In addition, private developers from Toronto and Barrie, also confirmed policy-makers' assertions and pointed out that they were willing to contribute towards affordable housing because they believed everyone can benefit from a healthy. In fact, Laurie pointed out that a healthy housing market is good for business, as it tends to attract investors and potential homebuyers to the community.

\subsubsection{Mandatory IZ Practices}

Both the City of Toronto and Barrie, also utilize involuntary IZ practices, in which developers are mandated to produce a certain percentage of affordable housing in new builds. For example, Toronto's mandatory IH policy is done through the city's Large Site Policy. Sean, the Director of Housing, City of Toronto, pointed out that the city's Large Site Policy is an involuntary IZ tool which mandates that " $20 \%$ " of housing on new developments "covering 5 hectares of land 
or larger remain affordable.” Laurie, a Toronto private developer agreed with Sean and further elaborated that "under the city's official planning, if you have a plan that is five hectares, your priority Community Benefit is supposed to be affordable housing. ... so the city is pretty much saying to developers 'we approve your development, and then you in turn provide affordable housing units or donate them to non-profit organizations in under developed neighbourhoods'.' Furthermore, Sean also revealed that a developer who "takes down or demolishes the existing rental housing ...there is a requirement to replace that housing in the new development." It was however noted that replacement units can be off-site hence there is a risk of the displacement of low-income households, to make way for higher income households.

Mayor Lehman also pointed out that to address the exponential growth pressures, the city of Barrie had embarked on a mandatory intensification program, "designed to support the construction of affordable built-forms" in all new developments in Barrie. In this regard, the city of Barrie had moved to utilize density bonusing on the annexed land and elsewhere in Barrie. Mayor Lehman reiterated that there are "new suburban communities that are being approved right now for development over the next few years, and those communities are all being built with $10 \%$ affordable housing in the mix." The mayor emphasized that "instead of building very low density suburbs on that land, we are going to build much more compact suburbs... about twice the density of our existing suburban neighbourhoods, much, much, more dense.” One such example, according to Mayor Lehman, is, "a high-rise development that has just been approved at Bayfield and Hwy 400," noting, "they are going to build some affordable housing, about 90 units in their otherwise market rental development, in exchange for some high density."

Moreover, Mayor Lehman was hopeful that the density bonusing in the annexed Innisfil land would yield a considerable number of affordable housing for low-income-households in the form of multi-dwellings. He further revealed that following consultations with Barrie's home 
builders, the city began "to look at innovative built-forms for affordable houses, so laneway homes called granny flats, apartments over garages, container houses, back-to-back townhomes, and stacked townhomes" were suggested. The mayor pointed out that whereas in the past, the city of Barrie "hadn't really had them proposed," such built-forms were common in places such as Mississauga and Brampton." Moreover, at a global scale, according to Mayor Lehman, these built forms were also, “...very common in Australia ...Europe and other few places.” In choosing the feasibility of built-forms, Mayor Lehman, noted that the City of Barrie, considered "our harsh weather," among other factors, such that, when it comes to container houses, although the City of "Hamilton has a sea container development that just opened, and Vancouver has got a few," Barrie did not considered such built-form. In fact, Mayor Lehman revealed that the annexed land development would include a mandatory $10 \%$ affordable housing in the form of back-to-back townhomes and stacked townhomes, noting:

What the City looked at is back-to-back townhouses and stacked townhomes, we have changed our planning policies so that we can do that now, which allows you to accomplish greater density in a ground oriented form. The magic in the density is that the land cost is lower for the developer, so that can be passed on in the form of lower purchase prices or lower rent (Mayor J. Lehman, City of Barrie, personal communication, November 7, 2017)

Apart from awarding higher density in new developments, the mandatory intensification program also centres on "developing an area at a higher density than currently exists through, redevelopment, infill and expansion or conversion of existing buildings" to create affordable units.

\subsubsection{Land Donation and Discount}

One the biggest drawback to the production of affordable housing is the scarcity and high cost of land, which tends to slow down or even hamper development. According to developers in this study, the biggest challenge, particularly in Toronto, was the cost of land. Laurie, a developer in Toronto, cautioned that "land costs drive up the cost of housing development" and in turn "drives 
up the cost of housing." She further argued that developers cannot be expected to absorb the high cost of land plus the cost of providing affordable housing units, noting:

If I am going to pay more to develop my site, I am going to pass those cost on, logically put it in the cost of the overall project and then you will have the affordable units being subsidized by the non-affordable ones and that may have an impact of raising prices overall which isn't helpful. So we are left with those logistics and trying to figure out how to address them. (L. Payne, personal communication, November 28, Toronto, 2017)

Although policy-makers admitted to the challenges around the cost of land, they were quick to add that through IH policy, developers can receive several incentives that enable developers to build at a cheaper and more affordable rate. For example, Mayor Lehman, pointed out that the City of Barrie, has utilized land donation and discounts, to incentivize the construction affordable housing in Barrie. Likewise, Sean, the Director of Housing, Toronto municipal, also suggested that The City of Toronto has also directly supported or incentivized the development of affordable housing, by selling-off provincial and city owned land to developers for a dollar or a toonie. For example, the city of Toronto put out a request for proposal (RFP) for the Madison Ave. property and it was sold to a private developer, Madison View Homes Inc., last year, for a toonie. In exchange, the developer committed to providing 82 affordable rental units at 77 per cent of the average market rent, for 50 years (Toronto Start, 2015).

While acknowledging issues raised by developers regarding high cost of land, a policymaker from the County pointed out that the County of Simcoe is "constantly working towards greater partnership for the greater good," with its municipalities, to achieve, "visions of what affordable housing really means for selective client groups, by looking at opportunities and also articulating opportunities," such as, "let's have RFP, let's have a dialogue, where the municipality will offer an incentive upfront in an affordable housing build-partnership." In this regard, the municipality, "could upfront property, [or] land that the partner municipality already owns and is 
willing to ...partner and say, here is the land, we have six parking lots, say in downtown Barrie, here is one parking lot and we want to see social housing in it. So well, let's do it." The Mayor Lehman, agreed with his colleagues and noted that the City of Barrie, had already, "identified some parking lots in our downtown that we're willing to have redeveloped for affordable housing and we've offered them up as sites." With limited funding from the province, policy-makers believed donating city land will go a long way to lowering development cost and will situate local authorities a step "closer to the reality of building an apartment complex with limited funding."

However, although developers and stakeholders in this study saw great value in the donation of city land, they believed, given the growing demand for affordable housing in Toronto and Barrie, more land need to be made available for the development of mixed communities. Particularly given the scarcity and high cost of land in Toronto, a Manager from Habitat for Humanity GTA was concerned that, compared to other jurisdictions such as Peel Region, the city of Toronto appears to lagging behind in availing land for purposes of affordable housing. He indicated that although "most of our current projects are in the Region of Peel, we do work with various municipalities and do our best to ...bid on land [or] to get some type of opportunity to get some donated land, or to have some of the fees and charges removed." The Manager, Habitat for Humanity GTA went on to reveal that although some "municipalities, particularly the Region of Peel, have been quite generous to Habitat for Humanity, in terms of waiving some fees, receiving some land donations and ...facilitating ...the reduction of costs for most of our projects," the same could not be said for The City of Toronto. He believed more could be done in Toronto, to bring down the cost of land. Laurie, a private developer with Diamond Corp, Toronto, agreed with Habitat for Humanity, and further suggested that given that the "public sector owns a lot of land, ...if they contribute land and the developers build buildings with a portion of the buildings that is affordable, that's a huge incentive because it is very expensive to buy land in Toronto's hub." 
Toronto policy experts in this study confirmed the challenges around the scarcity of land in Toronto and raised the dilemma that, whereas they acknowledged land donation as an important tool in negotiating IHP, Toronto was running out of green-fields for development. The Director of Housing, Sean Gadon, pointed out that given that Toronto was more urbanized than Barrie, the City of Toronto was struggling with lack of virgin land for affordable housing developments. As a result, according to Sean, the majority of affordable housing developments in Toronto centred around brown-fields, and may include the reuse of under-utilized land on existing builds, clearing of contaminated land, demolishing and upgrading of pre-existing structures. As such, the City of Toronto offers brownfield-grants to incentive private developers to take on revitalization projects that will create mixed-housing communities. However, Emily, a Toronto policy expert and housing advocate, raised issue the revitalization projects and pointed out that Toronto is losing affordable housing because large affordable housing complexes are being turned into mostly unaffordable condo units. She gave an example of the Regent Park revitalization project and revealed that the majority of affordable housing there has been replaced with expensive condos that those with lowincomes, including many women, cannot afford.

In direct contrast, Mayor Lehman revealed that, whereas Toronto utilizes brown-field grants to incentivize private developers to take on expensive revitalization projects, the city of Barrie had an abundant supply of green-fields for IHP projects. In fact, Mayor Lehman was confident that despite the influx of Torontonians to Barrie and "provided investment in affordable housing continues by all parties, the feds, province, municipalities, non-profit and, private developers, Barrie is not likely to run out of land." He welcomed, the decision by the province to "annex land from Innisfil" for purposes mixed community developments. He further revealed that the city of Barrie had “enough land, such that we don't need to annex for many, many decades, like generations, there is at least a 50 year, supply" of land for development. 
Given the abundance of land in Barrie, Barrie policy experts revealed that the City of Barrie has been pushing for IH policies that focus on incorporating affordable housing in every new development. Mayor Lehman called this approach, smart planning, noting, “it's always easier to do it right from the beginning. .., its far easier than trying to retrofit it into an area where it has never been there" Moreover, the availability of land in Barrie, will make it possible for the City of Barrie to engage the mayor's smart planning approach, and will also help to keep the development costs down.

\subsubsection{Financial Incentives:}

In striving to boost affordable housing stock within a market-based housing landscape, Toronto and Barrie policy makers in this study talked about offering financial incentives to private developers, non-profit organizations, and charity providers, who commit to the production of affordable housing and supportive housing in their cities. In making a case for the use of financial incentives as an effective in the implementation of IH strategies, a policy-maker from the County of Simcoe put forward that, when local governments "buy into the market," they "help finance the construction cost," of housing and, "in the long term, [they] are saying," a certain percentage of the units have to remain affordable for a period of time. Emerging data in this study revealed that financial incentives are done voluntarily in two ways, through "development fee reduction and abatement" and through "government funding" grants and loans.

The City of Barrie, through its Community Improvements Plans (CIPs) offers "development fee reduction and abatement" to charitable organizations/NGOs, private homeowners and private developers, in return for below market housing or supportive housing. Mayor Lehman pointed out that the higher the degree of housing support produced, the deeper the discount for private developers or NGOs, noting “it's on a sliding scale for discounts on fees, ... shelters would receive 
$100 \%$ discount on development charges, ... supportive housing $75 \%$ and ... social housing to market affordable, up to $25 \%$ discount." So basically, the higher the degree of support, the deeper the discount on fees, noting, "it's substantial, between $\$ 60,000$ and $\$ 80,000$ for a single detached home and between $\$ 40,000$ and $\$ 60,000$ for an apartment.”

Likewise, Sean the Director of Housing with the City of Toronto indicated that his municipality utilizes financial means to "incentivize the inclusion of some affordable housing in new developments." For example, according to Sean, the developers payment contribution under "section 37 of the Planning Act ... has often been converted directly back into the payment of affordable units purchased by the city." Sean further reinforced that "in some instances rather than making the section 37 payment," the city "will say to the developer, we will take some housing units within the development instead or in exchange of the payment." These units are awarded to a community-housing agency, which will keep them affordable perpetually, unless an application to reverse this arrangement is submitted and approved by the city.

Whereas policy makers in this study indicated that the majority of financial incentives are in the form of discounts on land and planning fees, grant funding was also offered to incentivize Developers to build below market housing in Toronto and Barrie. According to Mayor Lehman, local authorities have sought to establish how much of their "funding will buy in regards to a new building, that's going to have both market and subsidized units." The majority of funding comes from the province's Affordable Housing Act or Fair Housing Plan (Ontario Government, 2017). A policy implementation manager from the County of Simcoe further explained that through voluntary negotiations, the County of Simcoe "will partner with a private organization for a new built, ... [and] will provide funding for [say] thirty units" that will meet the "affordability threshold laid out by the County. However, "in order to make rental succeed," the developer may "need 50 units at market value." He further argued that "that's the way you influence the market." 
The County of Simcoe also offer grant funding to private homeowners or charitable organizations willing to develop below market rental units or transitional units in pre-existing dwellings. In the case of second suites, a homeowner can receive up to $\$ 25,000$ forgivable grant towards the construction of an affordable legal basement apartment in their home, on top of their garage or at the back of the house. These second suites are owned and operated by an NGO such as Redwood Community Park Homes or private homeowners. Mayor Lehman, however was quick to point out that given that the city mainly focuses on green-field developments, Barrie was more likely to give fee breaks which lower the cost of development, rather than offer direct grants, except in a few specific cases, such as in the case of a brown field remediation. In this regard, according to Mayor Lehman, the city offers a grant to any developer who takes on a contaminated site, clean it up and reuse it for any use, including affordable housing.

A noticeable difference in Toronto's IH strategies is that developments centres on brownfields in the sense of renovation of old buildings, and revitalization of neighbourhoods. Laurie, a Toronto developer noted that the "province or city sale buildings that they no longer needed with a condition that $20 \%$ of those units they build is affordable." As well Sean pointed out that it is the City's policy that "any existing rental house demolished in a new development should be replaced." This will help to ensure that the City is not losing out on affordable housing stock, to market-based housing in new developments.

\subsection{Structure and Tenure of IZ units}

Following the incentives and trade-offs negotiated with private developers, local governments may buy or receive a donation of a percentage of the total housing in the new development. Generally, the local government negotiate the structure, tenure and degree of affordability with the private developers, and according to Mayor Lehman, the questions that need 
answering in these negotiations include, "what will our funding buy", for "how long" and for "how much"? Whereas according to Mayor Lehman, Barrie requires that a minimum of $10 \%$ or more of the total housing in a new development remain affordable, Toronto requires that $20 \%$ or more be given up as affordable. This means Toronto is more likely to receive a higher stock of affordable housing units than Barrie, all things being equal.

The structure and tenure ${ }^{35}$ of IH units produced in Toronto and Barrie was also discussed. The IH policy produces a wide array of housing, from supportive, temporary units such as emergency shelters, transitional housing and senior residents housing, to permanent affordable rentals and home ownership. These units varied from 1 to 2 bedroom apartments in a condo or rental apartment building, to basement apartments, over-the-garage apartments, granny suites laneway apartments, back-to-back townhomes and stacked townhomes. While, Toronto had more affordable units situated within condo buildings, Barrie appears to have more secondary suites in private homes than in Toronto. The tenure of these units also varied from was also raised in this study and a policy-maker from The County of Simcoe revealed that when local governments "buy into the market," they "help finance the construction cost," and, "in the long term, we are saying a certain percentage of units will remain affordable for 20 to 25 years, 30 years, that's all written in the agreement" (Policy Implementation Manager, County of Simcoe, personal communication, October 23, 2017)

Whereas the move to extend the responsibility for affordable housing to the private sector through IZ gained traction in the past twenty years in Ontario, yet the 47 service managers in Ontario did not have explicit legal authority to back up IH policies (Mah \& Hackworth 2011). Toronto and various other municipalities in Ontario were reluctant to implement inclusionary policies that could easily be challenged or appealed by developers, and turned back by the Ontario

\footnotetext{
${ }^{35}$ See appendix L: Inclusionary Housing Projects in Toronto and Barrie, p.257.
} 
Municipal Board (OMB) (Toronto 2016; Mah \& Hackworth 2011; Mah 2009). However, with the recent introduction of Bill 7 of the Affordable Housing Act, 2016, developers can no longer appeal the requirement for affordable housing in new developments, to the OMB, although they can appeal incentives such as allowing for greater building height and the density of projects (Ministry of Housing Ontario, 2016). What remains to be discovered is how effective this policy is in contributing to the affordable housing stock in Ontario and in easing the affordability burden on women. As such, using a gender-based impact assessment tool (Feminist Critical Policy Analysis), the following chapter will focus on exploring the perceived outcomes of the implementation of the IH policy in Toronto and Barrie. 


\section{CHAPTER 9}

\section{Perceived Outcomes of the Implementation of Inclusionary Housing Policies in Toronto and Barrie}

Should and when the province provide us with IZ legislation, (as I have indicated that legislation was passed but we are waiting for the right directions), we will develop policies and the programs by 2020/2021. That is when we might be in a position to implement a more broadly based focus IZ policy so that, essentially as the city buildings grow at a pace of fifteen to twenty thousand units per year, some of those units will be captured into an affordable housing initiative.

(Policy Implementation Manager, Simcoe County, Personal communication, November 9, 2017)

\subsection{Introduction}

As mentioned earlier in this study, municipalities and local governments have been seeking for innovative ways and alternative policies to address the wicked problem of housing throughout Canada. The call for a big society, and the move towards public-private partnerships (PPPs), where the government shares the burden and risks of affordable housing, with private developers, appear to have taken shape in Toronto and Barrie. Given that the IH policy is situated within the backdrop of a big society and its call for innovative partnerships and collaboration between stakeholders, it was proper that this study sought to discover to what extent has the $\mathrm{IH}$ policy contributed to the affordable housing stock in Toronto and Barrie, and the easing of housing affordability for women. I utilized the Feminist Critical Policy Analysis (FCPA) for evaluative purposes of the IH policy.

The evaluative process of the FCPA cannot be considered as an event, but rather, an ongoing process that begins with agenda setting and continues throughout the legitimation, implementation, evaluation and maintenance stages. The FCPA questions the silencing of women's voices within new forms of governance, and queries why women's issues and concerns are "declared irrelevant, postponed, co-opted, put on the back-burner, assigned responsibilities with no training, budget 
personnel, or time, or otherwise ignored" (Marshall, 1997 p.ix). As such, it is with this background that this study sought to understand the perceived effect of IZ strategies as an alternative policy response, following the devolution of housing to lower levels of government, and the subsequent housing affordability crisis in Toronto and Barrie.

\subsection{Slow Legitimation and Adoption Process:}

Whereas women and frontline workers in this study saw the urgent need to expand affordable housing stock in Toronto and Barrie, emerging data revealed that despite the growing move towards IH strategies by municipalities, the province was slow in passing and formalizing laws that would make IZ effective. First, although the province of Ontario had passed Bill 7, Promoting Affordable Housing Act, on the $8^{\text {th }}$ of December 2016, which gave municipalities power to require affordable housing units in new development projects, it did not immediately provide guidelines as to how these powers would be implemented. Consequently, at the time of the interviews, policy makers and various stakeholders were anxious about the lack of clarity by the province with regards to the regulatory framework for the implementation of IZ practices. For example, Laurie, a private developer in Toronto argued that "the inclusionary zoning is a new concept that while it has been approved by the province as a policy, there are no regulations yet to implement it. So, right now, there is no in-effect inclusionary zoning in Ontario.”

A Senior Manager from The County of Simcoe also agreed with Private Developer Laurie and expressed concern over the "delay in the roll-out" of the IH policy. Sean, the Housing Director, City of Toronto, concurred with his counterpart in Simcoe County and pointed out that given that "the regulations in relation to IZ have not yet been released," municipalities do "not have a broad policy on IZ where affordable housing is required ...in new developments.” In addition, there was an outcry from civic groups about the inadequacy of the proposed regulations for Bill 7, such the 
Ontario Human Rights Commission (OHRC) wrote a letter to the Minister of Affairs, raising their concerns (OHRC, 2017). Amongst some of the concerns was the 5\% cap on affordable housing units Municipalities were allowed to require in a new development, the $40 \%$ cost difference between affordability and market rates that municipalities were required to pay developers, the temporary nature of IHP, and reducing the number of affordable units produced by excluding rental developments from IZ practices (OHRC, 2017).

The delay in the implementation of a policy with the potential of easing the housing affordability burden of women, points to issues raised earlier in this study, regarding a lack of political will to end hidden homelessness, particularly from upper levels of government. For example, it was not until April 11, 2018, almost, a year and half since the passing of Bill 7, that the Ontario government released, the regulation framework $232 / 18^{36}$ of The Planning Act, which provides specific guidelines as to how municipalities were to implement IZ strategies. Whereas the province appeared to have listened to the outcry of civic groups, much of the decisions regarding the implementation of IH strategies were left to municipalities to decide. For example, individual service managers were given discretionary powers to decide on the percentage of affordable housing units they would require in new developments, as well as the tenure of inclusionary housing (Ontario Government Laws, 2018).

However, despite the release of the regulatory framework from the province, each municipalities is required to prepare a housing assessment report, which will make way for the development of Official Plans Policies authorizing inclusionary zoning (Ontario Government Laws, 2018), before they can fully utilize IH strategies. The Assessment Report must include an analysis population demographic of the municipality, average household income, existing and planned

\footnotetext{
${ }^{36}$ Also see https://www.ontario.ca/laws/regulation/r18232
} 
housing supply, the average market prices for various households, an analysis of the potential impacts that inclusionary zoning on the housing market and the financial viability of development in the municipality (Ontario Government Laws, 2018).

Once the Assessment Report has been prepared, municipalities may begin preparing Official Plan Policies, as well as Zoning By-laws to implement IH policies. These Official Plans will lay out the minimum size of units and size of bedrooms private developers are supposed to follow. According to Mayor Lehman, the "minimum size for Barrie IH units is "four hundred square feet (400 sqf), plus the number of bedrooms and the minimum bedroom size, is one hundred square feet (100 spf). So a one bedroom must be 500 sqf, two bedroom is 600 sqf and so on," in order to pass city standards. It is not surprising that a Senior Manager with The County of Simcoe went as far as suggesting that "with the provincial elections in June, 2018, it may take until 2020/21 for the IZ to be fully implemented."

Table 6: Time Frame - Implementation of IH Policy in Ontario

\begin{tabular}{|l|l|l|l|}
\hline Policy Stage & Date Passed & Actioned by & Legitimation process \\
\hline $\begin{array}{l}\text { Bill 7 of the Promoting } \\
\text { Affordable Housing Act }\end{array}$ & $\begin{array}{l}\text { December 6, } \\
2016\end{array}$ & Province & $\begin{array}{l}\text { Provide power to } \\
\text { Municipalities to require } \\
\text { inclusionary housing in new } \\
\text { developments through IZ } \\
\text { practices }\end{array}$ \\
\hline $\begin{array}{l}\text { Regulation 232/18 of the } \\
\text { Planning Act }\end{array}$ & April 7,2018 & Province & $\begin{array}{l}\text { Provides regulatory } \\
\text { framework or legal guidelines } \\
\text { on how to implement IZ } \\
\text { practices }\end{array}$ \\
\hline $\begin{array}{l}\text { Assessment Report required } \\
\text { prior to adopting IZ }\end{array}$ & TBA & $\begin{array}{l}\text { An analysis of the condition } \\
\text { of the local housing market, } \\
\text { population demographics, } \\
\text { average household income, } \\
\text { etc. }\end{array}$ \\
\hline to prepare and \\
make public
\end{tabular}




\begin{tabular}{|l|l|l|}
\hline 5 & $\begin{array}{l}\text { would qualify as } \\
\text { affordable } \\
\text { 2. The minimum size of } \\
\text { project, locations and } \\
\text { areas where } \\
\text { inclusionary IZ by- } \\
\text { laws would apply. } \\
\text { The range of household } \\
\text { that would qualify for } \\
\text { affordable housing } \\
\text { The rate of affordability } \\
\text { and tenure to which } \\
\text { housing would remain } \\
\text { affordable } \\
\text { The incentives and } \\
\text { thade-offs. } \\
\text { The purpose in which } \\
\text { offside units can be } \\
\text { allowed }\end{array}$ \\
\hline
\end{tabular}

Even with the passing a the regulatory framework on the $11^{\text {th }}$ of April, 2018, it is not until the Official Plan Policies to guide IZ are drawn, that the municipalities can adopt IZ practices. A senior implementation manager from the Simcoe of County summed up the slow legitimation ${ }^{37}$ process noting,

Should and when the province provide us with IZ framework, (as I have indicated that legislation was passed but we are waiting for the right directions), we will develop policies and the programs by 2020/2021. That is when we might be in a position to implement a more broadly based focus IZ policy so that, essentially as the city buildings grow at a pace of fifteen to twenty thousand units per year, some of those units will be captured into an affordable housing initiative.

As such, the City of Barrie and City of Toronto, will continue to utilizing section 37 of the Planning Act to implement IH strategies. Nonetheless, up until municipalities complete and make

${ }^{37}$ Legitimation is the official authorization of a policy, as in receiving a Royal Assent, or Passing of a bill by Parliament. 
public the Assessment Report, Official Plans cannot be drawn, and current there is no in-effect inclusionary zoning in Ontario. This means that at the moment, municipalities are powerless to enforce IH strategies, outside Section 37 of Community Benefits, particularly the Large Site policy in Toronto and the Intensification Program in Barrie.

\subsection{Implementation Gaps}

Lack of provincial standards and the voluntary nature of IZ practice in Ontario, limit the potential of this policy in adding to the affordable housing stock and easing the plight of women experiencing hidden homelessness. The recently introduced Bill 7 and the subsequent regulatory framework is fraught with several limitations and weaknesses that were raised in this study. First, IH policy is voluntary and the province leaves it up to Municipalities to decide whether to adopt IH policies or not. A Senior Manager at the County of Simcoe indicated that the dangers of making the IH policy available to municipalities but not mandating its adoption, is that "some developers may choose to go to other jurisdictions that do not have IZ practices." Second, the voluntary nature of IZ strategy extends to private developers, such it may be difficult for municipalities to enforce IZ practices when developers choose not to participate, thereby rendering this practice ineffective. For example, whereas Toronto's City's Large Site Policy mandate that $20 \%$ of the housing on developments on 5 hectares of land or larger remain affordable, it does not apply to smaller developments. As a result private developers may divide housing development projects into several smaller projects, to get around IZ practices. Without strong legislations to back up IH policy, Sean pointed out that the city of Toronto has not achieved the result that the city would want because the IZ strategies are either voluntary or small scale.

Third, given the recently released IZ regulatory framework leaves it up to Municipalities to decide, through their by-laws, the degree of affordability, the percentage of units to be set aside 
as affordable and how long the units are to remain affordable, some cities may do better than others. As such in the absence of clear guidelines from the province IH policy will result in uneven affordability levels across cities because. Forth, whereas the new law prohibits a private developer from appealing a by-zoning law, it still allows private developers to appeal IZ measure and incentives to the Ministry of Municipal Affairs (Ontario Government Laws, 2018) and given that IZ depends on negotiations and trade-offs based, it erodes the negotiating power of local governments. In fact developers have been pushing back and Premier Doug Ford appear to be giving in to their demands for more incentives and to limit tools that the cities can use to negotiate IH strategies (The Star, 2019).

In addition to the implementation gaps mentioned here and the voluntary nature of $\mathrm{IH}$ strategies, weakens the intended effect of the IH policy, participants mentioned several bureaucratic hurdles that slows down the effect of this policy in contributing to the affordable housing stock and easing the burden of affordability on women.

\subsubsection{Bureaucratic Hurdles}

Private developers in this study expressed concern that while they are willing to work in partnerships to contribute towards affordable housing their effort was tied up in bureaucracy associated with the zoning and plan approval process. Laurie, the Vice President of Diamond Corp, Toronto, revealed that "it takes a very long time and a lot of money to go through a zoning process.” Rhonda, from Redhood Community Parks, a private developer from Barrie, agreed with Laurie and added the bureaucratic processes related to development approval by the County of Simcoe, weakens the intended benefits of IZ strategies. For example in spite of Mayor Lehman's suggestion that "secondary suites are a good source of housing," in Barrie, Rhonda, revealed that “there are so few secondary units available right now, because the County's process is ...slow, 
expensive, laborious, and very difficult to manoeuvre," such that "some people have returned the grant funds to the County and de-enrolled from the program."

In the past few years, there is evidence that the local authorities have been responding to the concerns of developers. For example, the City of Toronto, recently introduced the Open Door Initiative IZ tool, to help "cut the red tape," "streamline the process," and provide more funding for affordable housing (Toronto Star, 2017). Through its open door policy, the city is able to "fast tracks planning approval ...forgives building fees, development charges, planning fees, parkland dedication and provide tax relief totalling about $\$ 40,000$ per rental unit.” (Toronto Star, 2015). In exchange, the city secures a portion of units at or below the city's average market rent and the units are to remain affordable for at least 25 years (Toronto Star, 2017). Similarly, according to Mayor Lehman, in the past 10 years, the city of Barrie and the County of Simcoe has been working to make the rezoning and approval process easier, faster, and affordable for the homeowner, to encourage the development basement apartments, laneway suites, over-the-garage suites, granny suites or detached garage conversion.

However, private developers in this study maintained that the application approval application is long is long and cumbersome. In fact, Laurie, She suggested that although it is hard to measure, one of the biggest incentives is accelerating the project approval time. In fact, Laurie suggested that "if by contributing affordable housing, the process becomes easier, more efficient and one that brings the housing to the market faster, and helps affordability, most developers are willing to pay for it." Likewise Rhonda also suggested that it would be helpful to simplify and shorten the approval process. 


\subsubsection{Contentions over Cost-sharing: Finding a Happy Medium}

Although private developers welcomed the idea of sharing the burden of affordability to create a healthy housing market, they were concerned about the added cost of funding affordable units. While, conceding that the grants, land donations, higher density bonusing, discounts on development costs and fast tracking planning approvals, "are all cutting edge strategies in trying to figure out how to do inclusionary type policies," Laurie, a private developer in Toronto, believed these incentives do not match the rising cost of producing a move-in-ready unit. She revealed that it is a challenge trying to figure out "what is reasonable contribution without writing out cost." of the unit. Rhonda, also indicated that the cost of producing affordable units continue to rise such that her organization has resorted to appealing to the community for more donations to fill in the gap between the cost of developing affordable housing and the grant funding from the province and county or discounts on development fees from the city.

Lack of a happy medium creates a dilemma for lower-level policy-makers and slows down the implementation process, while weakening future maintenance and sustainability of $\mathrm{IH}$ policies in Ontario. In laying out the dilemma of situating affordable housing within the market, Mayor Lehman, while acknowledging the need to engage private developers in addressing the housing crisis, was worried about the quality and size of units produced through IZ, noting:

It is hard to build quality, when you are trying to build as cheap as possible. I can remember a particular developer saying to me that 'there are three enemies of affordable housing,' and this is from a developer's perspective right, 'one is the cost of land, two is common area charges for condo fees, and three is city fees.' I remember him walking me through the mathematics to show that before they even build the first wall, this is how much it cost, just to get the lot paid for, and the servicing and the city fees, before they even start construction. And he said, I can build relatively inexpensively and I can build higher density, but, you know, when the city wants me to have an amenity area of $X$, and driveways of $\mathrm{Y}$, and boulevards of $\mathrm{Z}$, and all these other requirements in planning, it drives up the land cost, and that goes straight into the cost of the housing. So the cost is passed on to the buyer or renter in the case of institutional money where they 
build it (Mayor J. Lehman, City of Barrie, personal communication, November 7, 2017).

Given the underfunding of affordable housing, it was clear that developers were feeling over-stretched with the burden of funding affordable housing. For example, Laurie revealed if IH policies continue to "add more cost onto the project," there is a huge possibility that "the cost of affordable rental housing is going to be passed on to unaffordable housing buyers." Laurie further cautioned that that IH policy may in fact "slow down or stall the development of new housing" because of the added cost. In addition, Mayor Lehman (personal communication, Barrie, November 7, 2017) and Emily, (personal communication, Toronto, November 30, 2017), argued that given the high cost to producing affordable housing, the physical quality of units produced through IH strategies may be compromised. Mayor Lehman further cautioned that in trying to cut costs, some of the units may be substandard and may life-cycle out sooner, such that over time and they will be expensive to maintain. Emily, a housing advocate in Toronto, also expressed similar sentiments and pointed out that there is a high possibility that that the units produced through IZ practices will be too small, segregated and hidden compared to the rest of the units in a condo building.

The unintended consequences of IZ policy, are therefore, that the cost of affordable housing can be passed on to unsuspecting unaffordable homebuyers, or developers may stall development or compromise on size and quality, to try and cut back the production cost. In addition Mayor Lehman cautioned that whereas as a municipality, the focus is on tenant success, the province and federal government tend to focus more on unit counts, construction timelines and jobs created. He believed that whereas these aspects are all good by-products of investing in affordable housing, he cautioned against the production of poor quality housing in a bid to mass produce housing, meet timelines and create jobs, noting that some developers may end up making the units more compact, 
depending on who is building and funding the project, and their vision.

\subsection{Perceived Outcomes of IZ strategies on Canadian Housing Landscape}

Despite the slow legitimation process and various implementation gaps, there were several examples where the city of Toronto and Barrie, partnered with the private sector to support the development of affordable housing through models similar to inclusionary zoning ${ }^{38}$. For example, "according to data provided by [Toronto] city staff, the Open Door program has managed to secure 855 ...rental units ... at below average market rent" Whereas 704 of these units were obtained at around 80 per cent of average market rent, the rest of the units were presented at " 60 per cent or below" (Toronto Star, 2016). As well, Mayor Lehman pointed out that, of the 223 second suites produced, between July 2016-December 2018, “when Barrie first legalized secondary suites two years ago," 200 of them were added to the affordable rental housing stock. Moreover, 33 of the 200 new affordable second suites received County grant assistance (Simcoe County Annual Affordable Housing Report, 2027).

Besides adding to the affordable rental stock, a Manager with Habitat for Humanity added that the IH policy had "a positive impact in that it enabled low-income working families, to move into home ownership. A Manager from Habitat for Humanity GTA further noted, the IZ model is essential in removing a lot of barriers to homeownership for working low-income families, who otherwise could not afford to become homeowners and are living in some tough situations. He revealed that through IZ practices, Habitat for Humanity has been able to partner with private developers, who put aside one or two units in a current development so that Habitat for Humanity is able to move low-income families directly into those units without down payment and at an affordable rate. The Manager, Habitat for Humanity, further revealed that through IZ practices,

\footnotetext{
${ }^{38}$ See fig 2_Examples of IZ practices in Barrie and Toronto
} 
since its inception in 1998, Habitat for Humanity GTA had helped 360 families move into houses and about 250 more homes were in the pipeline by 2021, in the GTA.

Whereas The Manager, Habitat for Humanity, Toronto, as well as Laurie, a private developer in Toronto, talked about homeownership for low-income working families, in Barrie there was no mention of home ownership for low-income families. In fact, stakeholders in Barrie talked about transitional housing for women fleeing abuse. Rhonda a Barrie private developer felt that transitional housing created through IZ was effective in filling the gap between the time women leave the shelter and the time they find permanent housing. However, she was concerned that IZ strategies in Barrie had not created enough permanent affordable housing, through second suites or other IZ programs.

Failure to produce enough permanent affordable housing through IH policies can have devastating consequences for women. For example, Rhonda further observed that women in transitional housing find it particularly difficult to get a job and get back on their feet because they do not have a permanent address. To close this gap, Redwood Park Communities had partnered with the County of Simcoe and the city of Barrie to convert the Bars Motel into permanent affordable housing. However, the number of units that will come out of this project, as well as other IZ projects, will not make any significant dent on the waitlist facing the city of Barrie.

Although IZ strategies raised awareness of the need for a healthy housing market, policymakers and stakeholders in both cities concluded that houses produced through most IZ regimes, are minimal, very small, and negligible, such that more needs to be done. For example, Emily, a policy expert in Toronto, argued that despite "the claim that the City of Toronto has $20 \%$ affordable units in new developments, that is not the case at all." Although she believed that some councillors may have been able to work with some developers, to produce affordable housing through IZ strategies, she argued that for the most part, "there is no such regulatory requirement in Toronto at 
this time," therefore, "the city has not been successful." She went as far as suggesting that the city of Toronto had approved many, new developments that don't include a single unit of affordable housing."

Sean, a policy-maker with the City of Toronto, agreed with Emily and expressed disappointment that IH strategy in Toronto had not yielded significant number of affordable units, to add value to the affordable housing stock. Sean pointed out that "I don't have the list in front of me, but they are really, really minimal, they are not significant". He however, did point out that "the biggest accomplishment was done in the West Donlands neighbourhood which is owned by the provincial government, and over 500 units of affordable housing were developed there as part of the Large Site Policy, and as a special initiatives of the Pan American games." In addition, Laurie, a Toronto private developer pointed out that the biggest project her organization worked on produced 250 units of affordable housing.

Whereas Laurie, believed that the city was moving in the right direction and that IH policy was chipping away to a certain extent. She was quick to add that, the city had a long ways to go and more needed to be done to enhance affordable housing stock and lower what she described as the long waitlist and the sheer amount of families needing decent affordable housing in the city.

When it comes to IZ practices in Barrie, Mayor Lehman, revealed that the IH policy has not had much effect on the housing landscape because it is a newer and relatively foreign to some. He pointed out that in a politically charged environment, the implementation of a progressive, yet "controversial" strategy such as IH can be a challenge. Particularly in the case of secondary suites, as indicated previously, that the move to relax zoning requirements for secondary suites and offer incentives, was viewed as "disastrous," and "a political third rail." The different paradigms held by various authorizing departments tend to slow down the implementation process, as suggested by Mayor Lehman, that: 
People have different opinions about what the proper role of the government is in housing and those opinions range from a very libertarian view that says, 'the government should stay out of housing,' to socialist views that say 'the government should be providing housing on a mass scale' and then there is everything in between. The policy approach of local governments can swing, as they get mayors and councils that have different views on that spectrum and that can reduce or increase affordable housing stock. (Mayor Lehman, Barrie, November 7, 2017)

Mayor Lehman also suggested that the impact of IZ had not been felt yet because Barrie has just started implementation of this policy. He pointed out that the Community Improvement Plans (CIPs) requiring $10 \%$ affordable housing in new developments are only about a year old and, the Affordable Housing Strategy itself is only about 2 years old, and the city is still rolling some of it out. Mayor Lehman believed that with the newly introduced $10 \%$ rule, plus the vast projects earmarked under the annexed lands, there is going to be a substantial increase of affordable housing units produced through IZ. Just as an example, Mayor Lehman pointed out that "of the six subdivision approved for 2018, a total of six 7000 units, will produce six 700 affordable units, that's starting to really make an impact".

\subsection{Shallow Level of Affordability}

Furthermore, the degree of affordability regarding units produced through IZ practises, cast a dark shadow on its effectiveness in addressing the need of low-income women. Sean, a Toronto policy expert with city of Toronto, pointed out IZ regulations and programs have not managed to get to the deep, deep housing affordability levels that persons who are homeless require. Emily, a Toronto housing advocate concurred and put forward most IZ programs target affordability that is just below market, such that people experiencing homelessness, in shelters or on the waitlist for affordable housing are left falling through the cracks. In a similar manner, Mayor Lehman expressed concern that given that IZ tend to produce lower-end market, or medium affordable 
housing, policy-makers may very well be missing on how to connect the most vulnerable people into social housing. Moreover, when it comes to the homeownership side, Habitat for Humanity, was having difficulties finding the right families would fit the criteria for affordable housing through IZ strategies. According to the Manager for Habitat for Humanity GTA, the homeownership program target a niche clientele who are low-income but are able to make affordable mortgage payment to the and pay property taxes. Regrettably, most low-income families are unable to afford such payments.

\subsection{Maintenance and Sustenance of IH Strategies:}

The maintenance and sustainability of IH policy was also brought into question. Although local governments in the United Kingdom and Australian successfully used their legal powers to negotiate S106 planning agreements with developers as a sustainable way of providing affordable housing (Morrison \& Burgess 2014), this was not the case in this study. Despite the need to have strong leadership from the province, mandating IH practices in all new developments, the recently introduced Bill 7, does not mandate inclusionary zoning policies and municipalities cannot force developers who choose not to participate. Policy-makers in this study relied heavily on incentives and trade-offs in what appeared to be mostly voluntary IH policy, according to participants in this study.

The sustainability of IH policies is also closely tied to a continued supply of affordable land for new developments. Mayor Lehman noted that all the good sites for intensification in Barrie, are gone because of the real estate boom. As a result, according to Mayor Lehman it is becoming increasing harder to find sites that can work more economically for affordable housing." However, he was hopeful that the annexed land would sustain the city's IH strategies for up to 50 or 60 years. In addition, The City of Toronto, having run out of green-fields, was forced to focus more on 
working with brownfields to sustain $\mathrm{IH}$ policies. However, renovating and revitalization programs increases, construction cost.

It is not surprising that Sean, the Director of Housing, City of Toronto and Emily, a housing advocate, University of Toronto, were concerned that IH policies have failed to produce deeply affordable housing, particularly for low-income families. Moreover, poor conceptualization of hidden homelessness, and its pre-occupation with limited tenure and non-monetary aspects of hidden homelessness, coupled with a lack of clear guidelines as to what constitutes affordable housing, has resulted in IH policy producing temporary, shallow levels of housing affordability that do not address the immediate and long-term needs of low-income women.

Moreover, sustainability of IH policy also hinges on close monitoring to determine its impact on affordable housing stock. However the challenge with the marketization of social housing is that local authorities do not have effective ways of tracking and monitoring the market given that some units are managed by private developers, and as well as individual homeowners. Although local governments can track affordable housing produced through their application approval process, there is no way of knowing for sure the extent to which the units will remain affordable, for the period cited in the application. In addition, there is no way of monitoring changes in household income to make way for other needy households, prior to the expiration of the affordability period.

A Social Policy Implementation Manager at the County of Simcoe conceded that the "government has not yet figured out how to deal with hidden forms of homelessness, and do not have ways to determine the extent of hidden homelessness homeless, in particular among women. He pointed out that Simcoe County tried enumeration count, held focus groups, and even used 1800 number, yet poor responses made it "very challenging to determine the extent of hidden homelessness, that's true across Canada." This confirms pre-existing studies that show that 
statistics on homelessness are mostly based on shelter counts and excludes the hidden population (Gaetz, et al, 2014; Gaetz, Ritcher \& Redman, 2016; Crawley, 2013). Failure to account for women experiencing hidden forms of homelessness also means that resources are not allocated to this group and their plight remains hidden and unrecognized at policy level (Gaetz, Ritcher \& Redman, 2016; Crawley, 2013 p.674)

Furthermore, the IH policy was described by policy makers in this study as "patch work" and "temporary" because it is mostly focused on short term housing affordability of up to 20 to 30 year term or transitional housing. As well, despite the growing need for permanent, safe housing for women victims of domestic violence, the only housing offered to women fleeing abuse in Barrie, was mostly "temporary transitional housing." Danielle, a housing worker in Barrie, pointed out that although transitional housing enables abused women to "catch a break and pay below market rent until they get into social housing," it does not provide housing stability for women. Rhonda, a developer in Barrie, put forward that transitional housing "buys them [women victims of violence] a year break to focus on their healing...go back to school or take up training to increase their income so that they can now transition into a full market rent units". She was concerned however, that lack of permanent affordable housing stalls the healing process and may lead women to go back to their abuser. Yet the IH policy has failed to produce a significant number of deeply affordable houses both in Toronto and in Barrie.

\subsection{Recommendations in Light of Women's Experiences:}

From the perspectives of women in this study, policy makers and politicians were not taking their experiences with hidden homelessness seriously. As mentioned earlier, several women in this study believed that their local authorities did not care about the plight of the poor, and that priorities of mayors were skewed towards higher income earners who are able to pay property taxes. Failure 
to create deeply affordable housing through IH policies, appear to confirm the cynicism widely held by women in this study, towards politicians and bureaucrats.

Moreover, the province's inability to provide effective leadership in the face of a housing crisis may be seen as a form of indifference to the plight of women experiencing hidden homelessness. Most notable, the delay in the roll-out of the IH policy, with the potential of easing the housing affordability burden for women, is a good example of how women's issues are often ignored, co-opted or put on the back-burner (Marshall, 1997). Furthermore, local authorities did not have a tracking system in place to track affordable units produced through housing strategies in Toronto and Barrie. However, although they believed the impact of IH policies is minimal and rather insignificant, in the absence of specific gendered statistics on homelessness and failure to track affordable housing produced through IH policies, brings into question issues of political will to end homelessness among women in Canada. In addition, the temporary nature of IH strategies has been criticized by policy makers and stakeholders in this study and housing advocates in Toronto (OHR, 2018).

The political will to end homelessness among women begins with an acknowledgement of the systemic violence in the lives of women resulting from, the feminization and racialization of poverty, job precarity, inadequate income supports and a lack of affordable housing, as laid out in this study. It extends to proper conceptualization of hidden homelessness and re-defining of housing affordability levels, to reflect the diverse experiences of women. In addition, to redefining the boundaries of hidden homelessness, the province should view hidden homelessness as a serious human rights issue that require urgent and unambiguous policy responses. As such to effectively deal with hidden homelessness though the IH policy, the province can move from incentive-based approaches to mandatory approaches. Mandatory IH strategies have been found to yield better outcomes than incentive-based approaches, in Cities across the United States of America, Britain, 
Australia and New Zealand (Karki, 2015; Armstrong et al, 2007; Lerman, 2006; Schueltz et al, 2009; Been, Meltzer \& Schuetz, 2007).

Through mandatory IH policy, the province would (a) require all local authorities to adopt IH policy in new and pre-existing developments, (b) give local authorities greater powers to influence the production of affordable housing in all new developments no matter how small; (c) provide specific guidelines and standards in the implementation of mandatory IH policies across the province, (d) put in place a tracking system to track affordable housing units produced through $\mathrm{IH}$ (according to policy makers in this study, tracking can be done through the municipal application approval process), (e) enforce the tracking of affordable housing units produced through mandatory IH such that municipalities that appear to be under-performing may be asked to account for areas that they may require further support from the province or elsewhere.

Whereas the Federal government is beginning to show interest in gender-based homelessness, through major funding and active engagement with stakeholders and lower levels of government, it is early to know for sure how far the newly released NHS (2018), will go in easing the burden of hidden homelessness among women. What we know is that the cost-sharing initiative will help to boost collaborative partnerships that may influence the production of affordable housing through IH strategies. However, what is required is ongoing commitment from the Federal government, to fund the production of affordable housing.

Moreover given the diverse needs of women experiencing hidden homelessness, what is required to end homelessness among women is a more robust and integrative approach. As such, the next chapter will explore a way forward to ending hidden homelessness among diverse groups of women, using an integrative intersectional gender-based analysis. 


\section{CHAPTER 10}

\section{Way Forward to Ending Hidden Homelessness among Women: An Integrative Approach}

The expected pathway to re-housing women includes community services. ....What we have often seen is a woman will go from the women's shelter, to transitional housing, to getting her call from Ontario Housing. During that time, she may have gone back to school, so let's just say ...to become a nurse and when she graduates she gets a nursing job, or she may have started a business, and her income goes up and up. As her income increases, so does her subsidized housing rent, until she gets to a point whereby she is paying market rent in an Ontario Housing Unit. So at that point then she is ready to go to market rent, she finds a town-home and she is ready to move on from social housing or subsidized housing. So she has gone through the expected path of shelter, transitional, rent-geared-toincome and market. And throughout that process, the goal is that in the transitional phase, we are able to provide some support that she is pursuing her school, starting her business, finding a job. All of that foundation is laid while she is in transitional housing ...so that when she goes out into her next phase of housing ... she has that supportive community in place to take her through that next step.

(R. Kent, personal communication, Barrie, November 10, 2017)

\subsection{A Holistic Approach to Housing}

Policy-makers and frontline workers in this study pointed out that when it comes to hidden homelessness among women, what was lacking was an integrative holistic approach that caters for the diverse needs of women they serve. Besides housing affordability issues and lack of affordable housing, municipalities were not fully equipped to deal with individuals with past and ongoing concurrent trauma, or mental health and addiction problems, due to the underfunding of programs by upper levels of government. For example, Mayor Lehman pointed out that with "the opioid crisis ...hitting some of our communities ...it's not enough to just get the roof, you need the services to support tenants too." Likewise, David Reycraft, a frontline worker in Toronto concurred with Mayor Lehman's assertion and further revealed that: 
Drugs are a growing problem in North America and the developed world and Toronto is grappling with the increased use of opioids and the arrival of fentanyl and speaking from the perspective of working with men and women with mental health issues and concurrent disorders (mental health and addictions), we know that a lot of those challenges are going to continue once people move into housing, that's why health supports are the critical piece of the work we do with individuals experiencing concurrent disorders and housing insecurity. (D. Reycraft, personal communication, November 7, 2017)

Yet despite the glaring need for an integrative, holistic approach to tackling hidden homelessness, the shrugging off of women's issues and concerns in the policy-making processes speaks to issues of greed, power and privilege (Marshall, 1997). Moreover, not only are the needs of women minimized, there is a tendency of victim bashing and re-victimization of women in need of housing. For example, Charlene, the Director of Programs, with Elizabeth Fry, further suggested that, trauma survivors and women struggling with mental health and substance abuse are often criminalized and/or lose their jobs such that they are unable to find a home or remain housed. In addition, Charlene revealed that women are "falling through the gaps," noting that she has, "heard stories of trauma survivors living in unsafe housing, ... hiding in their cars" and women on bail and peace bonds, who do not have anywhere else to go. It goes to say that there is a disconnection between policy-makers and policy responses, and women experiencing homelessness and their diverse needs.

The critical feminist policy approach argues that although everyone has an equal right to be consulted and heard, some groups, particularly women, are often ignored and their issues remain unheard or declared irrelevant at policy planning tables. Hence, budgets often do not reflect the needs of women (Marshall, 1997). This was confirmed by frontline workers in this study who suggested that lack of funding for programs related to supporting women to move out of homelessness and to keep their housing, limit the work and mandate of their organizations. For example, Charlene Blancard, a mental health worker with Elizabeth Fry, pointed out that there is 
just "not enough individualized supports for women struggling with mental health and substance abuse problems," due to "underfunding and budget cuts to programs."

When it comes to a more holistic approach to addressing chronic homelessness among women with concurrent disorders, the Housing First ${ }^{39}$ (HF) initiative is arguably a more holistic approach. In fact, randomized clinical trials of the HF program in Los Angeles (Henwood et al, 2013) and in cities across Canada (Aubry, Nelson, \& Tsemberis, 2015; Kirst et al, 2014;

Stergiopoulos et al., 2015), revealed a strong correlation between providing permanent housing and enhancing/triggering a sense of hope, recovery and a fresh start for individuals struggling with chronic homelessness and mental health and addition problems. Housing first is client centred and recovery oriented, and it focuses on providing housing with personalized wrap-around services within the community, for people with mental health and addiction problems (Aubry, 2015). Regrettably, while positive outcomes of the HF initiative have been acknowledged by many, the underfunding of social programs, tend to hamper their ability to effectively respond to the needs of women. For example, a cross-case analysis of the sustainability of Canada's largest HF program, At Home/Chez Soi's (AHCS) was conducted at each of the project's five sites (Toronto, Vancouver, Montreal, Winnipeg and Moncton). Results revealed that the underfunding of this program has in fact resulted in the closure of three sites and jeopardized the daily operations of the remaining sites, particularly challenges around sustaining rent supplements and the cost of supportive services (Nelson et al, 2018). In addition to measures undertaken through the Housing First program, other holistic initiatives have been proposed to support vulnerable populations such as women who are not necessarily afflicted with mental health and addition problems.

\footnotetext{
${ }^{39}$ Housing First is a national-wide housing and homelessness initiative, which focuses on ensuring that individuals struggling with chronic homelessness, mental health and, addiction problems, are provided with unconditional permanent housing with wrap-around services, to help them reintegrate into their communities (Homelessness Hub, 2019)
} 


\subsection{Moving Forward: Debating the Issue}

At this point in the study, I sought to understand what it would take to end the issue of hidden homelessness among women. Whereas some spoke of innovative approaches to end homelessness, others pointed out that the best way to end homelessness is to prevent it. Yet all participants in this study believed that there is no one way to end homelessness. According to Sean, the Director of Housing, City of Toronto, "the IZ strategy is ...only one of the tools in the toolkit [but] it's not a panacea or a full solution to the housing crisis," that the city of Toronto and Barrie were facing. Sean also added that, "keeping in mind that the IZ initiative does not develop deeply affordable homes, other income support programs and other types of initiatives would be needed to compliment IZ if it was to be targeted to low-income households."

Consequently, all policy-makers and frontline workers in this study suggested an integrative approach to hidden homelessness. They put forward that the most effective way to address the issue of hidden homelessness is to have an all-encompassing policy that integrate various policy tools, mechanisms and programs to (a) prevent people from losing their homes (b) enable high risk individuals to keep their homes and (c) lastly, allow homeless individuals and families to be permanently housed in a fast and efficient manner. Whereas some policy-makers pointed towards, the homelessness prevention strategy ${ }^{40}$ and argued that it incorporates poverty reduction strategies, and various social housing initiatives to boost affordable housing stock for low-income households. However, others argued that our social housing system works well for people who don't need a lot of services but it doesn't work very well for those who need wrap-around services.

As such, Mayor Lehman emphasized the urgent need for wrap-around services, noting that "with the opioid crisis hitting some of our communities, it's not enough to just get the roof, you

\footnotetext{
40 Affordable Housing Initiative (AHI) and the Poverty Reduction Strategy, the government of Ontario committed to capital investment in the building and maintenance of safe, affordable housing, providing low-income homeowners with assistance and supporting various homelessness programs (Ontario Government, 2018 https://www.ontario.ca/page/ending-homelessness-ontario).
} 
need ongoing supports." He went on to call upon the federal government to focus on maximizing "tenant success, and rather than focusing on the number of units government funding can buy," he suggested that the federal government should be focusing on community and income supports required to house and keep women housed. David, the director of housing with Dixon Neighbourhood Hall, agreed with Mayor Lehman and added that, "there needs to be a collaborative approach and a focus on wrap around services, particularly medical supports and tenant supports ...to deal with addictions and mental health" problems. Moreover, Danielle, a housing worker at Barrie Women \& Children's Shelter, indicated that there is a pressing need to "provide adequate, safe and appropriate housing" to meet the diverse needs of women, not only those fleeing abuse but those struggling with addictions and mental health problems.

A good example of this integrative approach to homelessness was articulated by Rhonda, a local private developer in Barrie, who pointed out that her organization, Redwood Park Communities:

Operate, manage, and maintain transitional housing across Barrie...and we partner with other agencies who provide the clients with intensive case management. We provide day to day support, casual, friendship-type support to families and individuals and we conduct regular maintenance of the units. So we maintain the units and we support the families, and in the case of our second suites we also support the homeowner and we help smooth-out things between the homeowner and the tenant, whenever there is any tensions. ( $R$. Kent, personal communication, Barrie, November 10, 2017)

Whereas it was acknowledged that there are many residences who do not need wrap-around services, yet some policy-makers and frontline workers saw the importance of matching people's needs to built-form at affordability levels, to enable a smooth transition from living on the street, shelter system, and/or couch surfing, to getting permanent housing.

Besides the urgent need to provide adequate, safe and appropriate housing, with wraparound services for women, Meghan Chamber, the Director of Residential Programs, Elizabeth Fry, 
pointed out that there was also a glaring need for the "overhaul of the justice system" so that "we do not incarcerate people for things that could be dealt with differently." In the same spirit of social justice, she also suggested that the gap between racialized groups and mainstream in the justice system requires attention. She revealed the need to "provide support for poor racialized groups coming out of prison," particularly from First Nation's communities. Encouraging affordable housing within the market can be instrumental in achieving this. Hence, some women and frontline workers suggested tightening of the rent control and providing adequate guaranteed income, for women in need. Whereas the Ontario government had recently passed the Rental Fairness Act 2017, which became effective in 2018, capping annual rent increase at $1.8 \%$ of women in the study were struggling to keep up with current market rent. Even "an increase of up to $1 \%$," was considered "too much and unaffordable" according to Elaine, a woman a precariously housed woman on ODSP.

\subsection{Strengthening Community Supports}

In a society driven by hegemonic masculinity, frontline workers and stakeholders working with women to end homelessness argued that women need to be given a chance to maximize their potential, so that they can break the glass ceiling in the workforce. As such Rhonda, a private developer who also runs transitional housing for women in Barrie, pointed out that an important piece to ending hidden homelessness among women is to "provide them with opportunities to advance themselves" particularly after leaving abusive relationships, rehab centres, incarceration, and also after graduating high school. As such, Rhonda revealed the successful reintegration of women victims of domestic violence or other forms of hidden homelessness into their communities follows a pathway, that requires community services and a robust community support network argued that: 
What we have often seen is a woman will go from the women's shelter, to transitional housing, to getting her call from Ontario Housing. During that time, she may have gone back to school, so let's just say ...to become a nurse and when she graduates she gets a nursing job, or she may have started a business, and her income goes up and up. As her income increases, so does her subsidized housing rent, until she gets to a point whereby she is paying market rent in an Ontario Housing Unit. So at that point then she is ready to go to market rent, she finds a town-home and she is ready to move on from social housing or subsidized housing. So she has gone through the expected path of shelter, transitional, gear-to-income and market. And throughout that process, the goal is that in the transitional phase, we are able to provide some support that she is pursuing her school, starting her business, finding a job. All of that foundation is laid while she is in transitional housing ...so that when she goes out into her next phase of housing ... she has that supportive community in place to take her through that next step. (Rhonda, Barrie, November 10, 2017)

Frontline workers, including those from Elizabeth Fry, Barrie Women and Children's Shelter and Dixon Hall Neighbourhood services, emphasized that housing should be attached to community services particularly, systems navigation, therapeutic relationships, and housing and income supports. Moreover, Danielle, a housing worker in Barrie and working women in Toronto, suggested loosening up eligibility criterion so that working women are not disqualified from housing subsidy, start-up, first and last rent, and childcare subsidy, due to their working activities, because they are not making enough to cover market rent. Furthermore, Barrie women on Ontario Works (OW) and Ontario Disability Support Program, (ODSP), pointed out that they could benefit from an increase in income supports, to reflect the current cost of living. As well given the food insecurity mentioned in previous chapters, low-income women may also benefit from income enhancement programs such as the food supplement program. Food supplement programs have been found to reduce food insecurity in low-income families (McFadden, et al, 2014).

\subsection{Broadening Affordable Housing Options:}

Some policy-makers argued that a successful housing strategy needs to produce a broad range of deeply affordable housing that focuses on fulfilling the housing needs for the most 
vulnerable populations, in our society. To begin with, policy-makers could use a balance of a number of different mechanisms which include, social housing, and other forms of non-market housing, such as co-ops, subsidized housing, supportive housing, and transitional housing. Moreover, a Senior Manager at the County of Simcoe pointed out that the need to consider indigenous women's needs particularly, in Barrie, cannot be overlooked given its proximity to the Northern Communities. He revealed that whereas, the Indigenous Transitional Housing in Orillia serves as a starting point in providing support and in dealing with mass migration of women from Northern communities, Barrie does not have any such housing and more needed to be done in Simcoe County, to support First Nations women coming from the Northern communities.

Although, Mayor Lehman suggested that IH policies supports non-profit organizations to operate affordable units, within the market and encourages private developers to "build smarter" in order to produce "deeply affordable units and supportive units in the market," he however expressed the need to "monitor the quality size of units produced through IZ strategies." He pointed out that as land become more and more expensive, it becomes increasingly difficult to find, good sites that can work more economically for affordable housing. As such, the possibility of private developers compromising on the size and quality of units, to cut down on development costs was considered high. Consequently, Mayor Lehman suggested that having minimum standards and follow-ups, can be helpful in preventing such incidents and in making sure the units being produced aligns with North American standards and values. Mayor Lehman went on to reveal that although “in other parts of the world like Japan, it's not uncommon to have tiny apartments, but in North America, we do have certain minimum standards that we feel are important and that we should hold up."

However, private developers and some women in this study, believed that building smaller can in fact encourage the production of deeply affordable units. In fact, Laurie, a private developer 
from Toronto, proposed an overhaul of the IH policy to allow developers to build much smaller and more compact units, noting, "it's about shifting attitudes from laws insisting on larger houses, to people having to recognize that as affordability and resource become scarce we all need to live smaller." Furthermore, Sophia, a woman from Barrie concurred with Laurie and went as far as suggesting the broadening of affordable housing options to include communities with tiny homes. She argued that such approaches have been successfully implemented in the USA and women enjoy the sense of community, camaraderie and supports they get in those developments. As well, Rhonda, a private developer and housing stakeholder in Barrie, agreed with Laurie and Sophia, and added that builders are striving to find more effective and cheaper ways of utilizing space when building affordable housing. As such her organization's goal, was to build the first ever tiny home community, in Barrie, as a follow up to phase one of the motel conversion project.

\subsection{The Question of Political Will to End Homelessness}

Although combating homelessness by having a proper range of housing in our communities is the right thing to do, it remains politically difficult. It is challenging in the wake of fiscal restraint and tight budgets, a multitude of social problems requiring government funding, powerful interests groups pushing their agenda at policy tables, and opposing views and beliefs of politicians and policy-makers at various levels of government. As Mayor Lehman believed that "it will take a strong political will" for "the government ...to come in and say, 'you know this is important'," and to potentially "even fund projects that will be unpopular" at the local, provincial or national level, and that could potentially cost one a political career. A good example, (despite backlash from powerful businesses and right wing groups ${ }^{41}$ ), was the former Premier Kathleen Wynne's increase of the minimum wage from $\$ 11,40$ to $\$ 15,00$ staggered over the period from 2018 to 2019 , because

\footnotetext{
${ }^{41}$ https://www.youtube.com/watch?v=NU-RUw5-8kw - Former Premier Wynne receives backlash for increasing minimum wage.
} 
she was convinced and "knew it is the right thing to do". ${ }^{42}$ Some may argue that this increase (which is still below the minimum living wages for Toronto and Barrie) cost her an election. The policy change did, however, result in tangible improvements in the lives of millions of women who work minimum wage jobs. As such when it comes to housing and homelessness, some policy experts charged that in the face of serious budget constraints, the political will has to be there to commit dollars to housing.

\subsection{Participatory Democracy, Diversity and Inclusion}

Gender-based intersectional analysis is concerned with power dynamics underpinning the policy processes. It calls for the participation of women and racialized groups at planning tables and decision-making bodies informing housing and homelessness policy. The underlying belief is that diversity and inclusion in public policy can engender various talents and ways of knowing thereby encouraging positive change. Yet emerging data revealed that women are grossly underrepresented in decision-making processes, particularly at policy level. For example, all public administrators I interviewed for this study, at municipal and county level, responsible for policy formulation related to housing and homelessness, were male while frontline workers were predominantly women. The under representation of women in positions of authority, in this study point to a system rigged against women. Hence, although predominantly male public administrators somewhat understood factors influencing women's experiences with hidden homelessness, some were hesitant to speak of women's issues, noting that they did not have women's lived experience. In addition, while others acknowledged risk factors associated with lack of social housing, long wait times and the underfunding of affordable housing, not much emphasis was placed on systemic factors and how they render women powerless and vulnerable to experiences of hidden

\footnotetext{
42 https://twitter.com/kathleen_wynne/status/973605892192161794?lang=en - Former Premier Wynne believed raising "minimum wage was the right thing to do."
} 
homelessness. In fact, emphasis was placed on individual and interpersonal risk factors associated with lack of education, being single and having children, domestic violence, relationship breakdown, divorce and separation, and lack of family supports. Nonetheless, giving women a voice begins with hiring practices that seek to create an environment of diversity, at higher levels of authority and extends to a culture of ongoing practices of inclusiveness and openness to new ideas from diverse groups of people, regardless of their gender, race, ethnicity or sexual orientation.

Although Emily, a housing advocate revealed that "the City of Toronto is just at the very beginning of implementing grass-root types of models," to address women's housing concerns. She was however quick to add that the extent to which these models are bottom-up, is still in question. She argued for the urgent need to ensure that there is broad representation from people with lived experience and that the policy agenda is not driven by the city. She further suggested that in the absence of participatory democracy, policy-makers may fail to consider the full range of solutions thereby designing programs that do not work for everybody. Moreover, Emily pointed out that in the absence of strong grass-root mechanisms, public administrators may fall into the trap of having "a pre-determined policy agenda, and the perpetuation of the status quo influenced by very powerful actors with very powerful economic interests, who have quite a bit of access to policymakers and decision makers and have a very strong input in the policy." (Emily, Housing Advocate, Toronto). As such, the recent move towards IH requires an assessment of its perceived impact on women.

Giving women a voice ends with a woman friendly state in which participatory democracy is used to empower disadvantaged women to take charge of their lives in addressing issues of concern. However, although policy-makers identified grassroots organizations that advocate for vulnerable women experiencing homelessness, the invisibility of women experiencing hidden 
homelessness presented a challenge for active participation of women experiencing hidden

homeless. For example, Mayor Lehman suggested that whereas:

The Simcoe Alliance to End Homelessness (SCATEH) ...the Poverty Reduction Taskforce, and the women and children's shelter are very much aware of some of the issues regarding single moms and the cost of childcare, wage gap, and so forth I don't think there is community engagement round table involving women, specifically on that issue of hidden homelessness (Mayor J. Lehman, personal communication, Barrie, November 7, 2017)

Moreover, although policy-makers in Simcoe County and Barrie indicated that there are women with lived experience of poverty, who are actively engaged in addressing issues of poverty in the County, they were not aware of an organized group, community engagements, or policy planning tables involving women with lived experiences of hidden homelessness.

In articulating the invisibility of women and lack of participatory democracy in Toronto, David, the Director of Housing, Dixon Hall Neighbourhood put forward that those who work in the homeless community are already stretched with the people who are visibly homeless and often do not have the capacity to reach out to women experiencing hidden homelessness "because it's a difficult population to access". However, he pointed out that, there are excellent organization like Sistering, Fred Victor, and Violence Against Women (VAW) Shelters, who focus on women and homelessness"

As well, a couple of community stakeholders such as Redhood Community Parks in Barrie and Habitat for Humanity in Toronto, talked about involving women in coming up with solutions to their problems. For example, Habitat for Humanity works with women who qualify for homeownership program by allowing them to volunteer a minimum of 500 hours of community services as down payment for their homes. Women who were actively involved as volunteers in the building of habitat for humanity community homes in Scarborough found it "empowering and 
gratifying to give back" and help other families in need ${ }^{43}$. Likewise Redwood Community Parks consult women in their United House transitional home, on matters of interest to come up with mutually satisfying solutions to their housing problems.

However, emerging data revealed that overall, the IH is a top-down approach and is gender neutral. Lack of a gendered lens in the designing of IH policy may lead some to question the sincerity of policy-makers in addressing women's concerns. Better still, the "top-down” approach of the IH policy, is a reflection of hegemonic patriarchal attitudes that drive the policy processes. Policy makers and homelessness advocates in this study agreed that feminist driven policies can only come from leadership from grassroots communities. Public administrators revealed that there were widespread consultations that went into the National Housing Strategy. They revealed that women experiencing homelessness as well as organizations that work with women were involved in those discussions. It is not surprising that all policy-makers in this study welcomed the reintroduction the National Housing Strategy with a gendered lens.

It has been argued that good practices in gender main streaming requires clear documentation of strategies in which gender-equality concerns are being made central to policymaking, legislation, planning, implementation, monitoring, allocation of resources and evaluation of programmes (EIGE, 2013). Yet there was no denying that existing housing policies, including the IH policy, have not embraced a gendered lens. Sean, a policy-maker from Toronto confirmed this gap, and pointed out that:

Up until the recent re-introduction of the National Housing Strategy by the federal government, in November 2017, where they took a genderbased lens to describe how women are disadvantaged economically compared to men, and the conditions that women find themselves with children and also with victims of violence and sexual human trafficking, ...women were disadvantaged when it comes to the housing market. (Sean, Toronto, personal communication, November 23, 2017).

\footnotetext{
${ }^{43}$ (http://www.theforecaster.net/in-scarborough-habitat-for-humanity-builds-a-community-of-women/).
} 
In this regard, gender equality concerns should cut across all policies and programmes, in ways that that reflect the goals of gender mainstreaming and lead to action, methods or strategies that increase equality between women and men.

\subsection{The Re-gendering of Homelessness: Gender-based National Housing Strategy}

Notwithstanding the diversity of ideas, policies, programs and strategies mentioned in this study, policy-makers strongly believed that perhaps the most important element to ending hidden homelessness among women is having a more robust approach that focuses on capital investments in affordable housing. Moreover, the need to move away from gender-neutral policies to policies that address the gender gap resulting from the feminization and racialization of hidden homelessness; inadequate housing and income supports, the under representation of women in positions of power, gender-income disparities, intimate partner violence, human trafficking, childrearing and racism and other forms of discrimination and violence against women.

Policy-makers in this study suggested that the newly introduced National Housing Strategy (2017) had many components that respond to human rights and the needs of women. Specifically Sean, the Director of Housing, City of Toronto, applauded the terms of "recogniz[ing] the right to adequate housing, the creation of an oversight mechanism, such as the Housing Advocate, the Advisory Council and the mix of different types of interventions that it proposes." Danielle, a housing worker in Barrie, was also "heartened by the National Housing Strategy's introduction of the portable housing benefits" which allow housing benefits to be attached to a person rather than a unit. In addition, Mayor Lehman applauded the "bold move" by the current government in the reintroduction of an enhanced NHS, noting that for the first time since the devolution of affordable housing to lower levels of government in the 1980 s, "the federal government is proposing to invest significant amounts, ... up to 40 billion dollars, to housing initiatives and housing benefits that 
target those most in need."

Whereas the first step in addressing the issue of homelessness and the prevailing housing crisis was the release of the National Housing Strategy2017 as a framework that views housing as a fundamental human right and acknowledges that women, aboriginal peoples, visible minorities, new immigrants, and other vulnerable groups are disproportionately affected by lack of affordable housing. The second vital step was to allocate more moneys to improving the current affordable housing stock in provinces and territories. Mayor Lehman advised that the federal government pledged 40 billion dollars over the next 10 years, to go towards various affordable housing initiatives throughout Canada.

The third and equally important step was the call for strong, collaborative partnerships with provinces, municipalities, non-government organizations and the private sector in addressing the housing crisis. Hence the NHS supports IZ programs through a $\$ 15.9$ billion co-investment fund consisting of $\$ 4.7$ billion in financial incentives, and $\$ 11.2$ billion in low-interest loans, all meant to attract partnerships from the province, municipalities, NGOs, co-operatives and the private sector, to focus on new construction of affordable housing and preservation or renewal of existing affordable housing stock (Ontario Government, 2018). Provinces and municipalities are expected to contribute towards the co-investment initiative by providing land to private developers and NGOs such as Habitat for Humanity, Redwood Community Park and Diamond and Corp, to build more affordable homeownership and rental options across Canada.

Beyond non-monetary contributions, the success of the NHS further hinges on a 20.5 billion cost-sharing initiative between the federal government and provinces/territories (Ontario Government, 2018). According to Mayor Lehman, about $\$ 9$ billion $^{44}$ of the $\$ 20.5$ billion federal

\footnotetext{
${ }^{44}$ Also refer to page 16 of the National Housing Strategy policy document https://www.placetocallhome.ca/pdfs/Canada-National-HousingStrategy.pdf
} 
support to provinces and territories was expected to come from provinces and territories. However, despite the announcement by the NHS in November, 201745, it was not until April, 2018, that Ontario and all regions except Quebec, came out and agreed to match about \$7.7 billion in planned spending on affordable housing through to 2028 (Global News, 2018; Toronto Star, 2018).

Despite the visible excitement in welcoming the NHS as an essential piece to ending homelessness at a large scale, lower level policy-makers in this study cautioned that the successful implementation of the NHS will depend on how much the provincial, and territorial governments, will partner with the federal government in delivering this strategy. They pointed out that the speed at which the provincial and territorial governments were able to come to a conclusion and negotiate something that they can deliver together with the federal government was yet to be seen. In fact notwithstanding the growing housing crisis in the province in general and particularly in Toronto and Barrie, a Senior Policy Maker at The County of Simcoe believed the cost-sharing initiative will only "came together in 2018 and will be in full delivery mode in 2019."

\subsection{Collaboration and Partnership}

In a politically charged multi-tier government system, co-operation and collaboration between the different levels of government, not rationality, drives the policy process. As such, some called for the federal government to be of the view that housing is a shared responsibility and actively consult with the right stakeholders in agenda setting and drafting of the housing policy.

Mayor Lehman went as far as to suggest that:

There is no way around it, political will is where it starts and in some cases where it ends. Without the political will, the national housing strategy is unlikely to succeed because you really need the will to follow through. (Mayor Lehman, Barrie, Novermber, 7, 2017)

\footnotetext{
${ }^{45}$ https://globalnews.ca/video/3875651/justin-trudeau-announces-national-housing-strategy
} 
In view of the above, Sean, a Director of Housing, City of Toronto, suggested that the federal and provincial governments hold the keys in making those partnerships on built-forms happen, by managing their budgets and target[ing] their investments on social housing. Mayor Lehman, agreed and further suggested that even if it means "taking pools of money from somewhere and funnelling it through affordable housing, it needs to be done." He however cautioned that "it takes political will, co-operation and collaboration between the federal and provincial government, for it to happen.

Whereas previous administrations failed to acknowledge these important partnerships, and shared responsibility, policy-makers and stakeholders acknowledge that the current NHS was born out of wide consultations with various constituencies. Mayor Lehman pointed out that the "Federal Minister Jean-Yves Duclos, is a very, very smart man, he has done a lot of consultations and he recognizes that $\mathrm{CMHC}$ is a major player" on the Canadian housing landscape and that "CHMC was a major reason why so much social housing got built in the 1960s and 70s and the major reason why it didn't in the 1980 and 90s and he concluded that, we have to get back into the game". A Manager from Habitat for Humanity agreed with Mayor Lehman, and reiterated, that having the right stakeholders in the development of housing policy and making sure that we are heard on the table will help to establish a successful housing strategy. He went on to reveal that Habitat for Humanity Canada, was actively involved at the planning tables for a lot of these discussions, and has worked closely with CMHC.

Beyond co-operation and collaboration between two upper levels of governments, the successful implementation of the National Housing strategy is closely connected to the degree in which lower level bureaucrats and community stakeholders are willing to buy into federal and provincial vision in implementing programs and strategies as laid out by higher level bureaucrats, 
within their communities. According to middle level bureaucrats at the County of Simcoe, municipalities, as the service managers, need to be in it all the way. Sean agreed, noting that because housing is a local issue, all the decisions relay on local delivery and municipalities will take some time to work through and discover what the issues, priorities, and selections are, and how they want to implement, policies and programs, that meet the local needs of their communities.

\subsection{The Critical Feminist Policy Analysis and Participatory Democracy}

Although the gender-based analysis argues that the onus is on policy-makers to come up with policies that work for both women and men, the top-down approach of the IH policy, goes against the major tenets of a democratic society and was critiqued by women and female stakeholders. Emily, a policy expert and housing advocate cautioned against this top-down approach noting that, when so much power is vested on a small group of people, with no lived experiences of homelessness, to make all the decisions, the possibility of coming up with policies that do not work for the majority of people is high. Particularly women experiencing hidden homelessness felt unheard by their mayors and politicians and they believed the current housing policies were unresponsive to their needs. Frontline workers also alluded to similar sentiments, and

Danielle, a frontline worker working with women, noted that:

We need to get the powers that be involved, let's be honest, we can talk about the need for affordable housing forever, but we need to actually create affordable housing by engaging our policy creators, landlords and property managers, so that there isn't this big divide between the affordable housing and the living condition of affordable housing. Those that are paying the big bucks get the nice places and those that don't have money, don't get. ...speaking of our mayor, I know he wants to create affordable housing here in Barrie. He is on social media, he is on Facebook. He is saying, he wants affordable housing, but does he really know the challenges that women are facing? Does he really know the units that women are able to afford right now? Does he really know what the condition of those units are? Has he walked through those units? Has he sat down with the woman and heard their stories, like 'I had bugs, they came in when I moved in and here is what I had to go through?' We need more conversation ... more interaction, to have our voices heard. ....I think to keep providing the mayor with grassroots information 
so that he knows what women are experiencing is important (emphasis added).

(Danielle, Barrie, personal communication, November 9, 2017)

The need for participatory democracy was echoed by private developers, policy makers and frontline workers, working to end gendered homelessness. For example, Laurie, a private developer in Toronto, pointed out that although the municipalities, provincial and federal governments, recognize and acknowledge that there is a housing problem and were doing something to address it, the answer has not yet been found. As such, according to Laurie, it is important that all stakeholders contribute to resolve the housing problem. In fact, others pointed out that beyond opening up space in the policy-making process for participatory democracy, community stakeholders should be held accountable in creating a thriving and healthy housing market (Danielle, November 9, 2017; Rhonda, November 10, 2017). Hence, Mayor Lehman suggested the importance of community engagement at the local level, and the need to work toward developing and strengthening partnerships with non-profit organizations and private companies.

\subsection{Broadening Responsibility for Housing}

The need to broaden the responsibility for housing and homelessness to encompass, not only the public sector, but also the private sector and third-sector, was echoed by both policymakers and stakeholders in this study. Participants in this study alluded that the housing system should be viewed as an equal system in which the needs of all individuals who live in our cities are addressed, including the complex needs of women, who may also be single parents, low-income earners, racialized, immigrants, and refugees. As such, David, a representative from Dixon Neighbourhood, pointed out that, "landlords, private developers, not-for-profit organizations and Daisy organizations, all have a responsibility" and role to play to end homelessness and address the complex needs of these groups. He went on to reveal that churches tend to be very large land owners in the City of Toronto and therefore, they can help by selling their land to developers at a 
discounted rate and they have some capacity to demand and request that housing built on those lands be affordable and deeply affordable.

Furthermore, given that adequate housing is a basic human right, Danielle, a housing worker in Barrie suggested that "landlords have the responsibility of maintaining their properties in an effective, respectful and dignified way." It is not surprising that some advocacy groups such as Simcoe County Alliance to End Homelessness (SCATEH) have resorted to consciousness raising regarding the role landlords can play in providing adequate housing to women. Danielle, revealed that "engaging landlords, and ...informing them of the needs and experiences of women, creating education and awareness forums or panels, where landlords and women can interact, so that there is that sharing of information, is one of the things we do regularly at SCATEH." She also revealed that both landlords and women "want the same thing," a mutually beneficial relationship. Whereas "women want to live in an environment that is safe and affordable, and have pride in their space to raise their children, landlords want to have pride in ownership, they purchased the building and they just want the rent paid.” As such, engaging in participatory democracy and opening up conversation around "those two commonalities," can create a "win-win situation." In these forums, women are able to address some of the issues raised in this study, while landlords may also share their concerns?

Moreover, Danielle, a housing worker working with women in Barrie, called upon "the third sector, which is the not-for-profit sector," to "make sure that ...the supports exists to help women maintain their housing," noting that, "transitional housing, and supportive and supported housing, is critically important as well. Similar sentiments were echoed by policy-makers in Toronto and Barrie who reaffirmed the need for strengthening partnerships between the public and private sector. In particular, Sean, the Director of Housing, City of Toronto, noted that "there is no social housing that's been built in Toronto or across the country that does not involve the private sector." 
The introduction of IZ strategies is by far drawing private sector's attention to the housing problems in Toronto and Barrie. However, whereas private developers, believed the IZ policy is "a tool that can have some positive benefits if it's applied right," other stakeholders particularly front line workers believed that "there needs to be a greater expectation and pressure on the private sector to build, deeply affordable housing." For example, David, a Toronto stakeholder with Dixon Hall Neighbourhood Community pointed out that because:

Homelessness is a problem we all share and it affects all of us, ...the private sector needs to be held accountable and we need to be demanding that the private sector build affordable units to meet the need of a growing number of people who are homeless and the growing number of people who can no longer afford to live in our City. (David, Toronto, December 10, 2017)

Yet, despite the call for more IZ initiatives, the issue of "who owns the house after it's been build" requires attention. Whereas the IH policy is vague about who owns and control the housing when it is completed, most policy-makers suggested that we should be building more housing that is owned and controlled by the non-profit sector, even though those houses will be built by the private sector.

Rhonda, a private in Barrie, believed that "that homelessness is not the problem, it's a symptom of a deeper problem." She revealed that "often there are other issues attached to homelessness and unless there is a stable housing as a base, as in Maslow's hierarchy," other levels of needs such as safety, security and self-actualization, becomes unattainable. Consequently, Rhonda suggested that beyond affordability, there is need to provide "safety, hope and some community" support. David, a housing Director with Dixon Neighbourhood Toronto, agreed with Rhonda and asserted that "those of us who work in the homeless sector could do a better job of making more units available for women, that are safe", further noting that "some projects ...have been built here, one of them in Richmond Street and Church Streets, for people, primarily women 
who work in hospitality industry".

\subsection{Smart Planning:}

One of the most profound suggestions from policy-makers, stakeholders and women was the call for smart planning. Smart Planning involves being proactive rather than reactive when it comes to housing policies and strategies. It was clear that preventing homelessness before it happens speaks to addressing issues of social justice and pushing for women friendly policies that reduce the affordability burden on women. Working towards narrowing the gender income gap through more equitable labour laws that provide women with a living wage and adequate incomes supports is a more effective response to easing housing affordability burden among women, than setting up rent banks, furniture banks and food banks. As well driving housing policies that seek to increase affordable housing stock, reduce wait-times, provide adequate housing supports and assist with childcare costs, align with the values of a women-friendly state.

IZ strategy as it relates to new developments provides innovative ways that ensure affordable housing is not viewed as an after-thought, but rather as an important piece throughout city planning. It puts to rest arguments that slow down or hinder the development of high density developments in communities who resist IZ strategies based on not-in-my-backyard-arguments. Mayor Lehman noted that "it's always easier to do it right from the beginning ...than trying to retrofit it into an area where it has never been there". As such in the development approval process, smart planning requires new innovative built-forms that effectively utilize space. Policy-makers from both Barrie and Toronto, spoke of density bonusing that allow more units in less in space, such as high rise apartments and condos, back-to-back/stacked townhomes, second suites basement apartments, laneway homes, granny flats.

Beyond affordability of housing, smart planning considers the quality and appropriateness 
of housing. In addition, adequate housing is attached to other community services needed to ensure that women remain housed, such as, access to subsidy, first and last month rent, start-up grant, therapeutic relationships and systems navigation. Moreover, smart planning provides vulnerable people with "hope and choice."

As well, rather than situating housing within the private sector, non-profit organizations have a role to play in providing adequate, long term affordable housing to the people of Toronto and Barrie. Sean pointed out that social housing is "built on the wonderful legacy of hundreds of thousands of existing social housing stock and we need to grow it, and as the housing stock grows, so should social housing." The growth of social housing has to meet contemporary requirements of mixed communities rather than segregated communities, hence the intensification programs through IZ strategies and revitalization projects. Finding a happy medium can be helpful in growing the IZ strategies. Developers submitted that they would want to contribute towards a healthy housing market but called on municipalities to be fair and reasonable, and avoid writing off development cost. Municipalities are aware that partnership and collaboration is key to a successful housing strategy and whereas they are willing to offer tax credits and fee aversion to lower development fees, they need a clear direction and mandate from the provinces to effectively implement the new IZ policy.

The call for a big society, where everyone contributes, was inevitable, given ongoing clawbacks on capital investments in affordable housing. Yet the politics and dynamics within a big society often results in various implementation gaps and unintended consequences. Nonetheless participatory democracy is key in addressing the issue of hidden homelessness. Allowing the voices of all players to be heard at the planning table can lead to successful housing strategies. This can be attained through lasting partnerships and collaborative relationships formed through commonalities, between various levels of government, the public sector, private sector and third 
sector, the landlord and the tenant, public administrators and community stakeholders, frontline workers, advocacy groups and women with lived experiences of hidden homelessness. Opening up channels of communication and allowing women to have a voice is perhaps one of the most important factor in ending gender based hidden homelessness. Particularly engaging women with lived experiences in planning issues of concern and opening up space for women to hold positions of power, can contribute to smart planning, when it comes to hidden homelessness.

\subsection{Towards a New Social Housing Agenda}

Emerging data from this study pointed to the rebirth of a new innovative social housing agenda that addresses contemporary issues, such as gendered hidden homelessness. The need to be innovative and find cheap ways to turn underutilized space in people's homes and in old buildings and turn it into affordable housing was echoed by both private developers and policy-makers. Yet this plays into neoliberal tenets where provision of affordable housing is pushed from the public domain to the private domain. The marketization of housing was primed with flowery language driven by neoliberal views. The notion that rather than reinvent the wheel, let's partner with the private sector and NGOs already on the ground, to create affordable housing and avoid duplication of services, should be taken with a grain of salt. David, whose organization is on the frontline in Toronto, revealed that despite these partnerships, there are still "challenges around the availability and the physical form of social housing..." In the meantime, women situated within the market were struggling to make ends meet and were living in houses that need repair, while at the mercy of slumlords and abusive roommates.

Whereas higher levels of government are not directly involved in the planning and implementation of housing programs, low-level bureaucrats believe the Federal government and the province are key players in "influencing housing programs" and supporting local governments through huge capital investments. Mayor Lehman, pointed out that the participation of higher levels 
of government is crucial, noting that when it comes to affordable housing, municipalities are "stuck between a rock and a hard place." Whereas they are not being supported enough, they still have to live up with their constituency’s expectations.

Despite prevailing challenges, for some there was hope that the National housing strategy will translate to some cleaning up of existing social housing that we have and make sure that they are back in shape. For others, there is hope that the National Housing strategy will bring to reality ideas to deliver more affordable housing and help people to become, either homeowners or sustainable renters. According to Sean, the Director of Housing Toronto, the new NHS has the potential to rebuild the capacity of the social housing stock especially "if we can drive it through, the non-profit sector builds" and because it focuses on new models of social housing that are more permanent, sustainable and innovative, compared to the old social housing concept. The drive to expand and renovate existing social housing, and utilize existing government owned land to create both mixed income communities, expand the choice of housing affordability for low-income families, and discourage segregated communities, is commendable. This approach mirrors the British concept of council housing, which thrives on creating mixed income social housing. The only difference is that affordable units produced here will be managed by non-profit organizations, co-operatives and at times developers own and rent the units directly.

Needless to say, the NHS has the potential to provide a sustainable flow of affordable housing stock and unlike IZ practices, Emily, a housing advocate in Toronto, argued that when it comes to the NHS "we all know that it's going to be there for 75 years as opposed to 20 years, because the non-profit will be there forever. The Market can walk away after 25 years."

The following chapter is the concluding chapter and it provides an overview of findings from this study as it relates to previous and future studies. It also discusses the limitations and delineations of the study. 


\section{CHAPTER 11}

\section{Conclusion and Further Studies}

The IZ strategy is ...only one of the tools in the toolkit [but] it's not a panacea or a full solution to the housing crisis that the city is facing, and keeping in mind that the IZ initiative does not develop deeply affordable homes, other income support programs and ...initiatives would be needed to compliment IZ if it was to be targeted to lowincome households."

(S. Gadon, Director of Housing, City of Toronto, personal communication,

November 23, 2017)

\subsection{Overview of Findings}

Data from participants has revealed that hidden homelessness among low to middle-income women in Toronto and Barrie is more prevalent than normally reported. Policy-makers admitted that current indicators are not looking good, with Toronto viewed as the second and Barrie third most expensive places to buy or rent a house in Canada. All participants conceded that the affordability burden disproportionately affects women due to gender income gap and the systemic targeting and disqualification of women from accessing social housing and government income supports. Women in this study were mostly situated within the private market and were struggling to pay the high market rentals. Policy-makers raised various market pressures and suggested that the high demand for affordable housing, coupled with a low supply of housing, has resulted in the “sky-rocketing prices" of housing, further exacerbating women's experiences with hidden homelessness.

In addition, policy-makers in this study went into great pains in trying to explain poor responses to the problem of hidden homelessness in Toronto and Barrie. They suggested that 
hidden homelessness, particularly among women is fueled by "a mix of everything." 46 It begins with individual factors related to related to family breakdown, lack of education, mental health and addiction problems, and extends to structural factors, particularly the devolution of housing to lower levels of government resulting in claw-backs and underfunding of public housing, the impact of migration, strict mortgage rules, market pressures, 2008/2009 recession, and developers stalling the construction of housing and/or opting to build expensive condos.

Notwithstanding the fact that the risk factors presented here are multi-faceted, from the personal to the systemic, yet what was most revealing in this study are the systems of domination that render women powerless. For example, it was obvious that although the need to respond to housing and food insecurity was acknowledged, translating issues of concern into action was less visible and rather blurry and, points to deeper underlying problems in the policy-making process. First, poor conceptualization of the problem of hidden homelessness, coupled with the invisibility of women experiencing hidden homelessness, resulted in poor responses to this problem. It has been argued that "if problems are poorly understood, goals are ambiguous and if decision makers have other things in mind," important issues may not be attended to (Cairney, 2012, p.234).

Second, whereas the move towards the IH policy was more evident with the introduction of Bill 7, slow implementation process, challenges in negotiating a happy medium with developers and lack of political will to end the problem of hidden homelessness, particularly from higher levels of government, dampens the impact of IH strategies. In addition, although policy-makers may want to address all issues of concern, yet "problem overload" and time constraints, coupled with limited resources and limited information, regarding hidden homeless, resulted in policy stagnation and

\footnotetext{
${ }^{46}$ See appendix K: Factors influencing women's experiences with hidden homeless (in participants' own words), p.256.
} 219 
watered down policies (Zahariadis, 2003 p.714). For example, whereas the IH policy is a new policy, its impact was said to be minimal and appeared to only "satifice"47 (Simon 1956).

Third, in attempting to push for policy change, policy-makers in this study utilized feedback from previous programs in Canada and elsewhere, to highlight "what works and what may not have worked" (Zahariadis 2014 p.816-17). When it comes to housing and homelessness, most policies from the past still existed with minor incremental changes (Lindblom, 1959). Nonetheless, policymakers where particularly interested in the NHS. In fact, the mayor of Barrie and the Director of Housing, Toronto, suggested that the National Housing Strategy and active participation of the federal government and CMHC, "was the reason why lots of housing was built in the 1960s and 70s, and it was also the reason why limited public housing was built in the 1980s when it was withdrawn." They were encouraged that the federal government had finally realized that they needed to "get back into the game," hence the introduction of the NHS with a gendered lens.

As well, in pushing for policy change, policy-makers in this study confirmed previous evidence that has shown that policy-makers in the 21 st century, have continued to use "focusing events and election cycles" (Kingdon,1995; Birkland,1997; 2004; 2006) to draw attention to “problematic conditions" (Zahariadis, 2014 p.g 707). For example, Mayor Lehman pointed out that after receiving a bad review by the Toronto Star as one of the worst offenders in "anti-affordable housing policies," the city moved to loosen up its by-laws to allow secondary suites and higher density in new developments. Furthermore, following a report in the media showing Barrie as having the second-highest rent in Ontario, after Toronto, the Barrie MPP, Ann Hoggarth, announced that the province of "Ontario was providing "over $\$ 1.5$ million to provide development charge rebates to developers who want to build affordable housing units in the city" (Global News,

\footnotetext{
47 Satifice is a term coined by Herbert A. Simon in 1956, to explain the behavior of decision makers under circumstances in which an optimal solution cannot be achieved. He expounded the notion of satificing in his book Administrative Behaviour, in 1947, to describe how public administrators pursue a course of action that will satisfy the minimum requirements necessary to achieve a particular goal.
} 
2018). However, whereas the province's one-time funding will go a long way in boosting Barrie's rental housing market, what was lacking was a commitment to ongoing capital investment in affordable housing, from the province and federal government.

In recent years, a shift in the housing policy was a result of new government and new leadership both at federal and provincial levels. Policy-makers appeared hopeful with the reintroduction of the National Housing Strategy by the Liberal Government of Justin Trudeau government, which has taken a gendered lens. Yet there are various complexities in the implementation of such a program in the contemporary housing market that need to be explored by future studies. In particular, the logistics of the cost sharing initiatives, given that it is not mandatory, some provinces and territories may choose to opt out.

Problematic conditions and focusing events often draw extensive media attention, which the public, politicians and policy-makers cannot ignore. The City of Toronto has not lived up to its commitment of "building 1,000 new units of affordable housing annually between 2010 and 2020" (Toronto Foundation, 2015 p.118) due to budgetary constraints (Toronto Foundation, 2015, p.50). This study revealed that the City of Toronto and Barrie appear to be grappling with trying to choose a policy option that works. Given that policy-makers are limited by resources and budget constraint, sharing the cost with the private market was considered desirable as it would ease the affordability burden on municipalities. However, although there is growing evidence that the $\mathrm{IH}$ policy is by far one of the most innovative and viable way in bridging the old and the new policy processes together. It also is ideal in encouraging partnerships and collaboration between the public and private sectors in the provision of affordable housing, in a wide range of contexts (Buitelaar, Needham and De Kam. 2014; Mah 2009; Morrison, 2014). Evidence from this study revealed that the perceived effect of this policy in adding affordable housing stock is very minimal. In these agreements, the developers become "an important source of private funding for affordable housing 
and local infrastructure provision" (Morrison, 2014 p. 426). Evidence from this study revealed the complexities of trying to find a happy medium through incentives and trade-offs" particularly given that private developers are in the business of making profit, not so much in solving social problems. Moreover, unlike in previous studies where IZ practices where yet to be legislated (Mah, 2000), policy-makers in this study revealed that the IZ strategy had been passed by the province but municipalities were still waiting specific directions and guidelines from the province, on how to effectively implement this policy.

Fourth, although future clarification and guidelines by the province could be helpful in reducing this uncertainty in the implementation process, the question of who owns the units when completed, could still remain contestable. Some policy-makers alluded that IH units should be given to the third sector, mainly the co-ops, community housing or other NGOs such as Habitat for Humanity and Dixon Hall Neighbourhoods. Others were of the mind that private developers can still run and maintain the units for the period of 20 to 25 years. However, the question of what happens after the 25 years, cast a shadow on the sustainability of IZ practices.

It is therefore, not surprising that participants in this study concluded that IZ should not considered as a full solution to the housing problem, but rather as one tool in the tool kit, that can be used to address housing problems. They proposed a multi-dimensional, more integrative approach that addresses the diverse needs of women. This aligns with past literature that puts forward the notion that, policy responses that address a wide range of housing needs, are more effective and more acceptable tools in city planning and development (Crook and Monk 2011).

\subsection{An Integrative Approach to Housing}

Ending hidden homelessness among women requires a multi dimensional approach, with several tools. Participants in this study suggested that unless we develop a strong political will to end homelessness and shift the way we view homelessness, particularly among women, 
ending hidden homelessness can be a challenge. Below is a summary of responses from participants in attempting to answer the question: In your own opinion what will it take to establish a successful housing strategy in Canada?

a) Engaging all members of the community in addressing the housing problem

a. Working collaboratively, creating partnership with shared responsibilities.

b. Community engagement with everybody contributing their fair share.

c. Finding a happy medium and being realistic about what the goals are.

b) Having a "strong political will" to end homelessness

a. Investing heavily in new and pre-existing affordable housing to help reduce the long wait-time for affordable housing.

b. Producing a broad range of deeply affordable housing, that includes market-based low-interest homeownership and affordable rental, as well as non-market-based housing such as social housing, co-op housing, subsidized housing, supportive housing, transitional housing and tiny home communities.

c. Adequately funding programs and measures to prevent homelessness before it starts, reduce homelessness and help individuals and families keep their homes.

\section{c) Smart planning:}

a. Tackling housing problems on a broader scale, by mandating affordable housing in all new developments.

b. Maintaining of existing stork and providing rent supplement programs

c. Providing permanent, safe, adequate, suitable and affordable housing with wraparound services which may include community support, fully furnished tiny homes, subsidized daycare and other housing and income supports.

d. Protecting women from intimate partner violence, abusive male roommates and slumlords by developing women friendly policies that enables women to become independent, for example, loosening up the eligibility criteria for social housing, childcare and other income supports.

e. Reducing food insecurity by making housing more affordable and introducing effective rent control system.

\section{d) Shifting co-values and attitudes regarding homelessness and housing}

a. Seeing people who are inadequately housed as people.

b. Listening to low-income women and treating women experiencing hidden homelessness as their own mothers or sisters.

c. Giving low-income women hope and safety and security by viewing housing as a base upon which women are able to re-build their lives.

d. Shifting attitudes and changing laws insisting on larger housing, and opening up to the possibility of living smaller as resources and affordability get scarce.

As well, findings from this study indicated that unless a commitment is made in trying to understand women's experiences with homelessness and re-define hidden homelessness in 
ways that encapsulate those experiences, the health and wellbeing of women will remain at high-risk. As such, in light of women's experiences in this study, and with a deep appreciation that how we frame a problem determines how we respond to it, another important aspect which may be helpful in effectively tackling the issue of hidden homelessness among women is:

\section{e) Broadening the current definition of hidden homelessness to include}

a. Those forced to live with abusive partners, abusive friends and abusive relatives to avoid absolute homelessness.

b. Those who are forced to return to abusive relationships due to lack of affordable housing.

c. Those earning $\$ 60,000$ or less and spending more than $30 \%$ of their income on housing costs and unable to meet other basic needs like food and clothing.

d. Those who are marginally housed in unsafe, substandard dwellings that require major service and are exposed to bug infestation, weather elements, mould and constant crimes related to guns, drugs and burglary.

e. Those who are unable to access safe, adequate and suitable housing due to discriminatory tendencies from landlords or community housing workers, based on gender, race, ethnicity, immigrant status, sexuality and age, from landlords or community housing workers.

\subsection{Challenges and Future Studies}

The greatest challenge I faced in trying to make sense of the IH policy as it relates to women was that the IH policy is a fairly new policy that had passed legislature but local administrators did not have concrete tools as to how it should be implemented. As well, the effect of IZ practices may have been over shadowed by the concurrent announcement of the National Housing Strategy 2017 during the interview period. Policy-makers become more inclined to talk about the all-encompassing NHS than they were to talk about the IH policy.

Given the slow implementation process for IZ strategies, future studies could revisit the impact assessment of IZ policy following its full implementation, presumably by 2021, according to some policy-makers. As well, future studies could examine the extent to which the recently introduced gender-based NHS is in fact meeting the needs of women and other vulnerable groups, as laid out in its policy documents, and presupposed by policy-makers. 


\subsection{Limitations and Delimitations}

As you may recall, this study sought to explore the issue of gendered hidden homelessness in Toronto and Barrie, by situating women's experiences with homelessness, within the context of a neoliberal driven IH policy. However, it should be noted that whereas the case study approach allows for a rich, thick description and analysis of the phenomenon of hidden homelessness, a detailed account is beyond the scope of this study, given the time and financial resources required to devote to such an undertaking. Whereas I endeavoured to condense the findings from this study, the need for a grounded analysis, rooted in the lived experiences of real people, resulted in a long version of this study. Moreover, whereas certain critical information may be lost along the way, only important aspects relating the hidden homelessness and the IH policy was included in this report.

In addition, despite using snowball sampling techniques, informants and various referral sources, the response rate for women and policy-makers in Toronto was lower than expected because women experiencing homelessness constitute a hard to reach population and access to experts and bureaucrats is a challenge due to busy schedules and gatekeepers. Furthermore, although comparing multiple cases across geography and participant identities enhances the validity of this study, results from this study cannot be generalized beyond Toronto and Barrie.

Whereas most housing experts spoke candidly about challenges with hidden homelessness in their jurisdictions, some may have endeavoured to protect their careers by justifying their organization's processes and procedures. As a result, data from such sources may be fraught with biases and partialities. Moreover, since this study is feminist driven, some may find it one sided. However, triangulation of multiple data sources enabled me to cross-reference responses across participants and across geographical areas. 
In addition, although some existing studies have shown that hidden homelessness and other forms of homelessness disproportionally affects men (Gaetz et al, 2014; Rodgridgue, 2016), others have argued that woman experiencing hidden homelessness are under researched and their experiences have not been well captured in current definitions of and enumeration of hidden homelessness in Canada (Drabble 2017; National Housing Strategy NHS 2017; Spring \& Klassen; 2015), hence providing the impetus for this study. When we broaden the definition of hidden homelessness to account for people living in permanent housing but with abusive partners, or people who may be paying rent but living in houses they cannot afford, and/or people living in houses that need major repairs to avoid absolute homelessness, women can potentially make up a greater number of those experiencing hidden homelessness. As such permanent accommodations should not be used to imply that women do not wish to leave. Women in this study wanted alternative accommodation and alternative living arrangements but felt stuck. Systemic barriers, particularly the feminization and racialization of poverty, lack of social housing and personal circumstances (e.g. children, safety issues), prevented them from doing so.

Although there is no denying that there are several households in core housing need, with a household income of over $\$ 60,000$, my choice of earnings below $\$ 60,000 /$ annum, was informed by CCAP's livable wage that allows individuals to pay for housing and still obtain a basic standard of living (CCAP, 2015). This boundary enabled me to narrow down the breath of this study, while focusing on the most vulnerable, least visible and often ignored group of people. As well, whereas I could have included the rural Simcoe County in this study, I chose to focus on urban Barrie as it is more comparable to Toronto. 


\subsection{Conclusion}

Although several studies have sought to understand women's experiences with overt forms of homelessness, not much focus has been given to women's experiences with hidden homelessness, particularly in Toronto and Barrie. As a result women experiencing hidden homelessness have remained invisible, and so has their struggles with housing insecurity, violence and poor health outcomes. Using an intersectional gender-based analysis, this study sort to understand women's experiences with hidden homelessness and the policy responses grounded in the neoliberal paradigm.

Findings from this study revealed that, poor conceptualization of hidden homelessness and the absence of gendered statistics on housing and homelessness mask women's experiences with hidden homelessness, resulting in poorly designed policies that fail to meet the needs of women. Moreover, gender neutrality in the formulation and implementation of the IH policy, and a lack of political will to end the problem of homelessness, particularly from higher levels of government, exacerbates women's experiences with hidden homelessness. Therefore, women in this study were forced to live in substandard, overcrowded conditions, some with their abusers, to avoid absolute homelessness.

The current study confirms findings from various feminist scholars, who have connected women's experiences with homelessness to broader systemic issues namely the feminization and racialization of poverty (Drabble, 2017; Klowdawsky, 2015; 2006), the persistence of gender income gap (OECD, 2017), a shrinking welfare state and claw-backs in the area of housing and homelessness (Gaetz at al 2016; OCHFC, 2016; ONPHA 2016; Toronto Foundation 2016). Ultimately, this study argued for the re-defining of hidden homelessness in Canada, to capture women's experiences. It expands on the works of feminist scholars Drabble (2017) and Spring and 
Klassen (2015), as well the Homelessness Hub (n.d), in attempting to add a gendered lens to the definition of hidden homelessness in Canada.

Lastly, this study contributed towards the limited discourse on the inclusionary housing policy in Canada. Although existing literature revealed that $\mathrm{IH}$ policy is proving to be the most viable option in an environment of fiscal restraint (Buitelaar, Needham \& Kam 2014; Mah 2009; Armstrong, A., Been, Meltzer \& Schuetz, 2007), findings from this study reveal that difficulties in negotiating a middle ground, the cost of land, slow legitimation process and bureaucratic hurdles, slow down the effect of inclusionary housing policy in Toronto and Barrie. Consequently, the effect of IZ practices on the Canadian housing landscape was viewed by policy makers and private developers as rather minimal and inconsequential. Policy-makers and some stakeholders in this study argued that the IH has failed to create deeply affordable housing, required to cushion women from experiences of hidden homelessness.

In the end, participants in this study called for a holistic approach to hidden homelessness that encompasses wrap around services, to support women to get housing and remain housed. At the national level, this study revealed that policy-makers are beginning to acknowledge the vulnerability of women to homelessness. The introduction of a NHS that embodies a gendered lens is testament to shifting attitudes regarding gendered homelessness. However, its effect is yet to be discover, as such future studies can focus on evaluating the NHS in light of women's experiences. 


\section{Appendices:}

\section{Appendix A: Recruitment Poster for Women participants}
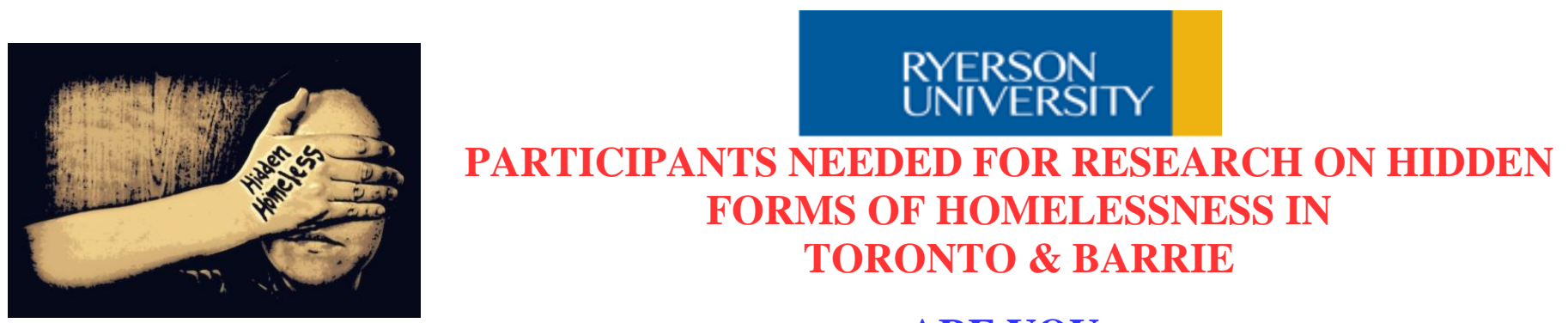

ARE YOU:

1. A single or married woman from any racial or ethnic background?

2. Between the ages of $\mathbf{2 0}$ to $\mathbf{6 5}$, with a total household income of less than $\mathbf{\$ 6 0 , 0 0 0 . 0 0}$ ?

3. Living in Toronto or Barrie?

4. Experiencing (or have you experienced) one of the following housing problems lasting for more than 6 months:-

- spending $30 \%$ or more of your income on rent,

- living in an overcrowded and/or rundown house or apartment, due to housing affordability issues

- doubling up with friends and relatives to avoid being homeless

- staying in an abusive relationship to avoid being homeless

- living in a temporary housing, such as a transitional housing, hospital, rehab centre, with nowhere else to live

o on the waiting list for affordable housing

People who are homeless don't always sleep on the street.

\section{If you answered yes to all four questions above,}

\section{YOU ARE INVITEDTO VOLUNTEER IN A STUDY,}

focusing on women's experiences with under-housing and housing affordability in Toronto and Barrie. Women experiencing hidden forms of homelessness are less visible and often unnoticed at policy level. This study seeks to give voice to this group.

\section{YOU WILL BE ASKED TO:}

participate in interviews regarding your experiences with hidden homelessness in

Toronto or Barrie

\section{YOUR PARTICIPATION WILL INVOLVE:}

one session lasting for a duration of 90 minutes,

during the period of November 1, 2017 to February 28, 2018

IN APPRECIATION FOR YOUR TIME, YOU WILL RECEIVE:

\$20.00 Tim Horton's Gift Card, transit tokens (max \$10.00),

child care reimbursement where applicable with receipt $(\max \$ 50.00)$

If you are interested in participating in this study or for more information please contact:

Rosemary Muzorewa RP, RSW, MSW, PHD Social Policy Candidate at:

e-mail: rmuzorewa@ryerson.ca 


\section{Appendix B: Recruitment Letter to Experts in the Field}

RYERSON

UNIVERSITY

September $16^{\text {th }}, 2017$

Manager, Social Policy and Planning

County of Simcoe County

Administration Centre

1110 Highway 26

Midhurst, Ontario

LOL 1 X0

Dear Sir,

My name is Rosemary Muzorewa and I am a PHD student, at Ryerson University in the Department of Public Policy and Administration. I am contacting you to see if you or your surrogate might be interested in participating in a research study on hidden homelessness.

This research is being done as part of my $\mathrm{PhD}$ project and my supervisor's name is Dr. Melanie Knight. The focus of the research is to explore how the inclusionary housing policy is being used to address the phenomenon of hidden homelessness or under housing among women in Toronto and Barrie.

I have selected you to participate as policy expert (community stakeholder) in the area of housing and homelessness in Barrie, to collaborate with the data that will be collected from women experiencing hidden forms of homelessness in Barrie.

If you agree to volunteer, you or your surrogate will be asked to participate in an interview. Questions that will be asked are related to housing and homelessness policies in general and specifically to inclusionary housing programs and initiatives that seek to address the issue of hidden homelessness among women in your jurisdiction. These questions will be provided in advance via e-mail.

Your participation will involve a single session, lasting for between 45-90 minutes. You can decide on the most suitable time for the interview, preferably at your offices or other public spaces that are private and quiet.

In appreciation of your time, you will receive a \$20.00 Tim Hortons Gift Card.

The research is funded by the primary researcher and has been reviewed and approved by the Ryerson University Research Ethics Board.

Your participation or your surrogate's participation is completely voluntary, and if you or your surrogate choose not to participate, it will not impact your relationship with Ryerson University, if any, or any incentive you may have received in connection to this study. 
If you or your surrogate are interested in further clarification regarding this study, or would like to volunteer, please reply to this letter via e-mail at rmuzorewa@ryerson.ca. You may also reach my supervisor Dr.

Melanie Knight, via e-mail at melanie.knight@ryerson.ca.

Sincerely,

Rosemary Muzorewa RP, RSW, MSW, Phd Student.

Ryerson University 


\section{Appendix C: Informed Consent: Housing Expert/Stakeholder}

\section{RYERSON UNIVERSITY}

\section{Rosemary Muzorewa}

Phd Social Policy Student

Tel: 705-719-7466, Email: rmuzorewa@ryerson.ca

\section{Dear Participant:}

\section{Informed Consent: Housing Experts}

You are being asked to participate in a research study. Before you give your consent to participate, it is important that you read the following information and ask as many questions as necessary to be sure you understand what you will be asked to do. This document describes the research proposal and data collection process, to help you decide if you would like to participate in this project. Please take time to read this handout carefully.

\section{Principal Investigator: Rosemary Muzorewa e-mail: rmuzorewa@ryerson.ca}

\section{Supervisor's Name: Dr. Melanie Knight}

Tel: 416-979-5000, ext. 4191; melanie.knight@ ryerson.ca.

\section{Purpose of the study:}

The purpose of this comparative case study is to discover how the inclusionary housing policy is being used to address the issue of hidden homelessness among women in Toronto and Barrie. This research project is part of the fulfillment for my PhD Social Policy dissertation at Ryerson University in Toronto. Findings from this study will add to the discourse of housing and homelessness as it relates to policies, programs and initiatives targeting low-income women experiencing hidden homelessness. As well, results from this study will be used in publications and conference presentations, related to social policy and women's issues. Dr. Melanie Knight, will supervise this project.

\section{Description of the study:}

You are invited to participate in this study because your input is valuable in shading light on how the inclusionary housing policy (inclusionary zoning), is being used to address the problem of hidden homelessness among women in Toronto and Barrie. During the study, you will be asked open-ended questions to which there is no wrong or right answer. I will endeavor to minimize disruptions to your daily routine therefore; the interviews will be conducted at your most convenient time and place, within a public building such; as in your office or boardroom, a public library, college, university or human service organization in your area. Interviews can also be done via skype or over the phone and will be recorded. The interview process will last for about 45 to 90 minutes.

You will be asked questions regarding your views on housing affordability in Toronto/Barrie and your experiences with the implementation of the inclusionary housing strategy. You have the right to opt out of the study at any time, before or during the study, without any questions or penalty.

These are sample questions that will be asked during the interviews:

- How do you view housing affordability in Toronto (Barrie)?

- How has your organization used the inclusionary zoning to address the issue of hidden homelessness among women, in your area?

- What challenges have you faced in the implementation and maintenance of the inclusionary housing policy? 
- In your opinion, to what extent has the inclusionary housing policy contributed to an increase in affordable housing stock in Toronto (Barrie)?

\section{Incentives to participants:}

You will receive an honorarium in the form of a \$20.00 Tim Horton's gift card, for your participation in the interview. Please note that, this study is funded by the primary researcher and any incentives you may receive, pertaining to this study, will not be affected by your decision to withdraw from the study, at any given time.

\section{Risks or discomforts:}

There are few risks involved with this research. Whereas I will make an effort to minimize emotional or psychological discomfort to you, by confining the research questions to your experiences with housing and homelessness in Toronto/Barrie, I would like to note however, that:-

a. You may be asked to give honest responses to open ended-interview questions that may make you feel uncomfortable because of the personal nature of the questions.

b. You may be asked to evaluate government or organizational policies and programs thereby risking reprisal or sanctions from your employer.

c. You may be exposed to a degree of psychological, emotional and physical discomfort, having to narrate or re-live your experiences with hidden homelessness.

I will hold a short debriefing session with you before the interview, to ensure that you understand the research project in which you are participating. Whereas you are encouraged to answer all questions, you have the right to refuse to answer any question that you deem as causing undue psychological, emotional and physical discomfort. You can skip any question or stop the interview at any time. If you change your mind during an interview, and are unwilling to proceed, the meeting will automatically end.

\section{Benefits of the study:}

The goal of this research is to improve our understanding hidden homelessness among women and identify gaps in policy for purposes of advancing issues of equity and social justice for vulnerable women. Whereas I cannot promise any personal benefits to participants, findings from this study may positively influence future housing policy and add to the discourse on affordable housing in Canada.

\section{Confidentiality:}

Should you agree to take part in this study, you will be asked to sign this consent form, giving me permission to audiotape your interview responses. I will take all the necessary steps to maintain your privacy and confidentiality to the extent allowed by law. As such, if there is any indication that you may do harm to yourself or others, I have a duty to report this information to the appropriate authorities.

To ensure that your privacy and confidentiality is protected during and after the study, I will make an effort to ensure that;

1. Any information you give is only for the purpose of this study and your name, phone or email address will not be shared with anyone else.

2. Only pseudonyms will be used throughout the study and in the final report, so that no one can connect the research information to the participants.

3. No other person apart from me, as the primary researcher, will have access to the consent forms and interview transcripts, and these will be destroyed as soon as the findings of this dissertation are published by April 2018.

4. All. electronic raw data will be securely stored on my computer with a strong password and firewall, and no other person is able to access the computer without a password. Paper records pertaining to the study will be kept in a safe secure place, where no one can access them. For example, all audio tapes, electronic disks with original transcripts, researcher's field notes and memos, will be stored in a safe, locked cabinet, in my private office

5. The information collected during this study is for the primary purpose of advancing issues of social justice and adding to the discourse of housing and homelessness in Canada. No names, identity or personal information will be used in any current publication or report of the current study, or in future research - without consent from participants.

6. Duty to report: All information collected will be absolutely private and confidential unless if there is belief that you are in danger of hurting yourself or others. In this case, I am obligated to inform proper authorities. 


\section{Voluntary Nature of Participation:}

I am seeking for 8 policy experts and 8 community stakeholders in Toronto and Barrie, to participate in this study. Participation in this study is voluntary and all participants should be over 20 years old and able to consent to the study. Your decision to take part (or not) will in no way influence your current or future opportunities and relationship with Ryerson University, or with any of the researchers involved in this study. If you decide to participate, you are free to refuse to answer any question, stop participation altogether, and withdraw your consent at any time. If you withdraw your consent before December $15^{\text {th }}, 2017$, your data will be withdrawn from the study. However, after this date, you will not be able to withdraw your data from the study. Your specific rights to participating in interviews and observations are as follows:

7. It is entirely your decision to participate or not to participant in the research interviews and observations. This means which ever decision you make is completely voluntary.

8. By agreeing to participate in this study, you are not giving up your legal rights. You have the right to change your mind at any time before, during and immediately after the interview and observations. If you decide to leave the interview or observation process there is no penalty.

9. You have the right to refuse any questions. Some questions might be too personal and too sensitive to answer. These open-ended questions are important to the research process so that the researchers can critique their findings and compare their results based on existing literature. It is important that you answer the questions honestly, and in a safe manner.

10. A copy of the consent form will be provided to all participants. If you decide to participate in the interview, you will sign the consent form.

\section{Questions about the Study:}

11. If you have any questions about the research, please feel free to ask me, as the primary researcher. If you have questions later, you can contact me, Rosemary Muzorewa, via email at, rmuzorewa@ ryerson.ca

12. If you have concerns about this study, please contact my supervisor, Dr. Melanie Knight: at Tel: 416-9795000, ext. 4191; or via email: melanie.knight@ ryerson.ca.

13. This study has undergone review through the Ryerson University Research Ethics Board. If you have any questions or concerns about this research, feel free to contact the Chair of the Research Ethics Board at rebchair@ryerson.ca.

\section{Consent Agreement Form:}

By agreeing to participate in this research, you are not giving up or waiving any legal right in the event that you are harmed during the research. Your signature below indicates that:

a) You have read the information in this agreement and have had a chance to ask as many questions you have about this study.

b) You agree to be in the study and have been told that you can change your mind and withdraw your consent to participate as any time.

c) You have been given a copy of this agreement.

d) You have been told that by signing this consent agreement you are not giving up any of your legal rights. , agree to (check were applicable)

\section{Participant's Name}

(a) ___ participate in this study

(b) ___ have my voice audio-taped during interviews

(c) ___ have my name used in this study

(d) ___ receive a brief summary of research findings from this study. 
Signature of Participant:

Signed in Ontario on: of 2017

Name of Principal Researcher: Rosemary Muzorewa

Signature of Principal investigator: 


\section{Appendix D: Debriefing: Housing Experts/Stakeholders}

\section{RYERSON}

UNIVERSITY

\section{Rosemary Muzorewa}

Phd Social Policy Student

Tel: 705-719-7466, Email: rmuzorewa@ ryerson.ca

\section{Debriefing: Housing Experts \\ Redefining the boundaries of hidden homelessness: An examination of the experiences of women in Toronto and Barrie.}

I would like to take this opportunity to thank you for agreeing to participate in the study! Very little is known about the inclusionary housing policy in Canada and how it is being implemented to address the problem of hidden homelessness among women in Toronto and Barrie. As such, the purpose of this comparative case study is to discover how local municipalities are using inclusionary zoning programs and initiatives to address the problem of housing and homelessness among women in their jurisdictions. It is my intention that findings from this study will positively influence the housing policy.

You were considered as a participant in my study on the basis of your background as an expert in working to address the problem of housing and homelessness in Toronto or Barrie.

I am hoping that the information obtained from this study will go a long way in opening up a dialogue regarding policy responses to the problem of hidden homelessness among women, in modern day society, in order to bring about positive change.

If you feel anxious, traumatized or depressed as a result of your participation in this study, please feel free to contact your preferred healthcare provider or healthcare professionals from the list provided with this form.

If you have any questions or concerns about this study, please feel free to contact me via email at,

rmuzorewa@ ryerson.ca. You can also contact my supervisor, Dr. Melanie Knight, at Tel: 416-979-5000, ext. 4191; or via email: melanie.knight@ @ryerson.ca, if you have any questions or concerns.

This study was approved by the Ryerson Research Ethics Board. As such, if you have any questions or concerns regarding the process, or your rights as a participant in the study, please feel free to contact the research ethics board at:

Ryerson University Research Ethics Board

c/o Office of the Vice President, Research and Innovation

Ryerson University

350 Victoria Street

Toronto, ON M5B 2K3

e-mail: rebchair@ryerson.ca

Thanking you in Advance

RMuzorewa

Rosemary Muzorewa RP, RSW, MSW, Phd Social Policy Candidate 
Ryerson University Department of Public Policy and Administration 


\section{Appendix E: Informed Consent: Women Participants}

\section{RYERSON}

UNIVERSITY

\section{Rosemary Muzorewa}

Phd Social Policy Student

Tel: 705-719-7466, Email: rmuzorewa@ ryerson.ca

\section{Dear Participant:}

\section{Informed Consent: Women Participants}

You are being asked to participate in a research study. Before you give your consent to participate, it is important that you read the following information and ask as many questions as necessary to be sure you understand what you will be asked to do. This document describes the research proposal and data collection process, to help you decide if you would like to participate in this project. Please take time to read this handout carefully.

\section{Principal Investigator: Rosemary Muzorewa}

e-mail: rmuzorewa@ryerson.ca

Supervisor's Name: Dr. Melanie Knight

Tel: 416-979-5000, ext. 4191; melanie.knight@ ryerson.ca.

Purpose of the study:

The purpose of this case study is to better understand the phenomenon of hidden homelessness as it relates to lowincome women in Toronto and Barrie. This research project is part of the fulfillment for my $\mathrm{PhD}$ dissertation at Ryerson University in Toronto. Findings from this study will add to the discourse on homelessness and policy responses to this problem. As well, results from this study will be used for publications and conference presentations, related to social policy and women's issues. Dr. Melanie Knight, will supervise this project.

\section{Description of the study:}

You are invited to participate in this study because your input is valuable in shading light on women's experiences with hidden homelessness in Toronto/Barrie. During the study, you will be asked open-ended questions about your experiences with hidden homelessness, to which there is no wrong or right answer. The interview will take place in a safe environment, in private rooms, located, at a public library, college, university or human service organization in your area. I will endeavor to minimize disruptions to your daily routine therefore; the interviews will be conducted at your most convenient time and place, and will last for about 60 to 90 minutes.

I will ask you questions related to your experiences with housing and homelessness and the interview will be recorded. You have the right to opt out of the study at any time, before or during the study, without any questions or penalty.

\section{Sample Questions for women participants experiencing hidden homelessness:}

- How would you describe housing affordability in Toronto (Barrie)?

- How would you describe your current living arrangement and your experience living there?

- Can you describe the challenges you have faced since you started living in your current residence?

\section{Incentives to participants:}

You will be given an honorarium in the form of a $\$ 20.00$ Tim Hortons gift card, for your participation in the interview. You will be reimbursed for travel expenses related to this study, up to a maximum of $\$ 10.00$, and any childcare expenses you may incur as a result of this study will also be reimbursed, up to a maximum of $\$ 50.00$. Please note that, receipts will be required in order to be reimbursed for travel and childcare expenses. This study is funded by 
the primary researcher and any incentives you may receive pertaining to this study will not be affected by your decision to withdraw from the study, at any given time.

\section{Risks or discomforts:}

There are few risks involved with this research. However, whereas I will make an effort to minimize emotional or psychological discomfort to you, by confining the research questions to your experiences with housing and homelessness in Toronto/Barrie,

I would like to note that:-

d. You may be asked to give honest responses to open ended-interview questions that may make you feel embarrassed or uncomfortable because of the personal nature of the questions.

e. You may be asked to evaluate government or organizational policies and programs thereby risking reprisal in the form of loosing services.

f. You may be exposed to a degree of psychological, emotional and physical discomfort, having to narrate or re-live your experiences with hidden homelessness.

I will hold a short debriefing session with you before the interview, to ensure that you understand the research project in which you are participating. Whereas you are encouraged to answer all questions, you have the right to refuse to answer any question that you deem as causing undue psychological, emotional and physical discomfort. You can skip any question or stop the interview at any time. If you change your mind during an interview, and are unwilling to proceed, the meeting will automatically end.

\section{Benefits of the study:}

The goal of this research is to improve our understanding of hidden homelessness among women and identify gaps in policy for purposes of advancing issues of equity and social justice for vulnerable women. Whereas I cannot promise any personal benefits to participants, findings from this study may positively influence future housing policy and add to the discourse on affordable housing in Canada.

\section{Confidentiality:}

Should you agree to take part in this study, you will be asked to sign this consent form, giving me permission to audiotape your interview responses. I will take all the necessary steps to maintain your privacy and confidentiality to the extent allowed by law. As such, if there is any indication that you may do harm to yourself or others, I have a duty to report this information to the appropriate authorities.

To ensure that your privacy and confidentiality is protected during and after the study, I will make an effort to ensure that;

14. Any information you give is only for the purpose of this study and your name, phone or email address will not be shared with anyone else.

15. Only pseudonyms will be used throughout the study and in the final report, so that no one can connect the research information to the participants.

16. No other person apart from me, as the primary researcher, will have access to the consent forms and interview transcripts, and these will be destroyed as soon as the findings of this dissertation are published by April 2018.

17. All electronic raw data will be securely stored on my computer with a strong password and firewall, and no other person is able to access the computer without a password. Paper records pertaining to the study will be kept in a safe secure place, where no one can access them. For example, all audio tapes, electronic disks with original transcripts, researcher's field notes and memos, will be stored in a safe, locked cabinet, in my private office.

18. The information collected during this study is for the primary purpose of advancing issues of social justice and adding to the discourse of housing and homelessness in Canada. No names, identity or personal information will be used in any current publication or report of the current study, or in future research - without consent from participants.

19. Duty to report: All information collected will be absolutely private and confidential unless if there is belief you are in danger of hurting yourself or others, then I am obligated to inform proper authorities.

\section{Voluntary Nature of Participation:}

I am seeking for 8 women in Toronto and 8 women in Barrie, to participate in this study. Participation is completely voluntary and all participants should be between the ages of 20-65 years old and able to consent to the study. Your 
decision to take part (or not) will in no way influence your current or future opportunities and relationship with Ryerson University, and/or any of the researchers involved in this study. If you decide to participate, you are free to refuse to answer any question, stop participation altogether, and withdraw your consent at any time. If you withdraw your consent before December $15^{\text {th }}, 2017$, your data will be withdrawn from the study. However, after this date, you will not be able to withdraw your data from the study. Your specific rights to participating in interviews and observations are as follows:

20. It is entirely your decision to participate or not to participant in the research interviews and observations. This means which ever decision you make is completely voluntary.

21. By agreeing to participate in this study, you are not giving up your legal rights. You have the right to change your mind at any time before, during and immediately after the interview and observations. If you decide to leave the interview or observation process there is no penalty.

22. You have the right to refuse any questions. Some questions might be too personal and too sensitive to answer. These open-ended questions are important to the research process so that the researchers can critique their findings and compare their results based on existing literature. It is important that you answer the questions honestly, and in a safe manner.

23. A copy of the consent form will be provided to all participants. If you decide to participate in the interview, you will sign the consent form.

Questions about the Study:

24. If you have any questions about the research, please feel free to ask me, as the primary researcher. If you have questions later, you can contact me, Rosemary Muzorewa, via email at, rmuzorewa@ ryerson.ca

25. If you have concerns about this study, please contact my supervisor, Dr. Melanie Knight: at Tel: 416-9795000, ext. 4191; or via email: melanie.knight@ ryerson.ca.

26. This study has undergone review through the Ryerson University Research Ethics Board. If you have any questions or concerns about this research, feel free to contact the Chair of the Research Ethics Board at rebchair@ryerson.ca.

\section{Consent Agreement Form:}

By agreeing to participate in this research, you are not giving up or waiving any legal right in the event that you are harmed during the research. Your signature below indicates that:

e) You have read the information in this agreement and have had a chance to ask as many questions you have about this study.

f) You agree to be in the study and have been told that you can change your mind and withdraw your consent to participate as any time.

g) You have been given a copy of this agreement.

h) You have been told that by signing this consent agreement you are not giving up any of your legal rights.

I

Participant's Name , agree to (check were applicable)
(a) ___ participate in this study
(b) __ _ have my voice audio-taped during interviews
(c) ___ have my name used in this study
(d) ___ receive a brief summary of research findings from this study.

\section{Signature of Participant:}

Signed in Ontario on: of 2017 
Name of Principal Researcher: Rosemary Muzorewa

Signature of Principal investigator: 


\section{Appendix F: Debriefing, Women Participants}

\section{RYERSON UNIVERSITY}

\section{Rosemary Muzorewa}

Phd Social Policy Student

Tel: 705-719-7466, Email: $\underline{\text { rmuzorewa @ ryerson.ca }}$

\section{Debriefing: Women Participants}

\section{Redefining the boundaries of hidden homelessness: An examination of the experiences of women in Toronto and Barrie.}

I would like to take this opportunity to thank you for agreeing to participate in the study! Very little is known about women's experiences with hidden homelessness in Toronto and Barrie. In this regard, the general purpose of this study is to better understand women's experiences with hidden homelessness and to discover how the inclusionary housing policy is being used to address this problem in Toronto and Barrie. It is my intention that the voice of women experiencing hidden homelessness will be heard at policy level.

You were considered as a participant in my study on the basis of either your background as an expert in your lived experience with hidden forms of homelessness in Toronto or Barrie.

I am hoping that the information obtained from this study will go a long way in opening up a dialogue regarding policy responses to the problem of hidden homelessness among women, in modern day society, in order to bring about positive change.

If you feel anxious, traumatized or depressed as a result of your participation in this study, please feel free to contact healthcare professionals from the list provided with this form. As well the list details other community organizations in Toronto/Barrie who offer housing services.

If you have any questions or concerns about this study, please feel free to contact me via email at, rmuzorewa@ ryerson.ca. You can also contact my supervisor, Dr. Melanie Knight, at Tel: 416-979-5000, ext. 4191; or via email: melanie.knight@ryerson.ca, if you have any concerns.

This study was approved by the Ryerson Research Ethics Board. As such, if you have any questions or concerns regarding the process, or your rights as a participant in the study, please feel free to contact the research ethics board at:

Ryerson University Research Ethics Board

c/o Office of the Vice President, Research and Innovation

Ryerson University

350 Victoria Street, Toronto, ON M5B 2K3, e-mail: rebchair@ryerson.ca

Thanking you in Advance

RMuzorewa

Rosemary Muzorewa RP, RSW, MSW, Phd Social Policy Candidate

Ryerson University Department of Public Policy and Administration 
Appendix G: Community Resources: Barrie

\section{BARRIE COMMUNITY RESOURCES \\ HOMELESSNESS \\ MENTAL HEALTH \\ FOODBANKS \\ FAMILY SERVICES}

\section{$\underline{\text { Organization }}$}

Canadian Mental Health Association. Simcoe County Branch. Barrie Head Office - 15

Bradford St. Housing Support

15 Bradford St, Barrie, ON L4N 1W2

705-726-5033 * Intake information 705-726-7490 | Website

Barrie

Elizabeth Fry Society of Simcoe County. Joyce Kope House

102 Maple Ave, Barrie, ON L4N 1S4 Tel 705-725-0613 | Website

Green Haven Shelter for Women. Orillia - Unpublished

705-327-7383* Administration \& Donation | Website

Women and Children's Shelter of Barrie. No Physical Address

Shelter: 705-728-2544* Office: 705-728-6300* Outreach Services: 705-721-9977| Website

Barrie and Community Family Health Team. Barrie - Common Roof - 165 Ferris Lane. Mental Health Services

The Common Roof, 165 Ferris Lane, Barrie, ON L4M 2Y1

Booking Clerk 705-726-4225 Ext 2273 | Website

Family Mental Health Initiative of Simcoe County

128 Anne St South, Barrie, ON L4N 6A2

705-725-0363 | Website

Barrie Food Bank

42 Anne St South Unit 2, Barrie, ON

705-725-1818 | Website

Churchill United Church

6306 Yonge St, Churchill, ON L0L 1K0

705-456-1714 
Appendix H: Community Resources: Toronto

\section{BARRIE COMMUNITY RESOURCES HOMELESSNESS \\ MENTAL HEALTH FOODBANKS \\ FAMILY SERVICES}

\author{
Single Women's Shelters \\ Fred Victor Centre Women's Hostel \\ 416-368-2642 \\ 86 Lombard Street \\ fredvictor.org \\ 3 pm-9:30 am \\ Homes First Society - Women's Interim \\ 647-260-1559 \\ 702 Kennedy Road \\ homesfirst.on.ca \\ admin@ homesfirst.on.ca
}

Homes First Society - Savard's

416-395-0932

1322 Bloor Street West

homesfirst.on.ca

admin@homesfirst.on.ca

$18+$ with mental health issues

Nellie's

416-461-1084

confidential address

nellies.org

community@nellies.org

$16+$ or women with children

Salvation Army - Evangeline Residence 416-762-9636

2808 Dundas Street West

salvationarmy.ca

Salvation Army - Florence Booth

416-603-9800

723 Queen Street West

salvationarmy.ca
St. Vincent De Paul - Elisa House

416-259-2528

60 Newcastle Street

svdptoronto.org

elisahouse.svdptoronto@rogers.ca

St. Vincent De Paul - Mary's Home

416-595-1578

70 Gerrard Street East

svdptoronto.org

boluwolerotimi.maryshome@rogers.com

Street Haven at the Crossroads

416-967-6060

87 Pembroke Street

streethaven.com

info@streethaven.com

Women's Residence Main Site

416-392-5500

674 Dundas Street West

toronto.ca/housing

ssha@toronto.ca

YWCA First Stop Woodlawn

Crisis line 416-922-3271

80 Woodlawn Avenue East

ywcatoronto.org

lintake@ywcatoronto.org

FOOD BANK

Parkdale Community Food Bank

1499 Queen St W, Toronto, M6R 1A3

Contact (416) 5312375

Thorncliff Food Bank

1 Leaside Park Dr, \#5B, Toronto ON M4H

1R1

Contact (647) 4279755 


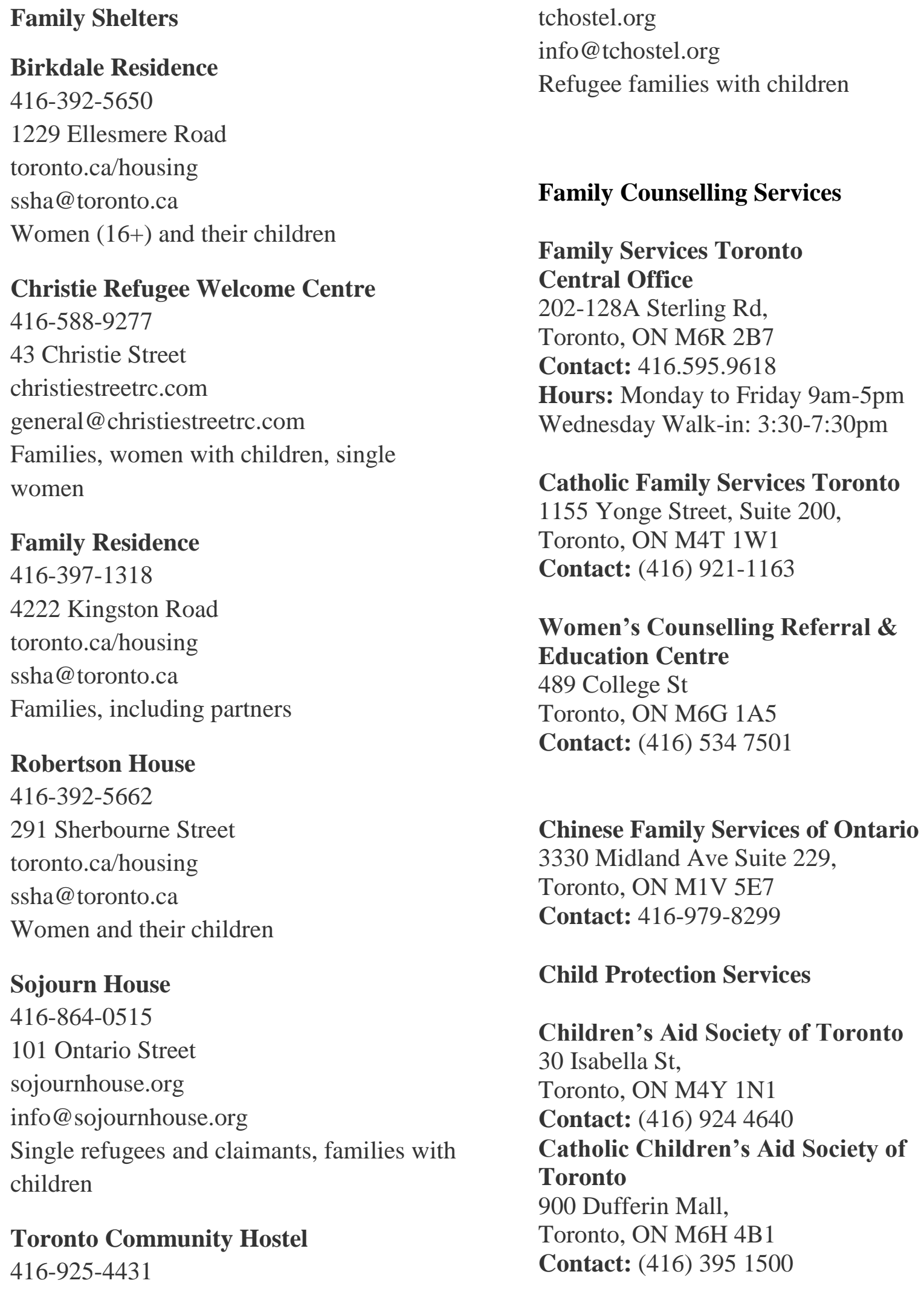

191 Spadina Road 


\title{
Appendix I: Interview Protocol: Experts/Stakeholders
}

\author{
Interview Protocol - Housing Expert
}

Date:

Location:

Name of Interviewer:

Interview with Housing Expert/

Stakeholder:

1. In your opinion, how would you describe the condition of social housing in Toronto (Barrie)?

2. How do you view housing affordability in Toronto (Barrie)?

3. What is your understanding of the issue of hidden homelessness among women in Toronto (Barrie)?

4. What factors do you think influences higher incidences of hidden homeless among women in Toronto (Barrie)?

5. How has your organization/municipality used the inclusionary zoning or inclusionary housing policy to address the issue of hidden homelessness among women, in your area?

6. What types of incentives and trades offs are used in the process?. What challenges has your organization/municipality faced in implementing inclusionary zoning strategies?.

7. Are you aware of community engagements or policy planning tables involving women in the drafting, implementation or maintenance of the inclusionary housing policy?

8. How do you track the affordable housing produced? What is the structure and tenure of these housing units?. In your opinion, to what extent has the inclusionary housing policy contributed to an increase in affordable housing stock in Toronto (Barrie)?

9. What challenges have you faced in the implementation and maintenance of the inclusionary housing policy?

10. In your own opinion, what will it take to establish a successful housing strategy in Canada? 


\section{Appendix J: Interview Protocol: Women Participants}

\section{Interview Protocol - Woman Participant}

Date:

Location:

Name of Interviewer:

Name of Interviewee:

Interview with woman

Participant:

1. Can you please provide a brief description of your family background, your country of origin and how long you have lived in Canada?

2. How long have you lived at your current residence?

3. How would you describe your living arrangement and your experience living there?

4. How would you describe housing affordability in Toronto (Barrie)?

5. Can you describe the challenges you have faced since with housing, here in Barrie and at your current residence?

6. How have you been coping with these challenges?

7. Have you tried looking for another place to live? (a) If no, what stops you from looking for a better place to live? (b) If yes, what was your experience with house hunting?

8. What factors do you think contribute to your experiences with housing affordability in Toronto (Barrie)?

9. What kind of assistance have you received either from the government or NGOs to help you with housing or income supports?

10. How has living here affected your physical, mental and emotional health?

11. Why do you think hidden homelessness persist? 


\section{Appendix K: Factors influencing women's experiences with hidden homelessness}

The following summarizes, in participant's words, various factors contributing to experiences of hidden homelessness among women.

\section{Figure 1: Factors influencing women's experiences with hidden}

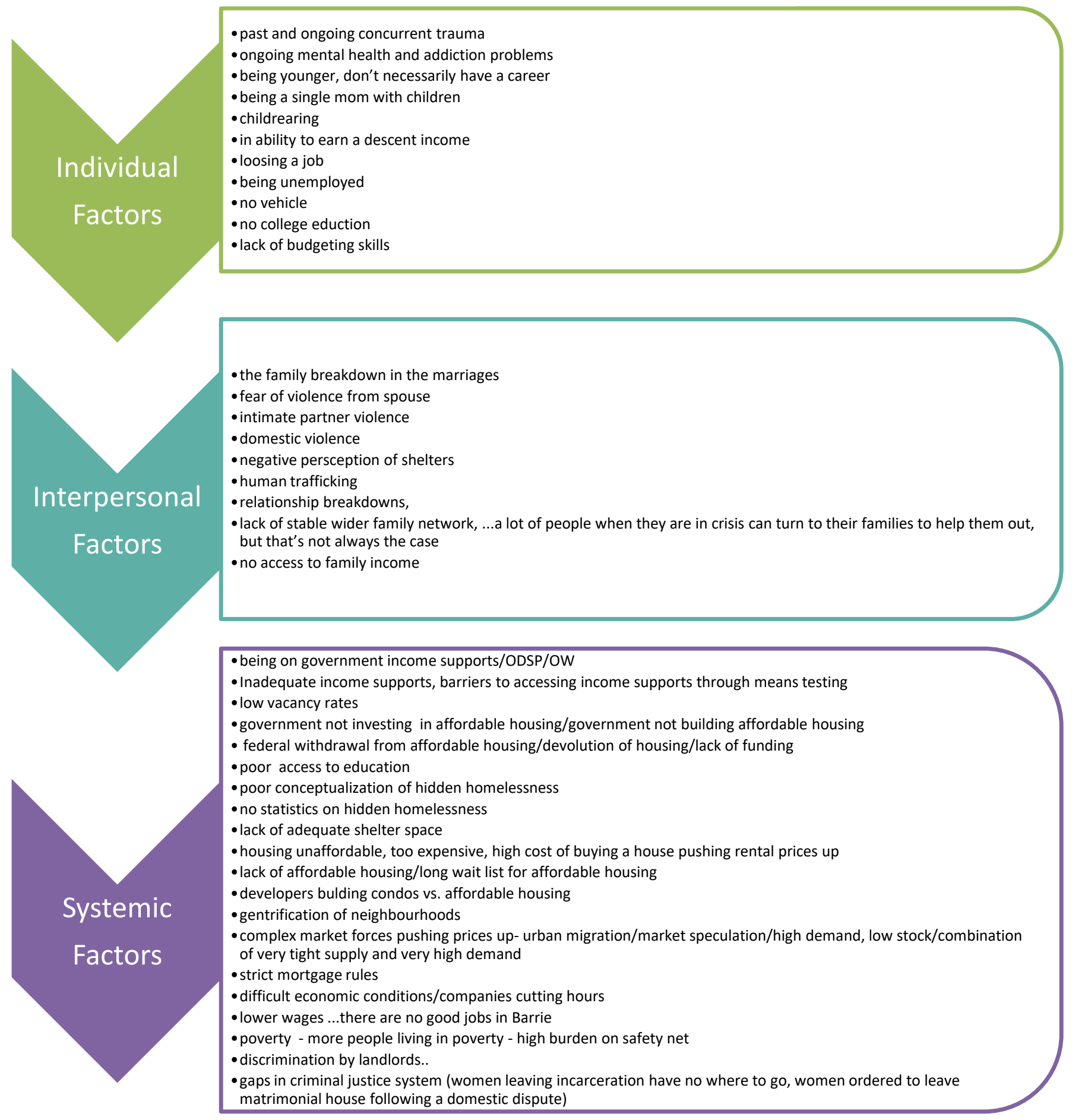




\section{Appendix L: Inclusionary Housing Projects in Toronto and Barrie:}

"What we do is we provide homeownership with no down payment for a home. ...On top that, we offer interest free mortgages, so families don't have to pay interest for their mortages and Habitat for Humanity is actually the mortgage holder for those families. So they are paid off within a 20 year term and the mortgage payments, on a monthly basis, are actually kept at $30 \%$ of their household income. So they are able to afford other necessities for themselves and their families as well." (Manager, Habitat for Humanity GTA, December 6, 2017)

\section{IH Policy with private developers: (e.g Diamond Corp)}

Developers build units and allocate all or a certain number of units for affordable housing to NGOs/Housing Corporations dealing with housing and homelessness, who then provide the clients and sale/rent at an affordable rate.

\section{IH Policy with Non-profit Developers (e.g Habitat for Humanity/Redwood Community Parks)}

NGOs build units and either provide low-income families with access to homeownership by carrying low-interest mortgages on behalf of clients, or provide access to affordable rental units through government subsidies.

\section{Table 7: Inclusionary Housing Projects in Barrie:} CITY OF BARRIE IZ INITIATIVES

\begin{tabular}{|c|c|c|}
\hline \multicolumn{3}{|c|}{ CITY OF BARRIE IZ INITIATIVES } \\
\hline Partnerships & Programs and number of units produced & Structure and Tenure of units \\
\hline $\begin{array}{l}\text { Barrie } \\
\text { Private developers }\end{array}$ & $\begin{array}{l}\text { Intensification Program } \\
\text { All new Suburbian Developments in Barrie } \\
\text { and the Innisfil annexed land } \\
\text {--waiving fees up to } 40,000 \text { to } 60,000 \\
\text {--density bonusing }\end{array}$ & $\begin{array}{l}\text {--10\% of builds to be provided at an } \\
\text { affordable rate of } 10 \% \text { below market rent or } \\
\text { market purchase price for a home } \\
\text {--Back-to-back townhomes } \\
\text {--Staked Townhomes } \\
\text {-- Units to remain affordable for } 25 \text { years }\end{array}$ \\
\hline $\begin{array}{l}\text { City of Barrie } \\
\text { Mooregate Estates (Danny Salvatore) }\end{array}$ & $\begin{array}{l}\text { Intensification Program } \\
\text {-Density bonusing: -rezoning from second } \\
\text { density, residential single detached dwelling, } \\
\text { to first density, residential apartment dwelling } \\
\text {-allowing for residential/commercial landuse }\end{array}$ & $\begin{array}{l}\text { High Rise Apartments } \\
90 \text { units affordable } \\
\text {--10\% below market rent }\end{array}$ \\
\hline $\begin{array}{l}\text { City of Barrie } \\
\text { Private homeowners } \\
\text { Private Developers }\end{array}$ & $\begin{array}{l}\text { Second Suites initiatives } \\
\quad--\$ 25,000 \text { Funding Grants for second suites } \\
\text { on private property } \\
\text {--Re-zoning tax relief/discount on } \\
\text { development fees } \\
\text {-- homeowner assisted with grant and permit } \\
\text { applications, planning and construction of } \\
\text { unit according to city building codes } \\
\text {-- use of Housing subsidy to finance } \\
\text { affordable rental income }\end{array}$ & $\begin{array}{l}\text { Use of under-utized space on homeowner's } \\
\text { property to create affordable } \\
\text { - } \quad \text { Basement apartment } \\
\text { - } \quad \text { Laneway Suites } \\
\text { - } \quad \text { Over-the-garage suites } \\
\text { - } \quad \text { Granny suites } \\
\text { - } \quad \text { Detached garage conversion }\end{array}$ \\
\hline $\begin{array}{l}\text { County of Simcoe } \\
\text { City of Barrie } \\
\text { Private Developer } \\
\text {--Redwood Park Communities Developer } \\
\text { NGO } \\
\text {--Busby Centre }\end{array}$ & $\begin{array}{l}\text { Community Improvement Plan } \\
\text { Motel Conversion - (In Pipeline) to house } \\
\text { chronically homeless individuals with mental } \\
\text { health and addiction challenges } \\
\text {--Provincial funding: } \$ 2.1 \\
\text {--Donations } \$ 300,000 \\
\text {-- discounts/exemptions on development } \\
\text { fees up to } 75 \% \text { (supportive housing) }\end{array}$ & $\begin{array}{l}\text { Affordable housing complex with } 17 \text { units in } \\
\text { a renovated motel (Approved, in pipeline) } \\
\text {---12 Bachelor pads } \\
\text {--- } 5 \text { Beds for women coming from rehab } \\
\text { Rental Garden Community } \\
\text {---10 Tiny homes (Future development) }\end{array}$ \\
\hline $\begin{array}{l}\text { County of Simcoe/Province } \\
\text { Private Developer } \\
\text {--Redwood Park Communities Developer } \\
\text { NGO } \\
\text {--Salvation Army }\end{array}$ & $\begin{array}{l}\text { Community Improvement Plan } \\
\text { Family Emergency Shelter (Projected) } \\
\text {--Provincial funding } \\
\text {--City land } \\
\text {--Community Donations } \\
\text {-- discount/exemptions on development } \\
\text { fees up to } 100 \% \text { ( for Shelter) }\end{array}$ & $\begin{array}{l}\text { Transitional in renovated old building } \\
\text {---12 units (Future development) }\end{array}$ \\
\hline
\end{tabular}




\begin{tabular}{|c|c|c|}
\hline $\begin{array}{l}\text { City of Barrie } \\
\text { County of Simcoe supports } \\
\text { Redwood Park Communities } \\
\text {-Barrie Women \& Children's shelter } \\
\text { partnerships } \\
\text {-Private Homeowners }\end{array}$ & $\begin{array}{l}\text { Community Improvement Plan Program } \\
\text { to provide Transitional Housing operated } \\
\text { through Redwood Park Communities ( } 16 \\
\text { units total) } \\
\text {-- use of Housing subsidy to finance } \\
\text { affordable rental income } \\
\text {-- } \$ 25,000 \text { Funding Grants for second suites } \\
\text { on private property } \\
\text {-- homeowner assisted with grant and permit } \\
\text { applications, planning and construction of } \\
\text { unit according to city building codes }\end{array}$ & $\begin{array}{l}\text { Rental apartments in under-utilized space } \\
\text { within existing built forms } \\
\text { United House: Bought and renovated a } \\
\text { century old house house into } \\
\text {---5 VAW transitional units } \\
\text {---Tenure a year minus a day } \\
\text { Bought } 2 \text { century old houses and renovated } \\
\text { them into } \\
\text {---4 Family Units } \\
\text {----average tenure: } 60 \text { to } 120 \text { days } \\
\text { Apartments in private homes } \\
\text {---7 VAW units } \\
\text {---Perpetual if homeowner and tenant are in } \\
\text { agreement }\end{array}$ \\
\hline
\end{tabular}

Table 8: Inclusionary Housing Projects in Toronto:

\begin{tabular}{|c|c|c|}
\hline \multicolumn{3}{|c|}{ CITY OF TORONTO IH PROGRAMS \& INITIATIVES } \\
\hline Partnerships & Programs & Structure and Tenure of units \\
\hline $\begin{array}{l}\text { City of Toronto } \\
\text { Private Developers such as } \\
\text {--Diamond Corp } \\
\text {-- Malvern Inc } \\
\text { NGOs } \\
\text {--Toronto Community Housing Corp } \\
\text {--Habitat for Humanity } \\
\text {--Dixon Hall Community } \\
\text { Neighbourhoods } \\
\text {--Toronto Community Housing }\end{array}$ & $\begin{array}{l}\text { Involuntary/Mandatory IH } \\
\text {-- Large Site Policy } \\
\text { Large development sites of } 5 \text { hectares or larger are mandated } \\
\text { make } 20 \% \text { of the housing on the land available to provide } \\
\text { affordable housing and to remain affordable. } \\
\text {-- Revitalization Projects } \\
\text { any new development that takes down or demolishes existing } \\
\text { rental housing, is required to replace that housing in the new } \\
\text { development. } \\
\text { Voluntary IH practices through: } \\
\text { Open door program } 2016 \\
\text { The city incentivize and accelerate the construction of } \\
\text { affordable housing through } \\
\text {-- capital funding (from the Federal/Provincial Investment in } \\
\text { Affordable Housing IAH Grant) } \\
\text {-- forgiving building fees, development charges, planning } \\
\text { fees, parkland dedication fees and provides property tax } \\
\text { relief up to @ } \$ 40,000 \text { per rental unit } \\
\text {-- fast-tracking planning approvals, "cutting the red tape, } \\
\text { stream lining" the approval process } \\
\text {-- activating surplus public land. } \\
\text {-- Section } 37 \text { Community Benefits Progam } \\
\text { Developers who opt to include affordable housing units in } \\
\text { new developments on green-field or brownfield lands are } \\
\text { incentivized through City supports such as: } \\
\text {-- re-zoning for higher density at no charge } \\
\text {-- discounts/examptions on planning fees } \\
\text {-- discounts/donation of city land } \\
\text {--donating old buildings or previously used sites for } \\
\text { redevelopment } \\
\text {--brownfield grants to clear contaminated land or demolish } \\
\text { old buildings }\end{array}$ & $\begin{array}{l}\text { In return Private Developers donate } \\
\text { affordable housing units onsite or } \\
\text { elsewhere, to Toronto } \\
\text { Community Housing or other } \\
\text { NGOs such as, Habit for } \\
\text { Humanity and Dixon Hall } \\
\text { Neighbourhood Services, } \\
\text { working with under-housed } \\
\text { individuals and families. } \\
\\
\text {--rental units to remain affordable for } \\
25 \text { - 50 years } \\
\text {--homeownership units - perpetually } \\
\text { affordable } \\
\text {--High rise condo buildings } \\
\text {--Multi-storey, multi-purpose } \\
\text { buildings with shops and offices at } \\
\text { the lower levels } \\
\text {--Back-to-back townhomes } \\
\text {--Stacked townhomes }\end{array}$ \\
\hline
\end{tabular}




\begin{tabular}{|c|c|c|}
\hline \multicolumn{3}{|c|}{ EXAMPLES OF IH IN TORONTO } \\
\hline $\begin{array}{l}\text { City of Toronto } \\
\text { Private Developers } \\
\text { Community Housing Organizations }\end{array}$ & $\begin{array}{l}\text { OPEN DOOR PROGRAMS } 2016 \\
\text { https://www.thestar.com/news/city_hall/2015/04/28/mayor- } \\
\text { john-tory-wants-to-open-doors-for-new-affordable- } \\
\text { housing.html }\end{array}$ & $\begin{array}{l}\text { Total rental units produced } 885 \\
\text { between } 2015-17 \\
--706 \text { Units at } 80 \% \text { average market } \\
\text { rent } \\
--179 \text { Units at } 60 \% \text { or below market } \\
\text { rent }\end{array}$ \\
\hline $\begin{array}{l}\text { City of Toronto } \\
\text { Madison View Homes Inc. }\end{array}$ & $\begin{array}{l}\text { Madison Ave. property } \\
\text {-- a request for proposal was put out by the city } \\
\text {--property was sold for a toonie } \\
\text {--examption for development fees and taxes }\end{array}$ & $\begin{array}{l}\text {-- Developer will provide } 82 \text { rental } \\
\text { units } \\
\text {-- at } 77 \% \text { of average market rent } \\
\text {-- for } 50 \text { years }\end{array}$ \\
\hline $\begin{array}{l}\text { City of Toronto } \\
\text { Naismith Housing Co-operative Inc } \\
\text { Developer: Tridel }\end{array}$ & $\begin{array}{l}\text { 10 York Street } \\
\text { https://www.toronto.ca/legdocs/bylaws/2017/law0429.pdf } \\
\text { http://urbantoronto.ca/database/projects/ten-york-street- } \\
\text { condos } \\
\text {---exempt from the payment of development charges in } \\
\text { respect of the Eligible Premises imposed by the City under the } \\
\text { Developmen } \\
\text { t Charges Act, 1997, S.O. 1997, c. } 27 \text {, }\end{array}$ & $\begin{array}{l}\text { Of the } 725 \text { condo units, } 12 \text { will be } \\
\text { affordable rental units for } 20 \text { years }\end{array}$ \\
\hline $\begin{array}{l}\text { City of Toronto } \\
\text { Habitat for Humanity (GTA) } \\
\text { Private Developers }\end{array}$ & $\begin{array}{l}\text { Habitat for Humanity Homeownership Program } \\
\text { Homeownership program to fill an important housing niche of } \\
\text { the working poor in Toronto } \\
\text {--city donates land or } \\
\text {--exemption of development fees and charges } \\
\text {-target low-middle income earners and first home buyers who } \\
\text { cannot afford market prices } \\
\text {--homeowner donate 500hrs in luei of downpayment for } \\
\text { housing } \\
\text {--interest free mortgage carried by Habit for Humanity }\end{array}$ & $\begin{array}{l}\text { Home ownership in new } \\
\text { developments } \\
\text {-mostly town homes and stacked } \\
\text { townhomes } \\
\text {--mortgage payment kept at } 30 \% \text { of } \\
\text { household income } \\
\text {-- } 1998-2017=360 \text { families housed } \\
\text {-- } 2017=29 \text { families housed } \\
\text {-- By Oct } 2019=50 \text { Units in pipeline } \\
\text { at Pinery Trail Project (Scarborough) } \\
\text {-- By } 2021=250 \text { (units projected and } \\
\text { in the pipeline) }\end{array}$ \\
\hline $\begin{array}{l}\text { City of Toronto } \\
\text { Diamond Corp } \\
\text { Private Developers } \\
-- \text { Lifetime Developments, and } \\
-- \text { Context Development. } \\
\text { NGOs }\end{array}$ & $\begin{array}{l}\text { Wynford Green Project } \\
\text {-- credits against development cost } \\
\text {--density bonusing } \\
\text {-- lower fees } \\
\text {--accelerating approval time }\end{array}$ & $\begin{array}{l}-- \text { one of the largest IH project in } \\
\text { Toronto } \\
--57 \% \text { of home density to be } \\
\text { provided as affordable homes } \\
\text {-- contributing plus/minus } 250 \\
\text { affordable units } \\
- \text {-- for } 25 \text { years }\end{array}$ \\
\hline $\begin{array}{l}\text { City of Toronto } \\
\text { NGO: Wigwamen Incorporated } \\
\text { Developer: Tim Welch Consulting } \\
\text { Inc. }\end{array}$ & $\begin{array}{l}\text { 14 Spadina Road, Toronto. } \\
\text {-density bonusing from } 3 \text { storey to } 6 \\
\text { storey } \\
\text {-fee exemption }\end{array}$ & $\begin{array}{l}\text { Construction of a building containing } \\
24 \text { affordable housing units or such } \\
\text { other number of units for aboriginal } \\
\text { and non-aboriginal seniors }\end{array}$ \\
\hline $\begin{array}{l}\text { City of Toronto } \\
\text { Developer: } 2346 \text { weston Ltd }\end{array}$ & $\begin{array}{l}\text { Open Door Policy (Proposed Project) } \\
2346 \text { Weston Road } \\
\text {--density bonusing - re-zoning from 2001, } 10 \text { storey, } 49 \text { unit } \\
\text { apartment building, to15 storey, } 157 \text { units apartment tower } \\
\text {--exemption from development fee and charges } \\
\text { http://urbantoronto.ca/news/2018/02/15-storey-affordable- } \\
\text { housing-project-proposed-weston-road }\end{array}$ & $\begin{array}{l}15 \text { Storey rental apartment tower } \\
\text {---with } 157 \text { affordable housing rental } \\
\text { Units } \\
\text {--- a mix of } 15 \text { bachelor units with } \\
\text { average sizes of } 278 \mathrm{ft}^{2}, 84 \text { one- } \\
\text { bedroom units with average sizes of } \\
414 \mathrm{ft}^{2}, 43 \text { two-bedroom units with } \\
\text { average sizes of } 571 \mathrm{ft}^{2} \text {, and } 15 \text { three- } \\
\text { bedroom units with average sizes of } \\
719 \mathrm{ft}^{2} \text {. }\end{array}$ \\
\hline
\end{tabular}




\section{References:}

Ackerly, B., \& Attanasi, K. (2009). Global feminisms: Theory and ethics for studying gendered injustice. New Political Science, 31(4), 543-555. doi:10.1080/07393140903322604

Advocacy Centre for Tenants Ontario. (n.d.). Fact Sheet: Homelessness in Canada and Ontario. Tenant Duty Program. Retrieved August 1, 2019, from https://www.acto.ca/production/wp-content/uploads/2017/07/Factsheet-5-HousingAffordability-Crisis.pdf

Alvarez, S. (1997). Contradictions of a "Women's Space" in a male-dominant state: The political role of the commissions on the status of women in post authoritarian Brazil. In K. Staudt (eds.) Women, International Development, and Politics: The Bureaucratic Mire $\left(2^{\text {nd }}\right.$ Ed.), pp. 59-100. Philadelphia, PA: Temple University Press.

Anthias, F. (2014). The intersections of class, gender, sexuality and 'Race': The political economy of gendered violence. International Journal of Politics, Culture, and Society, 27(2), 153-171. doi:10.1007/s10767-013-9152-9.

Armstrong, A., Been, V., Meltzer, R. \& Schuetz J. (2007). The Effects of Inclusionary Zoning on Local Housing Markets: Lessons from the San Francisco, Washington DC and Suburban Boston Areas; Furman Center for Real Estate \& Urban Policy, Working Paper 07-05, November 2007.

Association of Municipalities of Ontario AMO, (2016, October 21). National Housing Strategy: Submission to the Government of Canada. Retrieved April 24, 2017, from https://www.amo.on.ca/AMOPDFs/Reports/2016/NationalHousingStrategyConsultationSubmission20161.aspx

Aubry, T., Nelson, G., \& Tsemberis, S. (2015). Housing first for people with severe mental illness who are homeless: A review of the research and findings from the at home-chez soi demonstration Project at home-chez soi. Canadian Journal of Psychiatry, 60(11), 467.

Bacchi, C., \& Eveline, J. (2004). Mainstreaming and neoliberalism: A contested relationship. Policy and Society: Journal of Public, Foreign and Global Policy 22(2): 98-118.

Bach, S. (2012). Shrinking the state or the big society? Public service employment relations in an era of austerity: Shrinking the state or the big society? Industrial Relations Journal, 43(5), 399-415. doi:10.1111/j.1468-2338.2012.00693.x

Baker, C. K., Billhardt, K. A., Warren, J., Rollins, C., \& Glass, N. E. (2010). Domestic violence, housing instability, and homelessness: A review of housing policies and program practices for meeting the needs of survivors. Aggression and Violent Behavior, 15(6), 430-439.

Baker, M. (1997, January 01). The restructuring of the Canadian Welfare state: Ideology and policy. Social Policy Research Centre: Discussion Paper, 77, 1-33. ISSN: 733415598 
Balfour, C. (2010). Inclusionary zoning, Brownfield development and urban governance: Understanding affordable housing production in Concord's City Place and Pacific Place developments. Toronto: Department of Geography University of Toronto. ISBN: 978-0494-67526-7

Bardouille, N. C. (2000). The transformation of governance paradigms and modalities insights into the marketization of the public service in response to globalization. The Round Table, 89(353), 81-106. doi:10.1080/750459446

Beaumont, E. (2016). Gender justice v. the "Invisible hand" of gender bias in law and society. Hypatia, 31(3), 668-686. doi:10.1111/hypa.12260

Belcher, J. R., DeForge, B., \& Zanis, D.A., (2005). Why has the social work profession lost sight of how to end homelessness? Journal of Progressive Human Services (16)2 p5-23. doi:10.1300/J059v16n02_02.

Benschop, Y., \& Verloo, M. (2006): 'Sisyphus' sisters: can gender mainstreaming escape the genderedness of organizations?', Journal of Gender Studies, 15(1), 19-33.

Beveridge, F., Nott, S., \& Stephen, K. (2000). Mainstreaming and the engendering of policymaking: A means to an end? Journal of European Public Policy 7(3): 385-405.

Borchorst, A., \& Siim, B. (2008). Woman-friendly policies and state feminism: Theorizing Scandinavian gender equality. Feminist Theory, 9(2), 207-224. doi: $10.1177 / 1464700108090411$

Bourdieu, P. (1991). Language and symbolic power. Cambridge: Polity Press.

Boyce, C \&Neale, P, 2006; Conduction in-depth interviews: A guide for designing and conducting in-depth interviews for evaluation input. Pathfind International Tool Series: Monitoring and evaluation $\left(2^{\text {nd }} \mathrm{Ed}\right)$. http://www2.pathfinder.org/site/DocServer/m_e_tool_series_indepth_interviews.pdf

Brodie, J., \& Bakker, I. (2008). Budgets and Social policy. Where are the women? Gender equity, budgets and Canadian public policy. Ottawa: Canadian Centre for Policy Alternatives ISBN 978-1-897569-05-4.

Brownie, C. (2017, June 21). Habitat Project feels 'real' - Project helps young families. . Barrie Examiner p. A1-A2/Barrie Examiner online publication, Habitats for Barrie families . Retrieved June 22, 2017, from http://www.thebarrieexaminer.com/2017/06/21/habitats-forbarrie-families

Brushett, K. (2007). "Where will the people go: Toronto's emergency housing program and the limits of canadian social housing policy." 1944-1957. Journal of Urban History 33 (3): 375-99.

Brushett, K. (2007). "Where will the people go: Toronto's emergency housing program and the limits of canadian social housing policy." 1944-1957. Journal of Urban History 33 (3): 375-99. 
Bryant, T. (2009). Housing and Health: More than brick and mortar. In D. Raphael, (Ed.), Social Determinants of Health: Canadian Perspectives $2^{\text {nd }}$ Edition, 235-251. Toronto: Canadian Scholars' Press.

Buitelaar, E., \& de Kam, G. (2012). The emergence of inclusionary housing: Continuity and change in the provision of land for social housing in the Netherlands. Housing, Theory and Society. 29(1), 56-74.

Buitelaar, E., \& De Kam, G. (2012). The emergence of inclusionary housing: Continuity and change in the provision of land for social housing in the netherlands. Housing, Theory and Society, 29(1), 56-74. doi:10.1080/14036096.2011.592214

Buitelaar, E., Needham, D. B. \& de Kam. G. R. W. (2014). The embeddedness of inclusionary housing in planning and housing systems: Insights from an international comparison. Journal of Housing and the Built Environment 29 (3): 389-402.

Bukowski, K., \& Buetow, S. (2011). Making the invisible visible: A Photovoice exploration of homeless women's health and lives in central Auckland. Social Science \& Medicine, 72(5), 739-746.

http://doi.org/10.1016/j.socscimed.2010.11.029

Caglar, G. (2013). Gender mainstreaming. Politics \& Gender, 9(3), 336. doi:10.1017/S1743923X13000214

Cairney, Pl. (2012). Understanding Public Policy: Theories and Issues. New York, NY: Palgrave Macmillan, 2012.

Canada Mortage and Housing Corporation CMHC. (2018, June 22). Characteristics of Households in Core Housing Need in 2016. Retrieved June 27, 2019. https://www.cmhcschl.gc.ca/en/data-and-research/data-tables/characteristics-households-core-housing-needcanada-pt-cmas

Canada Mortgage and Housing Corporation (2016). CMHC Housing market information Portal Ontario average rent by bedroom type by metropolitan areas, census agglomerations and cities https://www03.cmhc-schl.gc.ca/hmip-pimh/en\#Profile/1/1/Canada

Canada Mortgage and Housing Corporation CMHC. (2014, January 1). Housing in Canada Online. Retrieved June 11, 2018, from http://cmhc.beyond2020.com/

Canada Mortgage and Housing Corporation. (2018, March 31). About affordable housing in Canada. Retrieved June 27, 2019, from https://www.cmhc-schl.gc.ca/en/developing-andrenovating/develop-new-affordable-housing/programs-and-information/about-affordablehousing-in-canada

Canada without Poverty. (2013). Canada needs a national housing strategy. Accessed March 28, 2016. http://www.dignityforall.ca/en/canada-needs-national-housing-strategy

Canadian Centre for Policy Alternatives (CCPA) 2015. Addressing Core Housing Need in Canada. Canadian Centre for Policy Alternatives. October 8, 2015. Accessed March 16, 
2016. https://www.policyalternatives.ca/publications/reports/addressing-core-housingneed-canada.

Canadian Housing \& Renewal Association (CHRA) (2014). Housing For All: Sustaining and Renewing Social Housing for Low-Income Households: A Call for Federal Reinvestment as Operating Agreements Expire. Accessed August 10, 2016 http://housing4all.ca/sites/default/files/chra_housing_for_all_report__final.pdf

Canadian Housing \& Renewal Association (CHRA). (2009). An Affordable Housing Policy for Canada. Ottawa: CHRA. Accessed March 19, 2016 http://www.chraachru.ca/media/content/CHRA_Policy_Affordable_English.pdf

Canadian Observatory on Homelessness (2010). Canadian Defiition of Homelessness: What's being done in Canada and elsewhere? https://www.homelesshub.ca/sites/default/files/attachments/BackgroundCOHhomelessdefi nition.pdf

Canadian Observatory on Homelessness (2012). Canadian definition of homelessness. Retrieved July 25, 2019 from https://www.homelesshub.ca/sites/default/files/COHhomelessdefinition.pdf

Canadian Real Estate Association - CREA (2017). Barrie and District home sales set new alltime record in March 2017. Barrie \& District Association of Realtors inc. Retrieved June 22, 2017, from http://creastats.crea.ca/barr/

Caragata, L. (2010). Housing and homelessness. In A. Westhues (Ed), Canadian Social Policy: Issues and Perspectives, 4th edition. (p 267-290). Waterloo: Wilfrid Laurier University Press.

Carroll, B. W., 1989. "Post-war trends in Canadian housing policy." Urban History Review 18 (1): 64-74.

Caufield, S. L., \& Wonders, N. A. (1993). Personal and political: Violence against women and the role of the state. In K. D. Tunnell (Ed.), Political crime in contemporary America (pp. 79-100). New York: Garland Press.

CBC (2018, November, 16). Rent control reforms could mark return to sky-high increases for Toronto tenants, advocates warn. https://www.cbc.ca/news/canada/toronto/rent-controlreforms-could-mark-return-to-sky-high-increases-for-toronto-tenants-advocates-warn$\underline{1.4908665)}$

Chamberlain, C. \& MacKenzie, D., 1992, Understanding contemporary homelessness: Issues of definition and meaning. Australian Journal of Social Issues, (27) 274-297. City of Calgary

Chamberlain, C., 2007, Defining and Counting Homeless People. Unpublished paper presented at Homelessness: Counting the Cost (Third National Homelessness Forum), Wellington: New Zealand. 
City of Toronto. (2018). Summary of Advice from the Toronto Planning Review Panel Meeting held September 15, 2018 Executive Summary (pp. 1-4, Rep.). Toronto, ON: City of Toronto.

City of Toronto. (2019, June 25). Social Housing Waiting List Reports. Retrieved July 8, 2019, from https://www.toronto.ca/city-government/data-research-maps/researchreports/housing-and-homelessness-research-and-reports/social-housing-waiting-listreports/

Cloke, P., Milbourne, P., \& Widdowfield, R. (2002). Rural homelessness: Issues, experiences and policy responses. Bristol: Bristol University Press. doi:10.2307/j.ctt1t89cd7

Clougherty, J. (2010). A Growing Role for Gender Analysis in Air Pollution Epidemiology. Environmental Health Perspectives, 118(2), 167-176. Retrieved from http://www.jstor.org/stable/25614978

Colderley, C. A. (1999). Welfare state retrenchment and the nonprofit sector: The problems, policies, and politics of canadian housing. Journal of Policy History 11 (3): 283-312.

Collins, D. (2010). Homelessness in Canada and New Zealand: A comparative perspective on numbers and policy responses. Urban Geography, 31(7), 932-952. doi:10.2747/02723638.31 .7 .932

Collins, P. H. (2000). Black Feminist Thought: Knowledge, Consciousness and the Politics of Empowerment. $2^{\text {nd }}$ Eds. Routledge: NY

Cool, J. (2010). Background paper: Wage gap between women and men. Library of Parliament, pp. 1-14. Retrieved May 13, 2013 http://www.parl.gc.ca/Content/LOP/ResearchPublications/2010-30-e.pdf

Cooper, S. \& Skelton, I. (2015). Addressing Core Housing Need in Canada. Winnipeg, MB: Canadian Centre for Policy Alternatives Manitoba.

Cooper, S. (2015). A Terrific Loss: The end of social housing operating agreements. In Brandon, J. \& Silver, J. (eds). Poor Housing: A Silent Crisis. Winnipeg, MB: Fernwood Publishing.

Council of Europe. (1998). Conceptual framework, methodology and presentation of good practices: Final report of activities of the Group of Specialists on Mainstreaming p.16-18 (EGSMS 2 (98), Strasbourg. Accessed March, 2018 https://rm.coe.int/1680596135

Crawley, J., Kane, D., Atkinson-Plato, L., Hamilton, M., Dobson, K., \& Watson, J. (2013). Needs of the hidden homeless - no longer hidden: A pilot study. Public Health, 127(7), 674-680. doi:10.1016/j.puhe.2013.04.006

Creese, G. (2011). Racializing Work/Reproducing White Priviledge. In V. Shalla, Working in a Global Era: Canadian Perspectives. p.181-212. Toronto: Canadian Scholar's Press.

Creese, G., \& Wiebe, B. (2012). 'Survival employment': gender and deskilling among African immigrants in Canada. International Migration, 50(5), 56-76. 
Crenshaw, K. (1989). Demarginalizing the intersection of race and sex: A black feminist critique of antidiscrimination doctrine, feminist theory and antiracist politics. University of Chicago Legal Forum: 1(8.) Accessed Feb 13, 2017 http://chicagounbound.uchicago.edu/cgi/viewcontent.cgi?article $=1052 \&$ context $=$ uclf

Creswell, J. W. (2013). Qualitative inquiry and research design: Choosing among five approaches. Thousand Oaks, CA: Sage.

Creswell, John W. 2009. Research design: Qualitative, quantitative, and mixed methods approaches (3rd ed.). Thousand Oaks, CA: Sage

Das Gupta, T. (1996). Racism and Paid Work. Garamond Press: Toronto.

Dean (2002). Liberal Government and Authoritarianism. Economy and Society 31(1), 37-61. doi:10.1080/03085140120109240.

Dearnaley, P. (2013). Competitive advantage in the new contrived social care marketplace: How did we get here? Housing, Care and Support, 16(2), 76-84.

doi:http://dx.doi.org.ezproxy.lib.ryerson.ca/10.1108/HCS-03-2013-0002

Dewey, S., Hankel, J., \& Brown, K. (2017). Transitional housing facilities for women leaving the sex industry: Informed by evidence or ideology? Sexuality \& Culture, 21(1), 74-95. doi:10.1007/s12119-016-9379-5.

Dhamoon, R.K. (2011). Considerations on mainstreaming intersectionality. Political Research Quarterly, 64:1, 230-243.

Di Cesare, A., Simon, M., \& O'Ferrall, K. (2018). Back to 2017: New Ontario government revokes pre-election employment law changes. (2018, November 27). Retrieved March 7, 2019, from https://www.osler.com/en/resources/regulations/2018/back-to-2017-newontario-government-revokes-pre-election-employment-law-changes

Donley, A. M., \& Wright, J. D. (2012). Safer outside: A qualitative exploration of homeless people's resistance to homeless shelters. Journal of Forensic Psychology Practice, 12(4), 288-306. doi:10.1080/15228932.2012.695645

Donnan, M. E. (2014). Life after neoliberalism in canada: how policy creates homelessness and how citizenship models fail to provide solutions. International Journal of Arts \& Sciences, 7(5), 585-596. Retrieved from http://ezproxy.lib.ryerson.ca/login?url=http://search.proquest.com/docview/1652445962?a ccountid=13631

Drabble, J. (2017). Finding Her Home: A Gender-Based Analysis of the Homelessness Crisis in Winnipeg. Winnipeg: Canadian Centre for Policy Alternatives ISBN 978-1-77125-333-8

Duchesne, 2. (2015, April 1). Women in homelessness: A briefing report. University of McGill, Centre for Research on Children and Families, Retrieved May 28, 2017, from https://www.mcgill.ca/socialdevelopment/files/socialdevelopment/women_in_homelessnes s_-_a_brief_report.pdf 
Edwards, S. (2018, August 29). How Toronto landlords use renovictions to force out tenants. Retrieved March 12, 2019, from https://nowtoronto.com/news/renovicted-toronto-rentalhousing/

Engender. (1998). Reflex: Getting the Balance Right, Edinburgh, ENGENDER

Eschle, C. (2000). Global Democracy, Social Movements, and Feminism. Boulder, CO: Westview Press

Esping-Andersen, G. (2014). The three worlds of welfare capitalism. In C. Pierson, F. G. Castles \& I. K. Naumann (Eds.), The Welfare State Reader (3 ${ }^{\text {rd }}$ Edition) (pg. 136-150). Cambridge UK: Polity Press.

European Institute for Gender Equity (EIGE). (2013). Mainstreaming gender into the policies and the programmes of the institutions of the European Union and EU Member States. Luxembourg: Publications Office. doi:10.2839/43849

Evans, Bryan, Richmond, Ted, \& Shields, John. (2005). Structuring neoliberal governance: The nonprofit sector, emerging new modes of control and the marketization of service delivery. Policy and Society, 24 (1), 73-97.

Evans, Mitchell B., \& Shields, John. (2010). The third sector and the provision of public good: Partnerships, contracting and the neo-liberal state. In Christopher Dunn (Ed), The handbook of Canadian publicadministration (2nd edition) (pp. 305-318). Toronto, ON: Oxford University Press.

Fairclough,Mulderrig \& Wodak (2011). Critical Discourse Analysis. Discourse Studies: A Multidisciplinary Introduction, edited by Tuen van Dijk, 357-378. London: SAGE Publications.

Farrugia \& Gerrard (2016). Academic knowledge and contemporary poverty: The politics of homelessness research. Sociology 50 (2), 267-284. doi:10.1177/0038038514564436.

Fiedler, R., Schuurman, N., \& Hyndman, J. (2006). Hidden homelessness: An indicator-based approach for examining the geographies of recent immigrants at-risk of homelessness in greater Vancouver. Cities, 23(3), 205-216. doi:10.1016/j.cities.2006.03.004

Fopp, R. (2009). Metaphors in homelessness discourse and research: Exploring "Pathways", "Careers" and "Safety nets" 1. Housing, Theory and Society, 26(4), 271-291. doi:10.1080/14036090802476564

Fotheringham, S., Walsh, C. A., \& Burrowes, A. (2014). 'A place to rest': The role of transitional housing in ending homelessness for women in Calgary, Canada. Gender, Place and Culture, 21(7), 834-853. doi:10.1080/0966369X.2013.810605

Frankish, C.; Hwang,, Stephen W.; Quantz, D. (2005), Homelessness and health in Canada: Research lessons and priorities. Canadian Journal of Public Health, 96 (2), S23-S29

Gaetz S., Dej E., Richter T., \& Redman M. (2016). The State of Homelessness in Canada 2016. Toronto: Canadian Observatory on Homelessness Press. ISBN: 978-1-77221-057-6. 
Retrieved May 5, 2016, from

http://homelesshub.ca/sites/default/files/SOHC16_final_20Oct2016.pdf.

Gaetz, S. (2010). The Struggle to End Homelessness in Canada: How we created the crisis, and how we can end it. The Open Health Services and Policy Journal, 3, 21-26.

Gaetz, S., Gulliver, T. \& Richter, T. (2014). The State of Homelessness in Canada 2014. Toronto: The Homeless Hub, ISBN: 978-1-77221-001-9, http://www.homelesshub.ca/sites/default/files/SOHC2014.pdf

Gaetz, S.; Barr, C.; Friesen, A.; Harris, B.; Hill, C.; Kovacs-Burns, K.; Pauly, B.; Pearce, B.; Turner, A.; Marsolais, A. (2012) Canadian Definition of Homelessness. Toronto: Canadian Observatory on Homelessness Press.

Galabuzi, G. E. (2009). Social exclusion. In D. Raphael, (Ed.), Social Determinants of Health: Canadian Perspectives $2^{\text {nd }}$ Edition, p.252-268. Toronto: Canadian Scholars' Press.

Global News. (2017, September 28). Toronto top city in the world at risk of a housing bubble: Report. By Katherine, Dangerfield Retrieved from https://globalnews.ca/news/3773995/toronto-housing-bubble/

Global News. (2018, April 27). Ontario announces \$1.5 million in funding to Barrie for affordable housing. Retrieved March 7, 2019, from https://globalnews.ca/news/4172405/barrie-affordable-housing-rebates/

Global News. (2018, April 30). \$4.2B going to Ontario under \$40B national housing plan. Retrieved March 7, 2019, from https://globalnews.ca/news/4177526/ontario-fundingnational-housing-plan/

Global News. (2018, October 23). Ontario government freezes minimum wage hike as part of labour reforms rollback. Retrieved March 7, 2019, from https://globalnews.ca/news/4586495/ontario-government-minimum-wage-labour-reform/

Government of Ontario. (Ed.). (2018, August). Average market rents in Ontario. Retrieved June 27, 2019, from http://www.mah.gov.on.ca/Page1117.aspx

Grace, J. (1997). Sending mixed messages: Gender-based analysis and the 'status of women'. Canadian Public Administration 40(4) Winter: 582-98

Gramsci, A. (1971). Selections from the prison notebooks (Q. Hoare \& G. N. Smith, Eds.). New York, NY: International.

Guba, E. G. (1990). The alternative paradigm dialog. In E. G. Guba (Ed.), The paradigm dialog (pp. 17-30). Newbury Park, CA: Sage.

Guest G.S., MacQueen, K.M, \& Namey, E.E. (2011). Applied Thematic Analysis. SAGE Publications.

Gustafsson (2017). Single case studies vs. multiple case studies: A comparative study. Academy of Business, Engineering and Science Halmstad University: Halmstad, Sweden. 
Habitat for Humanity (2018) http://www.theforecaster.net/in-scarborough-habitat-for-humanitybuilds-a-community-of-women/

Hansen, M.B, \& Lindholst, A.C. (2016) Marketization revisited, International Journal of Public Sector Management, Vol. 29 Issue: 5, pp.398-408, https://doi.org/10.1108/IJPSM-05-2016-0090

Harding, S. (1986). The Science Question in Feminism. Ithaca, N.Y.: Cornell University Press

Harding, S. (1987). Is there a Feminist Method? In Feminism and methodology, Sandra Harding, (Ed) 1-14. Bloomington: Indiana University Press

Harding, S. (1993). Rethinking standpoint epistemology: What is "strong objectivity?'. In L. Alcoff, \& E. Potter (Eds.), Feminist epistemologies (pp. 49-82). New York, NY: Routledge.

Henwood, B.F, Hsu, H., Winetrobe, H., Dent, D., Carranza, A. \& Wenzel, S.L. (2013). Transitioning fromhomelessness: A fresh start event. Journal of the Society of Social Work and Research. 4(1), 47-57.

Homelessness Hub (2018, January 01). Housing First. Retrieved January 14, 2019, from https://www.homelesshub.ca/solutions/housing-accommodation-and-supports/housing-first

Homelessness Hub. (n.d.). Single Women. Retrieved July 15, 2019, from https://www.homelesshub.ca/about-homelessness/population-specific/single-women

Housing Services Corporation HSC (2013). Social and Affordable Housing Primer. Retrieved April 24, 2017, from https://share.hscorp.ca/affordable-housing/?upf=dl\&id=4296

Huey, L., \& Berndt, E. (2008). 'You've gotta learn how to play the game': Homeless women's use of gender performance as a tool for preventing victimization. The Sociological Review, 56(2), 177-194. doi:10.1111/j.1467-954X.2008.00783.x

Huey, L., Fthenos, G., \& Hryniewicz, D. (2012). "I need help and I know I need help. Why won't nobody listen to me?" Trauma and homeless women's experiences with accessing and consuming mental health services. Society and Mental Health, 2(2), 120-134. Retrieved September 30, 2012, from the SAGE database.

Hulchanski, D. (2007). Canada's Dual Housing Policy: Assisting Owners, Neglecting Renters. Centre for Urban and Community Studies, Research Bulletin 38. Toronto: University of Toronto. ISBN-13 978-0-7727-1461 -9 38

Hulchanski, D. (2007). Canada's Dual Housing Policy: Assisting Owners, Neglecting Renters. Centre for Urban and Community Studies, Research Bulletin 38. Toronto: University of Toronto. ISBN-13 978-0-7727-1461-9 38

Hulchanski, D. (2009). Homelessness: What is in a word. In Finding home: Policy options for addressing homelessness in Canada, Cities Centre Press, University of Toronto, Homeless Hub (Online service), \& Canadian Homelessness Research Network eds. Toronto: Cities Centre Press. 
Hulchanski, David (2004). What Factors Shape Canadian Housing Policy? The Intergovernmental Role in Canada's Housing System, in The State of the Federation 2004 - Municipal-Federal-Provincial Relations in Canada, R. Young and C. Leuprecht, eds., Kingston: McGill-Queen's University Press, for the Queen's University Institute of Intergovernmental Relations, 2004

Hyett, N., Kenny, A., \& Dickson-Swift, V. (2014). Methodology or method? A critical review of qualitative case study reports. International Journal of Qualitative Studies on Health and Well - being , 9 , 23606.

Jacquot, S. (2006). The instrumentalisation of gender mainstreaming in the European Commission: between 'social engineering' and 'bureaucratic engineering', European Policy 20(1), 33-53.

Jacquot, S. (2010). The paradox of gender mainstreaming: Unanticipated effects of new modes of governance in the gender equality domain. West European Politics, 33(1), 118-135. doi:10.1080/01402380903354163

Joy, M., \& Sheilds, J. (2013). Social Impact Bonds: The Next Phase of Third Sector Marketization? Canadian Journal of Nonprofit and Social Economy Research, 4(2), 39-55

Kam, G. R. W. d., Needham, D. B., \& Buitelaar, E. (2014). The embeddedness of inclusionary housing in planning and housing systems: Insights from an international comparison. Journal of Housing and the Built Environment, 29(3), 389-402. doi:10.1007/s10901-0139354-5

Kantola, J., \& Squires, J. (2012). From state feminism to market feminism? International Political Science Review / Revue Internationale De Science Politique, 33(4), 382-400. doi:10.1177/0192512111432513

Karki, T. K. (2015). Mandatory versus incentive-based state zoning reform policiesfor affordable housing in the United States: A comparative assessment. Housing Policy Debate, 25(2), 234-262. doi:10.1080/10511482.2014.917691

Kelly (2001). Youth at Risk: Processes of Individualisation and Responsibilisation in the Risk Society. Discourse Studies in The Cultural Politics of Education 22(1), 23-33. doi:10.1080/ 01596300120039731.

Keung, B. N. (2012). New immigrants are the 'hidden homeless'. Retrieved September 12, 2016, from Canadian Immigrant News: http://canadianimmigrant.ca/featured/new-immigrantsare-the-hidden-homeless

Kingdon, J.W. (1984 [1995, 2010]). Agendas, alternatives and public policies. Boston, MA: Little, Brown.

Kirst, M., Zerger, S., Wise Harris, D., Plenert, E., \& Stergiopoulos, V. (2014). The promise of recovery: Narratives of hope among homeless individuals with mental illness participating in a housing first randomised controlled trial in Toronto, Canada. BMJ Open, 4(3), e004379. doi:10.1136/bmjopen-2013-004379 
Klassen, J, (2016). Social housing with supports: The case of West End Commons . Canadian Centre for Policy Alternatives. ISBN 978-1-77125-297-3. Accessed August $8^{\text {th }}, 2016$. https://www.policyalternatives.ca/sites/default/files/uploads/publications/Manitoba\%20Off ice/2016/07/WestEnd\%20Commons.pdf

Klodawsky, F. (2006). Landscapes on the margins: Gender and homelessness in Canada. Gender, Place \& Culture, 13(4), 365-381. doi:10.1080/09663690600808478

Klodawsky, F., Aubry, T., Behnia, B., Nicholson, C., \& Young, M. (2015). The panel study on homelessness: Secondary data analysis of responses of study participants whose country of origin is not Canada (p. 52). Ottawa: National Secretariat on Homelessness

Knight, M. (2016). Race-ing, classing and gendering racialized women's participation in entrepreneurship. Gender, Work \& Organization, 23(3), 310-327. doi:10.1111/gwao.12060

Knight, M., \& Rodgers, K. (2012). “The government is operationalizing neo-liberalism”: Women's organizations, status of women canada, and the struggle for progressive social change in canada. NORA - Nordic Journal of Feminist and Gender Research, 20(4), 266282. doi:10.1080/08038740.2012.747786

Kuskoff, E. (2018). The importance of discourse in homelessness policy for young people: An Australian perspective. Journal of Youth Studies, 21(3), 376-390. doi:10.1080/13676261.2017.1380789

Lerman, B. R. (2006). Mandatory inclusionary zoning - the answer to the affordable housing problem. Boston College Environmental Affairs Law Review, 33(2), 383

Levy, S. (2017, January 29). Regent Park revitalization \$107 million in the hole . Toronto Star. Retrieved June 13, 2017, from http://www.torontosun.com/2017/01/29/regent-parkrevitalization-107-million-in-the-hole

Li, P. (2000). Earning disparities between immigrants and native-born Canadians. Canadian Review of Sociology and Anthropology, 37(3), p.289-311

Liamputtong, P. (2007). Feminism and Feminist Research in chapter 1 of Researching the vulnerable: A guide to sensitive research methods. Thousand Oaks: SAGE Publications Ltd. Kindle edition.

Liladrie, S. (2010). 'Do not disturb/please clean room': Hotel housekeepers in Greater Toronto. Race \& Class, 52(1), 57-69. doi:10.1177/0306396809354177

Lindblom, C. E. (1959; 2010). The science of "muddling" through. Emergence : Complexity and Organization, 12(1), 70.

Lindblom, C. E. (1982). The market as prison. The Journal of Politics, 44(2), 323-336. doi: $10.2307 / 2130588$

Little, M. (2015).Between the abuser and the street: An intersectional analysis of housing challenges for abused women, Canadian Review of Social Policy/ Revue Canadienne de Politique Sociale, (72/73), 35-65. 
Loopstra, R. \& Tarasuk, V., (2012). The relationship between Food Banks and Household Food Insecurity among Low-Income Toronto Families. Canadian Public Policy / Analyse de Politiques, 38 (4), 497-514. Retrieved from http://www.jstor.org/stable/41756766

Maguire, M. (2012). Response 1: Big society, the voluntary sector and the marketization of criminal justice. Criminology \& Criminal Justice, 12(5), 483-494. doi: $10.1177 / 1748895812459002$

Mah, J. (2009). Can Inclusionary Zoning Help Address the Shortage of Affordable Housing in Toronto? Toronto: Canadian Policy Research Networks (CPRN). Retrieved on May 19, 2017 from http://rcrpp.ca/documents/51952_EN.pdf

Mah, J., \& Hackworth, J. (2011). Local politics and inclusionary housing in three large Canadian cities. Canadian Journal of Urban Research, 20(1), 57.

Majone, G. (1989). Evidence, Argument, and Persuasion in the Policy Process. New Haven: Yale University Press.

Marshall, C. (1999). Researching the margins: Feminist critical policy analysis. Educational Policy, 13(1), 59-76. doi:10.1177/0895904899131006

Marshall, C. (Ed.). (1997a). Feminist critical policy analysis: A perspective from primary and secondary schooling. London: Falmer Press.

Marshall, C. (Ed.). (1997b). Feminist critical policy analysis: A perspective from postsecondary education. London: Falmer Press.

Mayo, S. (2011). Not to be forgotten: Homeless women in Hamilton, The Social Planning and Research Council of Hamilton. Retrieved May 8, 2012, from http://www.sprc.hamilton.on.ca/wp-content/uploads/2011/05/Not-to-Be-ForgottenHomeless-Women-in-Hamilton-Full-Report-May-2011.pdf

McFadden, A., Green, J. M., Williams, V., McLeish, J., McCormick, F., Fox-Rushby, J., \& Renfrew, M. J. (2014). Can food vouchers improve nutrition and reduce health inequalities in low-income mothers and young children: A multi-method evaluation of the experiences of beneficiaries and practitioners of the healthy start programme in england. BMC Public Health, 14(1), 148. doi:10.1186/1471-2458-14-148

McInturff, K. E., \& Canadian Centre for Policy Alternatives. (2014). The best and worst place to be a woman in Canada: An index of gender equality in canada's twenty largest metropolitan areas Canadian Centre for Policy Alternatives.

McIntyre, C., (April 4, 2016). Torontoist Explains: What is Inclusionary Zoning? Last Accessed July 07, 2017 from http://torontoist.com/2016/04/torontoist-explains-what-is-inclusionaryzoning/.

Mikkonen, J., \& Raphael, D. (2010). Social Determinants of Health: The Canadian Facts. $1^{\text {st }}$ Edition, p .3-62. Toronto: York University School of Health Policy and Management. ISBN 978-0-9683484-1 
Ministry of Housing Ontario MHO (December 7, 2016). Ontario passes legislation to create more affordable housing for families: province reducing red tape on secondary suites, allowing for Inclusionary Zoning. Ottawa: Ontario Government Online Press Release. Retrieved on May 21, 2017, from https://news.ontario.ca/mho/en/2016/12/ontario-passeslegislation-to-create-more-affordable-housing-for-families.html

Ministry of Municipal Affairs and Housing (MAH). (2017, March 10). Service managers and their service areas. Retrieved July 12, 2019, from http://www.mah.gov.on.ca/page1202.aspx

Monk, S. (2010) . England: Affordable housing through the planning system: the role of Section 106. In N.Calavita \& A. Mallach (Eds.), Inclusionary housing in international perspective: Affordable housing, social inclusion, and land value recapture (pp. 123-168). Cambridge, MA: Lincoln Institute of Land Policy.

Montgomery, A. E., PhD, Szymkowiak, D., PhD, \& Culhane, D., PhD. (2017). Gender differences in factors associated with unsheltered status and increased risk of premature mortality among individuals experiencing homelessness. Women's Health Issues, 27(3), 256-263. doi:10.1016/j.whi.2017.03.014

Morrison, N., \& Burgess, G. (2014; 2013;). Inclusionary housing policy in England: The impact of the downturn on the delivery of affordable housing through Section 106. Journal of Housing and the Built Environment, 29(3), 423-438. doi:10.1007/s10901-013-9360-7

Mullaly, B. (2007). The New Structural Social Work. (3rd Edition). Toronto: Oxford University Press.

Murray, S. (2011). Violence against homeless women: safety and social policy. Australian Social Work, 64(3), 346-360. doi:10.1080/0312407X.2011.552983

Muzorewa, R. (2014). Overcoming Systemic Violence against Homeless Women: A FeministStructural Approach (Master of Social Work thesis, Laurentian University, 2014) (pp. 1138). Sudbury, Ont.: Laurentian University.

Nelson, G., Caplan, R., MacLeod, T., Macnaughton, E., Goering, P., \& Piat, M. (2016). The At Home/ Chez Soi Project: Cross- Site Report on the Sustainability of Housing and Support Programs Implemented (pp. 1-99, Rep.). Ottawa, Canada: Mental Health Commission of Canada. doi:https://www.mentalhealthcommission.ca/sites/default/files/201611/at_home_sustainability_crosssite_report_eng.pdf

O'Campo, P., Stergiopoulos, V., Nir, P., Levy, M., Misir, V., Chum, A., . . Hwang, S. W. (2016). How did a housing first intervention improve health and social outcomes among homeless adults with mental illness in toronto? two-year outcomes from a randomised trial. BMJ Open, 6(9), e010581. doi:10.1136/bmjopen-2015-010581

OECD (2016). New OECD Affordable Housing Database. Social \& Welfare issues. Retrieved September 24, 2017, from http://www.oecd.org/social/affordable-housing-database.htm 
OECD (2017), Gender wage gap (indicator). doi: 10.1787/7cee77aa-en. Accessed on May 21, 2017 from https://data.oecd.org/earnwage/gender-wage-gap.htm

OECD (2012), Gender equality in employment in Closing the Gender Gap: Act Now, OECD Publishing, Paris. DOI: 10.1787/9789264179370-5-en. Retreived on May 5, 2017 from http://dx.doi.org/10.1787/9789264179370-5-en

OECD. (2016). Gender wage gap (Latest) - Retrieved June 18, 2016, from https://www.oecd.org/gender/data/genderwagegap.htm.

Ontario Co-operative Housing Federation of Canada OCHFC (2009). A Place for Co-op Housing in Ontario's Long-Term Affordable Housing Strategy: Submission of the Ontario Region of the Co-operative Housing Federation of Canada. Accessed February 10 $0^{\text {th }}, 2017$. http://www.chfcanada.coop/eng/pdf/ontdocs/LTAHS_Submission.pdf.

Ontario Co-operative Housing Federation of Canada OCHFC (2015). Putting Community First CHF Canada's Submission for the Long-Term Affordable Housing Strategy Update. Retrieved on May 212017 from https://chfcanada.coop/wp-content/uploads/2017/05/CHFCanada-LTAHS-Submission_web.pdf

Ontario Co-operative Housing Federation of Canada OCHFC (2016). Time for real progress on affordable housing: Submission to the Standing Committee on Finance and Economic Affairs, January 2016. Retrieved on May 21, 2017 from, https://chfcanada.coop/wpcontent/uploads/2017/05/2016_ON_Pre-budget_web.pdf

Ontario Government (2015, April 14). Rent-Geared-To-Income Assistance And Special Needs Housing O. Reg. 298/01: under Housing Services Act, 2011, S.O. 2011, c. 6, Sched. 1. Retrieved August 21, 2018, from https://www.ontario.ca/laws/regulation/010298/v4

Ontario Government (2018) Canada National Housing Strategy, 2017 https://www.placetocallhome.ca/pdfs/Canada-National-Housing-Strategy.pdf

Ontario Government (2018). Rental Fairness Act, 2017, https://news.ontario.ca/mma/en/2017/06/ontario-capping-rent-increases-for-tenants-in2018.html

Ontario Government (2018, November 19). Residential Tenancies Act, 2006, S.O. 2006, c. 17 Law Document English View. Retrieved March 12, 2019, from https://www.ontario.ca/laws/statute/06r17

Ontario Human Rights Commission, (2018, February 01). Proposed Regulation on Inclusionary Zoning - Concerns and recommendations. Retrieved March 24, 2019, from http://www.ohrc.on.ca/en/proposed-regulation-inclusionary-zoning---concerns-andrecommendations

Ontario Living Wage Network (2018). Living Wage by Region. Retrieved July 12, 2019, from https://www.ontariolivingwage.ca/living wage by region 
Ontario Non-profit Housing Association (n.d). Glossary of terms and acronyms. Retrieved July 10,2019 , from https://www.onpha.on.ca/Content/Resources/Glossary.aspx?WebsiteKey=49cb1e54-80a5$\underline{4 \text { daf-85fb-a49e833ec60b }}$

Ontario Non-Profit Housing Association ONPHA (2016). 2016 Waiting Lists Survey. Retrieved on May 21, 2017, from http://www.onpha.on.ca/web/Policyandresearch/2016_Waiting_List_Survey/Content/Polic yAndResearch/Waiting_Lists_2016/2016_Waiting_Lists_Survey.aspx?hkey=08cff4ce$\underline{7 f 97-4 a f 4-910 c-c 64954 d 28 a 4 a}$

Organisation for Economic Co-operation and Development (OECD). (2014). Gender Wage Gap. http://www.oecd.org/gender/data/genderwagegap.htm

Palys, T. (2008). Purposive sampling. In L. M. Given (Ed.) The Sage Encyclopedia of Qualitative Research Methods. (Vol.2). Sage: Los Angeles, pp. 697-8.

Paterson, S. (2010). What's the problem with gender-based analysis? Gender mainstreaming policy and practice in Canada. Canadian Public Administration, 53(3), 395.

Piercy, M. (1994). The Longings of Women. New York: Fawcett Crest.

Pierson, P.,. (2014). The New Politics of the Welfare State. In C. Pierson, F. G. Castles, \& I. K .Naumann, (Ed.), The Welfare State Reader (3rd ed., p.164-174). Cambridge, UK: Polity.

Premji, S., \& Shakya, Y. (2017). Pathways between under/unemployment and health among racialized immigrant women in toronto. Ethnicity \& Health, 22(1), 17-35. doi:10.1080/13557858.2016.1180347

Price, J. (2012). Structural violence: hidden brutality in the lives of women. Albany, NY: SUNY Press.

Prince, M. J. (2014). The universal in the social: Universalism, universality, and universalization in Canadian political culture and public policy. Canadian Public Administration, 57(3), 344-361. doi:10.1111/capa.12075

Pulkingham, J., Fuller, S., \& Kershaw, P. (2010). Lone motherhood, welfare reform and active citizen subjectivity. Critical Social Policy, 30(2), 267-291. doi:10.1177/0261018309358292

Purdy, S. (2003). "“It was tough on everybody": Low-income families and housing hardship in post-world war II.” Toronto. Journal of Social History 37 (2): 457-82.

Rahder, B. (2006). The crisis of women's homelessness in Canada. Women \& Environments International Magazine, (70/71), 38-39.

Rai, S. (2008). The Gender Politics of Development. London \& NewYork: Zed Books. 
Rai, S., \& United Nations. (2003;2013;). Mainstreaming gender, democratizing the state?: Institutional mechanisms for the advancement of women. England;United Kingdom;: Manchester University Press

Raising The Roof. (n.d.). Hidden Homeless Campaign - 10 Facts about the hidden homelessness Raising the Roof. Retrieved June 12, 2013, from http://www.raisingtheroof.org/OurPrograms/Hidden-Homeless-Campaign.aspx

Rapheal, E. (2009). Social Determinants of Health: Canadian Perspectives. $2^{\text {nd }}$ Ed. 252-268. Toronto: Canadian Scholars' Press.

Reeves, D. (2002). Mainstreaming gender equality: An examination of the gender sensitivity of strategic planning in great Britain. The Town Planning Review, 73(2), 197-214. doi:10.3828/tpr.73.2.4

Richards T, Bumphus, C., Garland, T., \& Thompson, R. (2010). "Personal and political?: Exploring the feminization of the American homeless population." Journal of Poverty 14 (1): 97-115. doi:10.1080/10875540903489496.

Rimawi, B. H., Mirdamadi, M., \& John, J. F. (2014). Infections and homelessness: Risks of increased infectious diseases in displaced women: Infections and homelessness. World Medical \& Health Policy, 6(2), 118-132. doi:10.1002/wmh3.95.

Roberto,L. \& Carroll, B.W. (2010). "Decentralisation and devolution in Canadian social housing policy." Environment and Planning C: Government and Policy 28 (3): 389-404.

Rodgers, K., \& Knight, M. (2011). "You just felt the collective wind being knocked out of us": The deinstitutionalization of feminism and the survival of women's organizing in canada. Women's Studies International Forum, 34(6), 570-581. doi:10.1016/j.wsif.2011.08.004

Rodridgue, S. (2016). Insights on Canadian Society - Hidden homelessness in Canada. Canadian Government News, Statistics Canada Policy Document number 75-006-X ISSN 22910840. https://www150.statcan.gc.ca/n1/pub/75-006-x/2016001/article/14678-eng.htm

Rosner, G. Q. (2014). The Wealth Gap: Perceptions and misconceptions in Canada (Rep.). Broadbent Institute. Retrieved March 2, 2017.

Rothkopf, D. J. (2012). Power, Inc.: The epic rivalry between big business and government--and the reckoning that lies ahead. New York: Farrar, Straus and Giroux.

Rovny, A. E., (2014). The capacity of social policies to combat poverty among new social risk groups. Journal of European Social Policy, 24(5), 405-423. doi: $10.1177 / 0958928714542732$

Royal Bank of Canada RBC, (April 2017). Canada's housing market. In RBC Economics Research: April issue. Retrieved, May 19, 2017, from http://www.rbc.com/economics/economic-reports/pdf/canadianhousing/ON_Housing_Affordability_Apr2017.pdf 
Sandhu, K., \& Stephenson, M. (2015). Layers of inequality--a human rights and equality impact assessment of the public spending cuts on Black Asian and minority ethnic women in coventry. Feminist Review, 109(1), 169-179. doi:10.1057/fr.2014.41

Sangha, J. K., Slade, B., Mirchandani, K., Maitra, S., \& Shan, H. (2012). An ethnodrama on work-related learning in precarious jobs: Racialization and resistance. Qualitative Inquiry, 18(3), 286-296. doi:10.1177/1077800411431555

Scala, F. (2008). Feminist ideals versus bureaucratic norms: The case of feminist researchers and the Royal Commission on New Reproductive Technologies. In Y. AbuLaban (Ed). Gendering the Nation State. (p. 97-119) UBC Press: BC.

Schuetz, J., Meltzer, R., \& Been, V. (2009). 31 flavors of inclusionary zoning: Comparing policies from San Francisco, Washington, DC, and Suburban boston. Journal of the American Planning Association, 75(4), 441-456. doi:10.1080/01944360903146806

Seeleib-Kaiser, M. (2008). Welfare state transformations in comparative perspective: shifting boundaries of 'public' and 'private' social policy? in Seeleib-Kaiser, M. (Ed.), Welfare State Transformations: Comparative Perspectives, Palgrave Macmillan, Basingstoke, pp. $1-14$.

Simon, H. A. (1956). Rational choice and the structure of the environment. Psychological Review, 63(2), 129-138. doi:10.1037/h0042769

Stake, R. (1995). The art of case study research. Thousand Oaks, CA: Sage

Statistics Canada. (2019, February 26). Canadian Income Survey, 2017. Retrieved July 12, 2019, from https://www150.statcan.gc.ca/n1/daily-quotidien/190226/dq190226b-eng.htm

Stratigaki, M. (2005). Gender Mainstreaming vs. Positive Action: An Ongoing Conflict in EU Gender Equality Policy. European Journal of Women's Studies 12 (2), 165-86.

Tarasuk, V., Dachner, N., \& Loopstra, R. (2014). Food banks, welfare, and food insecurity in Canada. British Food Journal, 116(9), 1405-1417. doi:10.1108/BFJ-02-2014-0077.

TD Bank (2017). Toronto housing: the heat is on, buyers caught up in the action. In Special Report - TD Economics, March, 20, 2017. Retrived on July 4, 2017, from https://www.td.com/document/PDF/economics/special/GTAHousing_Mar2017.pdf

Teghtsoonian, K. (2005). Disparate fates in challenging times: Women's policy agencies and neoliberalism in Aotearoa/New Zealand and British Columbia. Canadian Journal of Political Science 38(2): 307-333.

The Star, (Ed.) (2019, May, 24) Ford's Ontario: More for developers, less for residents. Retrieved June 29, 2019, from https://www.thestar.com/opinion/editorials/2019/05/24/fords-ontario-more-for-developersless-for-residents.html). 
Thomas, G. (2011). A typology for the case study in social science following a review of definition, discourse, and structure. Qualitative Inquiry, 17 (6), 511521.

Tiessen, Kaylie, 2015. Making ends need: Toronto's 2015 Living Wage. Canadian Centre for Policy Alternatives, 1(2), 1 -38. isbn 978-1-77125-197-6

Torfing, J. (2009). Rethinking path dependence in public policy research. Critical Policy Studies, 3(1), 70-83. doi:10.1080/19460170903158149

Toronto Foundation (2015) Toronto's Vital Signs: Toronto Foundations's 2015 Report on the State of the City. October 6, 2015. Accessed November 25, 2015. https://torontofoundation.ca/sites/default/files/OP-TVS 2015-Full-Report-PRINTING.pdf

Toronto Foundation (2016) Toronto's Vital Signs: Toronto Foundations's 2016 Report on the State of the City. October 4, 2016. Accessed May 5, 2016. http://torontosvitalsigns.ca/wpcontent/uploads/2016/10/WEB-OP-TorontosVitalSignsReport2016FINAL.pdf

Toronto Housing Connections. (2016, March 31). Housing Connections - 1st Quarter 2016 January 1st 2016 - March 31st 2016 . Retrieved July 8, 2017.

Toronto Real Estate Board. (2017, April 1). Strong Growth in New Listings in April . In Market Watch Online Magazine: Toronto. Retrieved May 05, 2017, from http://www.trebhome.com/market_news/market_watch/2017/mw1704.pdf

Toronto Star (2017) As mayor celebrates program, critics say definition of affordable housing needs review. By Jennifer Pagliaro \& Emily Mathieu https://www.thestar.com/news/city_hall/2017/10/02/as-projects-struggle-to-reachcompletion-critics-say-definition-of-affordable-housing-needs-reboot.html).

Toronto Star (2018) https://www.thestar.com/news/canada/2018/04/09/provinces-territoriesagree-to-spend-billions-under-liberals-national-housing-strategy.html.

Townson, M. and K. Hayes. (2007). Women and theEmployment Insurance Program. Toronto: Canadian Centre for Policy Alternatives.

True, J. (2003). Mainstreaming gender in global public policy, International Feminist Journal of Politics 5(3): 368-396

True, J., \& Mintrom, M. (2001) Transnational networks and policy diffusion: The case of gender mainstreaming. International Studies Quarterly 45: 27-57.

United Nations Economic \& Social Council. (1997, January 01). Intergovernmental Mandates: Coordination of the policies and activities of the specialized agencies and other bodies of the United Nations system . Retrieved January 15, 2017, from http://www.un.org/womenwatch/osagi/pdf/ECOSOCAC1997.2.PDF

United Nations Human Rights Committee (2009). United Nations Expert on Adequate Housing Calls For Immediate Attention To Tackle National Housing Crisis In Canada. Report of the Special Rapporteur on adequate housing as a component of the right to an adequate 
standard of living, and on the right to non-discrimination in this context: Mission to Canada (PDF). C (Report) (A/HRC/10/7/Add.3) (United Nations). Retrieved November 5, 2018

United Nations Human Rights Committee (2016). The sixth periodic report of Canada on the implementation of the International Covenant on Economic, Social and Cultural Rights (E/C.12/CAN/6) at its 6th and 7th meetings (E/C.12/2016/SR.6-7) held on 24 and 25 February 2016, and adopted the following concluding observations at its 20th meeting, held on 4 March 2016. Retrieved March 3, 2017 from http://tbinternet.ohchr.org/Treaties/CESCR/Shared\%20Documents/CAN/E_C12_CAN_CO_6_23228_E.pdf Retrieved March 5,

United Nations. (2002). Gender mainstreaming: An overview. Retrieved January 8, 2017, from the Office of the Special Adviser on Gender Issues and Advancement of Women: Department of Economic and Social Affairs http://www.un.org/womenwatch/osagi/pdf/e65237.pdf

Vannoni, M. (2015; 2014). What are case studies good for? Nesting comparative case study research into the Lakatosian Research Program. Cross Cultural Research, 49(4), 331-357.

Verloo, S. (2016). New and ongoing challenges to gender mainstreaming and intersectionality in Europe 2016 (pp. 1-14). Presentation at a GMT meeting Strasbourg - Council of Europe Conference, held on 24 May 2016, Nijmegen, Netherlands: Radboud University. Accessed, March $2^{\text {nd }}, 2017$ :

https://rm.coe.int/CoERMPublicCommonSearchServices/DisplayDCTMContent?documen $\underline{\mathrm{tId}=090000168065696 \mathrm{~d}}$

Walsh, C. A., Hanley, J., Ives, N., \& Hordyk, S. R. (2016;2015;). Exploring the experiences of newcomer women with insecure housing in Montréal Canada. Journal of International Migration and Integration, 17(3), 887-904. doi:10.1007/s12134-015-0444-y

Ward, A. (2017, October 16). Barrie rental rates third most expensive in Canada for another month: Report. CTV Barrie News. Retrieved August 12, 2018, from https://barrie.ctvnews.ca/barrie-rental-rates-third-most-expensive-in-canada-for-anothermonth-report-1.3634481

Washington, D. L., Yano, E. M., McGuire, J., Hines, V., Lee, M., \& Gelberg, L. (2010). Risk factors for homelessness among women veterans. Journal of Health Care for the Poor and Underserved, 21(1), 82-91. doi:10.1353/hpu.0.023.

Waterston, S., Grueger, B., Samson, L., \& Canadian Paediatric Society, Community Paediatrics Committee. (2015). Housing need in Canada: Healthy lives start at home. Paediatrics \& Child Health, 20(7), 403.

Watson \& Cuervo (2017). Youth Homelessness: A Social Justice Approach. Journalof Sociology 53(2), 461-475. doi:10.1177/1440783317705204. 
Watson, J. (2011). Understanding survival sex: Young women, homelessness and intimate relationships. Journal of Youth Studies 14(6), 639-655.

doi:10.1080/13676261.2011.588945

Watson, J., Crawley, J., \& Kane, D. (2016). Social exclusion, health and hidden homelessness. Public Health, 139, 96-102. doi:10.1016/j.puhe.2016.05.017

Watson, S. \& Austerberry, H. (1986). Housing and Homelessness. London: Routledge

Wattanaporn, K. A., \& Holtfreter, K. (2014). The impact of feminist pathways research on gender-responsive policy and practice. Feminist Criminology, 9(3), 191-207

Watters, H. (2018). Soaring rents in Barrie are making affordable housing an election issue. $C B C$ News. (2018, June 04). Retrieved from https://www.cbc.ca/news/canada/toronto/affordable-housing-election-1.4689932

Wellesley Institute, (2012). Affordable Housing: A Necessary Piece of the Foundation for Building a Healthier and More Equitable Ontario. In Ontario Budget - What to Lookfor. Shapcott, Micheal (editor) March 1, 2012. Accessed September 19, 2015. http://www.wellesleyinstitute.com/wp-content/uploads/2012/03/Ontario-Budget-2012Affordable-Housing1.pdf

Wellesley Institute. (2010). An introduction to inclusionary housing programs. Wellesley Institute , 1-12.

Wellesley Institute. (2010). Precarious housing in Canada. Wellesley Institute , 1, 1-100.

Whitzman, C. (2006). At the intersection of invisibilities: Canadian women, homelessness and health outside the 'big city'. Gender, Place \& Culture: A Journal Of Feminist Geography, 13(4), 383-399. doi:10.1080/09663690600808502

Williams, P. (2015). The affordable housing conundrum: Shifting policy approaches in Australia. Town Planning Review, 86(6), 651-676. doi:10.3828/tpr.2015.38

Wo “hl, Stephanie. 2007. Mainstreaming Gender? Contradiction of European and national gender politics. Koelnstein / Taunus: Ulrike Helmer Verlag

Yang, J. (2014). Welfare states' policy response to new social risk: Sequence analysis for welfare policy*. Development and Society, 43(2), 269-296. Retrieved from http://ezproxy.lib.ryerson.ca/login?url=https://search-proquestcom.ezproxy.lib.ryerson.ca/docview/1649650126? accountid=13631

Yin, R. K. (1994;2003;2009). Case study research: Design and methods. Thousand Oaks, CA: Sage.

Zahariadis, N. (2014). Ambiguity and Multiple Streams. in Theories of the Policy Process, edited by Paul A. Sabatier and Christopher M.Weible, Kindle Edition (3rd ed.) Boulder, Colorado: Westview Press, 2014. 
Zavos, A., \& Biglia, B. (2009). Embodying feminist research: Learning from action research, political practices, diffractions, and collective knowledge. Qualitative Research in Psychology, 6(1-2), 153-172. doi:10.1080/14780880902901380

Zolo Realty. (2017, May 1). Barrie Real Estate Trend: Housing Market Report for May 2017. https://www.zolo.ca/barrie-real-estate/trends 